\title{
PERSISTENT SHOULDER PAIN AFTER STROKE
}

Meyke Roosink 
The work presented in this thesis was financially supported by:

Stichting AMPHoraest

The publication of this thesis was financially supported by:

Dr. G.J. van Hoytema Stichting

www.hoytemastichting.nl

Roessingh Revalidatie Techniek

www.rrt.nl

Department of Biomedical Signals \& Systems (UT)

www.utwente.nl/ewi/bss

Department of Health Technology \& Services Research (UT) www.utwente.nl/mb/htsr

Their support is gratefully acknowledged.

Printed by:

TU/e Print service

Cover design:

Painting by Andrea Torjuul

Design by Tim Roosink and Meyke Roosink

\section{ISBN 978-90-365-3164-1}

Copyright (2011, Meyke Roosink, Eindhoven, the Netherlands

All rights reserved. No part of this publication may be reproduced or transmitted in any form or by any means, electronic or mechanical, including photocopy, recording or any information storage or retrieval system, without permission in writing from the author. 


\title{
PERSISTENT SHOULDER PAIN AFTER STROKE
}

\section{PROEFSCHRIFT}

\author{
ter verkrijging van \\ de graad van doctor aan de Universiteit Twente, \\ op gezag van de rector magnificus, \\ prof.dr. H. Brinksma, \\ volgens besluit van het College voor Promoties \\ in het openbaar te verdedigen \\ op donderdag 28 april 2011 om 14:45 uur
}

door

Meyke Roosink

geboren op 3 september 1982

te Hengelo (o) 
Dit proefschrift is goedgekeurd door de promotoren en assistent promotor:

Prof. dr. M.J. IJzerman

Prof. dr. A.C.H. Geurts

dr. ir. J.R. Buitenweg 


\section{Samenstelling promotiecommissie}

Voorzitter / Secretaris

Prof. dr. ir. A.J. Mouthaan

Universiteit Twente

Promotoren

Prof. dr. M.J. IJzerman

Universiteit Twente

Prof. dr. A.C.H. Geurts

UMC St Radboud

Assistent promotor

dr. ir. J.R. Buitenweg

Universiteit Twente

Referent

dr. R.T.M. van Dongen

UMC St Radboud

Leden

Prof. dr. J. Chae

Case Western Reserve University, Cleveland, $\mathrm{OH}, \mathrm{USA}$

Prof. dr. G. Kwakkel

VU Medisch Centrum

Prof. dr. ir. M.J.A.M. van Putten

Universiteit Twente, Medisch Spectrum

Twente

Prof. dr. M.M.R. Vollenbroek-Hutten

Universiteit Twente, Roessingh Research \&

Development

\section{Paranimfen}

Nicolas Hildenbrand

Jan Stegenga 



\section{Contents}

$\begin{array}{lll}\text { Chapter } 1 \text { General introduction } & 9\end{array}$

$\begin{array}{cll}\text { Part I } & \text { A mechanism-based view on post-stroke shoulder pain } & \mathbf{2 1} \\ \text { Chapter 2 } & \text { Towards a mechanism-based view on post-stroke shoulder } & 23 \\ & \text { pain: theoretical considerations and clinical implications } & \end{array}$

Part II Cross-sectional studies of persistent post-stroke shoulder pain

45

Chapter 3 Somatosensory symptoms and signs and conditioned pain

modulation in chronic post-stroke shoulder pain

Chapter 4 Altered cortical somatosensory processing in chronic stroke:

67

a relationship with post-stroke shoulder pain

Chapter 5 Classifying post-stroke shoulder pain: Can the DN4 be helpful?

Intermezzo An ongoing debate on post-stroke pain classification 105

$\begin{array}{lll}\text { Part III } \quad \text { Follow-up studies on the development of persistent } & 109\end{array}$ post-stroke shoulder pain

Chapter 6 Persistent shoulder pain in the first 6 months after stroke: 111

Results of a prospective cohort study

Chapter $7 \quad$ Somatosensory sensitization in persistent shoulder pain 131

after stroke: Results of a prospective cohort study

Chapter 8 General discussion: Towards a new view on PSSP? 155

$\begin{array}{ll}\text { Summary } & 171\end{array}$

$\begin{array}{ll}\text { Samenvatting } & 177\end{array}$

Dankwoord 183

$\begin{array}{ll}\text { Biography } & 186\end{array}$

$\begin{array}{ll}\text { Publications } & 187\end{array}$ 

Chapter 1

General introduction 


\section{Post-stroke pain}

In the Netherlands, each year, 41.000 new cases of stroke are diagnosed. 5 A stroke, or cerebrovascular accident (CVA), is caused by an obstruction or hemorrhage of a blood vessel supplying blood to the brain. As a result, brain function is (temporarily) disturbed. Many stroke survivors are left with permanent disabilities, including (partial) paralysis 22 , somatosensory deficits ${ }^{43}$, speech and language problems ${ }^{11}$, cognitive deficits 6,30 , fatigue ${ }^{24}$ and emotional ${ }^{46}$ or personality changes ${ }^{23}$. In addition, pain is common after stroke.1,18 Poststroke pain can be a great burden for the patient, increases hospital stay, reduces quality of life and interferes with functional recovery after stroke.3,21

The most commonly reported type of pain after stroke is post-stroke shoulder pain (PSSP), also named hemiplegic shoulder pain. In recent studies, PSSP occurred in $17 \%$ to $64 \%$ of patients.2,12,14,25,35,38,42 Older studies have reported incidences of PSSP ranging from 5\% to $84 \% .44,47$ Other types of post-stroke pain are central post-stroke pain (CPSP), shoulder-hand syndrome (SHS, also referred to as post-stroke complex regional pain syndrome) and poststroke (tension type) headache.50 CPSP is a central neuropathic pain that can occur after brain lesions affecting the central somatosensory nervous system. CPSP is often described as burning pain and patients report hypersensitivity at the affected side. Notably, CPSP can only be diagnosed when all other causes of pain have been ruled out, or are considered highly unlikely. ${ }^{19}$ The incidence of CPSP lies between 1\% and 12\%.19 Incidences of SHS range from $1.5 \%$ to $70 \% .10,15,20,31$ In SHS, pain is reported in the hemiplegic shoulder as well

as the hand and wrist and coincides with edema, coloring and sweating of the hand and wrist, suggesting a role for central sympathetic dysregulation and/or neurogenic inflammation. 7,15

The high variation in reported incidences of post-stroke pain is likely to be the result of differences in pain definitions, timing of assessment and/ or study populations. Indeed, the diagnostic process is hampered by the lack of a gold standard for post-stroke pain classification, the overlap in the clinical presentation of symptoms or even the combined presentation of pain types, and the high incidence of pre-stroke pain. ${ }^{37}$ These diagnostic uncertainties complicate the prognosis of post-stroke pain and, hence the selection of treatments.

\section{Post-stroke shoulder pain}

PSSP is usually diagnosed when pain is located in the affected shoulder region or arm, started after stroke (with no direct relation to trauma or injury) and is present during rest or during active or passive movement.13 Although PSSP may present early after stroke13,34,35, its typical onset is 2-3 months post stroke $2,14,17$. Many reviews have been written on the 
clinical presentation of PSSP and the multiple determinants associated with its development.4,8,33,44,47,53 Traditionally, PSSP is regarded as nociceptive pain resulting from tissue damage due to biomechanical changes around the shoulder joint. PSSP has been related to clinical conditions such as spasticity, glenohumeral subluxation, capsular inflammation, peripheral neuropathy, CPSP and autonomic dysfunction. ${ }^{44}$ Furthermore, several studies have suggested that reduced motor function, depression and reduced somatosensory function may contribute to the development of PSSP.13,14,17,25,27,29,34 The etiology of PSSP is, therefore, likely to be multifactorial.

\section{Classification}

The clinical assessment of PSSP is mainly focused on the shoulder joint, including active or passive pain-free range of motion tests ${ }^{34}$ and imaging of shoulder joint abnormalities using ultrasound ${ }^{32}$, radiography ${ }^{26}$ or $\mathrm{MRI}^{39}$. On the basis of such tests, PSSP is often classified into several etiological causes. However, there is no gold standard for classification and the current classifications often neglect the multi-dimensional nature of PSSP.41 For example, the classification by Teasell et al. is mostly based on shoulder anatomy, distinguishing between 'muscle', 'bone', 'joint', 'bursa', 'tendon', 'joint capsule' and 'other' etiologies.44 The classification by Gamble et al. is more physiological, distinguishing between 'central origin', 'chronic wide-spread pain', 'non-central causes' and 'mixed causes'.14 Importantly, Gamble et al. do acknowledge the multi-factorial etiology of PSSP by distinguishing 'mixed causes' as an etiological sub-group. Still, the relevance of these classifications for PSSP prognosis and treatment is unclear.40

In the field of pain research, several grading systems have been proposed to identify patients with neuropathic pain 45 or central post-stroke pain ${ }^{19}$, which, in theory, may be relevant for the classification of PSSP subtypes. However, the use of such grading systems to assess a peripheral or central neuropathic component in PSSP can be problematic. Based on the grading system for neuropathic pain, even patients with pure nociceptive PSSP might be classified as having neuropathic pain, simply because they have a relevant lesion affecting the central somatosensory system and the pain has a distinct neuroanatomically plausible distribution. On the other hand, CPSP can only be diagnosed if all other (e.g. nociceptive) causes of pain have been ruled out, which is difficult in the case of PSSP. ${ }^{37}$

\section{Treatment}

Although acute PSSP can resolve or improve spontaneously within the first 6 months after stroke ${ }^{14}$, shoulder pain is persistent in a significant number of patients ${ }^{25,49}$. Of the patients with PSSP at 4 months post-stroke, $65 \%$ also reported pain at sixteen months post-stroke, 
although pain intensity, frequency and pain during movement were reduced. ${ }^{25}$ Still, at sixteen months follow-up, more than half of these patients reported moderate to severe pain. ${ }^{25}$ It is not clear why some patients develop persistent PSSP whereas others recover spontaneously or with the help of treatment.

PSSP treatment mostly focuses at reducing biomechanical stressors or inflammation, including normalization of muscle tone (movement therapy, botulinum toxin injections), reduction of subluxation (strapping, movement therapy) and/ or treatment of the shoulder capsule (corticosteroid injections). ${ }^{44,48}$ However, pain relief is often unsatisfactory. Indeed, the evidence-base for therapeutic interventions is lacking or inconsistent.16,44 In addition, in the case of successful treatment, it often remains unclear how pain reduction was achieved. For example, neuromuscular electrical stimulation, aimed at reducing glenohumeral subluxation, provided pain relief in patients with PSSP while the degree of subluxation remained unaltered. 36

\section{Towards a new view on PSSP}

In order to improve the prevention, classification, prognosis and treatment of PSSP, a better understanding of the neurophysiological mechanisms underlying its development and perpetuation is needed.51 This demands a broadening of the traditional view on and assessment of PSSP as being a type of biomechanical nociceptive pain.

The theoretical framework underlying pain research is built on the notion that, although pain may be localized in one region of the body, the mechanisms causing pain may occur at any level of the somatosensory neuro-axis. ${ }^{28}$ Detailed assessment of pain complaints and somatosensory abnormalities is, therefore, a key element in pain research. ${ }^{51,52}$ Moreover, since chronic pain often involves spreading of the pain complaints and/or altered somatosensory function at non-painful body parts ${ }^{9}$, assessment is usually not limited to the painful region but also includes assessment of unaffected body parts.

Research into PSSP mechanisms should incorporate these basic concepts underlying pain research, from which further exploration of possible neurophysiological mechanisms may be started. However, methods commonly used in pain research have often not been validated for the stroke population. Moreover, many stroke patients have problems with attention and cognition or have other co-morbid conditions that complicate the interpretation of test results. Therefore it is essential to first address the usefulness of available "pain research tools" for the assessment of PSSP, i.e. the ability of these tools to reveal, under controlled conditions, meaningful differences between stroke patients with PSSP, pain-free stroke patients and healthy control subjects. The second step is to address whether and how these differences relate to possible neurophysiological pain mechanisms. 
Knowledge about the pathophysiological mechanisms of (persistent) PSSP, may provide a better understanding of the disappointing results from conventional preventive and therapeutic approaches to PSSP, and may provide a basis for improved clinical management of PSSP.

\section{Thesis objectives}

This thesis is the first to adopt a mechanism-based approach to the research of PSSP development. The primary objective of the thesis is to obtain a better understanding of the pathophysiological mechanisms responsible for the development of persistent PSSP. For this purpose a theoretical framework of possible mechanisms underlying PSSP is formulated, which will then be tested in several cross-sectional and longitudinal studies. The reason for focusing on patients with persistent PSSP is two-fold. First, in order to test the usability of "pain research tools", patients with PSSP and pain-free stroke patients should preferably show as much contrast as possible. That is, if no differences are found between patient groups in which the contrast on the primary outcome measure is highest, than it is questionable whether group differences can be found in less contrasting comparisons. Second, in previous prospective studies, PSSP assessment was often performed without reference to the onset of pain post stroke nor to the duration of the pain episode (i.e. recovered or persistent pain), so that causal relations remained largely unclear.13,14,17,25,35 By defining and targeting persistent pain, more knowledge may be obtained about factors and pain mechanisms involved in the initiation and perpetuation of PSSP.

\section{Part I: A mechanism-based view on post-stroke shoulder pain}

Chapter 2 introduces the terminology and the neurophysiological concepts of pain required to fully comprehend the remaining chapters. It describes the theoretical framework and methodology that is used for the assessment of pain and pain mechanisms in patients with PSSP in the following parts of this thesis.

\section{Part II: Cross-sectional studies of persistent PSSP}

The second part of this thesis comprises 3 cross-sectional studies that are undertaken to test the usability of "pain research tools" and the interpretation of their outcome in the light of possible neurophysiological pain mechanisms underlying persistent PSSP.

In Chapter 3, extensive assessment of somatosensory symptoms and signs is performed using subjective, but standardized "pain research tools", including clinical examination, quantitative sensory testing and conditioned pain modulation. Whereas somatosensory 
assessment in stroke patients is usually confined to the affected side and includes only a limited range of physical stimuli, this study uses a variety of different natural and electrical stimuli and assesses abnormalities at both the affected and unaffected side of the body. Using these methods, mechanisms relating to somatosensory loss, somatosensory sensitization and endogenous pain inhibition are addressed.

In Chapter 4 cortical somatosensory processing is assessed by recording evoked potentials using electroencephalography (EEG) and electrocutaneous stimulation. In contrast to the methods in Chapter 3, evoked potentials provide an objective measure of somatosensory function. In previous studies with stroke patients, evoked potentials have mostly been recorded to assess the functional connectivity between the peripheral nerves and the brain based on early components in the evoked potential. In this study we are specifically interested in the late components of the evoked potential that relate to mechanisms involved in the cognitive-affective processing of somatosensory stimuli and pain.

In Chapter 5 the neuropathic pain diagnostic questionnaire (DN4) is used to classify PSSP subtypes as having either neuropathic or nociceptive pain. By comparing patients with either subtype with regard to pain complaints and somatosensory symptoms and signs, the potential usefulness of the DN4 for the classification of PSSP subtypes is explored.

\section{Intermezzo: An ongoing debate on post-stroke pain classification}

The results of the studies from Chapters 3, 4 and 5 form the basis of a scientific discussion which is reprinted in this intermezzo. This discussion is about a grading system for CPSP which was proposed by researchers of The Danish Pain Research Center. ${ }^{19}$ Because the proposed grading system for CPSP is quite crude in its distinction between 'peripheral' and 'central' pain, it may have unintended implications for the assessment, diagnosis and, potentially, treatment of patients with 'mixed' (involving both peripheral as well as central pain mechanisms) types of post-stroke pain, including PSSP.

\section{Part III: Follow-up studies on the development of persistent PSSP}

The last part of this thesis focuses on the longitudinal assessment of persistent PSSP during the first 6 months post stroke, in which assessment is performed within 2 weeks, at 3 months and at 6 months after stroke.

Chapter 6 focuses on the identification of factors associated with the development of persistent PSSP during the first 6 months after stroke. Whereas the studies described in Chapters 3, 4 and 5 primarily focus on pain complaints in relation to somatosensory function, Chapter 6 focuses on the complete clinical picture of somatosensory, motor, cognitive, emotional and autonomic functions. The longitudinal design allows for the 
assessment of temporal and (possibly) causal relations between these different clinical functions and the development of persistent PSSP.

By extending the methods used in Chapter 6 (clinical examination) with the "pain research tools" described in Chapters 3 and 5 (i.e. extensive pain assessment, quantitative sensory testing and conditioned pain modulation), Chapter 7 further addresses possible pain mechanisms underlying the development of persistent PSSP by describing the relationship between persistent PSSP and somatosensory loss, somatosensory sensitization and endogenous pain inhibition in the first 6 months after stroke.

\section{General discussion: Towards a new view on PSSP?}

In Chapter 8 the results described in the previous chapters will be discussed and will be used to update the current knowledge on PSSP development. The implications for clinical practice will be discussed. Finally, directions for future research will be addressed based on identified knowledge gaps. 


\section{References}

1 Appelros P. Prevalence and predictors of pain and fatigue after stroke: a population-based study. Int J Rehabil Res 29:329-333, 2006.

2 Aras MD, Gokkaya NK, Comert D, Kaya A, Cakci A. Shoulder pain in hemiplegia: results from a national rehabilitation hospital in Turkey. Am J Phys Med Rehabil 83:713-719, 2004.

3 Barlak A, Unsal S, Kaya K, Sahin-Onat S, Ozel S. Poststroke shoulder pain in Turkish stroke patients: Relationship with clinical factors and functional outcomes. International Journal of Rehabilitation Research 32:309-315, 2009.

4 Bender L, McKenna K. Hemiplegic shoulder pain: defining the problem and its management. Disabil Rehabil 23:698-705, 2001.

5 Bots $M L$, Dis SJv. Factsheet beroerte 2006, editors. Den Haag: Nederlandse Hartstichting, 2006. pp. 1-8.

6 Buxbaum LJ, Ferraro MK, Veramonti T, Farne A, Whyte J, Ladavas E, Frassinetti F, Coslett HB. Hemispatial neglect: Subtypes, neuroanatomy, and disability. Neurology 62:749-756, 2004.

7 Chae J. Poststroke complex regional pain syndrome. Top Stroke Rehabil 17:151-162, 2010.

8 Chae J, Mascarenhas D, Yu DT, Kirsteins A, Elovic EP, Flanagan SR, Harvey RL, Zorowitz RD, Fang ZP. Poststroke Shoulder Pain: Its Relationship to Motor Impairment, Activity Limitation, and Quality of Life. Arch Phys Med Rehabil 88:298-301, 2007.

9 Curatolo $M$, Arendt-Nielsen $L$, Petersen-Felix S. Central Hypersensitivity in Chronic Pain: Mechanisms and Clinical Implications.
Phys Med Rehabil Clin N Am 17:287302, 2006.

10 Daviet JC, Preux PM, Salle JY, Lebreton $F$, Munoz M, Dudognon P, Pelissier J, Perrigot $M$. Clinical factors in the prognosis of complex regional pain syndrome type I after stroke: a prospective study. Am J Phys Med Rehabil 81:34-39, 2002.

11 Dickey L, Kagan A, Lindsay M P, Fang J, Rowland A, Black S. Incidence and Profile of Inpatient Stroke-Induced Aphasia in Ontario, Canada. Archives of Physical Medicine and Rehabilitation 91:196-202.

12 Dromerick AW, Edwards DF, Kumar A. Hemiplegic shoulder pain syndrome: frequency and characteristics during inpatient stroke rehabilitation. Arch Phys Med Rehabil 89:1589-1593, 2008.

13 Gamble GE, Barberan E, Bowsher D, Tyrrell PJ, Jones AK. Post stroke shoulder pain: more common than previously realized. Eur J Pain 4:313$315,2000$.

14 Gamble GE, Barberan E, Laasch HU, Bowsher D, Tyrrell PJ, Jones AK. Poststroke shoulder pain: a prospective study of the association and risk factors in 152 patients from a consecutive cohort of 205 patients presenting with stroke. Eur J Pain 6:467-474, 2002.

15 Geurts AC, Visschers BA, van Limbeek J, Ribbers GM. Systematic review of aetiology and treatment of post-stroke hand oedema and shoulder-hand syndrome. Scand J Rehabil Med 32:4$10,2000$.

16 Gustafsson L, Yates K. Are we applying interventions with research evidence when targeting secondary complications of the stroke-affected 
upper limb. Aust Occup Ther J 56:428435, 2009.

17 Hadianfard H, Hadianfard MJ. Predictor factors of hemiplegic shoulder pain in a group of stroke patients. Iran Red Crescent Me 10:215-219, 2008.

Jönsson AC, Lindgren I, Hallström B, Norrving $B$, Lindgren $A$. Prevalence and intensity of pain after stroke: a population based study focusing on patients' perspectives. J Neurol Neurosurg Psychiatry 77:590-595, 2006.

19 Klit H, Finnerup NB, Jensen TS. Central post-stroke pain: clinical characteristics, pathophysiology, and management. Lancet Neurol 8:857-868, 2009.

20 Kocabas $\mathrm{H}$, Levendoglu F, Ozerbil OM, Yuruten B. Complex regional pain syndrome in stroke patients. Int J Rehabil Res 30:33-38, 2007.

21 Kong KH, Woon VC, Yang SY. Prevalence of Chronic Pain and Its Impact on Health-Related Quality of Life in Stroke Survivors. Arch Phys Med Rehabil 85:35-40, 2004.

22 Kwakkel G, Kollen B, Twisk J. Impact of time on improvement of outcome after stroke. Stroke 37:2348-2353, 2006.

23 Langhorne $P$, Stott $D$ J, Robertson L, MacDonald J, Jones L, M cAlpine C, Dick F, Taylor GS, Murray G. Medical complications after stroke: a multicenter study. Stroke 31:12231229, 2000.

24 Lerdal A, Bakken LN, Kouwenhoven SE, Pedersen $G$, Kirkevold M, Finset A, Kim HS. Poststroke Fatigue--A Review. Journal of Pain and Symptom M anagement 38:928-949, 2009.

25 Lindgren I, Jönsson AC, Norrving B, Lindgren $A$. Shoulder pain after stroke:
A prospective population-based study. Stroke 38:343-348, 2007.

26 Lo SF, Chen SY, Lin HC, Jim YF, Meng $\mathrm{NH}, \mathrm{Kao} \mathrm{MJ}$. Arthrographic and clinical findings in patients with hemiplegic shoulder pain. Arch Phys Med Rehabil 84:1786-1791, 2003.

27 Lundström E, Smits A, Terént A, Borg J. Risk factors for stroke-related pain 1 year after first-ever stroke. Eur J Neurol 16:188-193, 2009.

28 Moseley GL. A pain neuromatrix approach to patients with chronic pain. M an Ther 8:130-140, 2003.

29 Niessen $\mathrm{MH}$, Veeger DH, Meskers CG, Koppe PA, Konijnenbelt $\mathrm{MH}$, Janssen TW. Relationship among shoulder proprioception, kinematics, and pain after stroke. Arch Phys Med Rehabil 90:1557-1564, 2009.

30 Patel MD, Coshall C, Rudd AG, Wolfe CDA. Cognitive impairment after stroke: Clinical determinants and its associations with long-term stroke outcomes. J Am Geriatr Soc 50:700706, 2002.

31 Pertoldi S, Di Benedetto P. Shoulderhand syndrome after stroke. A complex regional pain syndrome. Eura Medicophys 41:283-292, 2005.

32 Pong YP, Wang LY, Wang L, Leong CP, Huang YC, Chen YK. Sonography of the shoulder in hemiplegic patients undergoing rehabilitation after a recent stroke. J Clin Ultrasound 37:199-205, 2009.

33 Rajaratnam BS, Lim MG, Chia HLC, Chua YQS, Gan MC, Khalijah S, Tan YY. Clinical features associated with hemiplegic shoulder pain: A systematic review. Physiotherapy Singapore 11:1117, 2008.

34 Rajaratnam BS, Venketasubramanian N, Kumar PV, Goh JC, Chan YH. 
Predictability of simple clinical tests to identify shoulder pain after stroke. Arch Phys M ed Rehabil 88:1016-1021, 2007.

35 Ratnasabapathy Y, Broad J, Baskett J, Pledger M, Marshall J, Bonita R. Shoulder pain in people with a stroke: a population-based study. Clin Rehabil 17:304-311, 2003.

36 Renzenbrink GJ, IJzerman MJ. Percutaneous neuromuscular electrical stimulation (P-NMES) for treating shoulder pain in chronic hemiplegia. Effects on shoulder pain and quality of life. Clin Rehabil 18:359-365, 2004.

37 Roosink M, Geurts ACH, IJzerman MJ. Defining post-stroke pain: diagnostic challenges. Lancet Neurol 9:344-344, 2010.

Sackley C, Brittle N, Patel S, Ellins J, Scott M, Wright $C$, Dewey ME. The prevalence of joint contractures, pressure sores, painful shoulder, other pain, falls, and depression in the year after a severely disabling stroke. Stroke 39:3329-3334, 2008.

39 Shah RR, Haghpanah S, Elovic EP, Flanagan SR, Behnegar A, Nguyen V, Page SJ, Fang ZP, Chae J. M RI findings in the painful poststroke shoulder. Stroke 39:1808-1813, 2008.

Snels IA, Beckerman H, Lankhorst GJ, Bouter LM. Treatment of hemiplegic shoulder pain in the Netherlands: results of a national survey. Clin Rehabil 14:20-27, 2000.

41 Snels IA, Dekker JH, van der Lee JH, Lankhorst GJ, Beckerman H, Bouter LM . Treating patients with hemiplegic shoulder pain. Am J Phys Med Rehabil 81:150-160, 2002.

Suethanapornkul S, Kuptniratsaikul PS, Kuptniratsaikul $V$, Uthensut $P$, Dajpratha P, Wongwisethkarn J. Post stroke shoulder subluxation and shoulder pain: a cohort multicenter study. J Med Assoc Thai 91:1885-1892, 2008.

43 Sullivan JE, Hedman LD. Sensory dysfunction following stroke: Incidence, significance, examination, and intervention. Top Stroke Rehabil 15:200-217, 2008.

44 Teasell RW, Bhogal SK, Foley NC. Painful Hemiplegic Shoulder. In: Teasell RW, Bhogal SK, Foley NC, editors. Evidence-based Review of Stroke Rehabilitation. London, Ontario, Canada: University of Western Ontario, 2007. pp. 1-57.

45 Treede RD, Jensen TS, Campbell JN, Cruccu G, Dostrovsky JO, Griffin JW, Hansson P, Hughes R, Nurmikko T, Serra J. Neuropathic pain: redefinition and a grading system for clinical and research purposes. Neurology 70:16301635, 2008.

46 Turner-Stokes L, Hassan N. Depression after stroke: a review of the evidence base to inform the development of an integrated care pathway. Part 1: Diagnosis, frequency and impact. Clin Rehabil 16:231-247, 2002.

47 Turner-Stokes L, Jackson D. Shoulder pain after stroke: a review of the evidence base to inform the development of an integrated care pathway. Clin Rehabil 16:276-298, 2002.

$48 \quad$ Walsh K. Management of shoulder pain in patients with stroke. Postgrad Med J 77:645-649, 2001.

49 Wanklyn $\mathrm{P}$, Forster A, Young J. Hemiplegic shoulder pain (HSP): Natural history and investigation of associated features. Disabil Rehabil 18:497-501, 1996.

50 Widar $M$, Samuelsson L, KarlssonTivenius S, Ahlstrom G. Long-term pain conditions after a stroke. J Rehabil Med 34:165-170, 2002. 
51 Woolf $C$, Bennett GJ, Doherty $M$, Dubner $R$, Kidd $B$, Koltzenburg $M$, Lipton R, Loeser JD, Payne R, Torebjork E. Towards a mechanism-based classification of pain? Pain 77:227-229, 1998.

52 Woolf Cl, Decosterd I. Implications of recent advances in the understanding of pain pathophysiology for the assessment of pain in patients. Pain 82:S141-S147, 1999.

53 Yu D. Shoulder pain in hemiplegia. Phys Med Rehabil Clin N Am 15:683-697, 2004. 



\section{Part I}

\section{A mechanism-based view on post-stroke shoulder pain}



Chapter 2

\title{
Towards a mechanism-based view on post-stroke shoulder pain: Theoretical considerations and clinical implications
}

\author{
M eyke Roosink \\ Gerbert J Renzenbrink \\ Alexander CH Geurts \\ M aarten J IJzerman
}

Submitted 


\section{Abstract}

The assessment and treatment of post-stroke shoulder pain (PSSP) is largely based on the assumption that pain is due to biomechanical alterations within the shoulder joint after stroke. However, current treatment often provides limited pain relief, leading to a considerable number of patients with persistent pain. This suggests that PSSP may not be merely due to simple nociception from the shoulder joint. A better understanding of the neurophysiological mechanisms underlying the development and perpetuation of PSSP is needed. Here, a theoretical framework for presumed PSSP mechanisms and their assessment is presented based on key concepts applied in pain research. This theoretical framework assumes that although pain may be localized in one region of the body, the mechanisms causing pain may occur at any level of the somatosensory neuro-axis. Detailed assessment of pain complaints and somatosensory abnormalities should, therefore, be a key element in PSSP research. Studies aiming to further characterize the somatosensory functioning in patients with PSSP (initially) need to take a broad methodological approach including both clinical as well as more experimental pain research tools, such as quantitative sensory testing, conditioned pain modulation and the assessment of cortical somatosensory processing. A better understanding of pain mechanisms may explain why persistent PSSP and unsatisfactory pain relief are common despite active prevention and treatment strategies and may provide a basis for improved clinical management of PSSP. 


\section{Introduction}

The assessment and treatment of post-stroke shoulder pain (PSSP) is largely based on the assumption that pain is due to biomechanical alterations within the shoulder joint after stroke. Treatment is mostly focused at reducing biomechanical stressors or inflammation, including normalization of muscle tone (movement therapy, botulinum toxin injections), reduction of subluxation (strapping, movement therapy) and/ or treatment of the shoulder capsule (corticosteroid injections). ${ }^{71,84}$ However, using these interventions, pain relief is often unsatisfactory, leading to a considerable number of patients with persistent pain. ${ }^{42}$ Moreover, the evidence-base for therapeutic interventions is lacking or inconsistent.24,71 In addition, in the case of successful treatment, it often remains unclear how pain reduction has been achieved. For example, neuromuscular electrical stimulation, aimed at reducing glenohumeral subluxation, provided pain relief in patients with PSSP while the degree of subluxation remained unaltered ${ }^{59}$. The relatively high incidence of persistent PSSP and the ineffectiveness of PSSP treatment suggest that PSSP may not be merely due to simple nociception from the shoulder joint. This urges for a broadening of the traditional view on and assessment and treatment of PSSP as being a type of biomechanical nociceptive pain. Most importantly, in order to improve the prevention and treatment of PSSP, a better understanding of the neurophysiological mechanisms underlying its development and maintenance is needed. 90

In this paper, key concepts of pain research, involving the anatomy and neurophysiology of pain are summarized and integrated into a theoretical framework of presumed factors contributing to PSSP development. Such a "mechanism-based" theoretical framework requires different assessment methods than generally applied in the rehabilitation setting. Several "pain research tools" are suggested that may be used to obtain a better understanding of the pathophysiological mechanisms underlying the initiation and continuation of PSSP, which is deemed an essential step towards improved clinical management of PSSP.

\section{Key concepts of pain and pain research}

The International Association for the Study of Pain (IASP) has defined pain as 'an unpleasant sensory and emotional experience associated with actual or potential tissue damage, or described in terms of such damage'.48 Pain is thus a multidimensional experience. The experience of pain is a survival mechanism; it warns for potential tissue damage, it promotes sickness behavior to allow recovery from actual tissue damage and it induces long-term memories so that tissue damage can be avoided in the future. 
Table 2.1 Pain terminology.

\begin{tabular}{|c|c|}
\hline Term & Definition \\
\hline Pain & $\begin{array}{l}\text { An unpleasant sensory and emotional experience associated with actual or } \\
\text { potential tissue damage, or described in terms of such damage. }\end{array}$ \\
\hline \multicolumn{2}{|l|}{ Pain classification } \\
\hline Neuropathic pain & $\begin{array}{l}\text { Pain arising as a direct consequence of a lesion or disease affecting the } \\
\text { (central or peripheral) somatosensory system. }\end{array}$ \\
\hline Nociceptive pain & Pain arising from activation of nociceptors. \\
\hline \multicolumn{2}{|l|}{ Anatomy } \\
\hline Nociceptive neuron & A central or peripheral neuron that is capable of encoding noxious stimuli. \\
\hline Nociceptor & $\begin{array}{l}\text { A sensory receptor that is capable of transducing and encoding noxious } \\
\text { stimuli. }\end{array}$ \\
\hline \multicolumn{2}{|r|}{ (2) } \\
\hline Allodynia & Pain in response to a non-nociceptive stimulus \\
\hline Analgesia & $\begin{array}{l}\text { Absence of pain in response to stimulation which would normally be } \\
\text { painful. }\end{array}$ \\
\hline Dysesthesia & An unpleasant abnormal sensation, whether spontaneous or evoked. \\
\hline Hyperalgesia & Increased pain sensitivity. \\
\hline Hyperesthesia & $\begin{array}{l}\text { Increased sensitivity to stimulation, includes both allodynia and } \\
\text { hyperalgesia. }\end{array}$ \\
\hline Hypoalgesia & Decreased pain sensitivity. \\
\hline Hypoesthesia & Decreased sensitivity to stimulation. \\
\hline Paresthesia & An abnormal sensation, whether spontaneous or evoked. \\
\hline \multicolumn{2}{|l|}{ Pain mechanisms } \\
\hline Nociception & The neural processes of encoding and processing noxious stimuli. \\
\hline Sensitization & $\begin{array}{l}\text { Increased responsiveness of neurons to their normal input or recruitment of } \\
\text { a response to normally subthreshold inputs. }\end{array}$ \\
\hline $\begin{array}{c}\text { Peripheral } \\
\text { sensitization }\end{array}$ & $\begin{array}{l}\text { Increased responsiveness of nociceptors to stimulation of their receptive } \\
\text { fields }\end{array}$ \\
\hline Central sensitization & $\begin{array}{l}\text { Increased responsiveness of nociceptive neurons in the central nervous } \\
\text { system to their normal or subthreshold afferent input. }\end{array}$ \\
\hline \multicolumn{2}{|l|}{ Pain research } \\
\hline Nociceptive stimulus & $\begin{array}{l}\text { An actually or potentially tissuedamaging event transduced and encoded by } \\
\text { nociceptors. }\end{array}$ \\
\hline Noxious stimulus & An actually or potentially tissuedamaging event. \\
\hline Sensation threshold & The minimal intensity at which a stimulus can be perceived. \\
\hline Pain threshold & The minimal intensity of a stimulus that is perceived as painful. \\
\hline Pain tolerance level & $\begin{array}{l}\text { The maximum intensity of a stimulus that evokes pain and that a subject is } \\
\text { willing to tolerate in a given situation. }\end{array}$ \\
\hline
\end{tabular}

Adapted from Loeser \& Treede (2008) and M erskey \& Bogduk (1994).

Pain can be classified on the basis of its duration, being either acute (0-3 months) or persistent (> 3 months). In addition, pain can be classified on the basis of its presumed underlying cause. Nociceptive pain is initiated by tissue damage. Neuropathic pain can arise as a direct consequence of a lesion or disease affecting the somatosensory system and may be peripheral or central..$^{73}$ The generally accepted pain terminology is summarized in Table 2.1.43,48 
The theoretical framework underlying pain research is built on the notion that, although pain may be localized in one region of the body, the mechanisms causing pain may occur at any level of the somatosensory neuro-axis. ${ }^{11}$ Detailed assessment of pain complaints and somatosensory abnormalities is, therefore, a key element in pain research.90,91 Moreover, since persistent pain often involves spreading of the pain complaints and/or altered somatosensory function at non-painful body parts ${ }^{12}$, assessment is usually not limited to the painful region but also includes assessment of unaffected body parts.

\section{Anatomy \& neurophysiology of acute pain}

The experience of pain is mediated by the somatosensory system, comprising the peripheral nerves, the spinal dorsal horn, spinal ascending and descending pathways and the brain (Figure 2.1). Modulation of the pain experience is possible at all levels of the somatosensory neuroaxis. Important neurotransmitters in the modulation of the somatosensory system are endogenous opioids and mono-amines (e.g. serotonin, dopamine). Inhibitory modulation prevents the somatosensory system from an excitatory overshoot, whereas facilitatory modulation ensures attention for and a reaction to actual or potential tissue damage.

Since facilitatory and inhibitory modulation show great overlap with respect to the structures and neurotransmitters involved, the experience of pain always results from a complex interplay between inhibitory and excitatory mechanisms. Most importantly, in a healthy state, modulation is reversible, so that pain is temporary and subsides when the body recovers.

\section{Peripheral nervous system}

In the periphery, tissue receptors can detect a variety of different stimuli; i.e. thermoreceptors for the detection of thermal stimuli and low and high threshold mechanoreceptors for the detection of light touch or gross pressure respectively. These receptors are contacted by primary afferent fibers, of which the cell bodies are located in the dorsal root ganglion. Mechanoreceptors are mostly contacted by thick A $\beta$ fibers ( $~ 6-12$ $\mu \mathrm{m})$ with a high conduction velocity $(30-70 \mathrm{~m} / \mathrm{s})$. Thermo-receptors are contacted by thin myeliniated A $\delta$ ( $\varnothing$ 1-6 $\mu \mathrm{m}$, conduction velocity 4-36 m/ s) and unmyeliniated C fibers ( $\varnothing 0.2-$ $1.5 \mu \mathrm{m}$, conduction velocity $4-36 \mathrm{~m} / \mathrm{s}$ ). Free nerve endings of A $\delta$ and C fibers are called nociceptors that are involved in the experience of socalled "first" (sharp) and "second" (dull) pain, respectively. Nociceptors can be activated by thermal, mechanical or chemical stimuli when the stimulus is noxious, i.e. an actually or potentially tissue-damaging event.43 In a healthy person, somatosensory stimulation leads to a depolarization of peripheral tissue receptors and connected primary afferents. 


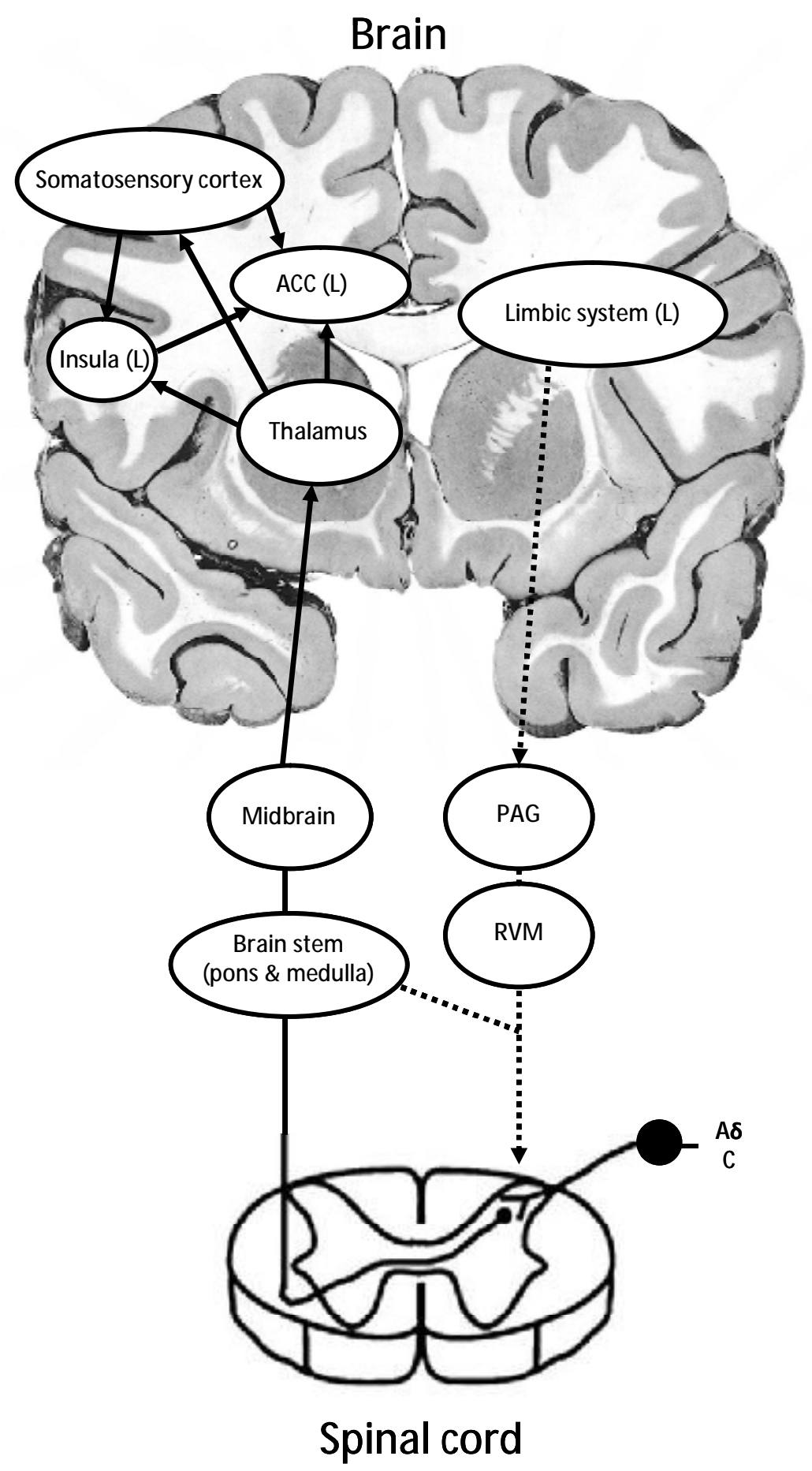

Figure 2.1 Schematic drawing of the anatomical structures involved in the neural processing of somatosensory input from A $\delta$ and C primary afferent fibers ascending via the spinothalamic tract (STT). The dotted arrows represent the descending modulation of neurons in the spinal dorsal horn by supraspinal structures. L: limbic system; ACC: anterior cingulated cortex; PAG: periaquaductal grey; RVM: rostroventral medulla. 
When the peripheral tissue is damaged, several (inflammatory) substances can increase the sensitivity of tissue receptors and nociceptors leading to decreased depolarization thresholds and an increased firing frequency. This phenomenon is referred to as peripheral sensitization.

\section{The dorsal horn}

Primary afferents project to several laminae within the dorsal horn, located posterior in the grey matter of the spinal cord. Within the dorsal horn, a total of 6 laminae can be distinguished. Primary A $\beta$ fibers project to laminae III-VI, A $\delta$ fibers to laminae I and V and C fibers to laminae I and II.78

Several types of dorsal horn neurons can be distinguished. Nociceptive-specific (NS) neurons are found in lamina I, are innervated by A $\delta$ fibers and respond to noxious mechanical and heat stimulation. Wide dynamic range (WDR) neurons are found in lamina $\mathrm{V}$ and receive input from both $\mathrm{A} \beta$ and $\mathrm{A} \delta$ primary afferents and from supraspinal structures. Interneurons can be found in all laminae, receive input from primary afferents and from supraspinal structures and project onto both pre-synaptic primary afferents and postsynaptic dorsal horn neurons.

The activation of dorsal horn neurons is dependent on the number and type of activated primary afferent fibers as well as on the frequency with which they are activated. In addition, the activation of dorsal horn neurons can be modulated indirectly by interneurons or directly by supraspinal descending pathways. Repetitive nociceptive input from primary afferents can lead to central sensitization in the dorsal horn, resulting in an increased responsiveness to subsequent stimuli. ${ }^{86}$ In addition, the activation of spinal projection neurons is dependent on the ratio between thick (tactile) and thin (pain) fiber activation and is mediated by inhibitory interneurons. This interaction between different somatosensory inputs at the spinal level forms the basis for the well known "gate control theory". ${ }^{47}$ This explains why rubbing a painful knee (i.e. providing tactile input) can (temporarily) reduce the pain sensation from this knee.

\section{Spinal tracts}

Dorsal horn neurons project to supraspinal structures, to the ventral horn and to local or intersegmental dorsal horn neurons. One of the pathways projecting to supraspinal structures ascends ipsilaterally and projects onto the medulla. Axons of projection neurons from the medulla then cross the midline, and this so-called dorsomedial lemniscal tract (DMLT) terminates in the ventroposterior lateral thalamus. This pathway is mainly supplied by tactile $A \beta$ primary afferents and subserves the "gnostic" sensibility (light touch, 
vibration, proprioception). Dorsal horn neurons receiving input from nociceptive A $\delta$ and C fibers terminate on projection neurons located in the contralateral anterolateral quadrant of the spinal cord via the spinothalamic tract (STT). The STT projects via an anterior (WDR neurons) and a lateral (NS neurons) pathway directly to different parts of the thalamus and subserves the sensibility of pain, temperature and gross pressure. The STT and the DMLT are both somatotopically organized. In addition to the STT and the DMLT, there are tracts projecting to reticular and homeostatic control regions of the medulla and brainstem and to the hypothalamus and ventral forebrain. ${ }^{83}$

\section{The brain}

Several brain structures are involved in the processing of innocuous and noxious somatosensory information, such as the thalamus, the somatosensory cortices and parts of the limbic system, such as the insula and the anterior cingulated cortices (ACC) (Figure 2.1).1,32,44,54,74 The cell bodies in the lateral part of the thalamus are highly somatotopically organized, project to the primary (S1) and secondary (S2) somatosensory cortices and are involved in the discriminative aspects of somatosensation. Cell bodies located in the medial part of the thalamus project to parts of the limbic system, such as the insula and ACC that are involved in the sensory quality, homeostatic functions and the motivational and emotional aspects of pain respectively 83 .

The activity of cortical neurons is mediated by afferent input as well as by other cortical neurons. Again, repetitive or ongoing nociceptive ascending input may lead to central sensitization. Moreover, the activity of cortical neurons can be modulated intracortically, for example by attention and anticipation.52,53 In turn, cortical activation modulates spinal (nociceptive) processing via descending pathways in the spinal cord. Cortical modulation is mediated by parts of the limbic system (amygdala), the periaquaductal grey (PAG) and the rostroventral medulla (RVM) and may be inhibitory as well as excitatory.49 Stress-induced ä?

le of such supra-spinal pain modulation. Another mechanism of supra-spinal modulation is subserved by diffuse noxious inhibitory controls (DNIC). ${ }^{39}$ DNIC are located in the brain stem (i.e. the dorsal reticular nucleus of the caudal medulla). DNIC can be activated by tonic noxious and possibly by innocuous activity from the periphery. ${ }^{57,81}$ When activated, DNIC exert an inhibitory effect on heterotopic spinal WDR neurons and, to a lesser extent, on NS neurons. This effect is also known as the pain-inhibiting-pain effect.

\section{Persistent pain}

Unlike acute pain, persistent pain is no longer functional and may no longer be related to the initial cause. The mechanisms underlying the development of persistent pain are not 
well understood, but are likely to involve a complex interplay of biological, psychological and social factors. ${ }^{51}$ Notably, persistent pain is often associated with personality traits (e.g. pain-catastrophizing), depression, anxiety and altered cognition.7,17,23,28,41,76 In patients with persistent pain, pain may cause a chronic interruption of attentional engagement.17 Ultimately, persistent pain is suggested to be due to a somatosensory imbalance of inhibitory and excitatory modulation, favoring the facilitation of nociception. ${ }^{12}$ Several neurophysiological mechanisms may contribute to this imbalance.10,90 Primary afferents may become sensitized, may change phenotype or may become hyperinnervated. In addition, silent nociceptors may be recruited. In the case of neuropathic lesions, neurons may acquire spontaneous and/ or increased stimulus-evoked activity. Dorsal horn neurons may become sensitized and/ or become functionally or structurally reorganized leading to summation and amplification of incoming stimuli. The activity in spinal dorsal horn neurons may also be facilitated or disinhibited by supraspinal descending controls. In addition, the supra-spinal somatosensory system may become sensitized, disinhibited, and/or functionally 30,88 or structurally 45 reorganized as a result of ongoing nociception or due to neuropathic lesions. 35

\section{Presumed mechanisms of post-stroke shoulder pain}

The mechanisms underlying the development of PSSP are largely unknown. Theoretically, PSSP may be nociceptive, peripheral or central neuropathic, or a combination of both nociceptive and neuropathic pain. In addition, the mechanisms responsible for the initiation of PSSP may be different from the mechanisms responsible for its perpetuation. This poses a challenge to those dealing with the diagnosis and treatment of post-stroke pain.35,63

As proposed for central post-stroke pain, a loss of somatosensory input due to stroke may directly lead to a loss of inhibition or increased facilitation of supra-spinal nociception.35,85 On the other hand, the brain lesion may lead to a facilitation or disinhibition of spinal nociception..$^{13,47}$ Moreover, brain lesions may lead to autonomic changes ${ }^{15,37}$ or changes in mood and cognition ${ }^{70}$ which could indirectly alter somatosensory processing. Although individual cases have been reported in which PSSP was thought to be solely due to the brain lesion, tissue damage of the upper-extremity is likely to play an initiating role in the majority of patients with PSSP.22 Tissue damage may be caused by altered neuromuscular control after stroke combined with reduced care-taking by the patient as a result of impaired somatosensory and cognitive functions.71,89 The upper extremity is especially prone to tissue damage due to its abundant degrees of (motion) freedom and its important role in many activities of daily living. Trauma is, thus, often repetitive and persistent as a result of which even minor injuries may eventually lead to tissue damage. 


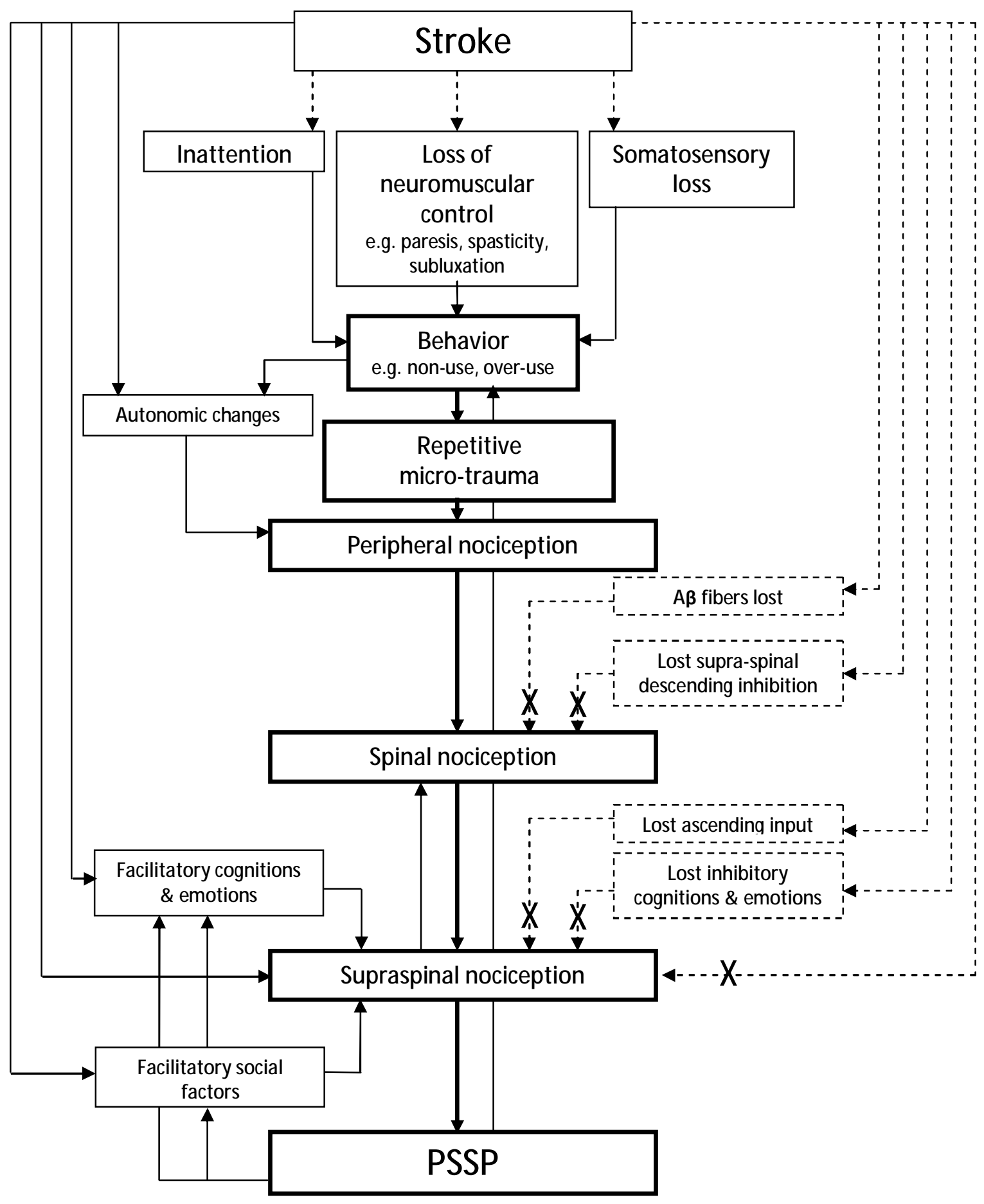

Figure 2.2 Presumed factors contributing to PSSP development. Dotted structures represent lost inhibitory functions. (Repetitive) micro-trauma at the upper extremity may initiate PSSP (i.e. nociceptive pain). Sensitization may contribute to PSSP maintenance or worsening and may be induced directly by ongoing nociception or the brain lesion, as well as indirectly by other factors, either pre-morbid, related to the brain lesion itself or related to prolonged nociception. 
In addition, prolonged immobility after stroke ${ }^{72}$ and the use of compensatory and potentially injurious movement strategies due to pain and reduced neuromuscular control may contribute to ongoing nociception. ${ }^{56}$ Prolonged nociception may induce structural reorganization at both spinal 10 and supra-spinal 45 neuronal levels, so that sensitization becomes permanent and even innocuous stimuli may become painful. In addition, prolonged nociception may lead to a permanent activation of $\mathrm{DNIC}^{2}$, resulting in ineffective endogenous inhibition. As mentioned in the previous paragraph, the presence of persistent pain may alter cognitions (e.g. attention) and emotions (e.g. anxiety levels) which may indirectly facilitate (supra)spinal nociception. ${ }^{14,28,41,76}$ Lastly, the consequences of both the stroke as well as the secondary pain may change the social environment of the patient (i.e. interpersonal relationships) and may (unwillingly) contribute to increased pain behavior and PSSP perpetuation. ${ }^{75}$ A summary of the presumed mechanisms underlying PSSP is presented in Figure 2.2. So far, these theoretical considerations have hardly been embedded in the clinical or scientific approach to PSSP.

\section{From theory to practice: somatosensory assessment}

The direct assessment of pain mechanisms (i.e. changes in synaptic transmission leading to altered pain processing) in humans is limited for ethical reasons, and is only possible in animal models ${ }^{27}$ or human models of experimentally induced pain 34 . However, pain mechanisms may be studied indirectly by relating somatosensory symptoms and signs of clinical pain to those observed in animal or experimental pain studies. For example, animal and experimental models have shown that positive signs such as allodynia 31,33 and secondary $20,33,36,98$ or generalized 40,55 hyperalgesia are mediated (partly) by central sensitization processes at the spinal and supraspinal level. However, one has to bear in mind that one mechanism may be responsible for multiple symptoms or signs and a single sign may be served by multiple pain mechanisms. In addition, the relation between etiology, clinical pain complaints and somatosensory abnormalities is not straightforward.18,19,26,29,58 Standardized assessment of somatosensory functions includes the assessment of spontaneously or stimulus-evoked negative (i.e. implicating somatosensory loss) and positive (i.e. implicating sensitization) symptoms and signs. Natural (receptor-mediated) and electrical (receptor-bypassed) sensations may be compared to assess whether peripheral receptors are (de)sensitized. Pain-free areas and the unaffected body side in unilateral stroke may be used for within-subject comparisons to assess local abnormalities. In addition, somatosensory abnormalities can be compared to a normative data set (i.e. pain-free stroke patients, healthy controls) to assess generalized (i.e. central) somatosensory changes. For example, the German Research Network on Neuropathic Pain 
(DFNS) proposed a standardized clinical test protocol to define sensory profiles of positive and negative somatosensory signs in patients with neuropathic pain, which can then be matched to sensory profiles of animal or experimental human pain models with known pain mechanisms. ${ }^{60,61}$ In addition, more experimental paradigms may be used, for example to specifically address endogenous inhibitory modulation (e.g. using conditioned pain modulation) or cortical somatosensory processing (e.g. using electroencephalography).

\section{Symptoms}

Somatosensory symptoms can be assessed with questionnaires, such as a visual analog scale (VAS) or a numeric rating scale (NRS) to assess pain intensity during rest or during movement ( 0 = 'no pain', 100 = 'worst pain imaginable'). Pain onset, duration, frequency, location, distribution, pain descriptors and impact of pain on daily living can be assessed in a standardized interview or using a pain questionnaire such as the McGill Pain Questionnnaire (MPQ) ${ }^{46,79}$ The ShoulderQ specifically assesses the timing and severity of hemiplegic shoulder pain. ${ }^{77}$ However, this questionnaire is only validated for the English language. Neuropathic pain may be assessed using the neuropathic pain diagnostic questionnaire (DN4) 8,80 $^{2}$ or the Leeds assessment of neuropathic symptoms and signs. ${ }^{3}$ These neuropathic pain questionnaires generally consist of a selected list of pain descriptors associated with neuropathic pain syndromes and have been validated for the detection of various types of neuropathic pain in a clinical context. ${ }^{4}$ Higher scores on neuropathic pain questionnaires corresponded to a higher certainty in clinicians that the pain was caused by neuropathic mechanisms. ${ }^{5}$ So far, none of the neuropathic pain questionnaires has been validated for post-stroke pain. Validation is difficult since both the classification and assessment of neuropathic pain after stroke are based on the same somatosensory symptoms and signs, leading to a circular argumentation. Classification based on questionnaires should, therefore, not be the sole basis for the prognosis and treatment of pain after stroke. Instead, the diagnostic work-up of patients with post-stroke pain should involve a thorough assessment of nociceptive and neuropathic pain complaints and somatosensory functions. 35,67

\section{Signs}

Clinical examination and quantitative sensory testing (QST)

Table 2.2 provides an overview of clinical and quantitative sensory tests to assess modality-specific receptors, primary afferents and central somatosensory pathways. 
Table 2.2 Clinical examination and QST.

\begin{tabular}{|c|c|c|c|c|c|c|}
\hline Mo & Stimulus & Receptors & Fiber & $\begin{array}{l}\text { Spinal } \\
\text { pathway }\end{array}$ & Clinical examination & QST \\
\hline \multirow[t]{6}{*}{ M } & Light touch & LTM & $A \beta$ & DMLS & Cotton wool tip & Semmes Weinstein (detection threshold) \\
\hline & Sharpness & $\begin{array}{l}\text { LTM \& free nerve } \\
\text { endings }\end{array}$ & $A \delta$ & $\mathrm{STT}$ & Pinprick & Calibrated pins (detection threshold) \\
\hline & Vibration & LTM & $A \beta$ & DMLS & Tuning fork & Vibrameter (detection threshold) \\
\hline & Discriminative & LTM & $A \beta$ & DMLS & $\begin{array}{l}\text { e.g. stereognosis, } 2 \text { point } \\
\text { discrimination }\end{array}$ & $\mathrm{x}$ \\
\hline & Proprioception & $\begin{array}{l}\text { Muscle spindles, joint } \\
\text { kinesthetic rec. }\end{array}$ & $|a| \mid$, & DMLS & Position sense & $\mathrm{cos}^{\circ} \mathrm{sec}$ \\
\hline & Pressure pain & LTM , HTM & $A \delta, C$ & $\mathrm{STT}$ & Examiner's thumb & Algometer (pressure pain threshold) \\
\hline \multirow[t]{4}{*}{$\mathrm{T}$} & Cold & Thermo-receptors & A $\delta$ & $\mathrm{STT}$ & $\begin{array}{l}\text { Cold metal object, thermo- } \\
\text { roller/tube }\end{array}$ & $\begin{array}{l}\text { Computerized thermal testing (detection } \\
\text { threshold) }\end{array}$ \\
\hline & Warmth & Thermo-receptors & C & $\mathrm{STT}$ & Thermo-roller/tube & $\begin{array}{l}\text { Computerized thermal testing (detection } \\
\text { threshold) }\end{array}$ \\
\hline & Cold pain & $\begin{array}{l}\text { Thermal/polymodal } \\
\text { nociceptors }\end{array}$ & $A \delta, C$ & $\mathrm{STT}$ & $x$ & $\begin{array}{l}\text { Computerized thermal testing (Cold pain } \\
\text { threshold) }\end{array}$ \\
\hline & Heat pain & $\begin{array}{l}\text { Thermal/polymodal } \\
\text { nociceptors }\end{array}$ & $A \delta, C$ & $\mathrm{STT}$ & $x$ & $\begin{array}{l}\text { Computerized thermal testing (Heat pain } \\
\text { threshold), Laser (laser pain threshold) }\end{array}$ \\
\hline \multirow[t]{3}{*}{$E$} & Sensation & none & $A \beta$ & DMLS & $x$ & $\begin{array}{l}\text { Electrical stimulator (sensation } \\
\text { threshold) }\end{array}$ \\
\hline & Pain & none & $A \delta(A \beta)$ & $\begin{array}{l}\text { STT } \\
\text { (DMLS) }\end{array}$ & $x$ & Electrical stimulator (pain threshold) \\
\hline & Pain tolerance & none & $A \delta, C(A \beta)$ & $\begin{array}{l}\text { STT } \\
\text { (DMLS) }\end{array}$ & $x$ & $\begin{array}{l}\text { Electrical stimulator (pain tolerance } \\
\text { threshold) }\end{array}$ \\
\hline
\end{tabular}

M o: modality; M: mechanical, T: thermal; E: electrical; LTM: low threshold mechanic; HTM: high threshold mechanic; DM LS: dorsomedial lemniscal system; STT: spinothalamic tract; QST: quantitative sensory testing. 
Most of these tests are regarded to be essential in the diagnostic work-up of neuropathic pain and provide a good starting point for the assessment of somatosensory abnormalities in PSSP. $6,11,16,25,26,82,97$

QST involves the application of stimuli with a predetermined intensity and frequency. Stimuli may be applied in several ways. The method of limits, using step-wise ascending and/ or descending stimulus intensities, is most commonly used.9,69 In this way, several sensory thresholds may be established. The minimal intensity to perceive a stimulus is the sensation threshold, the minimal intensity of a stimulus that is perceived as painful is the pain threshold, and the maximum intensity of a stimulus that evokes pain and that a subject is willing to tolerate in a given situation is the pain tolerance threshold (see Table 2.1).43 Combined with a pain intensity rating scale, these thresholds may be used to scale stimulus input for stimulus-response functions.

The advantage of QST over clinical testing is that it is better standardized, it allows assessment of abnormalities in affected and unaffected body regions, and it can be used to quantify (rather than merely identify) positive and negative sensory signs. ${ }^{26}$ However, both clinical testing and QST are dependent on the cooperation and judgment of the patient and, thus, remain subjective outcome measures.93 In addition, QST is more demanding in terms of cognitive function, requires training, and the necessary equipment is mostly lab-bound and expensive. Therefore, QST cannot be used in all populations and settings.9,69

So far, somatosensory assessment in patients with PSSP has mainly involved standard clinical neurological examination. PSSP has been shown to be associated with a loss of tactile and/or thermal sensations at the affected side.21,22,42,87 However, most of these studies mainly focused on the assessment of negative symptoms and signs. Only one study reported positive signs (i.e. allodynia) in patients with PSSP. 87

Moreover, the precise relation between these somatosensory changes, pain severity and the quality of shoulder pain was not investigated and, thus, remained unclear.

\section{Experimental methods}

In healthy subjects, the application of a tonic painful conditioning stimulus (e.g. a cold water bath) results in reduced pain in response to a painful test stimulus. This reduction in pain intensity (e.g. pain threshold increases, VAS score decreases) induced by the conditioning stimulus is thought to be mediated by DNIC and was recently termed conditioned pain modulation (CPM).57,81,94 In several types of persistent pain, CPM is reduced or does not occur.38,68 In addition, reduced CPM has been shown to predict the development of persistent post-operative pain. ${ }^{55} \mathrm{CPM}$ may therefore serve as a tool to assess the effectiveness of endogenous pain modulation. ${ }^{81}$ 
Cortical changes related to the presence of clinical pain or to the processing of noxious or innocuous somatosensory stimuli can be measured in various ways, including functional magnetic resonance imaging (fMRI), positron emission tomography (PET) and electroencephalography (EEG).74 The temporal and (to a lesser extent) spatial characteristics of somatosensory excitability can be assessed by measuring brain scalp activation using EEG in response to somatosensory stimuli applied to the skin or to a peripheral nerve. The timing of these so-called evoked potentials (EPs) is dependent on the modality of the stimulus (e.g. laser, electrical) and reflects both sensory-discriminative (early components) as well as cognitive-evaluative (late components) somatosensory processing. $.0,92,96$

\section{Conclusions}

Pain mechanisms underlying PSSP are likely to be complex and may involve both nociceptive and neuropathic mechanisms in both the peripheral and central nervous system. A better understanding of PSSP mechanisms starts with dedicated assessment of the pain complaints and the somatosensory system. Somatosensory assessment in patients with PSSP has, so far, been limited to clinical examination. Therefore, studies aiming to further characterize somatosensory functions in patients with PSSP (initially) need to take a broad methodological approach including clinical as well as more experimental pain research tools. Our research group has recently worked on study protocols applying this theoretical framework and some of these tools to further address the pathophysiology of persistent PSSP, and results are promising. Notably, we showed that persistent PSSP in the chronic phase after stroke was consistently associated with somatosensory loss as well as with somatosensory sensitization 65,67 and with central changes related to altered cognitiveevaluative somatosensory processing62. Many patients presented with neuropathic pain complaints67, which may contribute to diagnostic uncertainties in the clinic as well as in post-stroke pain research ${ }^{63}$. Most importantly, we showed that the influence of the presumed initiating factors may gradually decrease during the persistence of PSSP and that pain perpetuation may be related to a vicious circle of pain, limited range of motion, reinjury and somatosensory sensitization.64,66 The results of these studies warrant further investigations of peripheral and central pain mechanisms in patients with PSSP. Most importantly, such studies may explain why persistent PSSP and unsatisfactory pain relief are common after stroke, despite active prevention and treatment strategies, and may provide a basis for improved clinical management of PSSP. 


\section{References}

1 Apkarian AV, Bushnell MC, Treede RD, Zubieta JK. Human brain mechanisms of pain perception and regulation in health and disease. Eur J Pain 9:463484, 2005.

2 Arendt-Nielsen L, Sluka KA, Nie HL. Experimental muscle pain impairs descending inhibition. Pain 140:465471, 2008.

3 Bennett $M$. The LANSS Pain Scale: the Leeds assessment of neuropathic symptoms and signs. Pain 92:147-157, 2001.

4 Bennett MI, Attal N, Backonja MM, Baron R, Bouhassira D, Freynhagen R, Scholz J, Tolle TR, Wittchen HU, Jensen TS. Using screening tools to identify neuropathic pain. Pain 127:199-203, 2007.

5 Bennett MI, Smith BH, Torrance N, Lee A). Can pain can be more or less neuropathic? Comparison of symptom assessment tools with ratings of certainty by clinicians. Pain 122:289294, 2006.

6 Boivie J. Central pain and the role of quantitative sensory testing (QST) in research and diagnosis. Eur J Pain 7:339-343, 2003.

7 Borsook D, Becerra L, Carlezon WA, Jr., Shaw M, Renshaw P, Elman I, Levine J. Reward-aversion circuitry in analgesia and pain: implications for psychiatric disorders. Eur J Pain 11:7-20, 2007.

8 Bouhassira D, Attal $\mathrm{N}$, Alchaar $\mathrm{H}$, Boureau F, Brochet B, Bruxelle J, Cunin G, Fermanian J, Ginies P, GrunOverdyking A, Jafari-Schluep $H$, LanteriMinet $M$, Laurent B, Mick G, Serrie A, Valade $D$, Vicaut E. Comparison of pain syndromes associated with nervous or somatic lesions and development of a new neuropathic pain diagnostic questionnaire (DN4). Pain 114:29-36, 2005.

Chong PS, Cros DP. Technology literature review: quantitative sensory testing. Muscle Nerve 29:734-747, 2004.

10 Coderre TJ, Katz J. Peripheral and central hyperexcitability: Differential signs and symptoms in persistent pain. Behav Brain Sci 20:404-419, 1997.

11 Cruccu G, Anand P, Attal N, GarciaLarrea L, Haanpaa M, Jorum E, Serra J, Jensen TS. EFNS guidelines on neuropathic pain assessment. Eur J Neurol 11:153-162, 2004.

12 Curatolo $M$, Arendt-Nielsen $L$, Petersen-Felix S. Central Hypersensitivity in Chronic Pain: Mechanisms and Clinical Implications. Phys Med Rehabil Clin N Am 17:287302, 2006.

13 De Broucker T, Cesaro P, Willer JC, Le Bars D. Diffuse noxious inhibitory controls in man. Involvement of the spinoreticular tract. Brain 113:12231234, 1990.

14 Dick BD, Rashiq S. Disruption of attention and working memory traces in individuals with chronic pain. Anesth Analg 104:1223-1229, 2007.

15 Diserens $K$, Vuadens $P$, Michel $P$, Reichhart M, Herrmann FR, Arnold P, Bogousslavsky J, Ghika J. Acute autonomic dysfunction contralateral to acute strokes: a prospective study of 100 consecutive cases. Eur J Neurol 13:1245-1250, 2006.

16 Dworkin RH, Backonja M, Rowbotham MC, Allen RR, Argoff CR, Bennett GJ, Bushnell MC, Farrar JT, Galer BS, Haythornthwaite JA, Hewitt DJ, Loeser JD, M ax MB, Saltarelli M, Schmader KE, 
Stein C, Thompson D, Turk DC, Wallace MS, Watkins LR, Weinstein SM. Advances in neuropathic pain: diagnosis, mechanisms, and treatment recommendations. Arch Neurol 60:1524-1534, 2003.

Eccleston C, Crombez G. Pain demands attention: A cognitive-affective model of the interruptive function of pain. Psychol Bull 125:356-366, 1999.

18

Edwards RR, Fillingim RB. Self-reported pain sensitivity: Lack of correlation with pain threshold and tolerance. Eur J Pain 11:594-598, 2007.

Finnerup NB, Jensen TS. M echanisms of disease: mechanism-based classification of neuropathic pain-a critical analysis. Nat Clin Pract Neurol 2:107-115, 2006.

20 Fuchs PN, Peng YB. Psychophysical evidence that central sensitization contributes to secondary mechanical hyperalgesia in human subjects. Semin Pain M ed 1:132-138, 2003.

21 Gamble GE, Barberan E, Bowsher D, Tyrrell PJ, Jones AK. Post stroke shoulder pain: more common than previously realized. Eur J Pain 4:313$315,2000$.

22 Gamble GE, Barberan E, Laasch HU, Bowsher D, Tyrrell PJ, Jones AK. Poststroke shoulder pain: a prospective study of the association and risk factors in 152 patients from a consecutive cohort of 205 patients presenting with stroke. Eur J Pain 6:467-474, 2002.

23 Gureje 0. Psychiatric aspects of pain. Curr Opin Psychiatry 20:42-46, 2007.

24 Gustafsson L, Yates K. Are we applying interventions with research evidence when targeting secondary complications of the stroke-affected upper limb. Aust Occup Ther J 56:428435, 2009.
25 Hansson P. Neuropathic pain: clinical characteristics and diagnostic workup. Eur J Pain 6:47-50, 2002.

26 Hansson P, Backonja M, Bouhassira D. Usefulness and limitations of quantitative sensory testing: Clinical and research application in neuropathic pain states. Pain 129:256-259, 2007.

27 Henry JL. Central Poststroke Pain: An Animal Model. In: Henry JL, Panju A, Yashpal K, editors. Central Neuropathic Pain: Focus on Poststroke Pain. Seattle: IASP Press, 2007. pp. 171-180.

28 Janssen SA. Negative affect and sensitization to pain. Scand J Psychol 43:131-137, 2002.

29 Jensen TS, Baron R. Translation of symptoms and signs into mechanisms in neuropathic pain. Pain 102:1-8, 2003.

30 Jones $A K$, Watabe $\mathrm{H}$, Cunningham VJ, Jones T. Cerebral decreases in opioid receptor binding in patients with central neuropathic pain measured by [11C]diprenorphine binding and PET. Eur J Pain 8:479-485, 2004.

31 Jørum E, Warncke T, Stubhaug A. Cold allodynia and hyperalgesia in neuropathic pain: the effect of $\mathrm{N}$ methyl--aspartate (NMDA) receptor antagonist ketamine - a double-blind, cross-over comparison with alfentanil and placebo. Pain 101:229-235, 2003.

32 Kakigi R, Inui K, Tran DT, Qiu Y, Wang X, Watanabe S, Hoshiyama M. Human brain processing and central mechanisms of pain as observed by electro- and magnetoencephalography. J Chin Med Assoc 67:377-386, 2004.

33 Klede M, Handwerker HO, Schmelz M. Central origin of secondary mechanical hyperalgesia. J Neurophysiol 90:353359, 2003. 
$34 \quad$ Klein T, Magerl W, Rolke R, Treede R-D. Human surrogate models of neuropathic pain. Pain 115:227-233, 2005.

Klit $\mathrm{H}$, Finnerup NB, Jensen TS. Central post-stroke pain: clinical characteristics, pathophysiology, and management. Lancet Neurol 8:857-868, 2009.

36 Koltzenburg $M$, Lundberg LER, Torebjörk HE. Dynamic and static components of mechanical hyperalgesia in human hairy skin. Pain 51:207-219, 1992.

37 Korpelainen JT, Sotaniemi KA, Myllyla VV. Autonomic nervous system disorders in stroke. Clin Auton Res 9:325-333, 1999.

38 Kosek E, Ordeberg G. Lack of pressure pain modulation by heterotopic noxious conditioning stimulation in patients with painful osteoarthritis before, but not following, surgical pain relief. Pain 88:69-78, 2000.

39 Le Bars D, Dickenson AH, Besson JM. Diffuse noxious inhibitory controls (DNIC). I. Effects on dorsal horn convergent neurones in the rat. Pain 6:283-304, 1979.

Leffler AS, Hansson P, Kosek E. Somatosensory perception in a remote pain-free area and function of diffuse noxious inhibitory controls (DNIC) in patients suffering from long-term trapezius myalgia. Eur J Pain 6:149-159, 2002.

41 Legrain V, Damme SV, Eccleston C, Davis KD, Seminowicz DA, Crombez G. A neurocognitive model of attention to pain: Behavioral and neuroimaging evidence. Pain 144:230-232, 2009.

42 Lindgren I, Jönsson AC, Norrving B, Lindgren A. Shoulder pain after stroke: A prospective population-based study. Stroke 38:343-348, 2007.
43 Loeser JD, Treede R-D. The Kyoto protocol of IASP Basic Pain Terminology. Pain 137:473-477, 2008.

44 Lui F, Duzzi D, Corradini M, Serafini M, Baraldi $P$, Porro CA. Touch or pain? Spatio-temporal patterns of cortical fM RI activity following brief mechanical stimuli. Pain 138:362-374, 2008.

45 May A. Chronic pain may change the structure of the brain. Pain 137:7-15, 2008.

46 Melzack R. The McGill Pain Questionnaire: major properties and scoring methods. Pain 1:277-299, 1975.

47 Melzack R, Wall PD. Pain mechanisms: a new theory. Science 150:971-979, 1965.

$48 \quad$ Merskey H, Bogduk N editors|. Title|, Vol. Volume|. City| : Publisher|, Year|. ?]

49 Millan MJ. Descending control of pain. Prog Neurobiol 66:355-474, 2002.

50 Miltner W, Johnson R, Jr., Braun C, Larbig W. Somatosensory event-related potentials to painful and non-painful stimuli: effects of attention. Pain 38:303-312, 1989.

51 Moseley GL. A pain neuromatrix approach to patients with chronic pain. M an Ther 8:130-140, 2003.

52 Ohara PT, Vit JP, Jasmin L. Cortical modulation of pain. Cell Mol Life Sci 62:44-52, 2005.

53 Ohara S, Crone NE, Weiss N, Lenz FA. Analysis of synchrony demonstrates 'pain networks' defined by rapidly switching, task-specific, functional connectivity between pain-related cortical structures. Pain 123:244-253, 2006.

54 Peyron R, Laurent B, Garcia-Larrea L. Functional imaging of brain responses 
to pain. A review and meta-analysis (2000). Neurophysiol Clin 30:263-288, 2000.

Pfau DB, Rolke R, Nickel R, Treede RD, Daublaender $M$. Somatosensory profiles in subgroups of patients with myogenic temporomandibular disorders and fibromyalgia syndrome. Pain 147:72-83, 2009.

56 Pruimboom L, van Dam AC. Chronic pain: A non-use disease. Med Hypotheses, 2006.

57 Pud D, Granovsky Y, Yarnitsky D. The methodology of experimentally induced diffuse noxious inhibitory control (DNIC)-like effect in humans. Pain, 2009.

58 Rasmussen PV, Sindrup SH, Jensen TS, Bach FW. Symptoms and signs in patients with suspected neuropathic pain. Pain 110:461-469, 2004.

Renzenbrink GJ, IJzerman MJ. Percutaneous neuromuscular electrical stimulation (P-NMES) for treating shoulder pain in chronic hemiplegia. Effects on shoulder pain and quality of life. Clin Rehabil 18:359-365, 2004.

Rolke R, Baron R, Maier C, Tolle TR, Treede RD, Beyer $A$, Binder $A$, Birbaumer N, Birklein F, Botefur IC, Braune $S$, Flor $H$, Huge $V$, Klug $R$, Landwehrmeyer GB, Magerl $W$, Maihofner C, Rolko C, Schaub C, Scherens A, Sprenger $T$, Valet $M$, Wasserka B. Quantitative sensory testing in the German Research Network on Neuropathic Pain (DFNS): standardized protocol and reference values. Pain 123:231-243, 2006.

61 Rolke R, Magerl W, Campbell KA, Schalber C, Caspari S, Birklein F, Treede RD. Quantitative sensory testing: a comprehensive protocol for clinical trials. Eur J Pain 10:77-88, 2006.
62 Roosink M, Buitenweg JR, Renzenbrink GJ, Van Dongen RTM, Geurts AC, IJzerman MJ. Altered cortical somatosensory processing in chronic stroke: a relationship with post-stroke shoulder pain. NeuroRehabilitation in press, 2010.

63 Roosink M, Geurts ACH, IJzerman MJ. Defining post-stroke pain: diagnostic challenges. Lancet Neurol 9:344-344, 2010.

64 Roosink M, Renzenbrink GJ, Buitenweg JR, Van Dongen RTM, Geurts AC, IJzerman MJ. Persistent shoulder pain in the first six months after stroke: results of a prospective cohort study. Arch Phys Rehab Med accepted pending revisions, 2010.

65 Roosink M, Renzenbrink GJ, Buitenweg JR, van Dongen RTM, Geurts AC, IJzerman MJ. Somatosensory symptoms and signs and conditioned pain modulation in chronic post-stroke shoulder pain. J Pain in press, 2010.

66 Roosink $M$, Van Dongen RTM, Buitenweg JR, Renzenbrink GJ, Geurts $A C$, IJzerman MJ. Somatosensory sensitization in persistent shoulder pain after stroke: results of a prospective cohort study. Eur J Pain submitted for publication, 2010.

67 Roosink $M$, Van Dongen RTM, Renzenbrink GJ, IJzerman MJ. Classifying post-stroke shoulder pain: Can the DN4 be helpful? Eur J Pain 15:99-102, 2011.

68 Sandrini G, Rossi P, Milanov I, Serrao M, Cecchini AP, Nappi G. Abnormal modulatory influence of diffuse noxious inhibitory controls in migraine and chronic tension-type headache patients. Cephalalgia 26:782-789, 2006.

69 Shy ME, Frohman EM, So YT, Arezzo JC, Cornblath DR, Giuliani MJ, Kincaid JC, Ochoa JL, Parry GJ, Weimer LH. Quantitative sensory testing: report of 
the Therapeutics and Technology Assessment Subcommittee of the American Academy of Neurology. Neurology 60:898-904, 2003.

70

Suzuki R, Rygh LJ, Dickenson AH. Bad news from the brain: descending $5-\mathrm{HT}$ pathways that control spinal pain processing. Trends Pharmacol Sci 25:613-617, 2004.

71 Teasell RW, Bhogal SK, Foley NC. Painful Hemiplegic Shoulder. In: Teasell RW, Bhogal SK, Foley NC, editors. Evidence-based Review of Stroke Rehabilitation. London, Ontario, Canada: University of Western Ontario, 2007. pp. 1-57.

72 Terkelsen AJ, Bach FW, Jensen TS. Experimental forearm immobilization in humans induces cold and mechanical hyperalgesia. Anesthesiology 109:297307, 2008.

73 Treede RD, Jensen TS, Campbell JN, Cruccu G, Dostrovsky JO, Griffin JW, Hansson $P$, Hughes $R$, Nurmikko $T$, Serra J. Neuropathic pain: redefinition and a grading system for clinical and research purposes. Neurology 70:16301635, 2008.

74 Treede RD, Kenshalo DR, Gracely RH, Jones AK. The cortical representation of pain. Pain 79:105-111, 1999.

Turk DC. Cognitive-behavioral approach to the treatment of chronic pain patients. Reg Anesth Pain Med 28:573579, 2003.

Turk DC. Understanding pain sufferers: the role of cognitive processes. Spine J 4:1-7, 2004.

77 Turner-Stokes L, Jackson D. Assessment of shoulder pain in hemiplegia: sensitivity of the ShoulderQ. Disabil Rehabil 28:389-395, 2006.

78 Usunoff KG, Popratiloff A, Schmitt O, Wree $A$. Functional neuroanatomy of pain. Adv Anat Embryol Cell Biol 184:1115, 2006.

79 Van der Kloot WA, Oostendorp RA, Van der Meij J, Van den Heuvel J. [The Dutch version of the McGill pain questionnaire: a reliable pain questionnaire]. Ned Tijdschr Geneeskd 139:669-673, 1995.

80 Van Seventer R, Vos C, Meerding W, M ear I, Le Gal M, Bouhassira D, Huygen FJ. Linguistic validation of the DN4 for use in international studies. Eur J Pain, 2009.

81 van Wijk G, Veldhuijzen DS. Perspective on Diffuse Noxious Inhibitory Controls as a Model of Endogenous Pain Modulation in Clinical Pain Syndromes. J Pain 11:408-419, 2010.

82 Walk $D$, Sehgal $N$, Moeller-Bertram $T$, Edwards RR, Wasan A, Wallace $M$, Irving G, Argoff C, Backonja MM. Quantitative sensory testing and mapping: a review of nonautomated quantitative methods for examination of the patient with neuropathic pain. Clin J Pain 25:632-640, 2009.

83 Wall PD, Melzack R. Textbook of pain. London: Churchill Livingstone, 1999.

84 Walsh K. M anagement of shoulder pain in patients with stroke. Postgrad Med J 77:645-649, 2001.

85 Wasner G, Lee BB, Engel S, McLachlan E. Residual spinothalamic tract pathways predict development of central pain after spinal cord injury. Brain 131:2387-2400, 2008.

86 Wasner G, Schattschneider J, Binder A, Baron R. Topical menthol--a human model for cold pain by activation and sensitization of $\mathrm{C}$ nociceptors. Brain 127:1159-1171, 2004.

87 Widar $M$, Samuelsson L, KarlssonTivenius S, Ahlstrom G. Long-term pain 
conditions after a stroke. J Rehabil Med 34:165-170, 2002.

Willoch $F$, Schindler F, Wester HJ, Empl $M$, Straube A, Schwaiger $M$, Conrad B, Tolle TR. Central poststroke pain and reduced opioid receptor binding within pain processing circuitries: a [11C]diprenorphine PET study. Pain 108:213-220, 2004.

89 Wissel J, Schelosky LD, Scott J, Christe W, Faiss JH, Mueller J. Early development of spasticity following stroke: A prospective, observational trial. J Neurol 257:1067-1072, 2010.

90 Woolf Cl, Bennett GJ, Doherty $M$, Dubner $R$, Kidd $B$, Koltzenburg $M$, Lipton R, Loeser JD, Payne R, Torebjork E. Towards a mechanism-based classification of pain? Pain 77:227-229, 1998.

91 Woolf Cl, Decosterd I. Implications of recent advances in the understanding of pain pathophysiology for the assessment of pain in patients. Pain 82:S141-S147, 1999.

92 Yamasaki $H$, Kakigi $R$, Watanabe $S$, Hoshiyama M. Effects of distraction on pain-related somatosensory evoked magnetic fields and potentials following painful electrical stimulation. Brain Res Cogn Brain Res 9:165-175, 2000.

93 Yarnitsky D. Quantitative sensory testing. Muscle Nerve 20:198-204, 1997.

94 Yarnitsky D, Arendt-Nielsen L, Bouhassira D, Edwards RR, Fillingim RB, Granot M, Hansson P, Lautenbacher $S$, $M$ archand S, Wilder-Smith 0 . Recommendations on terminology and practice of psychophysical DNIC testing. Eur J Pain 14:339, 2010.

95 Yarnitsky D, Crispel $Y$, Eisenberg $E$, Granovsky Y, Ben-Nun A, Sprecher E, Best LA, Granot M. Prediction of chronic post-operative pain: Pre- operative DNIC testing identifies patients at risk. Pain 138:22-28, 2008.

96 Zaslansky $R$, Sprecher $E$, Katz $Y$, Rozenberg B, Hemli JA, Yarnitsky D. Pain-evoked potentials: what do they really measure? Electroencephalogr Clin Neurophysiol 100:384-391, 1996.

97 Zaslansky R, Yarnitsky D. Clinical applications of quantitative sensory testing (QST). J Neurol Sci 153:215-238, 1998.

98 Ziegler EA, Magerl W, Meyer RA, Treede RD. Secondary hyperalgesia to punctate mechanical stimuli. Central sensitization to A-fibre nociceptor input. Brain 122:2245-2257, 1999. 

Part II

Cross-sectional studies of persistent PSSP 



\title{
Chapter 3
}

\section{Somatosensory symptoms and signs and conditioned pain modulation in chronic post-stroke shoulder pain}

\author{
M eyke Roosink \\ Gerbert J Renzenbrink \\ Jan R Buitenweg \\ Robert TM van Dongen \\ Alexander $\mathrm{CH}$ Geurts \\ Maarten J IJzerman
}




\section{Abstract}

Persistent shoulder pain is a common complication after stroke. Its etiology and underlying mechanisms are not well understood and treatment is generally unsatisfactory. The objective of this study was to assess the role of central sensitization and disinhibition in chronic stroke patients with chronic PSSP $(n=19)$, pain-free stroke patients $(n=29)$ and healthy controls $(n=23)$. Positive and negative somatosensory symptoms and signs were assessed using clinical examination and electrical and mechanical quantitative sensory testing (QST). Conditioned pain modulation (CPM) was assessed by comparing QST thresholds before and after applying a cold pressor test. Sensory abnormalities were more frequently observed and more severe in patients with PSSP. These included positive signs, such as allodynia at the affected side and generalized hyperalgesia at the unaffected side. CPM was similar in stroke patients and healthy controls. This study showed that chronic PSSP was associated with several positive and negative somatosensory signs, implicating a role for central sensitization and possibly for disinhibition. Since the causal relationship remains unclear, and may be related to either neuroplasticity induced by ongoing nociception as well as to the neuropathic brain lesion, prospective studies are warranted. Prevention and treatment of PSSP could benefit from a more detailed analysis of both peripheral and central pain mechanisms. 


\section{Introduction}

Pain is a common complication after stroke.20,33 Post-stroke pain is a great burden for the patient and impedes rehabilitation. ${ }^{47,57}$ One of the most reported types is post-stroke shoulder pain (PSSP) which typically develops at the affected side after two to three months. ${ }^{13,15,20,41}$ Although its etiology is largely unknown, several clinical conditions such as spasticity, glenohumeral subluxation, capsular inflammation, peripheral neuropathy, central post-stroke pain (CPSP) and autonomic dysfunction have been related to PSSP.49,52,64 Furthermore, several studies have suggested that reduced motor function14,15,17,31,33,39, depression ${ }^{14,15,33}$ and reduced somatosensory function ${ }^{14,15,17,33,35,61}$ may contribute to the development of PSSP. Clinical presentations of PSSP, CPSP and post-stroke complex regional pain syndrome type 1 (shoulder-hand syndrome) may show considerable overlap complicating the diagnosis and prognosis of post-stroke pain..$^{24,45}$

PSSP may resolve spontaneously in the course of rehabilitation, but is persistent ( $>14$ months) in $65 \%$ of the patients. ${ }^{31}$ The evidence for effective therapeutic interventions for PSSP is lacking or inconsistent and, in the case of successful treatment, it is often unclear what mechanisms have been responsible for the pain reduction. ${ }^{42}$ Together, this suggests that the pain mechanisms underlying PSSP development and maintenance may be more complex than previously realized, and that the traditional view and approach of PSSP as purely ongoing nociceptive pain may need revision. 45

The assessment of positive and negative somatosensory symptoms and signs in relation to the pain complaints is one of the first steps towards a better understanding of pain mechanisms.43,44 Although the relationship between symptoms and signs and pain mechanisms is still under debate ${ }^{18}$, several symptoms and signs, such as sensory loss (e.g. spinothalamocortical tract lesions), allodynia, and generalized hyperalgesia, have been associated with experimentally induced central sensitization ${ }^{21,25,59}$ and/ or various forms of chronic nociceptive ${ }^{48}$ or neuropathic ${ }^{6,10,58}$ pain. In addition, endogenous pain modulation, involving supraspinal diffuse noxious inhibitory controls (DNIC), ${ }^{29}$ has been shown to be impaired in various types of chronic pain, such as painful osteoarthritis ${ }^{28}$, whiplash ${ }^{22}$ and neuropathic pain ${ }^{62}$. So far, little is known about the role of central sensitization or disinhibition in the development and maintenance of PSSP.

The objective of this study was to assess the role of central sensitization and disinhibition in chronic stroke patients (>6 months post-stroke) with chronic (duration $>3$ months) PSSP $(\mathrm{n}=19)$, pain-free stroke patients $(\mathrm{n}=29)$ and healthy controls $(\mathrm{n}=23)$. Positive and negative somatosensory symptoms and signs and were assessed using clinical examination and electrical and mechanical quantitative sensory testing (QST). Conditioned pain modulation (CPM) was assessed by comparing QST thresholds before and after applying a cold pressor 
test. It was expected that both the frequency as well as the severity of somatosensory abnormalities would be higher in the patients with PSSP and that, in addition to previously reported associations with negative signs, PSSP would be associated with positive somatosensory symptoms and signs indicative of central sensitization and/ or disinhibition such as allodynia, generalized hyperalgesia and impaired endogenous inhibitory pain modulation.

\section{Methods}

\section{Subjects}

This study included stroke patients with persistent shoulder pain (PSSP, $n=19$ ), pain-free stroke patients $(\mathrm{PF}, \mathrm{n}=29)$ and healthy controls $(\mathrm{HC}, \mathrm{n}=23)$. Stroke patients were recruited in two regional rehabilitation centers in the Netherlands (Roessingh Rehabilitation Center in Enschede and Sint Maartenskliniek in Nijmegen). The outpatient databases were searched for stroke patients that had been hospitalized in the two years prior to the start of inclusion (fall 2007). Patients fulfilling the inclusion and exclusion criteria were approached by mail. In addition, patients visiting the outpatient clinics with shoulder pain complaints were asked by their treating physician if they could be approached by one of the researchers (M.R.) by mail. Healthy subjects (age 40 - 60) were recruited through advertisements in local community centers and newspapers.

All stroke patients were 18 years or older and sustained a unilateral brain infarction with an onset at least 6 months prior to participation. For stroke patients to be included in the PSSP group, shoulder pain had to be unilateral, be confined to the affected side, have an onset after stroke and be persistent (daily pain, duration longer than 3 subsequent months). Patients were included in the PF group if they had no long-lasting ( $>1$ week in the last 3 months) pain complaints. Exclusion criteria were: pregnancy, trauma, infection, signs of any possible concomitant neurological condition (e.g. multiple sclerosis, HIV/ AIDS, peripheral neuropathy), not being able to reliably determine sensory thresholds during a training session prior to the experiment and other pain complaints than 'simple' shoulder pain (e.g. CPSP24, wide-spread pain or shoulder-hand syndrome). Healthy control subjects had to be free of any neurological or psychiatric disorder, diabetes mellitus, psychotropic medication or long-lasting ( $>1$ week in the last 3 months) pain complaints. When subjects considered for the PF or HC groups reported minor pain complaints at the time of the experiment, the experiment was postponed until subjects were pain-free for at least 2 weeks. The study was approved by the human ethics committee of the Roessingh Rehabilitation Center in Enschede, The Netherlands. All subjects received written and oral information about the 
study protocol and all participants gave informed written consent prior to their participation.

\section{Demographic data and medical examination}

General demographic characteristics such age, gender and (for the patients) lesion side, stroke onset and medication use were registered. Shoulder pain was evaluated both at rest and during movement with an 11-point Numeric Rating Scale (NRS, $0=$ no pain, $10=$ maximum conceivable pain). The emotional state was assessed using the ZUNG self-rating depression scale (score: 20 - 80) which has been validated for both healthy subjects and stroke patients. ${ }^{51}$ Cognitive state was assessed using the Mini Mental State Exam (MMSE, score: 0 - 30, cognitive impairment was defined as MMSE score < 24). ${ }^{0}$ Physical examination included the assessment of trophic changes in the arms and hands (severe color or perspiration changes or asymmetry, edema, assessed by visual inspection and subject reports), glenohumeral subluxation (assessed by palpation, scored in steps of 5 $\mathrm{mm}$ ), pain-free range of motion for passive shoulder elevation (0 - 180 degrees) and external rotation ( 0 - 90 degrees), severity of paresis of the upper extremity (assessed with the Motricity Index, $0=$ completely paretic, $100=$ no paresis $)^{9}$ and spasticity of elbow flexors and shoulder internal rotators (Modified Ashworth Scale, score: 0 - 5, spasticity was defined as MAS $>1)^{4}$. For passive pain-free ranges of motion (shoulder elevation and external rotation) a ratio between sides was calculated for further analysis (PSSP and PF: affected/ unaffected, HC: non-dominant/ dominant).

\section{Routine clinical examination}

Subjects were tested for sensation to touch, cold and sharpness at both upper arms (C5 dermatome) using, respectively, a cotton wool swab, a metal tuning fork at room temperature and a 6.65 (force: 300 grams) Semmes Weinstein filament (North Coast Medical, Inc, UK).56 Tests were always first performed at the unaffected (in PSSP and PF patients) or dominant (in HC) side. Proprioception was tested at the thumbs of both hands (joint position sense). Subjects had to indicate whether sensation was equal, diminished or increased compared to the opposite side (affected versus unaffected side in stroke patients, non-dominant versus dominant side in healthy controls). In healthy controls, all tests were perceived as being painless. If any of the evoked sensations was painful in patients, this was considered as allodynia (tactile, cold, sharpness). ${ }^{32}$ All tests were performed by the same experimenter (M.R.) 


\section{Quantitative sensory testing (QST)}

For all tests, the method of limits was used and the start-side of stimulation (affected or unaffected) was randomized between subjects. Modality specific assessment was performed using mechanical QST.18 The tactile detection threshold (TDT) was determined using five Semmes Weinstein filaments (sizes: 2.83, 3.61, 4.31, 4.56, 6.65; Touch-Test Hand Kit, North Coast Medical, Inc, UK). The filaments were applied on the upper arm over the higher and lower part of the middle deltoid muscle (C5 dermatome). The TDT was defined as the smallest filament that could be perceived at both locations. The pressure pain threshold (PPT) was determined using an experimenter-operated pressure-algometer (Somedic, Sweden). A stimulation surface of $1 \mathrm{~cm}^{2}$ and a slope of $50 \mathrm{kPa} / \mathrm{s}$ were used. The maximum pressure that could be delivered was $2000 \mathrm{kPa}$. Subjects were instructed to keep their arm in zero degrees shoulder abduction and 90 degrees elbow flexion to avoid displacement of the muscle. The PPT was determined at both upper arms at 3 locations over the middle deltoid muscle (higher, middle and lower part of the muscle, C5 dermatome). In response to the increasing pressure delivered at the arm by the experimenter, subjects were instructed to verbally indicate when they first perceived the pressure as painful. The 3 PPTs were averaged for further analysis. All mechanical thresholds were determined by the same experimenter (M.R.).

In addition, somatosensory changes were assessed using electrical QST. With electrical QST, the primary afferent is activated directly, without involvement of the peripheral receptor. Differences in electrical and natural QST thresholds can be used to assess the presence of peripheral receptor-mediated (de)sensitization. In the case of PSSP, this is relevant since sensitization may take place at both the peripheral as well as the central level. The electrical sensation threshold (EST), electrical pain threshold (EPT) and electrical pain tolerance threshold (EPTT) were determined using a custom build ambulant stimulator (Ambustim, University of Twente, the Netherlands). This stimulator operated via a Bluetooth connection with a personal computer. The stimulator settings were controlled via custom built software (labVIEW, National Instruments, USA). The stimulator was set to generate electrical pulses with an increasing amplitude (pulse width: $0.2 \mathrm{~ms}$, frequency: $100 \mathrm{~Hz}$, ramp: $0.4 \mathrm{~mA} / \mathrm{s}$, maximum stimulus amplitude: $16 \mathrm{~mA}$ ). The stimulator was attached to the upper arm via two Ag/ AgCl electrodes (stimulation surface: $95 \mathrm{~mm}^{2}$, AMBU, Denmark) that were placed just above the deltoid tuberosity of the humerus. Subjects could manually activate the stimulator by pressing a switch. To determine the EST, subjects were instructed to release the switch when the electrical pulses were perceived for the first time. To determine the EPT, subjects were instructed to release the switch when the electrical pulses were perceived as both stinging and annoying. To determine the EPTT subjects were 
instructed to release the switch when the electrical pulses were perceived as burning and very annoying. Subjects were trained to determine these thresholds reliably prior to participating in the experiment. All thresholds were determined 4 times on each side. The first threshold was considered a test-measurement. The remaining 3 thresholds were averaged for further analysis.

\section{Conditioned pain modulation}

After QST, subjects underwent a cold pressor test at the hand of the unaffected (in PSSP and PF patients) or dominant (in HC) side. Subjects had to place their hand in a polystyrene box filled with ice-water $(0-0.5 \stackrel{\circ}{\circ})$. The hand was immersed up to the wrist with the fingers spread. Subjects were instructed to keep their hand in the water as long as possible with a maximum of 3 minutes. Immersion time was recorded. After removing the hand from the water, subjects rated the pain in their hand using a NRS ( 0 = no pain, 10 = maximum conceivable pain). Directly afterwards, the EPT and PPT were determined twice at the affected (in PSSP and PF patients) or non-dominant (in HC) upper arm. The thresholds were determined after immersion since not all patients were able to use the patient-operated switch with their affected hand. Threshold determination was similar as before. The 2 thresholds were averaged for further analysis.

\section{Data processing}

For demographic data and medical examination, for each group (PSSP, PF, HC), average and standard deviations or frequencies were determined. For routine clinical examination, frequencies of abnormal, diminished and increased sensation and allodynia or hyperalgesia were calculated for each stimulus. QST thresholds were log-transformed prior to statistical analysis. In unilateral pain syndromes, QST side-to-side differences have shown to be more sensitive for the detection individual sensory abnormalities. 44 Therefore, in addition to the raw data, a within subject ratio was calculated for all QST thresholds (ratio in PSSP and PF patients was obtained by dividing affected/ unaffected, in the HC group by dividing nondominant/ dominant). Moreover, threshold abnormalities were determined by normalizing individual QST ratios of patients to the HC data set using a z-transformation to assess the frequency of individually increased or decreased somatosensory function. ${ }^{44}$ Hypoesthesia (TDT, EST) and hypoalgesia (EPT, EPTT, PPT) were defined as a z-score higher than 2. Hyperesthesia (TDT, EST) and hyperalgesia (EPT, EPTT, PPT) were defined as a z-score lower than -2. Cold pressor effects were assessed using both the pain thresholds determined before and after cold pressor testing as well as by calculating a pre-post ratio (post/ pre). All ratios were log-transformed prior to statistical analysis. ${ }^{44}$ 


\section{Statistical analysis}

Statistical software package SPSS 16.0 for Windows was used (SPSS Inc., Chicago, IL, USA). In order to identify the somatosensory changes related to PSSP, continuous data was statistically tested using one-way analysis of variances (ANOVA) with factor 'Group' (PSSP, PF, HC). The Least Significant Difference was used for post-hoc multiple comparisons. Ordinal data was tested using Chi-square tests. In addition, QST thresholds before and after cold pressor testing were analyzed using a repeated measures ANOVA with within-subjectsfactor 'Cold pressor' (pre, post) and between-subjects-factor 'Group' (PSSP, PF, HC). Differences between groups were attributed to PSSP when a significant difference between PSSP and PF and/ or a significant difference between PSSP and HC was observed.

Possible confounding effects of age, gender, dystrophic changes and depression scores were ruled out using additional multivariate analyses, with either 'QST thresholds' (affected, unaffected, ratios) or 'Cold pressor parameters' (post/pre ratios, immersion time, pain intensity) as dependent factors, 'Group' as a between-subjects-factor and either 'Age', 'Gender', 'Dystrophic changes' or 'ZUNG score' as a covariate. In brief, these analyses showed that gender was significantly related to QST parameters, however only to the electrical pain tolerance and pressure pain thresholds, not to any other parameter. In addition, adding sex as a covariate had no influence on the observed differences between groups for these or any of the other parameters. Therefore, data correction was considered unnecessary.

For all tests, statistical significance was assigned at the $\mathrm{p}<0.05$ level using 2-tailed analysis.

\section{Results}

\section{Demographics and medical examination}

A summary of the demographics and medical examinations for each group is presented in Table 3.1. Analgesics (cox-inhibitors or non-steroidal anti-inflammatory drugs) were used on a regular basis by seven PSSP patients. In addition, some patients used anti-depressants (9 PSSP, 4 PF) and/ or anti-epileptics (3 PSSP, 2 PF) either for pain, depression and/ or epilepsy. Analysis of demographics and medical examinations revealed several differences between groups (see Table 3.1). PSSP was associated with a higher frequency of trophic changes in the arm and hand, higher ZUNG scores and reduced ranges of passive pain-free shoulder elevation and external rotation. PSSP was not associated with the severity of paresis, spasticity or glenohumeral subluxation. 
Table 3.1 Demographics and medical characteristics, mean \pm SD or number of subjects (\%).

\begin{tabular}{|c|c|c|c|c|c|}
\hline & $\begin{array}{c}\text { PSSP } \\
(n=19)\end{array}$ & $\begin{array}{c}\text { PF } \\
(n=29)\end{array}$ & $\begin{array}{c}H C \\
(n=23)\end{array}$ & $\begin{array}{c}p \\
\text { (vs PF) }\end{array}$ & $\begin{array}{c}p \\
\text { (vs HC) }\end{array}$ \\
\hline Age (years) & $57 \pm 7$ & $61 \pm 10$ & $56 \pm 7$ & ns & ns \\
\hline Male & $10(53 \%)$ & $21(72 \%)$ & $10(43 \%)$ & ns & ns \\
\hline Right-hemispheric lesion & $16(84 \%)$ & $12(59 \%)$ & & ns & \\
\hline Time to stroke onset (months) & $22 \pm 14$ & $25 \pm 8$ & & ns & \\
\hline Cognitive deficits & $2(11 \%)$ & $1(3 \%)$ & $0(0 \%)$ & ns & ns \\
\hline Depression score (ZUNG) & $45.4 \pm 6.0$ & $35.9 \pm 6.0$ & $31.0 \pm 4.8$ & $<0.001$ & $<0.001$ \\
\hline Trophic changes hand/arm & $8(42 \%)$ & $3(14 \%)$ & $0(0 \%)$ & ns & 0.001 \\
\hline Severity of paresis (MI) & $46 \pm 38$ & $59 \pm 43$ & $100 \pm 0$ & ns & $<0.001$ \\
\hline ROM abduction & $0.41 \pm 0.19$ & $0.74 \pm 0.27$ & $1.00 \pm 0$ & $<0.001$ & $<0.001$ \\
\hline ROM external rotation & $0.41 \pm 0.34$ & $0.76 \pm 0.19$ & $1.03 \pm 9$ & $<0.001$ & $<0.001$ \\
\hline Spasticity elbow flexion & $15(79 \%)$ & $20(69 \%)$ & $0(0 \%)$ & ns & $<0.001$ \\
\hline $\begin{array}{l}\text { Spasticity shoulder internal } \\
\text { rotation }\end{array}$ & $13(68 \%)$ & $17(58 \%)$ & $0(0 \%)$ & ns & $<0.001$ \\
\hline Glenohumeral subluxation & $10(53 \%)$ & $11(38 \%)$ & $0(0 \%)$ & ns & $<0.001$ \\
\hline Severity $(\mathrm{mm})$ & $3.9 \pm 4.6$ & $3.8 \pm 4.9$ & $0 \pm 0$ & ns & $<0.001$ \\
\hline \multicolumn{6}{|l|}{ Pain intensity (NRS) } \\
\hline Rest & $3.5 \pm 2.8$ & & & & \\
\hline Movement & $5.7 \pm 3.0$ & & & & \\
\hline Pain duration (months) & $19 \pm 13$ & & & & \\
\hline
\end{tabular}

PSSP: stroke patients with post-stroke shoulder pain; PF: pain-free stroke patients; HC: healthy controls; $\mathrm{n}$ : number of subjects; $\mathrm{p}$ : p-value for statistical testing; SD: standard deviation; \%: percentage of patients; ZUNG: Zung self-rating depression scale; MI: Motricity Index; ROM : shoulder pain-free passive range of motion (patients: ratio score affected/unaffected side; HC: ratio score non-dominant/dominant side); NRS: numeric rating scale; ns: not significant ( $p>0.05)$.

\section{Routine clinical examination}

Table 3.2 presents the frequency of subjects with abnormal sensation, allodynia and hyperalgesia for each group. PSSP was associated with diminished touch sensation, abnormal cold sensation (both diminished and increased), cold allodynia, diminished sharpness sensation and sharpness allodynia.

\section{Quantitative sensory testing}

The results of QST are presented in Table 3.3. At the unaffected side, PSSP was associated with higher TDTs as compared to HC. In addition, EPTs and EPTTs were reduced in all stroke patients as compared to $\mathrm{HC}$, irrespective of the presence of pain. At the affected side, PSSP was associated with higher TDTs and ESTs as compared to both PF patients and HC.

Mean threshold ratios for each group are presented in Figure 3.1. PSSP was associated with higher TDT, EST and EPT ratios as compared to both PF patients and HC. Percentages of patients with abnormal z-scores (based on normalization of QST threshold ratios) are presented for PSSP and PF in Table 3.4. 
Table 3.2. Clinical examination: abnormal sensation and allodynia, number of subjects (\%).

\begin{tabular}{ccccccc}
\hline & & $\begin{array}{c}\text { PSSP } \\
\text { (n=19) }\end{array}$ & $\begin{array}{c}\text { PF } \\
\text { (n=29) }\end{array}$ & $\begin{array}{c}\text { HC } \\
\text { (n=23) }\end{array}$ & $\begin{array}{c}\mathbf{p} \\
\text { (vs PF) }\end{array}$ & $\begin{array}{c}\mathbf{p} \\
\text { (vs HC) }\end{array}$ \\
\hline $\mathrm{T}$ & abnormal & $13(68 \%)$ & $12(41 \%)$ & $2(9 \%)$ & $\mathrm{ns}$ & 0.000 \\
& diminished & $13(68 \%)$ & $9(31 \%)$ & $2(9 \%)$ & 0.021 & 0.000 \\
& increased & $0(0 \%)$ & $3(10 \%)$ & $0(0 \%)$ & $\mathrm{ns}$ & $\mathrm{ns}$ \\
& allodynia & $1(5 \%)$ & $0(0 \%)$ & $0(0 \%)$ & $\mathrm{ns}$ & $\mathrm{ns}$ \\
\hline $\mathrm{C}$ & abnormal & $15(79 \%)$ & $13(45 \%)$ & $2(8 \%)$ & 0.034 & 0.000 \\
& diminished & $9(47 \%)$ & $11(38 \%)$ & $1(4 \%)$ & $\mathrm{ns}$ & 0.000 \\
& increased & $6(32 \%)$ & $2(7 \%)$ & $1(4 \%)$ & 0.025 & 0.018 \\
& allodynia & $3(16 \%)$ & $0(0 \%)$ & $0(0 \%)$ & 0.027 & 0.048 \\
\hline $\mathrm{P}$ & abnormal & $13(68 \%)$ & $12(41 \%)$ & $0(0 \%)$ & $\mathrm{ns}$ & 0.000 \\
& diminished & $13(68 \%)$ & $12(41 \%)$ & $0(0 \%)$ & $\mathrm{ns}$ & 0.000 \\
& increased & $0(0 \%)$ & $0(0 \%)$ & $0(0 \%)$ & $\mathrm{x}$ & $\mathrm{X}$ \\
& allodynia & $0(0 \%)$ & $0(0 \%)$ & $0(0 \%)$ & $\mathrm{x}$ & $\mathrm{X}$ \\
\hline $\mathrm{S}$ & abnormal & $14(74 \%)$ & $14(48 \%)$ & $5(22 \%)$ & $\mathrm{ns}$ & 0.001 \\
& diminished & $10(53 \%)$ & $7(24 \%)$ & $3(13 \%)$ & $\mathrm{ns}$ & 0.002 \\
& increased & $4(21 \%)$ & $7(24 \%)$ & $2(9 \%)$ & $\mathrm{ns}$ & $\mathrm{ns}$ \\
& hyperalgesia & $5(26 \%)$ & $0(0 \%)$ & $0(0 \%)$ & 0.004 & 0.009 \\
\hline
\end{tabular}

PSSP: stroke patients with post-stroke shoulder pain; PF: pain-free stroke patients; HC: healthy controls; $\mathrm{n}$ : number of subjects; $\mathrm{p}$ : $\mathrm{p}$-value for statistical testing; $\mathrm{T}$ : touch; C: cold; P: proprioception; S: sharpness; ns: not significant $(p>0.05)$.

Table 3.3 Raw quantitative sensory testing thresholds, mean \pm SD.

\begin{tabular}{|c|c|c|c|c|c|c|}
\hline & & $\begin{array}{c}\text { PSSP } \\
(n=19)\end{array}$ & $\begin{array}{c}\text { PF } \\
(n=29)\end{array}$ & $\begin{array}{c}\mathrm{HC} \\
(n=23)\end{array}$ & $\begin{array}{c}p \\
\text { (vs PF) }\end{array}$ & $\begin{array}{c}p \\
\text { (vs HC) }\end{array}$ \\
\hline \multirow[t]{5}{*}{ UA (D) } & TDT (size) & $3.69 \pm 0.44$ & $3.52 \pm 0.46$ & $3.30 \pm 0.45$ & ns & 0.007 \\
\hline & EST (mA) & $1.01 \pm 0.40$ & $1.14 \pm 0.46$ & $0.93 \pm 0.33$ & ns & ns \\
\hline & EPT (mA) & $2.73 \pm 1.94$ & $2.94 \pm 2.05$ & $3.81 \pm 1.95$ & ns & 0.026 \\
\hline & $\mathrm{EPTT}(\mathrm{mA})$ & $5.18 \pm 3.07$ & $5.57 \pm 3.80$ & $7.40 \pm 2.48$ & ns & 0.007 \\
\hline & PPT (kPa) & $379 \pm 178$ & $434 \pm 207$ & $467 \pm 176$ & ns & ns \\
\hline \multirow[t]{5}{*}{$A(N D)$} & TDT (size) & $4.71 \pm 1.08$ & $3.89 \pm 0.73$ & $3.20 \pm 0.45$ & 0.001 & 0.000 \\
\hline & $\mathrm{EST}(\mathrm{mA})$ & $3.00 \pm 3.67$ & $1.48 \pm 0.80$ & $0.93 \pm 0.30$ & 0.018 & 0.000 \\
\hline & EPT $(m A)$ & $5.49 \pm 3.87$ & $4.03 \pm 3.00$ & $3.85 \pm 1.70$ & ns & ns \\
\hline & $\mathrm{EPTT}(\mathrm{mA})$ & $7.66 \pm 4.23$ & $7.92 \pm 5.48$ & $6.65 \pm 2.30$ & ns & ns \\
\hline & PPT (kPa) & $454 \pm 401$ & $451 \pm 230$ & $462 \pm 163$ & ns & ns \\
\hline
\end{tabular}

SD: standard deviation; PSSP: stroke patients with post-stroke shoulder pain; PF: pain-free stroke patients; $\mathrm{HC}$ : healthy controls; $n$ : number of subjects; $p$ : $p$-value for statistical testing; UA: unaffected side (patients); D: dominant side (HC); A: affected side (patients); ND: non-dominant side (HC); TDT: tactile detection threshold; EST: electrical sensation threshold; EPT: electrical pain threshold; EPTT: electrical pain tolerance threshold; PPT: pressure pain threshold; ns: not significant ( $p>0.05)$. 


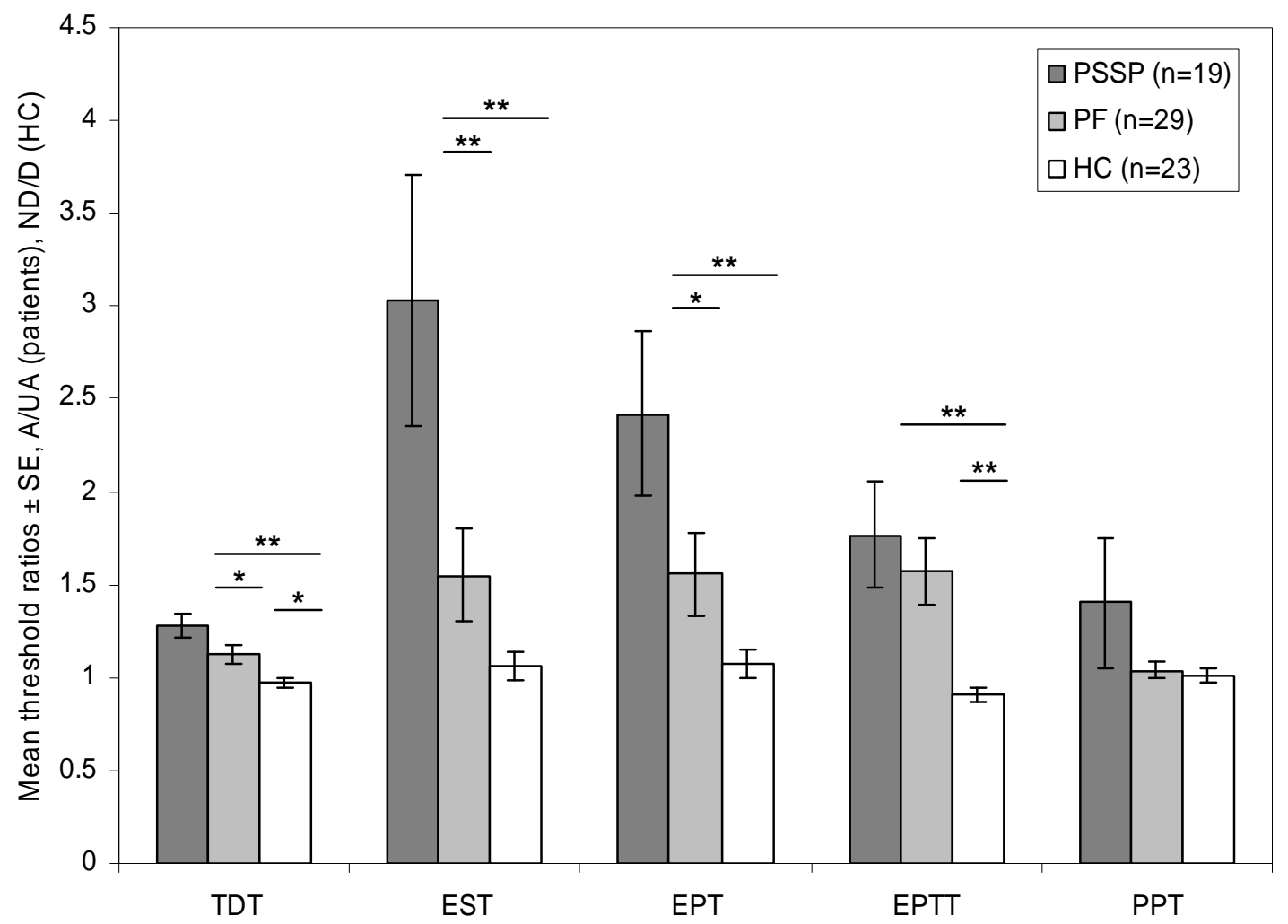

Figure 3.1 Threshold ratios (affected/unaffected) for each patient group (mean \pm standard error). A/UA: affected/unaffected; ND/D: non-dominant/dominant; TDT: tactile detection threshold; EST: electrical sensation threshold; EPT: electrical pain threshold; EPTT: electrical pain tolerance threshold; PPT: pressure pain threshold. $* p<0.05, * * p<0.01$.

Table 3.4 Abnormal z-scores of threshold ratios, number of subjects (\%).

\begin{tabular}{clccc}
\hline & & $\begin{array}{c}\text { PSSP } \\
(\mathbf{n = 1 9 )}\end{array}$ & $\begin{array}{c}\text { PF } \\
(\mathbf{n = 2 9})\end{array}$ & $\mathbf{p}$ \\
\hline TDT & hypoesthesia & $14(74 \%)$ & $20(34 \%)$ & 0.015 \\
& hyperesthesia & $0(0 \%)$ & $0(0 \%)$ & $\mathrm{ns}$ \\
EST & hypoesthesia & $10(53 \%)$ & $5(17 \%)$ & 0.014 \\
& hyperesthesia & $0(0 \%)$ & $0(0 \%)$ & $\mathrm{ns}$ \\
EPT & hypoalgesia & $9(47 \%)$ & $4(14 \%)$ & 0.015 \\
& hyperalgesia & $0(0 \%)$ & $0(0 \%)$ & $\mathrm{ns}$ \\
EPTT & hypoalgesia & $11(58 \%)$ & $17(59 \%)$ & $\mathrm{ns}$ \\
& hyperalgesia & $0(0 \%)$ & $0(0 \%)$ & $\mathrm{ns}$ \\
$\mathrm{H}$ PPT & hypoalgesia & $4(21 \%)$ & $3(10 \%)$ & $\mathrm{ns}$ \\
& hyperalgesia & $3(16 \%)$ & $1(4 \%)$ & $\mathrm{ns}$ \\
\hline
\end{tabular}

PSSP: stroke patients with post-stroke shoulder pain; PF: pain-free stroke patients; $\mathrm{n}$ : number of subjects; p: p-value for statistical testing; TDT: tactile detection threshold; EST: electrical sensation threshold; EPT: electrical pain threshold; EPTT: electrical pain tolerance threshold; PPT: pressure pain threshold; ns: not significant. Z-scores were obtained via the z-transformation of individual threshold ratios (affected/unaffected) to the healthy control data. Abnormality was defined as $-2>z>2$. 
A

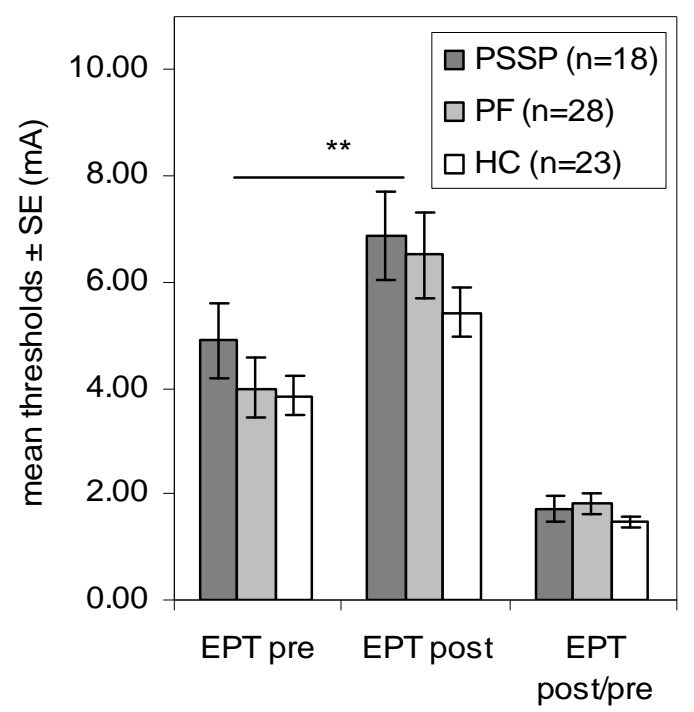

B

PPT

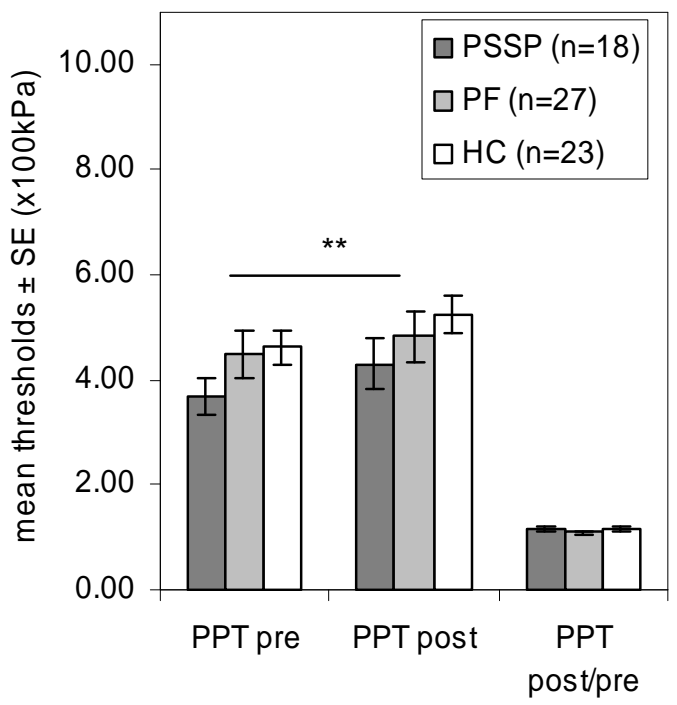

Figure 3.2 Electrical pain thresholds (A) and pressure pain thresholds (B) before (pre) and after (post) cold pressor testing. UA/D: unaffected (patients) or dominant (healthy controls); EPT: electrical pain threshold; PPT: pressure pain threshold. $* * p<0.01$.

Hypoesthesia (TDT, EST) and hypoalgesia (EPT) were more often observed in PSSP as compared to PF. Although no group mean differences were observed for the PPT, z-score analysis revealed both hypoalgesia and hyperalgesia for pressure pain stimuli in the patients groups. Hypoalgesia and hyperalgesia were more often observed in the PSSP group, but this was not statistically significant.

\section{Cold pressor test}

Mean thresholds before and after the cold pressor test and threshold ratios (post/pre) are depicted in Figure 3.2 A (EPT) and B (PPT). In 1 PSSP and 1 PF patient, it was not possible to determine QST thresholds after the cold pressor test (PSSP: QST thresholds before cold pressor already at maximum stimulator output, PF: strong physical response to cold pressor hand immersion). In another PF patient the PPT could not be determined due to a technical problem. In total, the effect of the cold pressor test could be determined in 18 PSSP, 28 PF and $23 \mathrm{HC}$ subjects with regard to the EPT and in 18 PSSP, 27 PF and $23 \mathrm{HC}$ subjects with regard to the PPT. Repeated measures analysis revealed significant higher EPTs $(p<0.001)$ and PPTs $(\mathrm{p}<0.001)$ after the cold pressor test. This effect was not different comparing groups ( $p>0.05$ ). In addition, also when comparing threshold ratios (post/pre) no significant differences were found comparing groups ( $p>0.05$ ). 
Mean duration \pm standard deviation of hand immersion was $76 \pm 62$ seconds for PSSP, $113 \pm$ 70 seconds for PF and $153 \pm 45$ seconds for HC. Hand immersion time (cold pain tolerance) was significantly reduced in patients with PSSP as compared to both PF patients $(\mathrm{p}=0.04)$ and controls $(p=0.02)$. Mean cold pressor pain intensity (NRS) \pm standard deviation was $6.5 \pm 1.7$ for PSSP, $6.4 \pm 2.3$ for PF and $6.3 \pm 1.5$ for $\mathrm{HC}$ and was not statistically different between groups.

\section{Discussion and conclusions}

This study investigated the role of central sensitization and disinhibition in chronic PSSP by assessing positive and negative somatosensory symptoms and signs and CPM in patients with chronic PSSP, comparing them to pain-free stroke patients and healthy controls. It was shown that chronic PSSP was associated with a higher frequency of and more severe somatosensory loss. In addition, PSSP was associated with several positive somatosensory signs, such as allodynia and hyperalgesia. Interestingly, abnormalities were observed at both the affected as well as the unaffected side. CPM was similar in stroke patients and healthy controls.

\section{Somatosensory loss}

Detailed somatosensory analysis in PSSP has seldom been performed and previous studies have mainly used clinical examination. Moreover, only a few have explicitly reported on the direction (increased/ decreased) of somatosensory abnormalities or on positive signs such as allodynia and hyperalgesia. Like in previous studies, this study showed that PSSP was associated with reduced tactile ${ }^{14,15,17,31}$ and cold $^{14,15}$ sensation and with reduced proprioception 35 at the affected side as compared to control groups. Besides being more frequent, somatosensory loss at the affected side for stimuli in the innocuous range was also more severe in patients with PSSP as observed with QST. Moreover, PSSP was associated with a small, but statistically significant, reduction of tactile sensation at the unaffected side compared with the $\mathrm{HC}$, but not the PF, group.

A higher frequency of somatosensory loss as compared to controls has also been reported for $\mathrm{CPSP}_{1,30,55}$ and for post-stroke complex regional pain syndrome ${ }^{11,36}$. Both the frequency ${ }^{1,16,30}$ and severity ${ }^{7}$ of somatosensory loss show considerable overlap with our findings in patients with chronic PSSP. Interestingly, an abnormal response (including both decreased and increased sensation) to thermal testing, a diagnostic criterion for central post-stroke pain 61 , was observed in $79 \%$ of PSSP patients.

Severe loss of sensory function may act as a risk factor for the development of PSSP since it puts the affected upper extremity at risk for repetitive micro-trauma. ${ }^{41}$ In addition, loss of 
sensory function, and specifically loss of spinothalamocortical tract function, has been implicated in mechanisms of central pain ${ }^{24}$ and is considered a prerequisite for the development of central neuropathic pain. In a sub-analysis, in which the PSSP patients from the present study were classified on the basis of their score on the neuropathic pain diagnostic questionnaire ${ }^{5}$, it was shown that loss of spinothalamocortical tract function was more frequently present in the patients classified as having a possible neuropathic component to their pain. ${ }^{46}$

\section{Positive somatosensory signs}

Only sharpness allodynia (by others also referred to as punctate hyperalgesia) has previously been implicated in PSSP. ${ }^{61}$ Generally, allodynia to touch or cold is considered as a supportive factor for the diagnosis of CPCP. $6,24,34$ In the present study, PSSP was clearly associated with positive signs. Allodynia (to touch, cold and sharpness) was only observed in patients with PSSP and PSSP was associated with a higher frequency of increased sensation to cold stimuli and with a higher frequency of pressure pain hyperalgesia at the affected side. Interestingly, positive signs were also observed at the unaffected side. Electrical pain and pain tolerance thresholds and cold pain tolerance were generally reduced in patients with stroke, but this reduction was more pronounced in patients with PSSP.

Positive somatosensory signs in PSSP may be related to peripheral and/or to central sensitization or disinhibition. Since peripheral sensitization is expected to influence the processing of natural but not of electrical stimuli, the observed hyperalgesia to blunt pressure at the affected side of PSSP patients (but also in some PF patients) in the absence of hyperalgesia to non-receptor mediated electrical stimuli indeed suggests that peripheral nociception was increased. ${ }^{23}$ This is supported by the observation that pain increased upon movement of the arm and that passive pain-free shoulder range of motion was reduced in patients with PSSP.

In addition, several of the positive findings may be due to central sensitization and/or disinhibition. Theoretically, central sensitization or disinhibition may occur at both the spinal and supra-spinal level and may be due to ongoing nociception (neuroplasticity) or to the brain lesion. From experimental studies it is known that cold allodynia ${ }^{3,21}$, punctate hyperalgesia ${ }^{59}$ and tactile (dynamic mechanical) allodynia ${ }^{26}$ are (partly or completely) caused by central sensitization. Moreover, a reduction in pain thresholds in an unaffected region of patients with chronic pain is considered to be mediated by central sensitization and/ or central disinhibition 840,48 , although a reduction in cold pain tolerance has also been related to disturbed cognitive and emotional aspects of clinical and experimental pain ${ }^{19}$. 
Nonetheless, and whatever the initiating cause, central sensitization and possibly disinhibition seem to play a role in chronic PSSP maintenance, and may explain why treatment aimed at reducing peripheral nociception is generally unsatisfactory.

\section{Conditioned pain modulation}

PSSP was not associated with impaired endogenous inhibition subserved by diffuse noxious inhibitory controls (DNIC) ${ }^{29}$. Using CPM paradigms, 54,60 DNIC have previously been shown to be impaired in several types of chronic pain, such as fibromyalgia ${ }^{27}$, osteoarthritis ${ }^{28}$ and whiplash ${ }^{22}$, and impaired DNIC may predict the development of chronic pain.22,63 However, in pain-free stroke patients with thalamic or cortical lesions, but also in patients with central post-stroke pain, CPM has been shown to be equal to controls. ${ }^{12,53}$ Therefore, based on these few studies, it seems that DNIC are functioning normally in patients with poststroke pain, although endogenous pain modulation may be impaired at a higher supraspinal level.53 Moreover, since CPM may have a differential effect on different test stimuli28,62, further study of the role of supraspinal disinhibition in post-stroke pain is warranted.

\section{Limitations}

Being the first in its focus, this study has several limitations. First, it provides no insight into the causal role of any of the somatosensory symptoms or signs in the development of chronic PSSP. Previous studies have indicated that impaired somatosensory functions may act as risk factors for PSSP.,215,33 On the other hand, signs of peripheral and central sensitization may either precede or follow the development of PSSP. This should be further explored in longitudinal studies.

Age, gender, trophic changes and depression scores could be ruled out as confounders in this study. However, some patients were using medications which, in theory, may have influenced somatosensory function. Analgesics, only used in the PSSP group, may have increased the pain thresholds of PSSP patients selectively, however, rather the opposite was observed, since pain thresholds at the unaffected side of both PSSP and PF patients were reduced and differences between PSSP and PF were also observed for innocuous stimuli.

A limitation regarding the assessment of CPM was that the duration of the conditioning stimulus was not equal across groups and that assessment was performed after, rather than during, the conditioning stimulus. We standardized the cold pressor pain using selfreported pain intensities. It may be hypothesized that a fixed time-standardization or assessment during the cold pressor test would have given different outcomes. However, literature is inconsistent regarding the relation between the intensity of the conditioning stimulus and the magnitude of CPM.38 Moreover, subjects may or may not adapt to tonic 
painful cold stimuli, involving a different timing of pain perception over the course of immersion. 37

It would be interesting to assess CPM in patients with PSSP using a different conditioning stimulus, such as ischemia-induced pain, in which assessment during conditioning may be more easily performed and the intensity of the conditioning stimulus may be better controlled.

\section{Conclusion}

The results from this study have clear implications for the clinical and the experimental approach to PSSP. This study showed that chronic PSSP was associated with several positive and negative somatosensory signs, implicating a role for central sensitization and possibly for disinhibition. Interestingly, chronic PSSP was not associated with biomechanical alterations commonly associated with the development of PSSP, such as the severity of paresis, spasticity and glenohumeral subluxation. Assessment of PSSP should, therefore, not only focus on the shoulder joint, but should also involve the somatosensory system. In this context, the use of "pain research tools", such as a thorough clinical examination, QST or CPM is important since they may establish the presence of peripheral and/or central sensitization by quantifying sensory changes on both the affected and unaffected side of the stroke patients and by assessing supraspinal inhibitory functions. The use of these tools should be promoted in order to better understand the mechanisms underlying PSSP. Since the causal relationship between altered somatosensory functions and chronic PSSP remains unclear, and may be related to either neuroplasticity induced by ongoing nociception as well as to the neuropathic brain lesion, prospective studies are warranted. 


\section{References}

1 Andersen G, Vestergaard K, IngemanNielsen $M$, Jensen TS. Incidence of central post-stroke pain. Pain 61:187193, 1995.

2 Appelros P. Prevalence and predictors of pain and fatigue after stroke: a population-based study. Int J Rehabil Res 29:329-333, 2006.

3 Binder A, Binder A, Maag R, Peller $M$, Wasner G, Siebner HR, Baron $R$. Differential coding of cold allodynia - A fmri study. Clinical Neurophysiology 118:e17-e17, 2007.

4 Bohannon RW, Smith MB. Interrater reliability of a modified Ashworth scale of muscle spasticity. Phys Ther 67:206207, 1987.

5 Bouhassira D, Attal $\mathrm{N}$, Alchaar $\mathrm{H}$, Boureau F, Brochet B, Bruxelle J, Cunin G, Fermanian J, Ginies P, GrunOverdyking A, Jafari-Schluep $H$, LanteriM inet $M$, Laurent $B, M$ ick $G$, Serrie $A$, Valade $D$, Vicaut $E$. Comparison of pain syndromes associated with nervous or somatic lesions and development of a new neuropathic pain diagnostic questionnaire (DN4). Pain 114:29-36, 2005.

6 Bowsher D. Allodynia in relation to lesion site in central post-stroke pain. Pain 6:736-740, 2005.

7 Bowsher D, Leijon G, Thuomas KA. Central poststroke pain: correlation of MRI with clinical pain characteristics and sensory abnormalities. Neurology 51:1352-1358, 1998.

8 Chu LF, Clark DJ, Angst MS. Opioid tolerance and hyperalgesia in chronic pain patients after one month of oral morphine therapy: A preliminary prospective study. Journal of Pain 7:4348, 2006.
9 Collin C, Wade D. Assessing motor impairment after stroke: a pilot reliability study. J Neurol Neurosurg Psychiatry 53:576-579, 1990.

10 Craig AD. Mechanisms of thalamic pain. In: Henry JL, Panju A, Yashpal K, editors. Central Neuropathic Pain: Focus on Poststroke Pain. Seattle: IASP Press, 2007. pp. 81-99.

11 Daviet JC, Preux PM, Salle JY, Lebreton $F$, Munoz M, Dudognon P, Pelissier J, Perrigot $M$. Clinical factors in the prognosis of complex regional pain syndrome type I after stroke: a prospective study. Am J Phys Med Rehabil 81:34-39, 2002.

12 De Broucker T, Cesaro P, Willer JC, Le Bars D. Diffuse noxious inhibitory controls in man. Involvement of the spinoreticular tract. Brain 113:12231234, 1990.

13 Dromerick AW, Edwards DF, Kumar A. Hemiplegic shoulder pain syndrome: frequency and characteristics during inpatient stroke rehabilitation. Arch Phys Med Rehabil 89:1589-1593, 2008.

14 Gamble GE, Barberan E, Bowsher D, Tyrrell PJ, Jones AK. Post stroke shoulder pain: more common than previously realized. Eur J Pain 4:313$315,2000$.

15 Gamble GE, Barberan E, Laasch HU, Bowsher D, Tyrrell PJ, Jones AK. Poststroke shoulder pain: a prospective study of the association and risk factors in 152 patients from a consecutive cohort of 205 patients presenting with stroke. Eur J Pain 6:467-474, 2002.

16 Greenspan JD, Ohara S, Sarlani E, Lenz FA. Allodynia in patients with poststroke central pain (CPSP) studied by statistical quantitative sensory testing 
within individuals. Pain 109:357-366, 2004.

17 Hadianfard H, Hadianfard MJ. Predictor factors of hemiplegic shoulder pain in a group of stroke patients. Iran Red Crescent Me 10:215-219, 2008.

18 Hansson P, Backonja M, Bouhassira D. Usefulness and limitations of quantitative sensory testing: Clinical and research application in neuropathic pain states. Pain 129:256-259, 2007.

19 Hirsh AT, George SZ, Bialosky JE, Robinson ME. Fear of Pain, Pain Catastrophizing, and Acute Pain Perception: Relative Prediction and Timing of Assessment. J Pain 9:806-812, 2008.

20 Jönsson AC, Lindgren I, Hallström $B$, Norrving $B$, Lindgren $A$. Prevalence and intensity of pain after stroke: a population based study focusing on patients' perspectives. J Neurol Neurosurg Psychiatry 77:590-595, 2006.

21 Jørum E, Warncke T, Stubhaug A. Cold allodynia and hyperalgesia in neuropathic pain: the effect of $\mathrm{N}$ methyl--aspartate (NMDA) receptor antagonist ketamine - a double-blind, cross-over comparison with alfentanil and placebo. Pain 101:229-235, 2003.

22 Kasch H, Qerama E, Bach FW, Jensen TS. Reduced cold pressor pain tolerance in non-recovered whiplash patients: A 1-year prospective study. Eur J Pain 9:561-569, 2005.

23 Kilo $S$, Schmelz $M$, Koltzenburg $M$, Handwerker HO. Different patterns of hyperalgesia induced by experimental inflammation in human skin. Brain 117:385-396, 1994.

Klit H, Finnerup NB, Jensen TS. Central post-stroke pain: clinical characteristics, pathophysiology, and management. Lancet Neurol 8:857-868, 2009.

25 Koltzenburg $M$, Lundberg LER, Torebjörk HE. Dynamic and static components of mechanical hyperalgesia in human hairy skin. Pain 51:207-219, 1992.

26 Koltzenburg M, Torebjörk HE, Wahren LK. Nociceptor modulated central sensitization causes mechanical hyperalgesia in acute chemogenic and chronic neuropathic pain. Brain 117:579-591, 1994.

27 Kosek E, Hansson P. Modulatory influence on somatosensory perception from vibration and heterotopic noxious conditioning stimulation (HNCS) in fibromyalgia patients and healthy subjects. Pain 70:41-51, 1997.

28 Kosek E, Ordeberg G. Lack of pressure pain modulation by heterotopic noxious conditioning stimulation in patients with painful osteoarthritis before, but not following, surgical pain relief. Pain 88:69-78, 2000.

29 Le Bars D, Dickenson AH, Besson JM. Diffuse noxious inhibitory controls (DNIC). I. Effects on dorsal horn convergent neurones in the rat. Pain 6:283-304, 1979.

30 Leijon G, Boivie J, Johansson I. Central post-stroke pain--neurological symptoms and pain characteristics. Pain 36:13-25, 1989.

31 Lindgren I, Jönsson AC, Norrving $B$, Lindgren $A$. Shoulder pain after stroke: A prospective population-based study. Stroke 38:343-348, 2007.

32 Loeser JD, Treede R-D. The Kyoto protocol of IASP Basic Pain Terminology. Pain 137:473-477, 2008.

33 Lundström E, Smits A, Terént A, Borg J. Risk factors for stroke-related pain 1 
year after first-ever stroke. Eur J Neurol 16:188-193, 2009.

34 Misra UK, Kalita J, Kumar B. A study of clinical, magnetic resonance imaging, and somatosensory-evoked potential in central post-stroke pain. J Pain 9:1116$1122,2008$.

35 Niessen $\mathrm{MH}$, Veeger DH, Meskers CG, Koppe PA, Konijnenbelt $\mathrm{MH}$, Janssen TW. Relationship among shoulder proprioception, kinematics, and pain after stroke. Arch Phys Med Rehabil 90:1557-1564, 2009.

Ram KC, Eisenberg E, Haddad M, Pud D. Oral opioid use alters DNIC but not cold pain perception in patients with chronic pain - New perspective of opioidinduced hyperalgesia. Pain 139:431438, 2008.

41 Ratnasabapathy Y, Broad J, Baskett J, Pledger M, Marshall J, Bonita R. Shoulder pain in people with a stroke: a population-based study. Clin Rehabil 17:304-311, 2003.
42 Renzenbrink GJ, IJzerman MJ. Percutaneous neuromuscular electrical stimulation (P-NMES) for treating shoulder pain in chronic hemiplegia. Effects on shoulder pain and quality of life. Clin Rehabil 18:359-365, 2004.

43 Rolke R, Baron R, Maier C, Tolle TR, Treede RD, Beyer A, Binder A, Birbaumer $N$, Birklein $F$, Botefur IC, Braune $S$, Flor $H$, Huge $V$, Klug $R$, Landwehrmeyer GB, Magerl W, Maihofner C, Rolko C, Schaub C, Scherens $A$, Sprenger $T$, Valet $M$, Wasserka B. Quantitative sensory testing in the German Research Network on Neuropathic Pain (DFNS): standardized protocol and reference values. Pain 123:231-243, 2006.

44 Rolke $\mathrm{R}$, Magerl W, Campbell KA, Schalber C, Caspari S, Birklein F, Treede RD. Quantitative sensory testing: a comprehensive protocol for clinical trials. Eur J Pain 10:77-88, 2006.

45 Roosink M, Geurts ACH, IJzerman MJ. Defining post-stroke pain: diagnostic challenges. Lancet Neurol 9:344-344, 2010.

46 Roosink $M$, Van Dongen RTM, Renzenbrink GJ, IJzerman MJ. Classifying post-stroke shoulder pain: Can the DN4 be helpful? Eur J Pain 15:99-102, 2011.

47 Roy CW, Sands M R, Hill LD. Shoulder pain in acutely admitted hemiplegics. Clin Rehabil 8:334-340, 1994.

48 Schneider GM, Smith AD, Hooper A, Stratford $P$, Schneider KJ, Westaway $M D$, Frizzell $B$, Olson L. Minimizing the source of nociception and its concurrent effect on sensory hypersensitivity: An exploratory study in chronic whiplash patients. BMC Musculoskeletal Disorders 11, 2010.

49 Teasell RW, Bhogal SK, Foley NC. Painful Hemiplegic Shoulder. In: Teasell RW, Bhogal SK, Foley NC, editors. 
Evidence-based Review of Stroke Rehabilitation. London, Ontario, Canada: University of Western Ontario, 2007. pp. 1-57.

50 Tombaugh TN, Mclntyre NJ. The MiniMental State Examination: A comprehensive review. J Am Geriatr Soc 40:922-935, 1992.

51 Turner-Stokes L, Hassan N. Depression after stroke: a review of the evidence base to inform the development of an integrated care pathway. Part 1: Diagnosis, frequency and impact. Clin Rehabil 16:231-247, 2002.

52 Turner-Stokes L, Jackson D. Shoulder pain after stroke: a review of the evidence base to inform the development of an integrated care pathway. Clin Rehabil 16:276-298, 2002.

53 Tuveson B, Leffler A-S, Hansson P. Influence of heterotopic noxious conditioning stimulation on spontaneous pain and dynamic mechanical allodynia in central poststroke pain patients. Pain 143:84-91, 2009.

54 van Wijk G, Veldhuijzen DS. Perspective on Diffuse Noxious Inhibitory Controls as a Model of Endogenous Pain Modulation in Clinical Pain Syndromes. J Pain 11:408-419, 2010.

55 Vestergaard K, Nielsen J, Andersen G, Ingeman-Nielsen $M$, Arendt-Nielsen $L$, Jensen TS. Sensory abnormalities in consecutive, unselected patients with central post-stroke pain. Pain 61:177186, 1995.

Walk D, Sehgal N, Moeller-Bertram T, Edwards RR, Wasan A, Wallace $M$, Irving G, Argoff C, Backonja MM. Quantitative sensory testing and mapping: a review of nonautomated quantitative methods for examination of the patient with neuropathic pain. Clin J Pain 25:632-640, 2009.
57 Wanklyn P, Forster A, Young J. Hemiplegic shoulder pain (HSP): Natural history and investigation of associated features. Disabil Rehabil 18:497-501, 1996.

58 Wasner G, Lee BB, Engel S, McLachlan E. Residual spinothalamic tract pathways predict development of central pain after spinal cord injury. Brain 131:2387-2400, 2008.

59 Wasner G, Schattschneider J, Binder A, Baron R. Topical menthol--a human model for cold pain by activation and sensitization of $C$ nociceptors. Brain 127:1159-1171, 2004.

60 Watanabe $S$, Kakigi R, Hoshiyama $M$, Kitamura $Y$, Koyama S, Shimojo $M$. Effects of noxious cooling of the skin on pain perception in man. J Neurol Sci 135:68-73, 1996.

61 Widar $M$, Samuelsson $L$, KarlssonTivenius S, Ahlstrom G. Long-term pain conditions after a stroke. J Rehabil M ed 34:165-170, 2002.

62 Witting $N$, Svensson $P$, Jensen TS. Differential recruitment of endogenous pain inhibitory systems in neuropathic pain patients. Pain 103:75-81, 2003.

63 Yarnitsky D, Crispel Y, Eisenberg E, Granovsky Y, Ben-Nun A, Sprecher E, Best LA, Granot M. Prediction of chronic post-operative pain: Preoperative DNIC testing identifies patients at risk. Pain 138:22-28, 2008.

64 Yu D. Shoulder pain in hemiplegia. Phys Med Rehabil Clin N Am 15:683-697, 2004. 


\title{
Chapter 4
}

\section{Altered cortical somatosensory processing in chronic stroke: a relationship with post-stroke shoulder pain}

\author{
M eyke Roosink \\ Jan R Buitenweg \\ Gerbert J Renzenbrink \\ Robert TM van Dongen \\ Alexander $\mathrm{CH}$ Geurts \\ Maarten J IJ zerman
}

NeuroRehabilitation, in press 


\section{Abstract}

Post-stroke shoulder pain (PSSP), traditionally regarded as purely nociceptive pain, is often persistent and the mechanisms underlying the pain complaints are not well understood. This explorative study is the first to address the possible changes in cortical somatosensory processing in patients with PSSP. Cortical potentials were recorded following intracutaneous electrostimulaton in stroke patients with chronic PSSP $(n=6)$, pain-free stroke patients $(\mathrm{PF}, \mathrm{n}=14)$ and healthy controls $(\mathrm{HC}, \mathrm{n}=20)$ using electroencephalography (EEG). Amplitudes and latencies of both sensory discriminative (N90) as well as cognitive evaluative (N150, P200, the N150-P200 peak-to-peak difference and P300) evoked potential components were evaluated. Stroke was associated with reduced N150 and P300 amplitudes and increased N90, N150 and P300 latencies at both sides. Compared to PF and HC, the P200 and N150-P200 latencies were increased in PSSP patients after stimulation at both sides, even when comparing subgroups with similar lesion size and location. Stroke was associated with reduced sensory-discriminative as well as cognitive-evaluative cortical somatosensory processing. This reduction was more pronounced in patients with PSSP and may be related to the central effects of persistent nociceptive pain. 


\section{Introduction}

Pain is a common complication after stroke. In recent studies, post-stroke shoulder pain (PSSP) has been reported in about 40\% of patients.1,21,22,35,38,47,52 PSSP is typically regarded as nociceptive pain. ${ }^{58}$ Nociception occurs after tissue damage and can be defined as the neural processes of encoding and processing noxious stimuli. ${ }^{37}$ In contrast, central poststroke pain (CPSP) is diagnosed when the pain is a direct consequence of a brain lesion affecting the central somatosensory system. ${ }^{37}$ CPSP is observed in $8 \%$ of stroke patients. ${ }^{34}$ In PSSP, treatment aimed at reducing peripheral nociception through relief of biomechanical stress or capsular inflammation (e.g. by strapping or corticosteroid injection) is often unsatisfactory and many patients report persistent pain. 35,58 In addition, patients with chronic PSSP may present with several signs of central sensitization (allodynia, generalized hyperalgesia). ${ }^{51}$ Indeed, the clinical presentations of patients with PSSP and CPSP show considerable overlap, suggesting that central (pain) processing may be altered in patients with PSSP. 34,49

Theoretically, altered central (pain) processing in PSSP may be directly due to the brain lesion and/ or indirectly due to central changes associated with ongoing nociception from the periphery. For example, brain lesions within the spinothalamocortical tract may lead to increased supra-spinal excitability and have been related to the development of CPSP. ${ }^{34}$ Indirectly, ongoing pain from the periphery may lead to sensitization of spinal and supraspinal structures. ${ }^{13}$ In addition, ongoing pain may induce functional 20 as well as structural ${ }^{40}$ cortical reorganization of somatosensory and motor systems, as has been observed in patients with chronic neuropathic or musculoskeletal pain. Moreover, the central processing of somatosensory stimuli has been shown to be impaired in patients with chronic pain in whom pain is suggested to cause a chronic interruption of attentional engagement. 19,57

The central processing of somatosensory stimuli can be objectively assessed using cortical evoked potentials (EPs). EPs can be measured at the scalp in response to various peripheral stimuli (i.e. laser, electrical stimulation). In pain-free stroke patients, abnormalities in early EPs after median (N20, P25) or tibial (N35, P40) nerve stimulation have been related to impaired processing of input from the dorsomedial lemniscal pathway, resulting in reduced touch sensation and proprioception ${ }^{33,64}$, whereas abnormalities in laser evoked potentials have been related to impaired processing of input from the spino-thalamo-cortical tract 7 , resulting in reduced thermal and sharpness sensations ${ }^{27,65}$. Late EP components, for example in response to electrocutaneous stimulation (N150, P200, P300), have been related to cognitive-evaluative processes involved in the processing of somatosensory stimuli.41,66,68 In stroke research, assessment of late electrical EP components has received little attention 
and results are inconsistent. ${ }^{15,67}$ So far, there is no report of any type of EP assessment in patients with PSSP. In patients with central pain, the presence of pain has been related to reduced amplitudes and/ or longer EP latencies suggesting that somatosensory deficits are a prerequisite for the development of neuropathic pain. ${ }^{10,25,29}$. In contrast, central pain ${ }^{26,53}$ and experimentally induced central sensitization ${ }^{39}$ have also been associated with increased EP amplitudes. So far, the precise relation between (clinical) pain complaints and alterations in EPs is, therefore, not well understood.

The goal of this explorative study was to investigate whether PSSP was associated with alterations in the cortical processing of somatosensory stimuli. Cortical potentials were evoked in stroke patients with chronic PSSP, pain-free stroke patients (PF) and healthy controls ( $\mathrm{HC}$ ) using intracutaneous electrical stimulation at the middle finger of both hands at 2 stimulation intensities and were recorded using EEG. Amplitudes and latencies of middle-late and late EP components (N90, N150, P200, the N150-P200 peak-to-peak difference and P300) were evaluated. In addition, sensory examination was performed using clinical examination and quantitative sensory testing (QST).

\section{Methods}

\section{Subjects}

Cortical somatosensory processing was assessed in stroke patients with persistent shoulder pain (PSSP, $n=10$ ), pain-free stroke patients ( $P F, n=17)$ and healthy controls ( $H C, n=21)$. Patients were recruited in a rehabilitation center in the Netherlands (Roessingh Rehabilitation Center in Enschede) as part of a larger cross-sectional study. 50 The outpatient databases were searched for stroke patients that had been hospitalized in the 2 years prior to the start of inclusion (fall 2007). Patients fulfilling the inclusion and exclusion criteria were approached by mail. In addition, patients visiting the outpatient clinics with shoulder pain complaints were asked by their treating physician if they could be approached by one of the researchers (M.R.) by mail. Healthy subjects (age 40 - 60 years) were recruited through advertisements in local community centers and newspapers.

All patients (age > 18 years) sustained a unilateral brain infarction (clinical diagnosis). All patients had a stroke onset of at least 6 months prior to participation. Patients with persistent shoulder pain (daily pain lasting longer than 3 subsequent months) with an onset post-stroke were allocated to the PSSP group. Pain-free patients with no long-lasting pain complaints ( $>1$ week in the last 3 months) were allocated to the PF group. Exclusion criteria were: pregnancy, trauma, infection, signs of any possible concomitant neurological condition (e.g. epilepsy, multiple sclerosis, peripheral neuropathy), the presence of other pain complaints (e.g. wide-spread pain, complex regional pain syndrome or shoulder-hand 
syndrome) or not being able to reliably determine sensory thresholds during a training session prior to the experiment. Healthy control subjects had to be free of any neurological or psychiatric disorder, diabetes mellitus, psychotropic medication or long-lasting pain complaints. The study was approved by the local human ethics committee. All subjects received written and oral information about the study protocol and all participants gave informed written consent prior to their participation.

\section{Demographics and medical examination}

General demographic characteristics such as age, sex and (for the patients) stroke latency, lesion side, lesion size, lesion location and medication use were registered. Lesion size (small, medium, large, very large) and lesion location (cortical, subcortical, both cortical and subcortical, involvement of insula, anterior cingulate cortex and/or thalamus) were assessed by a radiologist from computed tomography or magnetic resonance scans (when available). Cognitive state was assessed using the Mini Mental State Exam (MMSE, score: 0 30) and severe cognitive impairment was defined as a MMSE score $<24.59$ The emotional state was assessed using the ZUNG self-rating depression scale (score: 20 - 80) which has been validated for both healthy subjects and stroke patients. ${ }^{61}$ Arm function was assessed using the Motricity Index ( $0=$ complete paresis, $100=$ normal function $).{ }^{14}$ The presence of glenohumeral subluxation was assessed by palpation (in steps of $5 \mathrm{~mm}$ ). Shoulder pain intensity was evaluated both at rest and during movement with an 11-point Numeric Rating Scale (NRS, 0 =no pain, 10 = maximum conceivable pain). Pain duration was registered. In addition, neuropathic-like shoulder pain complaints were assessed using the neuropathic pain diagnostic questionnaire (DN4, score: 0 - 10). ${ }^{6}$ The DN4 consist of 10 items comprising pain descriptors and somatosensory signs. Scoring at least 4 items positively is suggestive of pain of predominantly neuropathic origin. Patients were classified as having neuropathiclike shoulder pain when scoring at least 4 on the DN4. ${ }^{6}$

\section{Sensory examination}

Sensory examination consisted of clinical examination and mechanical and electrical QST and took place in a separate experimental session, preceding the evoked potential recordings. Clinical examination included subjective sensation (normal, increased, diminished, allodynia) to touch, cold and sharpness at the upper arm and proprioception of the thumb. All QST thresholds were determined at the upper arm (C5 dermatome) using the method of limits and the start-side of stimulation was randomized between subjects. ${ }^{12}$ Tactile detection thresholds were determined using Semmes Weinstein filaments (sizes: $2.83,3.61,4.31,4.56,6.65)$. Pressure pain thresholds were determined using a somedic 
pressure algometer (stimulation surface: $1 \mathrm{~cm} 2$, slope: $50 \mathrm{kPa}$, maximum output: $2000 \mathrm{kPa}$ ). For the electrical QST thresholds an ambulant electrical stimulator was used (pulse width: $0.2 \mathrm{~ms}$, frequency: $100 \mathrm{~Hz}$, ramp: $0.4 \mathrm{~mA} / \mathrm{s}, \mathrm{Ag} / \mathrm{AgCl}$ electrodes (AMBU Denmark) with stimulation surface: $95 \mathrm{~cm} 2$ ). Subjects could manually activate the stimulator by pressing a switch. To determine the electrical sensation threshold (EST), subjects were instructed to release the switch when the electrical pulses were perceived for the first time. To determine the electrical pain threshold (EPT), subjects were instructed to release the switch when the electrical pulses were perceived as both stinging and annoying. To determine the electrical pain tolerance threshold (EPTT) subjects were instructed to release the switch when the electrical pulses were perceived as burning and very annoying. Patients were trained to determine electrical QST thresholds reliably prior to participating in the experiment. For analysis, absolute thresholds were used for the unaffected side and relative (affected/ unaffected) thresholds for the affected side. Ratios were log-transformed prior to statistical analysis. ${ }^{48}$

\section{Evoked potentials}

Electrical stimulation

Cortical potentials were evoked at the tip of the middle finger of both hands by intracutaneous electrical stimulation according to the method described by Bromm and Meier. ${ }^{8}$ With this method, combined activation of $\mathrm{A} \beta$ and $\mathrm{A} \delta$ cutaneous afferents is achieved. Two electrodes with $1 \mathrm{~mm}$ diameter gold tips embedded in insulating material were used. The electrode was placed in a small opening that was drilled in the upper layer of the skin using a dental gimlet (diameter: $1 \mathrm{~mm}$ ). The sensation threshold (Is) had to be below $1 \mathrm{~mA}$. If not, preparation was regarded insufficient and tried again. A rectangular surface electrode (4 $\mathrm{x} 9 \mathrm{~cm}$ Klinerva Blue Electrode) was placed at the distal part of the upper forearm as an anode. A battery-driven computer-controlled current stimulator was used to generate the stimuli. The stimulus was a bipolar rectangular current pulse with a stimulus duration of 0.2 $\mathrm{ms}$. The Is and pain threshold (Ip) were determined for each hand, using the ascending method of limits by increasing the stimulus amplitude from zero with steps of $0.1 \mathrm{~mA}$. The Is was defined as the stimulation amplitude at which the stimulus was perceived for the first time. The Ip was defined as the stimulation amplitude at which the stimulus was first perceived as painful. Is and Ip were each determined 3 times and averaged. The final fixed stimulation amplitude (Ie) was calculated by averaging Is and Ip.62 The intensity of the stimulus was varied using pulse modulation. Single pulses and pulse trains of 5 pulses were used. The inter-pulse interval used for the pulse trains was $5 \mathrm{~ms}$. To make sure that stimulation with the pulse trains was tolerable, the trains were applied with increasing 
amplitude starting from Is before starting the actual protocol. If necessary, Ie was adjusted so that pulse trains were described as a tolerable but clear pricking painful sensation.

\section{EEG recordings}

Electrical brain activity was continuously recorded using a 64-channel EEG Refa-72 system (ANT, the Netherlands). A 64-channel Waveguard EEG cap with Ag/ AgCl electrodes was used according to the international 10-5 system. All scalp electrode impedances were below $5 \mathrm{k} \Omega$. The ground electrode was placed at the forehead or just below the right eye (depending on what provided the best raw signal). Two Ag/ AgCl electrodes were placed just above and under the left eye to record the electrooculogram (EOG). Data was recorded using ASA software (ANT software BV, the Netherlands) with a sample frequency of 1024 $\mathrm{Hz}$. The signals were filtered offline at band-pass $0.3-120 \mathrm{~Hz}$. Data from -100 to $-10 \mathrm{~ms}$ prestimulus was used for baseline correction. The time window of analysis was -100 ms prestimulus to $400 \mathrm{~ms}$ post-stimulus. Data recorded at $\mathrm{Cz}$ was referred to linked earlobes (A1A2) and data recorded at C3 and C4 was referred to Fz. All off-line data analysis was performed in Matlab ${ }^{\circledR}$.

\section{Procedure}

The stimulus protocol consisted of 3 blocks. During each block, stimuli were delivered alternately to the affected and unaffected (PSSP and PF) or non-dominant and dominant (HC) side. Each hand was stimulated 20 times using 10 single pulse stimuli and 10 pulse train stimuli. The start-side of stimulation was randomized between subjects. The order of stimulus intensity ( 1 or 5 pulses) was semi-randomized. The inter-stimulus-interval between 2 successive stimuli varied randomly between 5 and 7 seconds. In order to maintain attention, subjects were asked to verbally rate the perceived strength of each stimulus on an 11-point numeric rating scale ( $0=$ no sensation, $10=$ maximum conceivable pain). The first stimulus corresponded to a pulse train stimulus. Subjects were instructed to rate this first stimulus as a 6 on the numeric rating scale. Each block was followed by a short break. For each subject the average Ie (across the 3 blocks) was calculated for further analysis. NRS scores were not further analyzed.

\section{EP analysis}

First, trials with an EOG artifact exceeding $\pm 70 \mu \mathrm{V}$ in a time window of -100 to -10 ms prestimulus and 60 to $400 \mathrm{~ms}$ post-stimulus were rejected. Non-rejected data was accepted after visual inspection for missed EOG or muscular artifacts. Over all blocks, at least 10 (out of 30) EP trials had to be available for analysis (for each hand and stimulus intensity) 
otherwise subjects were excluded. For each subject, the remaining trials were averaged separately for each of the used stimulus intensities (single pulse, pulse train) and for each hand (both hands: Cz-A1A2, right hand: C3-Fz, left hand: C4-Fz). In addition, EPs were averaged for each group (PSSP, PF, HC). Due to high variation across subjects, the amplitudes and latencies of late EP components were determined manually by visual inspection of the individual averaged EPs. The N90 EP component (around 90 ms poststimulus) was detected in the contralateral EP (C3-Fz for right hand stimulation and $\mathrm{C} 4-\mathrm{Fz}$ for left hand stimulation). At the vertex (Cz-A1A2), the amplitudes and latencies of the N150 peak (negative peak around $150 \mathrm{~ms}$ ), the P200 peak (positive peak around $200 \mathrm{~ms}$ ) and P300 peak (positive peak around $300 \mathrm{~ms}$ ) were determined. The peak-to-peak amplitude and latency for N150 and P200 (N150-P200) was calculated as well. For each group (PSSP, $\mathrm{PF}, \mathrm{HC}$ ), averages, standard deviations and standard errors were calculated for Ie (for each hand) and for the amplitude and latencies of the late EP components (N90, N150, P200, N150-P200 and P300 for each hand and stimulus intensity). Preliminary analysis showed that pulse train stimulation lead to higher EP amplitudes in all the EP components and in all groups alike. Furthermore, no latency differences were observed comparing single pulse to pulse train stimulation. Therefore, to increase statistical power, EPs after single pulse and pulse train stimulation were pooled.

\section{Statistical analysis}

Statistical software package SPSS 16.0 for Windows was used (SPSS Inc., Chicago, IL, USA). For each group, frequencies or means \pm standard deviations were calculated for the demographic data and for the results of medical and sensory examinations. Group differences for demographic, medical and sensory examinations were statistically tested using either Chi-square tests or Kruskal-Wallis (comparison of 3 groups) and MannWhitney $\mathrm{U}$ (pairwise comparisons) testing. Group differences for Ie and for amplitudes and latencies of the EP components (N90, N150, P200, N150-P200 and P300) were tested separately using a repeated measures analysis of variance with the between-subjects-factor 'Group' (PSSP, PF and HC) and the within-subjects-factor 'Side' (affected and unaffected for PSSP and PF, non-dominant and dominant for HC). Bonferroni correction was used for posthoc multiple comparisons between groups. Significant interaction effects between 'Group' and 'Side' were evaluated using 1-way analyses of variance for each side separately, using the factor 'Group' (PSSP, PF and HC). For all tests, statistical significance was assigned at the $\mathrm{p}<0.05$ level using 2-tailed analysis.

To control for the potential confounding of lesion size and location, a sub-analysis was performed in which all patients without a confirmed lesion or with a very large lesion were 
excluded. The PF group was matched for lesion size and location to resemble the PSSP group. The sub-analysis was performed similarly as the overall analysis, however, statistical testing was only performed for amplitudes and latencies of the EP components.

\section{Results}

\section{Demographics and medical characteristics}

Four PSSP and $3 \mathrm{PF}$ patients and $1 \mathrm{HC}$ subject were excluded from analysis because visible EP components were lacking or less than 10 (out of 30) EP trials (for each hand and stimulus intensity) were available.

Thus, data from a total number of 6 PSSP and 14 PF patients and 20 healthy controls could be used for analysis. In patients with PSSP, pain duration was $20 \pm 9$ (mean \pm SD) months and pain intensity was $3.7 \pm 1.5$ during rest and $6.0 \pm 1.4$ during movement. Notably, 2 PSSP patients scored at least 4 on the DN4 and were classified as having neuropathic-like pain complaints. A summary of the demographics and medical examinations is presented for each group in Table 4.1. The groups were comparable for gender, lesion side, stroke latency and severe cognitive deficits.

Table 4.1 Demographics and medical characteristics, mean \pm SD or number of patients (\%).

\begin{tabular}{lccc}
\hline & $\begin{array}{c}\text { PSSP } \\
(\mathbf{n = 6})\end{array}$ & $\begin{array}{c}\text { PF } \\
(\mathbf{n = 1 4 )}\end{array}$ & $\begin{array}{c}\text { HC } \\
(\mathbf{n = 2 0})\end{array}$ \\
\hline Age & $56 \pm 9$ & $61 \pm 9^{*}$ & $55 \pm 7$ \\
Male / Female & $4 / 2$ & $8 / 6$ & $8 / 12$ \\
Stroke latency (months) & $19 \pm 9$ & $24 \pm 9$ & \\
Right-hemispheric lesion & $6(100 \%)$ & $9(64 \%)$ & \\
Lesion confirmed (CT/M RI) & $5(83 \%)$ & $9(64 \%)$ & \\
Small / M oderate / Large / Very large & $2 / 0 / 2 / 1$ & $5 / 2 / 2 / 0$ & \\
Cortical / Subcortical / Both & $4 / 1 / 0$ & $5 / 2 / 2$ & \\
Insula / ACC / Thalamus & $3 / 2 / 0$ & $3 / 3 / 0$ & $0(0 \%)$ \\
Cognitive deficits (M M SE<-24) & $0(0 \%)$ & $1(7 \%)$ & $31 \pm 5$ \\
Depression score (20-80) & $49 \pm 5^{* *}$ & $34 \pm 6$ & $100 \pm 0$ \\
Arm function (0-100) & $56 \pm 44 *$ & $70 \pm 43^{*}$ & $0(0 \%)$ \\
Glenohumeral subluxation & $4(67 \%)^{*}$ & $4(29 \%)^{*}$ & \\
Analgesics & PC (3), NSAID (1) & & \\
Anti-depressants & TCA (3), SSRI (1) & TCA (1), SSRI (2) & \\
\hline
\end{tabular}

SD: standard deviation; PSSP: stroke patients with post-stroke shoulder pain; PF: pain-free stroke patients; $\mathrm{HC}$ : healthy controls; CT: computed tomography; MRI: magnetic resonance imaging; PC: paracetamol; ACC: anterior cingulate cortex; NSAID: non-steriodal anti-inflammatory drug; TCA: tricyclic antidepressant; SSRI: selective serotonin reuptake inhibitor. ${ }^{*}$ significantly different from $\mathrm{HC}(p<0.05) .{ }^{* *}$ significantly different from both PF and HC ( $p<0.05)$. 
Although many patients in this study had right-hemispheric lesions, none of them showed clinical signs of severe hemi-inattention. In addition, the MMSE intersecting pentagons subtask, assessing visuospatial neglect, was performed correctly by the majority of patients (only 1 PSSP patient and 3 PF patients failed on this sub-task). Age was significantly higher in the PF group. Larger brain lesions were more common in the PSSP group. PSSP was associated with significantly higher depression scores. Stroke was associated with reduced arm function, glenohumeral subluxation and dystrophic changes regardless of the presence of pain. Analgesics (paracetamol and non-steroidal anti-inflammatory drugs) were only used in the PSSP group. Several PSSP and PF patients used anti-depressants (either tricyclic antidepressants or selective serotonin reuptake inhibitors).

\section{Sensory examination}

The results of sensory examination are presented for each group in Table 4.2. At the affected side, diminished cold sensation and proprioception were more often observed in stroke patients (PSSP and PF) as compared to controls.

Table 4.2 Sensory examination, mean \pm SD or number of patients (\%).

\begin{tabular}{lllccc}
\hline & & $\begin{array}{c}\text { PSSP } \\
(\mathbf{n = 6})\end{array}$ & $\begin{array}{c}\text { PF } \\
(\mathbf{n = 1 4 )}\end{array}$ & $\begin{array}{c}\text { HC } \\
(\mathbf{n = 2 0})\end{array}$ \\
\hline CE & Touch & diminished & $2(33 \%)$ & $3(21 \%)$ & $1(5 \%)$ \\
& & increased & $0(0 \%)$ & $2(14 \%)$ & $0(0 \%)$ \\
& Cold & diminished & $3(50 \%)^{*}$ & $5(36 \%)^{*}$ & $0(0 \%)$ \\
& increased & $1(17 \%)$ & $0(0 \%)$ & $1(5 \%)$ \\
& Proprioception & diminished & $3(50 \%)^{*}$ & $4(29 \%)^{*}$ & $0(0 \%)$ \\
& increased & $0(0 \%)$ & $0(0 \%)$ & $0(0 \%)$ \\
& Sharpness & diminished & $3(50 \%)$ & $4(29 \%)$ & $2(10 \%)$ \\
& increased & $2(33 \%)$ & $3(21 \%)$ & $3(14 \%)$ \\
\hline QST & ratio A/UA, ND/D & $1.18 \pm 0.20 * *$ & $1.05 \pm 0.18$ & $0.97 \pm 0.11$ \\
& & EST & $1.94 \pm 1.26$ & $1.02 \pm 0.36$ & $1.05 \pm 0.39$ \\
& & $1.44 \pm 0.96$ & $1.45 \pm 0.95$ & $1.09 \pm 0.40$ \\
& EPT & $1.17 \pm 0.42$ & $1.48 \pm 0.98$ & $0.92 \pm 0.18$ \\
& EPTT & $1.04 \pm 0.24$ & $1.03 \pm 0.27$ & $1.03 \pm 0.17$ \\
& PPT & $3.47 \pm 0.56$ & $3.49 \pm 0.50$ & $3.33 \pm 0.45$ \\
& TDT (size) & $1.18 \pm 0.56$ & $1.21 \pm 0.55$ & $0.91 \pm 0.33$ \\
& ESA, D & EST (mA) & $4.25 \pm 2.64$ & $2.87 \pm 1.89$ & $3.57 \pm 1.83$ \\
& EPT (mA) & $6.72 \pm 3.60$ & $5.72 \pm 4.42$ & $7.12 \pm 2.12$ \\
& EPTT (mA) & $363 \pm 192$ & $391 \pm 137$ & $443 \pm 131$ \\
\hline
\end{tabular}

SD: standard deviation; CE: clinical examination; QST: quantitative sensory testing; PSSP: stroke patients with post-stroke shoulder pain; PF: pain-free stroke patients; HC: healthy controls; QST: quantitative sensory testing; A/UA: affected/unaffected (patients); ND/D: non-dominant/dominant (HC); TDT: tactile detection threshold; EST: electrical sensation threshold; EPT: electrical pain threshold; EPTT: electrical pain tolerance threshold; PPT: pressure pain threshold; UA: unaffected side (patients); D: dominant side $(\mathrm{HC})$. * significantly different from $\mathrm{HC}(\mathrm{p}<0.05)$. ** significantly different from both $\mathrm{PF}$ and $\mathrm{HC}(\mathrm{p}<0.05)$. 

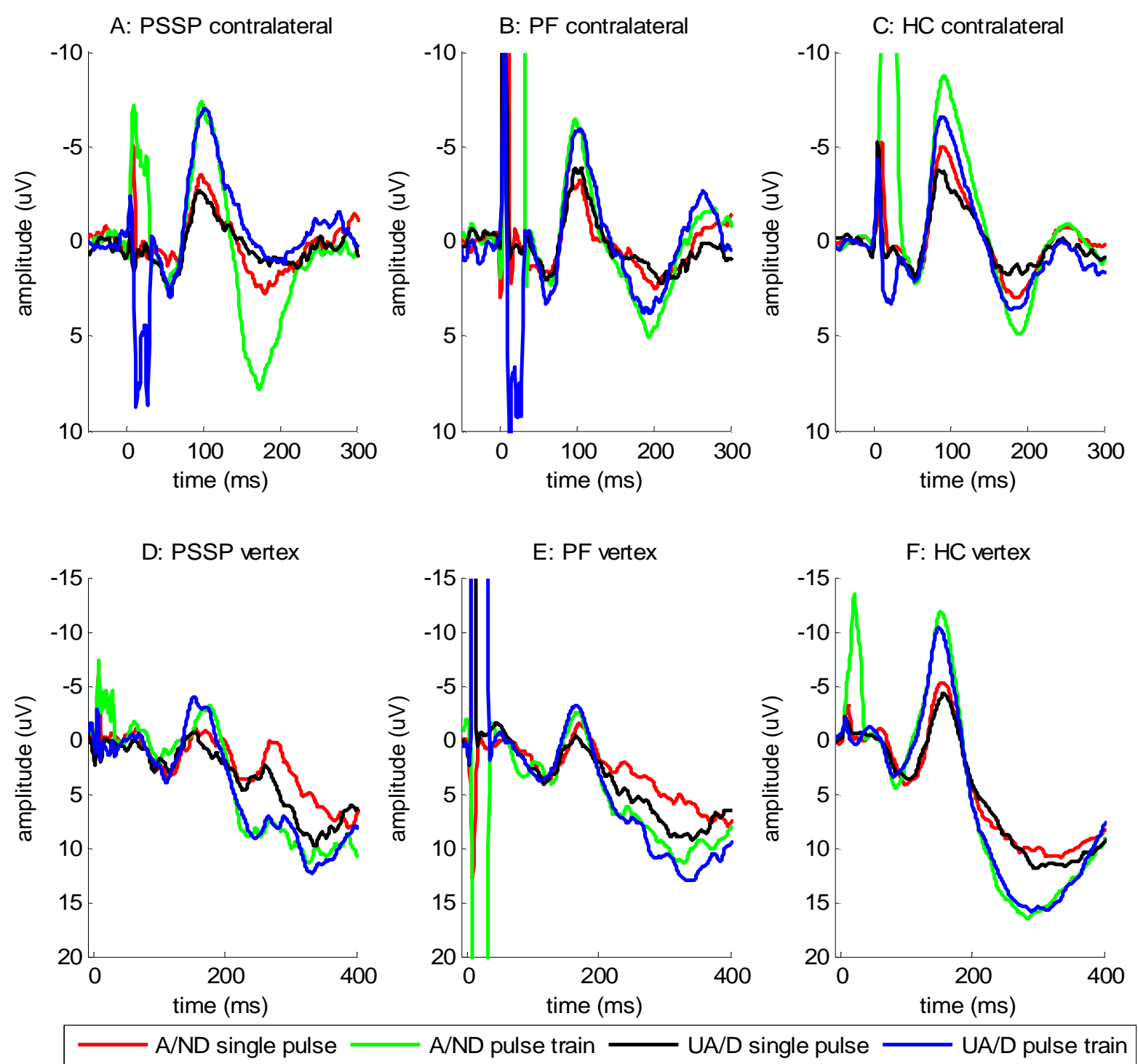

Figure 4.1 Grand average EPs recorded at the somatosensory cortex (C3/4-Fz) (A-C) and vertex (D-F). A\&D: PSSP ( $n=6) ; B \& E: P F(n=14) ; C \& F: H C(n=20)$. A/ND: affected side (patients)/non-dominant side (healthy controls); UA/D: unaffected side (patients)/dominant side (healthy controls).

Two PSSP patients reported pain in response to sharpness at the affected side. In addition, 1 of these patients also reported pain in response to the innocuous cold stimulus at the affected side. Tactile detection threshold ratios were significantly higher in patients with PSSP as opposed to HC. In addition, the mean electrical sensation threshold ratio was higher, however, this difference was not significant. At the unaffected side of PSSP patients, the mean electrical pain threshold was higher and the pressure pain threshold was lower, however, these differences were also not significant. 


\section{Evoked potentials}

Stimulation amplitude

Mean stimulation amplitude (mA) \pm standard deviation was $2.32 \pm 0.80$ (affected hand) and $1.88 \pm 0.51$ (unaffected hand) in PSSP patients, $1.91 \pm 1.00$ (affected hand) and $1.78 \pm 0.84$ (unaffected hand) in PF patients and $1.48 \pm 0.37$ (non-dominant hand) and $1.77 \pm 0.59$ (dominant hand) in $\mathrm{HC}$ subjects. Repeated measures analysis showed a significant interaction effect of 'Side' by 'Group'. Post-hoc testing showed that stimulation amplitude at the affected side was significantly higher in PSSP as opposed to HC ( $p<0.05)$.

\section{EP amplitudes}

The grand average EPs calculated for each group are presented in Figure 4.1. Mean amplitudes \pm standard errors of EP component are presented in Figure 4.2. Repeated measures analysis showed statistically significant differences between the groups $(\mathrm{F}(10,148)=3.34, \mathrm{p}=0.001)$. Post-hoc testing revealed that the N150 amplitude was significantly lower at both sides in stroke patients (both PSSP and PF) compared to controls $(\mathrm{p}<0.05)$. Moreover, the P300 amplitude was lower at both sides in patients as compared to controls, but this difference was only significant for PF $(p<0.05)$.

\section{EP latencies}

Mean latencies \pm standard errors of the EP components are presented in Figure 4.3.

Repeated measures analysis showed statistically significant differences between sides $(\mathrm{F}(5,73)=2.94, \mathrm{p}=0.018)$ and between groups $(\mathrm{F}(10,148)=5.81, \mathrm{p}<0.001)$ and $\mathrm{a}$ statistically significant interaction effect of 'Side' by 'Group' $(F(10,148)=2.68, p=0.005)$. Post-hoc testing showed that differences between sides were significant for the P300, differences between groups for all components and interaction effects for the N90 and the P300. One-way analysis of variance for each hand separately (N90 and P300 components) and post-hoc multiple comparisons (other components) showed that latencies of the N90, N150, P300 components were significantly higher at both sides in all stroke patients (PSSP and PF) compared to controls. In addition, only in PSSP patients, the N90 latencies at the affected side ( $p<0.05$ ), P200 latencies at both sides ( $p<0.05$ ) and N150-P200 peak-to-peak latencies at both sides $(\mathrm{p}<0.05)$ were significantly higher compared to both PF and HC. 
A

N90

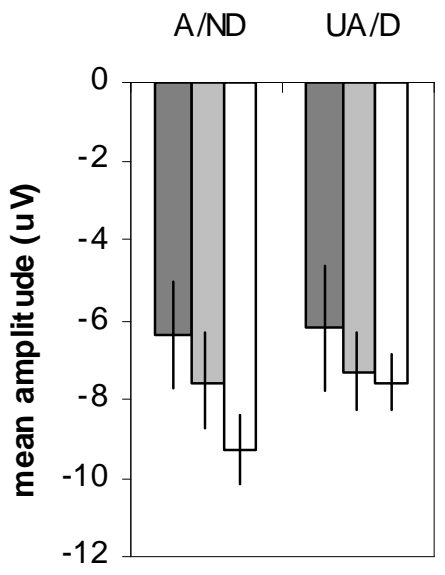

B

N150

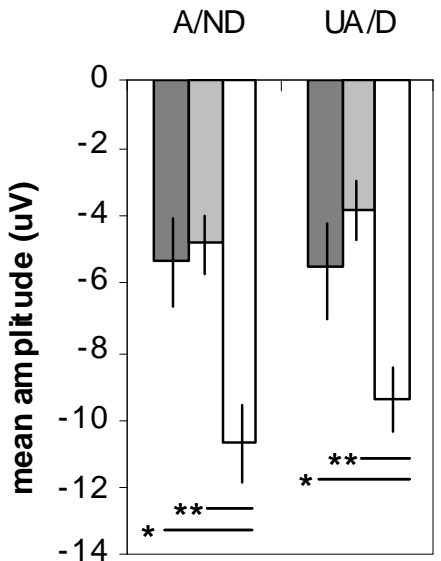

C

P200

D

N150-P200

E

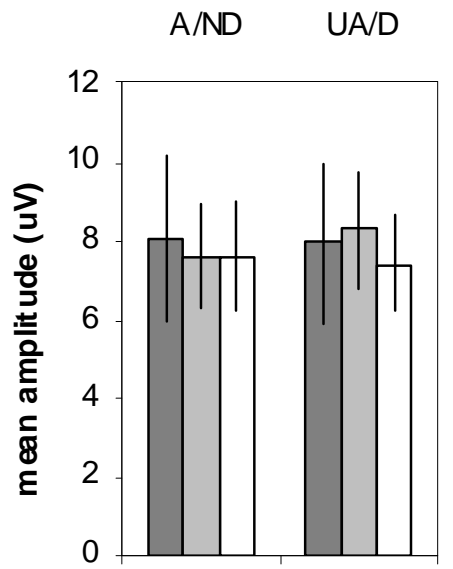

$\mathrm{A} / \mathrm{ND} \quad \mathrm{UA} / \mathrm{D}$
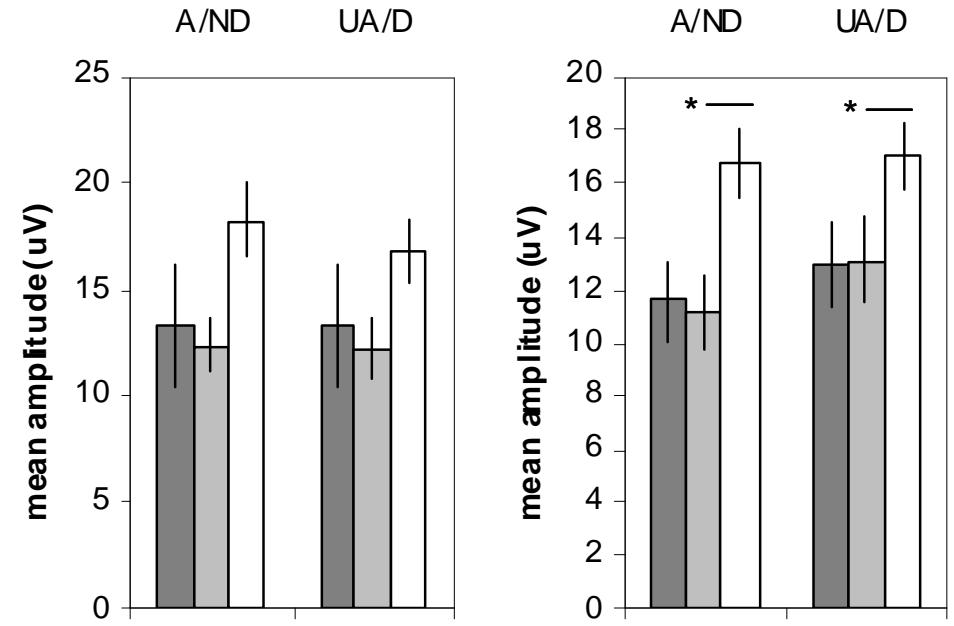

Figure 4.2 M ean amplitude $(\mu \mathrm{V}) \pm$ standard error of late evoked potential components. Dark grey bars: stroke patients with shoulder pain (PSSP, $n=6$ ), grey bars: pain-free stroke patients ( $P F, n=14$ ), white bars: healthy controls ( $H C, n=20)$. A/ND: affected side (patients)/non-dominant side (healthy controls); UA/D: unaffected side (patients)/dominant side (healthy controls). $* p<0.05, * * p<0.001$. 
A

N9O

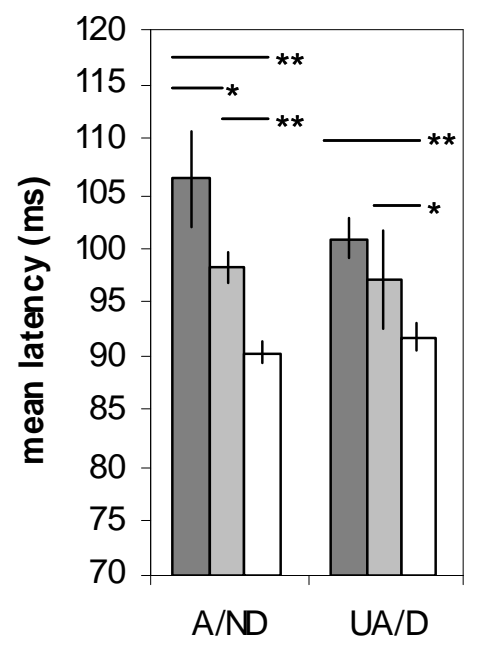

B

N150

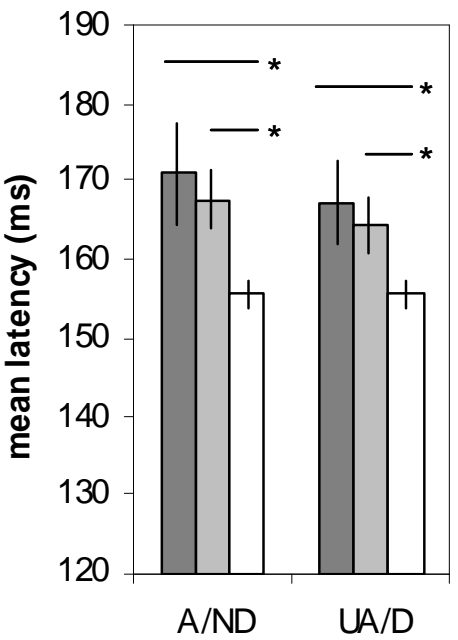

C

P200

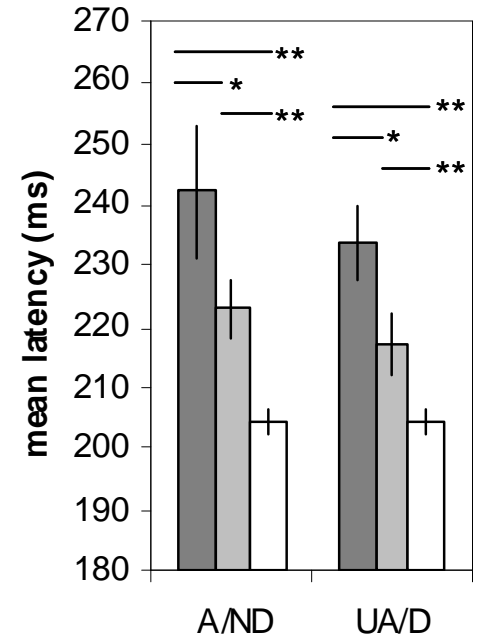

D

N150-P200

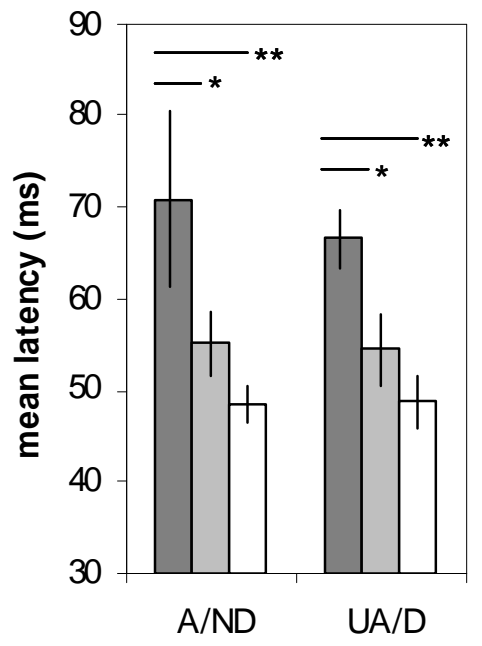

E

P300

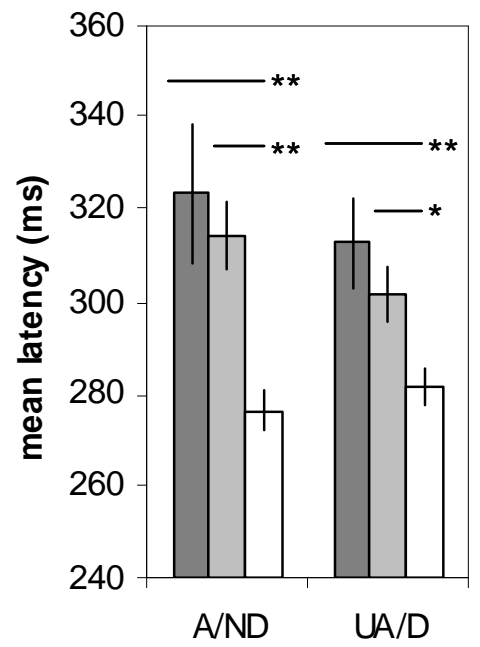

Figure 4.3 M ean latency (ms) \pm standard error of late evoked potential components. Dark grey bars: stroke patients with shoulder pain (PSSP, $n=6$ ), grey bars: pain-free stroke patients ( $P F, n=14$ ), white bars: healthy controls (HC, $n=20$ ). A/ND: affected side (patients)/non-dominant side (healthy controls); UA/D: unaffected side (patients)/dominant side (healthy controls). $* p<0.05, * * p<0.001$. 
Table 4.3 Sub-analysis: Demographic data and medical characteristics, mean [min-max] or number of patients.

\begin{tabular}{lcc}
\hline & $\begin{array}{c}\text { PSSP } \\
(\mathbf{n = 4})\end{array}$ & $\begin{array}{c}\text { PF } \\
(\mathbf{n = 4})\end{array}$ \\
\hline Age & $56[39-65]$ & $61[48-69]$ \\
Male / Female & $2 / 2$ & $3 / 1$ \\
Stroke latency (months) & $17[6-26]$ & $18[12-24]$ \\
Right-hemispheric lesion & 4 & 3 \\
$\quad$ Small / Large & $2 / 2$ & $2 / 2$ \\
$\quad$ Cortical / Subcortical & $3 / 1$ & $3 / 1$ \\
$\quad$ Insula / ACC & $2 / 2$ & $1 / 2$ \\
Cognitive deficits & 0 & 0 \\
Depression score (20-80) & $50[45-57]$ & $38[32-46]$ \\
Arm function (0-100) & $61[0-91]$ & $70[14-100]$ \\
Glenohumeral subluxation & 2 & 2 \\
Trophic changes hand/arm & 2 & 0 \\
Abnormal sensation (T/ C / P / S) & $1 / 3 / 2 / 3$ & $2 / 0 / 0 / 1$ \\
Analgesics & PC (1), NSAID (1) \\
Anti-depressants & TCA (2), SSRI (1) & \\
\hline
\end{tabular}

PSSP: stroke patients with post-stroke shoulder pain; PF: pain-free stroke patients; ACC: anterior cingulate cortex; T/C/P/S: touch/cold/proprioception/sharpness; PC: paracetamol; NSAID: non-steriodal antiinflammatory drug; TCA: tricyclic antidepressant; SSRI: selective serotonin reuptake inhibitor.

\section{Sub-analysis}

Lesion characteristics were not known for all patients in the overall analysis.

Demographic and medical characteristics of lesion-matched stroke groups (PSSP: $n=4, P F$ : $\mathrm{n}=4$ ) are presented in Table 4.3 .

For evoked potentials, mean stimulation amplitude (mA) [min-max] was 2.05 [1.54-2.97] (affected hand) and 2.07 [1.67-2.60] (unaffected hand) in PSSP patients, 1.27 [0.94-1.90] (affected hand) and 1.14 [0.95-1.43] (unaffected hand) in PF patients. Sub-analyses for amplitude and latency of evoked potential components are presented in Figure 4.4 and 4.5 respectively.

For amplitude, group differences were observed for the N150 $(p=0.014)$ and P300 ( $p=$ 0.037) components. Post-hoc testing revealed that N150 and P300 amplitudes were significantly lower at both sides in stroke patients compared to controls, however this was only significant for the PF group ( $p<0.05)$. 
A

$\mathrm{NOO}$

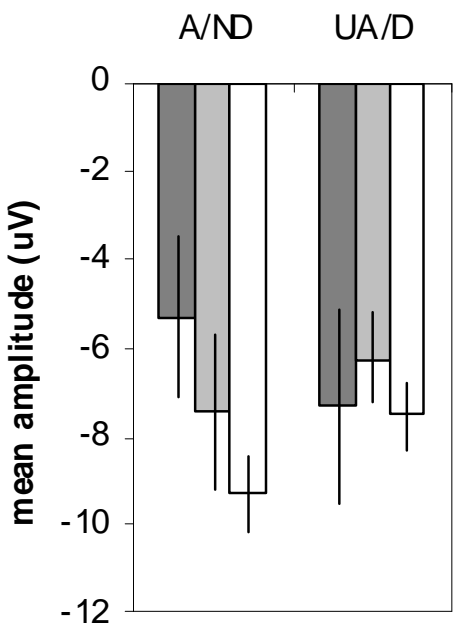

B

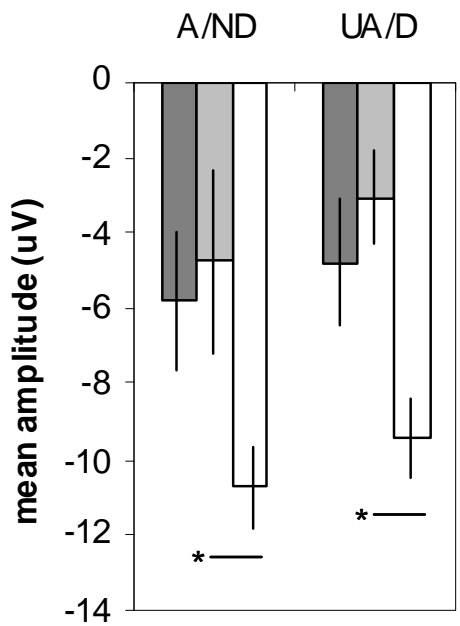

C

P200
D

N150-P200

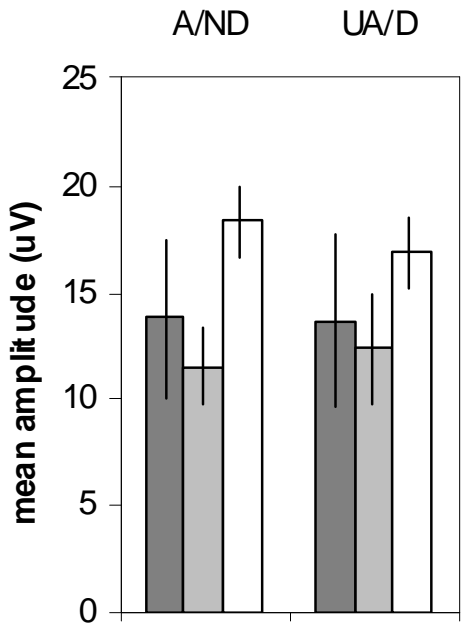

$\mathbf{E}$

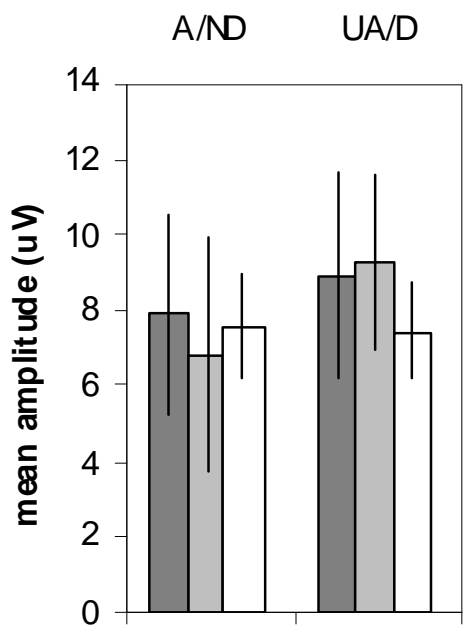

Figure 4.4 Sub-analysis: Mean amplitude $(\mu \mathrm{V}) \pm$ standard error of late evoked potential components. Dark grey bars: stroke patients with shoulder pain (PSSP, $n=4)$, grey bars: pain-free stroke patients ( $P F, n=4)$, white bars: healthy controls ( $\mathrm{HC}, \mathrm{n}=20$ ). $\mathrm{A} / \mathrm{ND}$ : affected side (patients)/non-dominant side (healthy controls); UA/D: unaffected side (patients)/dominant side (healthy controls). $* p<0.05, * * p<0.001$.

For latency, group differences were observed for all components $(\mathrm{p}<0.01)$. In addition, side differences and interaction effects of 'Side' by 'Group' were observed for the P200 ( $p<0.05$ ) and P300 ( $\mathrm{p}<0.05$ ). One-way analysis of variance for each hand separately ( P200 and P300 components) and post-hoc multiple comparisons (other components) showed that latencies of the N90, N150 and P300 components were higher at both sides in all stroke patients (PSSP and PF). 
For the N90 this was significant for both groups (PSSP, $\mathrm{p}<0.01 ; \mathrm{PF}, \mathrm{p}<0.05$ ), for the N150 this was significant for the PSSP group only $(p<0.05)$ and for the P300 this was significant for both the PSSP $(\mathrm{p}<0.01)$ as well as the PF group (affected side, $\mathrm{p}<0.01)$.

No significant difference was observed between the PSSP and PF group for the N90 latency. However, in PSSP patients, the P200 latency and N150-P200 peak-to-peak latency was significantly higher compared to both PF (P200, p < 0.05) and HC groups (P200, p < 0.01; N150-P200, $\mathrm{p}<0.01$ ).

A

N90

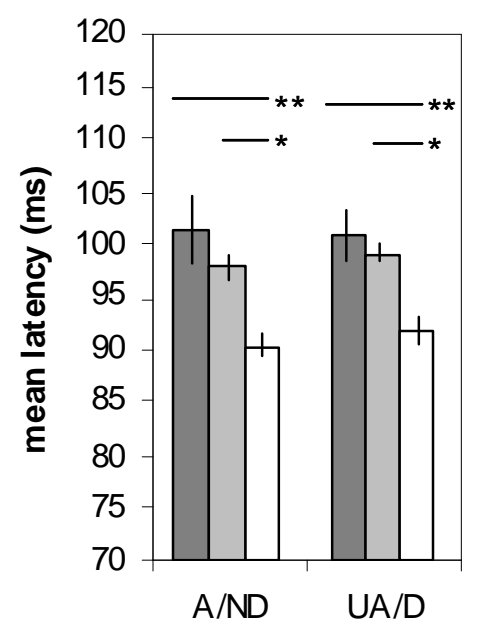

B

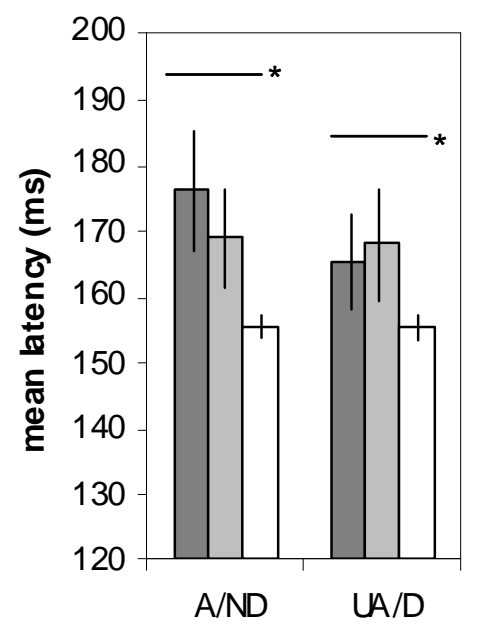

C

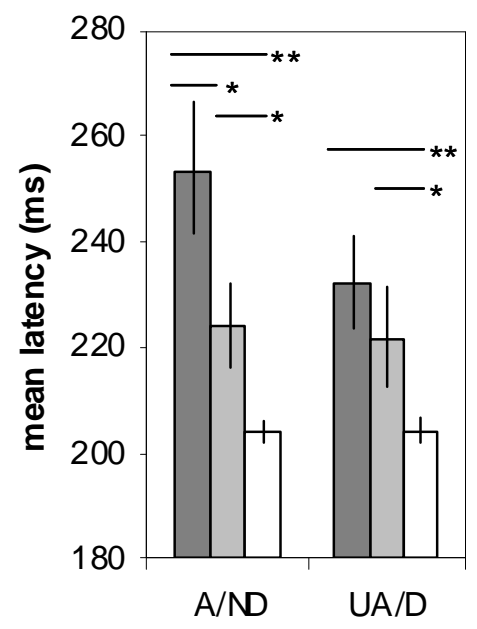

D N150-P200

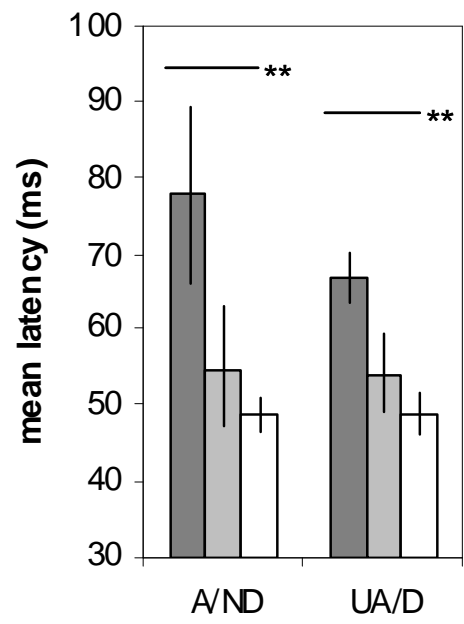

E

P300

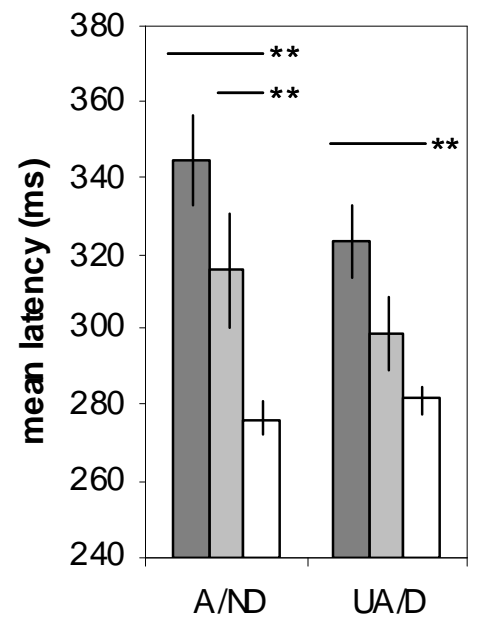

Figure 4.5 Sub-analysis: M ean latency (ms) \pm standard error of late evoked potential components. Dark grey bars: stroke patients with shoulder pain (PSSP, $n=4)$, grey bars: pain-free stroke patients ( $P F, n=4)$, white bars: healthy controls $(H C, n=20)$. A/ND: affected side (patients)/non-dominant side (healthy controls); UA/D: unaffected side (patients)/dominant side (healthy controls). $* p<0.05, * * p<0.001$. 


\section{Discussion}

This explorative study evaluated alterations in the cortical processing of somatosensory stimuli in stroke patients with unilateral brain lesions and chronic PSSP using electrocutaneous stimulation and EEG. Patients with PSSP were compared to both pain-free stroke patients and to healthy controls. In all stroke patients reduced EP amplitudes (N150, P300) and increased EP latencies (N90, N150, P300) were found in response to stimulation at both the affected and unaffected side. In addition, PSSP was associated with increased P200 and N150-P200 peak-to-peak latencies after stimulation at both sides.

\section{Intracutaneous electostimulation and EPs}

The method of intracutaneous electrostimulation used in this experiment activates both $\mathrm{A} \beta$ and A $\delta$ primary afferents. ${ }^{8}$ Stimulation was, thus, never nociceptive-specific, although subjects were stimulated with a low intensity (clear non-painful pricking sensation) and a high intensity (clear painful pricking sensation) stimulus. All EP components that were studied in this experiment were observed after stimulation with either the low or high intensity stimulus, with similar effects, so that data could be pooled. After a non-specific stimulus, based on the 'first come, first served' principle ${ }^{23}$, the EP is thought to reflect the processing of the activity from the fastest conducting fibers only, in this case A $\beta$ fibers. On the other hand, even when the stimulus is entirely noxious, the EP may not be nociceptivespecific. 44

\section{N90}

The N90, 1 of the first components to be observed in the EP after intracutaneous electrical stimulation, originates from the somatosensory cortex and reflects sensory-discriminative processes involved in stimulus perception. .930

This study showed increased N90 latencies in stroke patients (PSSP and PF) as opposed to healthy controls. In pain-free patients, similar increases in latency (7-8 ms delays) have been observed for early EP components, reflecting impaired processing of input from the dorsomedial lemniscal pathway.33 Remarkably, the N90 latency was increased after stimulation at both the affected and unaffected side, which may result from changes in sensory-discriminative processing at both the ipsilesional as well as contralesional hemisphere ${ }^{17}$ and/ or from a reduction in attentional arousal24. In patients with PSSP, a further increase in the N90 latency was observed after stimulation at the affected side as compared to the PF group, corresponding to increased tactile detection thresholds, quantitative electrical sensation thresholds (EST) and stimulation amplitudes (Ie) at the affected side of patients with PSSP. Since the electrical stimulation to evoke EPs in this study 
activated both $\mathrm{A} \beta$ and $\mathrm{A} \delta$ fibers, the increase in N90 latency reflects a loss of both dorsomedial-lemnisco-cortical as well as spino-thalamo-cortical integrity, and objectively confirms the clinical findings. Since the difference in N90 latency between PSSP and PF patients was not observed after matching for lesion size and location, the presence of PSSP appears to be independent of the (functional) loss of brain structures that are responsible for the generation of the N90 peak.

Several studies of central neuropathic (post-stroke) pain reporting on median and tibial electrical EPs29,42 or laser evoked potentials10,25 reported reduced EP amplitudes and/ or longer latencies in these patients. However, in these studies, patients with pain were only compared to healthy controls, so it cannot be concluded that the reported differences were specific for pain.

In contrast to Parkinson patients with central pain ${ }^{53}$ and fibromyalgia patients ${ }^{26}$, no signs of central hyperexcitability were observed for any of the EP components after stroke. However, in the patients with PSSP that could be included in this study, the incidence of clinical signs of central hyperexcitability (allodynia, generalized hyperalgesia) was generally low. In addition, ongoing central hyperexcitability after stroke may be masked by loss of somatosensory function and/ or loss of attentional capabilities. 60

\section{N150, P200, N150-P200}

The N150-P200 complex originates from the insula, secondary somatosensory and cingulate cortices $7,31,32$ and its peak-to-peak amplitude has been related to subjective ratings of stimulus intensity and pain9,11. Both the N150 and the P200 are, therefore, thought to reflect cognitive-evaluative processes involved in stimulus perception. In the present study, only the N150 but not the P200 or the N150-P200 peak-to-peak amplitude was significantly reduced in stroke patients. To our knowledge, selective attenuation of the N150 amplitude has not been reported before. Attenuation of the N150 peak may be related to lesions of the insula and anterior cingulated cortices. In addition, in previous studies, attenuation of the N150-P200 complex has been related to distraction and decreased states of arousal.5,66 The reduction in N150, therefore, might be explained by a (functional) loss of brain structures responsible for its generation and/ or by reduced cognitive (attentional) capacities resulting directly from the brain lesion. ${ }^{46}$

Latency shifts of the N150 and P200 have been reported before but not in relation to stroke or pain. Moreover, latency shifts have been reported inconsistently. In the current study, increased N150 and P200 latencies were observed in all stroke patients as opposed to healthy controls. In addition, the P200 and the N150-P200 peak-to-peak latencies were significantly more increased in patients with PSSP. Since calculation or memorization tasks 
have not been shown to affect the latency of N150 or P200 components ${ }^{66}$, loss of attentional capabilities cannot account for the observed differences between groups. However, the selective increase in P200 latencies in patients with PSSP may be explained by a disturbance in the perception of stimulus intensity, since the perception of stimulus intensity has previously been negatively correlated with the P200 latency. ${ }_{54,56}$ Since the difference in P200 latency was also observed in the sub-analysis in which PSSP and PF patients were matched for lesion size and location, it is likely that the abnormality in the P200 latency is related to the presence of PSSP.

P300

The P300 has been implicated in various cognitive processes, such as attention and distraction and target/non-target responses.7 Its latency provides an indirect indication of the duration of the processes involved in stimulus discrimination. ${ }^{28}$ Moreover, the P300 latency has been shown to be increased in patients with chronic pain, indicating that chronic pain may interfere with cognitive processes. ${ }^{57}$ The P300 amplitude has been related to stimulation intensity and subjective ratings of stimulus intensity at both painful and nonpainful stimulation levels. ${ }^{18,62}$ In response to painful electrical stimulation, the P300 may reflect an attention component, a pain component and a stimulus intensity component. ${ }^{4}$ In the current study, reduced P300 amplitudes and increased P300 latencies were observed in all stroke patients. Therefore, the changes in P300 likely represent a cognitive deficit in the discrimination of stimuli associated with the brain lesion but with no direct relation to PSSP.

\section{Limitations}

This study was the first to assess the cortical processing of somatosensory stimuli in patients with PSSP, and the results should therefore be interpreted with caution. Since this was a cross-sectional study, no conclusions can be drawn on any causal relation between the reported differences in somatosensory processing and the presence of pain.

One of the limitations of this study is the small sample size, which was predominantly due to the demands on cognitive and somatosensory functions necessary for the experimental setup. As a result, several factors, such as age, gender and depression, which have previously been related to EP amplitude or latency, were slightly different between groups. However, based on additional regression and correlation tests using the HC data, age and gender were not considered to form a relevant source of confounding for the current results. In addition, although the incidence of depressive symptoms in patients with PSSP was higher than in the PF patients, depressive symptoms were not severe69 and no group differences were 
observed for EP components previously related to major depression ${ }^{36}$. The influence of analgesic medication 2,3,43,55 and antidepressants $16,45,63$ was not considered to form a relevant source of confounding either, although confounding could not entirely be ruled out as a result of the sample size.

Another limitation is the fact that lesion characteristics could not be determined in several patients due to the unavailability of a CT or MRI brain scan. Moreover, high resolution scans were not available for any patient, so that lesion characteristics could only roughly be determined and diffuse white matter lesions might have remained undetected. To at least grossly evaluate the level of confounding introduced by lesion characteristics, a sub-analysis was performed in which PSSP $(n=4)$ and $P F(n=4)$ patients were matched for lesion size and location. Although no difference was observed for the N90 latency comparing the PSSP and PF groups, in this sub-analysis, PSSP was still related to increased P200 and N150-P200 latencies. Despite the small number of subjects in the sub-analysis, these results at least suggest that lesion characteristics alone cannot explain the observed differences between PSSP and PF groups, and that the observed abnormalities in evoked potential characteristics in PSSP patients may be related to the central effects of persistent nociceptive pain.

\section{Conclusion}

The present study showed that the cortical processing of somatosensory stimuli was generally reduced in patients with stroke, which may be related to attentional deficits and to deficits in the discrimination of stimuli as a result of the brain lesion. These deficits may put stroke patients at risk of developing any type of pain after stroke, since patients may not be able to adequately react to potentially harmful stimuli. In addition, in patients with PSSP, loss of somatosensory function was more severe and the cognitive processing of somatosensory stimuli was affected. This seemed to occur independently of lesion size and location and may, therefore, be related to the central effects of chronic pain. However, since this was an explorative study in a small number of patients, our findings should be confirmed in a larger study. 


\section{References}

1 Appelros P. Prevalence and predictors of pain and fatigue after stroke: a population-based study. Int J Rehabil Res 29:329-333, 2006.

2 Arendt-Nielsen L, Nielsen JC, Bjerring P. Double-blind, placebo controlled comparison of paracetamol and paracetamol plus codeine--a quantitative evaluation by laser induced pain. Eur J Clin Pharmacol 40:241-247, 1991.

3 Ashton H, Golding JF, Marsh VR, Thompson JW. Effects of transcutaneous electrical nerve stimulation and aspirin on late somatosensory evoked potentials in normal subjects. Pain 18:377-386, 1984.

Becker DE, Yingling CD, Fein $G$. Identification of pain, intensity and P300 components in the pain evoked potential. Electroencephalogr Clin Neurophysiol 88:290-301, 1993.

Beydoun A, Morrow TJ, Shen JF, Casey $\mathrm{KL}$. Variability of laser-evoked potentials: attention, arousal and lateralized differences. Electroencephalogr Clin Neurophysiol 88:173-181, 1993.

6 Bouhassira $D$, Attal $N$, Alchaar $H$, Boureau F, Brochet B, Bruxelle J, Cunin G, Fermanian J, Ginies P, GrunOverdyking $A$, Jafari-Schluep $\mathrm{H}$, LanteriM inet M, Laurent B, Mick G, Serrie A, Valade $D$, Vicaut $E$. Comparison of pain syndromes associated with nervous or somatic lesions and development of a new neuropathic pain diagnostic questionnaire (DN4). Pain 114:29-36, 2005.

7 Bromm B, Lorenz J. Neurophysiological evaluation of pain. Electroencephalogr Clin Neurophysiol 107:227-253, 1998.
Bromm B, M eier W. The intracutaneous stimulus: a new pain model for algesimetric studies. M ethods Find Exp Clin Pharmacol 6:405-410, 1984.

Bromm B, Scharein E. Principal component analysis of pain-related cerebral potentials to mechanical and electrical stimulation in man. Electroencephalogr Clin Neurophysiol 53:94-103, 1982.

10 Casey KL, Beydoun A, Boivie J, Sjolund $B$, Holmgren $H$, Leijon $G$, Morrow TJ, Rosen I. Laser-evoked cerebral potentials and sensory function in patients with central pain. Pain 64:485491, 1996.

11 Chen ACN, Richard Chapman C, Harkins SW. Brain evoked potentials are functional correlates of induced pain in man. Pain 6:365-374, 1979.

12 Chong PS, Cros DP. Technology literature review: quantitative sensory testing. Muscle Nerve 29:734-747, 2004.

13 Coderre TJ, Katz J. Peripheral and central hyperexcitability: Differential signs and symptoms in persistent pain. Behav Brain Sci 20:404-419, 1997.

14 Collin C, Wade D. Assessing motor impairment after stroke: a pilot reliability study. I Neurol Neurosurg Psychiatry 53:576-579, 1990.

15 Constantinovici A. Dissociation of parietal and frontal somatosensory evoked potentials in central nervous system diseases. Rom J Neurol Psychiatry 28:187-198, 1990.

16 d'Ardhuy $\mathrm{XL}$, Boeijinga $\mathrm{PH}$, Renault $\mathrm{B}$, Luthringer $R$, Rinaudo $G$, Soufflet $L$, Toussaint $M$, Macher J. Effects of serotonin-selective and classical 
antidepressants on the auditory P300 cognitive potential. Neuropsychobiology 40:207-213, 1999.

17 Desrosiers J, Bourbonnais D, Bravo G, Roy PM, Guay M. Performance of the 'unaffected' upper extremity of elderly stroke patients. Stroke 27:1564-1570, 1996.

18 Dowman R. Spinal and supraspinal correlates of nociception in man. Pain 45:269-281, 1991.

19 Eccleston C, Crombez G. Pain demands attention: A cognitive-affective model of the interruptive function of pain. Psychol Bull 125:356-366, 1999.

20 Flor H. Cortical reorganisation and chronic pain: implications for rehabilitation. J Rehabil Med:66-72, 2003.

21 Gamble GE, Barberan E, Bowsher D, Tyrrell PJ, Jones AK. Post stroke shoulder pain: more common than previously realized. Eur J Pain 4:313$315,2000$.

22 Gamble GE, Barberan E, Laasch HU, Bowsher D, Tyrrell PJ, Jones AK. Poststroke shoulder pain: a prospective study of the association and risk factors in 152 patients from a consecutive cohort of 205 patients presenting with stroke. Eur J Pain 6:467-474, 2002.

23 Garcia-Larrea L. Somatosensory volleys and cortical evoked potentials: 'First come, first served'? Pain 112:5-7, 2004.

24 Garcia-Larrea L, Bastuji H, M auguiere F. Mapping study of somatosensory evoked potentials during selective spatial attention. Electroencephalogr Clin Neurophysiol 80:201-214, 1991.

25 Garcia-Larrea L, Convers $\mathrm{P}$, Magnin $\mathrm{M}$, Andre-Obadia N, Peyron R, Laurent B, Mauguiere F. Laser-evoked potential abnormalities in central pain patients: the influence of spontaneous and provoked pain. Brain 125:2766-2781, 2002.

26 Gibson SJ, Littlejohn GO, Gorman M M, Helme RD, Granges G. Altered heat pain thresholds and cerebral eventrelated potentials following painful $\mathrm{CO} 2$ laser stimulation in subjects with fibromyalgia syndrome. Pain 58:185193, 1994.

27 Hansen HC, Treede RD, Lorenz J, Kunze $\mathrm{K}$, Bromm B. Recovery from brain-stem lesions involving the nociceptive pathways: comparison of clinical findings with laser-evoked potentials. J Clin Neurophysiol 13:330-338, 1996.

28 Hansenne M. The 300 event-related potential. I. Theoretical and psychological perspective. Neurophysiologie Clinique 30:191-210, 2000.

29 Holmgren H, Leijon G, Boivie J, Johansson I, llievska L. Central poststroke pain--somatosensory evoked potentials in relation to location of the lesion and sensory signs. Pain 40:43-52, 1990.

30 Inui K, Tran TD, Hoshiyama M, Kakigi R. Preferential stimulation of Adelta fibers by intra-epidermal needle electrode in humans. Pain 96:247-252, 2002.

31 Inui K, Tran TD, Qiu $Y$, Wang $X$, Hoshiyama M, Kakigi R. A comparative magnetoencephalographic study of cortical activations evoked by noxious and innocuous somatosensory stimulations. Neuroscience 120:235248, 2003.

32 Kakigi R, Inui K, Tran DT, Qiu Y, Wang X, Watanabe S, Hoshiyama M. Human brain processing and central mechanisms of pain as observed by electro- and magnetoencephalography. J Chin Med Assoc 67:377-386, 2004. 
33 Karnaze D, Fisher M, Ahmadi J, Gott P. Short-latency somatosensory evoked potentials correlate with the severity of the neurological deficit and sensory abnormalities following cerebral ischemia. Electroencephalogr Clin Neurophysiol 67:147-150, 1987.

$34 \quad$ Klit H, Finnerup NB, Jensen TS. Central post-stroke pain: clinical characteristics, pathophysiology, and management. Lancet Neurol 8:857-868, 2009.

35 Lindgren I, Jönsson AC, Norrving B, Lindgren A. Shoulder pain after stroke: A prospective population-based study. Stroke 38:343-348, 2007.

Linka T, Sartory G, Bender S, Gastpar M , Muller BW. The intensity dependence of auditory ERP components in unmedicated patients with major depression and healthy controls. An analysis of group differences. J Affect Disord 103:139-145, 2007.

37 Loeser JD, Treede R-D. The Kyoto protocol of IASP Basic Pain Terminology. Pain 137:473-477, 2008.

38 Lundström E, Smits A, Terént A, Borg J. Risk factors for stroke-related pain 1 year after first-ever stroke. Eur J Neurol 16:188-193, 2009.

39 Maihöfner C, Jesberger F, Seifert F, Kaltenhäuser $M$. Cortical processing of mechanical hyperalgesia: A MEG study. Eur J Pain 14:64-70, 2010.

May A. Chronic pain may change the structure of the brain. Pain 137:7-15, 2008.

41 Miltner W, Johnson R, Jr., Braun C, Larbig W. Somatosensory event-related potentials to painful and non-painful stimuli: effects of attention. Pain 38:303-312, 1989.

42 Misra UK, Kalita J, Kumar B. A study of clinical, magnetic resonance imaging, and somatosensory-evoked potential in central post-stroke pain. J Pain 9:11161122, 2008.

43 Moore UJ, Marsh VR, Ashton CH, Seymour RA. Effects of peripherally and centrally acting analgesics on somatosensory evoked potentials. $\mathrm{Br}$ J Clin Pharmacol 40:111-117, 1995.

44 Mouraux A, Iannetti GD. Nociceptive laser-evoked brain potentials do not reflect nociceptive-specific neural activity. J Neurophysiol 101:3258-3269, 2009.

45 Oranje $B$, Jensen $K$, Wienberg $M$, Glenthoj BY. Divergent effects of increased serotonergic activity on psychophysiological parameters of human attention. Int J Neuropsychopharmacol 11:453-463, 2008.

46 Patel MD, Coshall C, Rudd AG, Wolfe CDA. Cognitive impairment after stroke: Clinical determinants and its associations with long-term stroke outcomes. J Am Geriatr Soc 50:700706, 2002.

47 Ratnasabapathy Y, Broad J, Baskett J, Pledger M, Marshall J, Bonita R. Shoulder pain in people with a stroke: a population-based study. Clin Rehabil 17:304-311, 2003.

48 Rolke $R$, Magerl W, Campbell KA, Schalber C, Caspari S, Birklein F, Treede RD. Quantitative sensory testing: a comprehensive protocol for clinical trials. Eur J Pain 10:77-88, 2006.

49 Roosink M, Geurts ACH, IJzerman MJ. Defining post-stroke pain: diagnostic challenges. Lancet Neurol 9:344-344, 2010.

50 Roosink M, Renzenbrink GJ, Buitenweg JR, van Dongen RTM, Geurts AC, IJzerman MJ. Somatosensory symptoms and signs and conditioned pain 
modulation in chronic post-stroke shoulder pain. J Pain in press, 2010.

51 Roosink $M$, Van Dongen RTM, Renzenbrink GJ, IJzerman MJ. Classifying post-stroke shoulder pain: Can the DN4 be helpful? Eur J Pain 15:99-102, 2011.

52 Sackley C, Brittle N, Patel S, Ellins J, Scott M, Wright C, Dewey ME. The prevalence of joint contractures, pressure sores, painful shoulder, other pain, falls, and depression in the year after a severely disabling stroke. Stroke 39:3329-3334, 2008.

53 Schestatsky P, Kumru H, Valls-Sole J, Valldeoriola F, Marti MJ, Tolosa E, Chaves ML. Neurophysiologic study of central pain in patients with Parkinson disease. Neurology 69:2162-2169, 2007.

54 Shimojo M, Svensson P, Arendt-Nielsen $L$, Chen AC. Dynamic brain topography of somatosensory evoked potentials and equivalent dipoles in response to graded painful skin and muscle stimulation. Brain Topogr 13:43-58, 2000.

55 Stacher G, Bauer P, Ehn I, Schreiber E. Effects of tolmetin, paracetamol, and of two combinations of tolmetin and paracetamol as compared to placebo on experimentally induced pain. A double blind study. Int J Clin Pharmacol Ther Toxicol 17:250-255, 1979.

56 Svensson P, Beydoun A, Morrow TJ, L. Casey K. Non-painful and painful stimulation of human skin and muscle: analysis of cerebral evoked potentials. Electroencephalogr Clin Neurophysiol 104:343-350, 1997.

57 Tandon OP, Kumar S. P3 event related cerebral evoked potential in chronic pain patients. Indian J Physiol Pharmacol 37:51-55, 1993.
58 Teasell RW, Bhogal SK, Foley NC. Painful Hemiplegic Shoulder. In: Teasell RW, Bhogal SK, Foley NC, editors. Evidence-based Review of Stroke Rehabilitation. London, Ontario, Canada: University of Western Ontario, 2007. pp. 1-57.

59 Tombaugh TN, M clntyre NJ. The MiniMental State Examination: A comprehensive review. J Am Geriatr Soc 40:922-935, 1992.

60 Treede RD, Lorenz J, Baumgartner U. Clinical usefulness of laser-evoked potentials. Neurophysiol Clin 33:303314, 2003.

61 Turner-Stokes L, Hassan N. Depression after stroke: a review of the evidence base to inform the development of an integrated care pathway. Part 1: Diagnosis, frequency and impact. Clin Rehabil 16:231-247, 2002.

62 Van der Heide EM, Buitenweg JR, $M$ arani $E$, Rutten WL. Single pulse and pulse train modulation of cutaneous electrical stimulation: a comparison of methods. J Clin Neurophysiol 26:54-60, 2009.

63 van Laar MW, Volkerts ER, Verbaten $M N$, Trooster $S$, van Megen $H J$, Kenemans JL. Differential effects of amitriptyline, nefazodone and paroxetine on performance and brain indices of visual selective attention and working memory. Psychopharmacology (Berl) 162:351-363, 2002.

64 Watanabe $Y$, Shikano $M$, Ohba $M$, Ohkubo $M$, Niwa T. Correlation between somatosensory evoked potentials and sensory disturbance in stroke patients. Clin Electroencephalogr 20:156-161, 1989.

65 Yamamoto $M$, Kachi T, Igata A. Painrelated and electrically stimulated somatosensory evoked potentials in patients with stroke. Stroke 26:426429, 1995. 
Chapter 4

66 Yamasaki $H$, Kakigi $R$, Watanabe $S$, Hoshiyama M. Effects of distraction on pain-related somatosensory evoked magnetic fields and potentials following painful electrical stimulation. Brain Res Cogn Brain Res 9:165-175, 2000.

67 Yuya $H$, Nagata $K$, Takanashi $Y$, Satoh $Y$, Watahiki Y, Hirata Y, Yokoyama E, Buchan RJ. Scalp topography of SEP late components in patients with supratentorial lesions. Brain Topogr 8:333336, 1996.

68 Zaslansky $R$, Sprecher E, Katz $Y$, Rozenberg B, Hemli JA, Yarnitsky D. Pain-evoked potentials: what do they really measure? Electroencephalogr Clin Neurophysiol 100:384-391, 1996.

69 Zung WW. A Self-Rating Depression Scale. Arch Gen Psychiatry 12:63-70, 1965. 


\section{Chapter 5}

\section{Classifying post-stroke shoulder pain: Can the DN4 be helpful?}

M eyke Roosink

Robert TM van Dongen

Gerbert J Renzenbrink

M aarten J IJzerman

European Journal of Pain 2011;15:99-102 


\section{Abstract}

The etiology of post-stroke shoulder pain (PSSP) is largely unclear and may involve both nociceptive and neuropathic mechanisms. No gold standard is present for PSSP diagnosis. The neuropathic pain diagnostic questionnaire (DN4), was originally developed to identify neuropathic pain in the clinical context. In this study we used the DN4 to categorize PSSP patients and compared symptoms and signs suggestive of either nociceptive or neuropathic pain. Pain complaints and sensory functions were compared between patients with chronic PSSP scoring at least $4(\mathrm{DN} 4+, \mathrm{n}=9$ ) or less than 4 (DN4-, $\mathrm{n}=10)$ on the DN4. Pain was assessed using a numeric rating scale and the McGill pain questionnaire. Sensory functions were assessed using clinical examination and quantitative sensory testing combined with a cold pressor test. Patients classified as DN4+ reported constant pain, a higher pain intensity, a higher impact of pain on daily living, more frequent loss of cold sensation, reduced QST thresholds at the unaffected side and increased QST thresholds at the affected side. Notably, several symptoms and signs suggestive of either neuropathic or nociceptive pain corresponded to the subgroups DN4+ and DN4- respectively. However, since the pathophysiological mechanisms remain unclear and none of the sensory signs could be exclusively related to either DN4+ or DN4-, PSSP prognosis and treatment should not be solely based on the DN4. Nonetheless, a thorough assessment of neuropathic and nociceptive pain complaints and somatosensory functions should be included in the diagnostic work-up of PSSP. 


\section{Introduction}

Shoulder pain is a common complication after stroke of which the etiology is largely unclear.7,10 Traditionally, post-stroke shoulder pain (PSSP) is considered as a nociceptive pain. ${ }^{1,18}$ In addition, PSSP has been related to central post-stroke pain, complex regional pain syndrome type 1, depression and sensory abnormalities and may be caused and maintained by various pain mechanisms. $8,10,11,14$

Although the prognosis and treatment of PSSP is largely dependent on suspected involvement of nociceptive and/ or neuropathic pain mechanisms, there is no gold standard or consensus regarding the diagnostic tools to differentiate PSSP of predominantly neuropathic from that of predominantly nociceptive origin. The use of grading systems for neuropathic pain ${ }^{16}$ or central post-stroke pain ${ }^{9}$ is problematic in PSSP. Based on the grading system for neuropathic pain, even patients with pure nociceptive PSSP might be classified as having neuropathic pain, simply because they have a relevant lesion affecting the central somatosensory system and the pain has a distinct neuroanatomically plausible distribution. On the other hand, to be classified as central post-stroke pain, all other causes of pain must have been ruled out, which can be difficult in PSSP. ${ }^{13}$

Several neuropathic pain scales have been developed for defining neuropathic pain in clinical practice. One of these is the neuropathic pain diagnostic questionnaire (DN4) comprising pain descriptors and a sensory examination. ${ }^{4}$ Its scale ranges from 0 to 10 and a score of at least 4 has been suggested to correlate with pain of predominantly neuropathic origin. However, neither the DN4 nor any other neuropathic pain scale has been validated for post-stroke pain.

This pilot study was performed to explore whether the DN4 might be useful for the classification of PSSP subtypes. Therefore, different pain complaints and somatosensory functions as related to either nociceptive or neuropathic pain were compared between subgroups of PSSP as classified with the DN4. In brief, movement related pain, pain related to arm function and/ or biomechanical changes around the shoulder joint were expected to be associated with nociceptive pain ${ }^{8}$. Neuropathic pain after stroke has previously been associated with spontaneous or constant pain, touch and cold allodynia ${ }^{9}$ and impaired spino-thalamo-cortical tract function 3,22 and is possibly associated with disturbed diffuse noxious inhibitory controls (DNIC) ${ }^{19}$. Although none of these symptoms and signs has been exclusively related to neuropathic pain, the incidence of these symptoms and signs was expected to be higher in the group of patients classified as neuropathic pain. 


\section{Methods}

\section{Subjects}

Patients ( $\mathrm{n}=19$ ) were recruited in 2 regional rehabilitation centers in the Netherlands (Roessingh Rehabilitation Center in Enschede and Sint Maartenskliniek in Nijmegen). All patients (age > 18 years) sustained a unilateral brain infarction with an onset at least 6 months prior to participation and had daily shoulder pain at the affected side for more than 3 subsequent months with an onset post-stroke. None fulfilled the diagnostic criteria for central post-stroke pain. ${ }^{9}$ In addition, none of the patients had other concomitant chronic pain complaints, either stroke or non-stroke related. Exclusion criteria were: pregnancy, trauma, infection, signs of any possible concomitant neurological condition. The study was approved by the human ethics committee and all participants gave written informed consent prior to their participation.

\section{Demographic and medical assessment}

Demographics and medication use were registered. Depressive symptoms were assessed using the ZUNG self-rating depression scale. ${ }^{17}$ Cognitive impairment was defined using the Mini Mental State Exam (score < 24). ${ }^{15}$ Physical examination of the upper extremity included assessment of trophic changes (visual inspection), glenohumeral subluxation (palpation), pain-free range of motion for passive shoulder elevation and external rotation (ratio between sides, affected/ unaffected), motor function (Motricity Index, score $0=$ no function, score $100=$ normal function $)^{5}$ and spasticity of elbow flexors and shoulder internal rotators (Modified Ashworth Scale, score $\geq 1)^{2}$.

\section{Subjective pain evaluation}

Shoulder pain was evaluated at rest and during movement using a numeric rating scale $(0=$ no pain, 10 = maximum conceivable pain), the McGill Pain Questionnaire ${ }^{20}$ and the neuropathic pain diagnostic questionnaire (DN4) $)^{4,21}$.

\section{Somatosensory assessment}

Modality specific somatosensory assessment is important for the diagnosis of neuropathic pain. ${ }^{6}$ A clinical examination and quantitative sensory testing (QST) were performed at both the affected and unaffected side at upper and lower part of the middle deltoid (C5 dermatome). Differences between sides (sensation) and evoked pain (allodynia) were recorded in response to the application of a cotton wool stick (light touch), a cold metal object (cold sensation) and a Semmes Weinstein filament size 6.65 (sharpness). Proprioception was tested at the thumbs. The tactile detection threshold was determined 
using Semmes Weinstein filaments (Touch-Test Hand Kit, North Coast Medical, Inc, UK). The pressure pain threshold was determined using a Somedic pressure algometer $\left(1 \mathrm{~cm}^{2}\right.$, $50 \mathrm{kPa} / \mathrm{s}$ ). In addition, patients were trained to determine electrical sensation, pain and pain tolerance thresholds using an ambulant stimulator (settings: $0.2 \mathrm{~ms}, 100 \mathrm{~Hz}, 0.4 \mathrm{~mA} / \mathrm{s}$ ). For QST, the method of limits was used and the start-side of stimulation was randomized. For analysis, absolute thresholds (average of 3 recordings) were used for the unaffected side and relative thresholds (affected/ unaffected) for the affected side.

\section{DNIC function}

Following QST, patients immersed their unaffected hand in a polystyrene box filled with icewater $(0-0.5 \stackrel{\circ}{\circ})$. Subjects were instructed to keep their hand in the water as long as possible (maximum 3 minutes). Immersion time was recorded using a digital stopwatch. After removing their hand from the water, patients rated the cold pressor induced pain using a numeric rating scale ( $0=$ no pain, $10=$ maximum conceivable pain), immediately followed by another determination of the electrical pain threshold and pressure pain threshold at the affected upper arm. A ratio (post/pre) was calculated for the pain thresholds determined before and after cold pressor testing.

\section{Data analysis}

Subgroups were formed based on the DN4 score: $\geq 4$ (DN4+) or $<4$ (DN4-). All ratios were log-transformed prior to statistical analysis. Due to the small sample sizes, only the differences in abnormal sensation (chi-square tests), QST thresholds (independent t-tests) and cold pressor parameters were statistically tested. Statistical significance was assigned at the $\mathrm{p}<0.05$ level.

\section{Results}

\section{Demographics and medical examinations}

All demographic and medical data are presented in Table 5.1.

\section{Subjective pain evaluation}

Pain characteristics are presented in Table 5.2. Pain intensity was somewhat higher in DN4+ patients. Moreover, only DN4+ patients reported constant pain, whereas only DN4patients reported pain attacks. In all patients with pain attacks, pain was primarily related to movement. However, of the patients with intermittent pain, all but 1 (DN4 score: 0) also reported an increase in pain intensity (range: 1 - 5) during movement. In patients with constant pain, pain was only minimally exacerbated upon movement. 
Table 5.1 Demographics and medical characteristics, mean \pm SD or number of subjects (\%).

\begin{tabular}{lcc}
\hline & $\begin{array}{c}\text { DN4+ } \\
(\mathbf{n = 9})\end{array}$ & $\begin{array}{c}\text { DN4- } \\
\text { (n=10) }\end{array}$ \\
\hline Age (years) & $58 \pm 10$ & $57 \pm 5$ \\
Gender (male) & $3(33 \%)$ & $7(70 \%)$ \\
Right-hemispheric lesion & $7(78 \%)$ & $9(90 \%)$ \\
Stroke latency (months) & $24 \pm 10$ & $19 \pm 17$ \\
Depression score (20-80) & $47.7 \pm 5.8$ & $43.3 \pm 5.6$ \\
Cognitive impairments (M M SE <24) & $1(11 \%)$ & $1(10 \%)$ \\
Trophic changes & $2(22 \%)$ & $6(60 \%)$ \\
Glenohumeral subluxation & $3(33 \%)$ & $7(70 \%)$ \\
M otor function (0-100) & $57.8 \pm 34.4$ & $34.5 \pm 38.5$ \\
ROM shoulder abduction (A/UA) & $0.39 \pm 0.18$ & $0.43 \pm 0.21$ \\
ROM shoulder external rotation (A/UA) & $0.41 \pm 0.35$ & $0.42 \pm 0.35$ \\
Spasticity elbow flexion (M AS $\geq 1)$ & $8(89 \%)$ & $7(70 \%)$ \\
Spasticity shoulder external rotation(M AS $\geq 1)$ & $6(67 \%)$ & $7(70 \%)$ \\
Analgesics & $2(22 \%)$ & $5(50 \%)$ \\
Antidepressants & $3(33 \%)$ & $6(60 \%)$ \\
Anticonvulsants & $3(33 \%)$ & $0(0 \%)$ \\
Oral anti-diabetics & $2(22 \%)$ & $2(20 \%)$ \\
\hline
\end{tabular}

A/UA: affected/unaffected side; DN4t: patients with DN4 score $\geq 4$; DN4-: patients with DN4 score <4; MAS: Modified Ashworth Score; $n$ : number of patients; ROM: pain-free passive range of motion; SD: standard deviation.

Table 5.2 Pain characteristics, median [range], mean \pm SD or number of subjects (\%).

\begin{tabular}{llcc}
\hline & & $\begin{array}{c}\text { DN4+ } \\
(\mathbf{n = 9})\end{array}$ & $\begin{array}{c}\text { DN4- } \\
(\mathbf{n = 1 0 )}\end{array}$ \\
\hline DN4 score & $5[4-6]$ & $2[0-3]$ \\
Pain onset (months post stroke) & & $5 \pm 8$ & $2 \pm 3$ \\
Pain duration (months) & $20 \pm 9$ & $18 \pm 17$ \\
Pain intensity (0-10) & Rest & $4.7 \pm 2.9$ & $2.5 \pm 2.4$ \\
& Movement & $7.3 \pm 1.8$ & $4.4 \pm 3.2$ \\
Pain distribution & Localized & $8(90 \%)$ & $10(100 \%)$ \\
& Radiating & $5(56 \%)$ & $2(20 \%)$ \\
Pain incidence & Shooting & $1(11 \%)$ & $0(0 \%)$ \\
& Attacks & $0(0 \%)$ & $5(50 \%)$ \\
Impact on daily life $(0-27)$ & Intermittent & $5(56 \%)$ & $5(50 \%)$ \\
\hline
\end{tabular}

DN4+: patients with DN4 score $\geq 4$; DN4-: patients with DN4 score < 4; n: number of patients; SD: standard deviation. 


\section{Somatosensory assessment}

Results are presented in Table 5.3 and Figure 5.1. Diminished cold sensation was significantly more frequently observed in DN4+. With respect to QST, no significant differences were found comparing DN4+ and DN4-. However, in patients classified as DN4+ there was a trend towards lower pain thresholds at the unaffected side, and a trend towards higher sensation and pain thresholds (all thresholds) at the affected side.

Table 5.3 Abnormal sensation and allodynia at the affected upper arm.

\begin{tabular}{llcc}
\hline & & $\begin{array}{c}\text { DN4+ } \\
(\mathbf{n}=9)\end{array}$ & $\begin{array}{c}\text { DN4- } \\
(\mathbf{n = 1 0 )}\end{array}$ \\
\hline Touch & diminished & $7(78 \%)$ & $6(60 \%)$ \\
& increased & $0(0 \%)$ & $0(0 \%)$ \\
& allodynia & $1(11 \%)$ & $0(0 \%)$ \\
\hline Cold & diminished & $7(78 \%)^{*}$ & $2(20 \%)$ \\
& increased & $1(11 \%)$ & $5(50 \%)$ \\
& allodynia & $1(11 \%)$ & $2(20 \%)$ \\
\hline Proprioception & diminished & $6(67 \%)$ & $7(70 \%)$ \\
& increased & $0(0 \%)$ & $0(0 \%)$ \\
& allodynia & $0(0 \%)$ & $0(0 \%)$ \\
\hline Sharpness & diminished & $5(56 \%)$ & $5(50 \%)$ \\
& increased & $1(11 \%)$ & $3(30 \%)$ \\
& allodynia & $2(22 \%)$ & $3(30 \%)$ \\
\hline
\end{tabular}

DN4+: patients with DN4 score $\geq 4$; DN4-: patients with DN4 score $<4$; n: number of patients. $* p<005$.
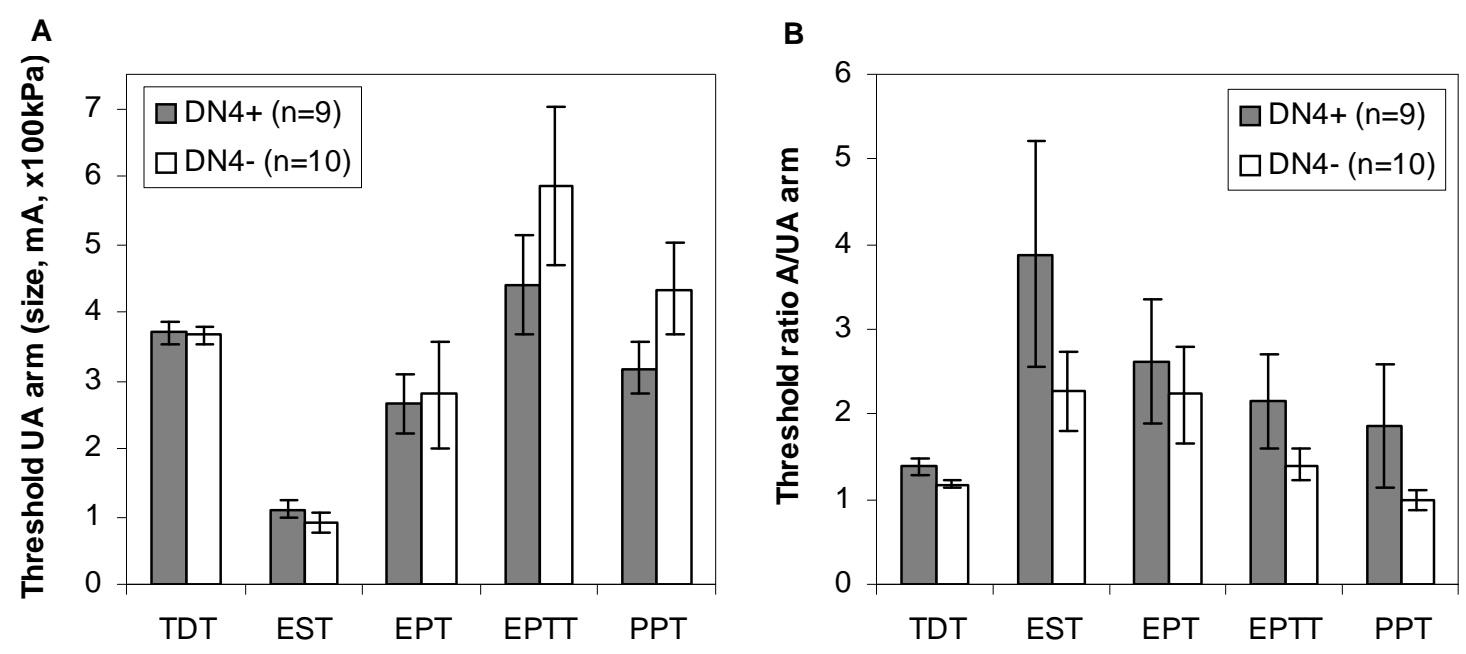

Figure 5.1 Thresholds at the unaffected arm (A) and threshold ratios (affected/unaffected) (B) for each patient group (mean \pm standard error). TDT: tactile detection threshold; EST: electrical sensation threshold; EPT: electrical pain threshold; EPTT: electrical pain tolerance threshold; PPT: pressure pain threshold. 


\section{DNIC function}

No significant differences were found for the duration of hand immersion ( $71 \pm 55$ vs. $80 \pm$ 70 seconds), cold pressor pain intensity (5.7 \pm 1.7 vs. $7.2 \pm 1.5$ ) or QST threshold ratios (post/pre, EPT: $1.71 \pm 0.63$ vs. $1.36 \pm 0.43$, PPT: $1.20 \pm 0.19$ vs. $1.13 \pm 0.23$ ) comparing DN4+to DN4-.

\section{Discussion and conclusions}

The aim of this pilot study was to explore whether the DN4 can be used to define subgroups of PSSP, differentiating between PSSP of predominantly neuropathic or nociceptive origin. Since no gold standard is available for the diagnosis of post-stroke pain, patients with PSSP were classified using the DN4 and subgroups were compared regarding well known symptoms and signs suggestive of either nociceptive or neuropathic pain.

Several symptoms and signs suggestive of neuropathic pain were observed in DN4+, such as the higher incidence of abnormal cold sensation suggesting impaired spino-thalamo-cortical tract function ${ }^{3,22}$, spontaneous (constant) pain ${ }^{9}$ and a higher degree of sensory loss at the affected side 22 . In addition, patients classified as DN4+ showed a trend towards reduced thresholds for pain at the unaffected side, suggestive of central sensitization. The primary sign suggestive of nociceptive pain in DN4- was that half of the patients reported pain attacks primarily related to movement. ${ }^{8}$ In addition, the incidence of subluxation was somewhat higher and arm function somewhat lower in these patients, which is in line with the traditional biomechanical view of PSSP.14 On the other hand, touch or cold allodynia at the affected side, regarded as supportive criteria for the diagnosis of central post-stroke pain 9 , were not clearly associated with either DN4+ or DN4-. DNIC function appears to be normal in patients with PSSP.

Unfortunately, the actual pathophysiological mechanisms leading to these pain complaints and sensory abnormalities in PSSP remain unclear. In chronic PSSP, symptoms and signs of central sensitization may be induced by both neuropathic as well as (ongoing) nociceptive pain mechanisms which may coexist in individual patients. Indeed, a large group of patients presented with mixed pain complaints (e.g. spontaneous and movement related pain). In addition, similar to previous findings, none of the sensory abnormalities could be exclusively related to either DN4+ or DN4-.12 The majority of PSSP patients may therefore not be classifiable as having either neuropathic or nociceptive pain.

Although the interpretation of this study is limited by the relatively low number of subjects in each subgroup, this study showed that the DN4 can be used to classify PSSP subgroups that differ with respect to pain complaints and sensory abnormalities. Notably, several symptoms and signs indicative of either neuropathic or nociceptive pain corresponded to 
the DN4 classification, suggesting that the DN4 may indeed be helpful in classifying PSSP. However, since the pathophysiological mechanisms remain unclear and none of the sensory signs could be exclusively related to either DN4+ or DN4-, classification using the DN4 should not be the sole basis for PSSP prognosis and treatment. Nonetheless, by showing that neuropathic pain complaints are common in PSSP this study provides a firm rationale to abandon the traditional view of PSSP as being a purely nociceptive, biomechanical pain problem. The diagnostic work-up of PSSP should involve a thorough assessment of both nociceptive and neuropathic pain complaints and somatosensory functions, similar as described for central post-stroke pain. ${ }^{9}$ This may help to further identify markers of nociceptive and neuropathic pain mechanisms in PSSP which, in the future, could lead to the development a (set of) tool(s) that specifically deal(s) with classifying and treating pain in the post-stroke pain population. 


\section{References}

1 Bender L, McKenna K. Hemiplegic shoulder pain: defining the problem and its management. Disabil Rehabil 23:698-705, 2001.

2 Bohannon RW, Smith MB. Interrater reliability of a modified Ashworth scale of muscle spasticity. Phys Ther 67:206207, 1987.

3 Boivie J, Leijon G, Johansson I. Central post-stroke pain--a study of the mechanisms through analyses of the sensory abnormalities. Pain 37:173185, 1989.

4 Bouhassira D, Attal N, Alchaar $\mathrm{H}$, Boureau F, Brochet B, Bruxelle J, Cunin $G$, Fermanian J, Ginies $P$, GrunOverdyking $A$, Jafari-Schluep $H$, LanteriMinet $M$, Laurent B, Mick G, Serrie A, Valade D, Vicaut E. Comparison of pain syndromes associated with nervous or somatic lesions and development of a new neuropathic pain diagnostic questionnaire (DN4). Pain 114:29-36, 2005.

5 Collin C, Wade D. Assessing motor impairment after stroke: a pilot reliability study. J Neurol Neurosurg Psychiatry 53:576-579, 1990.

6

Cruccu G, Anand P, Attal N, GarciaLarrea L, Haanpaa M, Jorum E, Serra J, Jensen TS. EFNS guidelines on neuropathic pain assessment. Eur J Neurol 11:153-162, 2004.

7 Dromerick AW, Edwards DF, Kumar A. Hemiplegic shoulder pain syndrome: frequency and characteristics during inpatient stroke rehabilitation. Arch Phys Med Rehabil 89:1589-1593, 2008.

8 Gamble GE, Barberan E, Laasch HU, Bowsher D, Tyrrell PJ, Jones AK. Poststroke shoulder pain: a prospective study of the association and risk factors in 152 patients from a consecutive cohort of 205 patients presenting with stroke. Eur J Pain 6:467-474, 2002.

Klit $\mathrm{H}$, Finnerup NB, Jensen TS. Central post-stroke pain: clinical characteristics, pathophysiology, and management. Lancet Neurol 8:857-868, 2009.

10 Lindgren I, Jönsson AC, Norrving B, Lindgren A. Shoulder pain after stroke: A prospective population-based study. Stroke 38:343-348, 2007.

11 Lundström E, Smits A, Terént A, Borg J. Risk factors for stroke-related pain 1 year after first-ever stroke. Eur J Neurol 16:188-193, 2009.

12 Rasmussen PV, Sindrup SH, Jensen TS, Bach FW. Symptoms and signs in patients with suspected neuropathic pain. Pain 110:461-469, 2004.

13 Roosink $M$, Geurts $A C H$, IJzerman $M J$. Defining post-stroke pain: diagnostic challenges. Lancet Neurol 9:344-344, 2010.

14 Teasell RW, Bhogal SK, Foley NC. Painful Hemiplegic Shoulder. In: Teasell RW, Bhogal SK, Foley NC, editors. Evidence-based Review of Stroke Rehabilitation. London, Ontario, Canada: University of Western Ontario, 2007. pp. 1-57.

15 Tombaugh TN, Mclntyre NJ. The MiniMental State Examination: A comprehensive review. J Am Geriatr Soc 40:922-935, 1992.

16 Treede RD, Jensen TS, Campbell JN, Cruccu G, Dostrovsky JO, Griffin JW, Hansson P, Hughes R, Nurmikko T, Serra J. Neuropathic pain: redefinition and a grading system for clinical and research purposes. Neurology 70:16301635, 2008. 
17 Turner-Stokes L, Hassan N. Depression after stroke: a review of the evidence base to inform the development of an integrated care pathway. Part 1: Diagnosis, frequency and impact. Clin Rehabil 16:231-247, 2002.

18 Turner-Stokes L, Jackson D. Shoulder pain after stroke: a review of the evidence base to inform the development of an integrated care pathway. Clin Rehabil 16:276-298, 2002.

19 Tuveson B, Leffler A-S, Hansson P. Influence of heterotopic noxious conditioning stimulation on spontaneous pain and dynamic mechanical allodynia in central poststroke pain patients. Pain 143:84-91, 2009.

20 Van der Kloot WA, Oostendorp RA, Van der Meij J, Van den Heuvel J. [The Dutch version of the McGill pain questionnaire: a reliable pain questionnaire]. Ned Tijdschr Geneeskd 139:669-673, 1995.

21 Van Seventer R, Vos C, Meerding W, M ear I, Le Gal M, Bouhassira D, Huygen FJ. Linguistic validation of the DN4 for use in international studies. Eur J Pain, 2009.

22 Widar $M$, Samuelsson L, KarlssonTivenius S, Ahlstrom G. Long-term pain conditions after a stroke. J Rehabil Med 34:165-170, 2002. 



\section{Intermezzo}

\section{An ongoing debate on post-stroke pain classification}

M eyke Roosink

Alexander CH Geurts

M aarten J IJzerman

The Lancet Neurology 2010;9:344 


\section{Defining post-stroke pain: diagnostic challenges}

Recently, a new grading system for central post-stroke pain (CPSP) was proposed, which might be used to distinguish patients with stroke who have central neuropathic pain from patients who have peripheral pain. ${ }^{1}$ Accordingly, for a CPSP diagnosis, all other causes of pain have to be excluded. Although this criterion has its purpose for defining CPSP as a separate entity, a too rigorous distinction between central and peripheral post-stroke pain might have drawbacks as well. Most importantly, by strictly following the proposed grading system, central pain mechanisms could be missed or even disputed in patients with other types of post-stroke pain. This possibility is particularly relevant as "mixed" pain and preexisting pain are common after stroke. ${ }^{1}$ For this reason, we would like to emphasize that peripheral nociceptive pain after stroke might coincide with symptoms characteristic of CPSP. To lend support to our concern, we present recent data on post-stroke shoulder pain (PSSP).

PSSP is commonly localized to the affected upper extremity and regarded as peripheral nociceptive pain. However, unsatisfactory treatment and the frequent occurrence of persistent pain ${ }^{2}$ suggest a role for other mechanisms. To try to understand the possible central mechanisms that underlie PSSP, we used some parts of the diagnostic assessment for neuropathic pain in 19 patients with chronic PSSP, none of whom could be classified as having CPSP. ${ }^{3}$ Several sensory abnormalities overlapped with those observed in CPSP. Of particular interest was the high prevalence of abnormal spinothalamocortical tract function in patients with PSSP (15 of 19) compared with pain-free stroke patients (13 of 29), as abnormal function of this tract has been implicated in CPSP. Moreover, supportive criteria for a CPSP diagnosis, such as touch or cold allodynia ( 4 of 19) and the absence of a primary relation with movement (7 of 19), were common in patients with PSSP, and PSSP was associated with abnormal sensory function in the unaffected side.

Our data strongly suggest that central pain mechanisms have an essential role in poststroke pain, even in patients who cannot be classified as having CPSP. Therefore, central pain mechanisms should be assessed in all patients with post-stroke pain and treatments used for patients with CPSP might also be appropriate for patients with other forms of poststroke pain. We hope that the CPSP grading system ${ }^{1}$ will not prevent clinicians and researchers in the fields of neurology, rehabilitation, and pain medicine from regarding and treating central pain mechanisms in patients with post-stroke pain who do not fulfill the criteria for CPSP. 


\section{Author's reply}

Klit $\mathrm{H}$, Finnerup NB, Jensen TS

Danish Pain Research Center (HK, NBF, TSJ) and Department of Neurology (TSI)

Aarhus University Hospital, Aarhus, Denmark

In their thoughtful letter, Roosink and colleagues raise the point that central pain mechanisms might be overlooked in patients with stroke who have pain if our proposed definition for central post-stroke pain (CPSP) is used. The essential point here is how we define central pain mechanisms. It is important to distinguish between central neuropathic pain and central mechanisms. When the nociceptive system is activated, physiologically short-lasting neuroplastic changes occur in the CNS. In persistent pain disorders, the molecular and cellular changes are more profound and sometimes irreversible, whether due to inflammation or a lesion of the nervous system. In neuropathic pain, there is damage to the somatosensory systems, causing peripheral and central neuroplastic changes that can sometimes be permanent. In inflammatory or simple nociceptive pain disorders, the somatosensory system is essentially intact, but it is in a state of heightened excitability that gradually returns to normal when the inflammation subsides. Specific sensory testing could be used to clarify whether there is a loss of sensory input to the nervous system, but such testing can be misleading. The abnormalities mentioned by Roosink and colleagues in assumed spinothalamic functions, such as temperature and pinprick response, are not necessarily an indication of central neuropathic pain. Central neuropathic pain requires a loss of function in a body part corresponding to the affected brain territory, whereas abnormal positive or negative spinothalamic sensory functions might be seen in both inflammatory and neuropathic disorders. In our experience, many patients with CPSP have a combination of both inflammatory and neuropathic pain elements. When located in the same area, it can be difficult to distinguish between them. In certain cases of post-stroke shoulder pain (PSSP), the pain is clearly nociceptive but in other cases the pain mimics that seen when CNS structures are damaged. Is it important to differentiate between neuropathic and nociceptive pain? We think so. Admittedly, available treatments for central neuropathic pain are only partially effective and have dose-limiting side-effects, but new compounds that target specific sites implicated in neuropathic sensitization events are emerging. Does our grading system exclude a central pain diagnosis in some cases of PSSP? In our opinion, patients with PSSP who have sensory abnormalities in the shoulder area corresponding to the lesion fulfill our proposed criteria for CPSP if there is no other obvious pathological abnormality in the shoulder that can fully explain the pain. 
Intermezzo

In conclusion, we believe the diagnosis of CPSP depends on a combination of history and clinical findings, in particular the sensory examination. Neuropathic PSSP is not excluded by the proposed definition.

Reprinted with permission

\section{References}

$1 \quad$ Klit H, Finnerup NB, Jensen TS. Central post-stroke pain: clinical characteristics, pathophysiology, and management. Lancet Neurol 8:857-868, 2009.

2 Lindgren I, Jönsson AC, Norrving B, Lindgren $A$. Shoulder pain after stroke: A prospective population-based study. Stroke 38:343-348, 2007.
3 Roosink M, Renzenbrink GJ, Buitenweg JR, Van Dongen RTM, Geurts ACM, IJzerman MJ. 120 Central neuropathic mechanisms in post-stroke shoulder pain. European Journal of Pain 13:S44S44, 2009. 


\section{Part III}

\section{Follow-up studies on the development of persistent PSSP}





\title{
Chapter 6
}

\section{Persistent shoulder pain in the first 6 months after stroke: Results of a prospective cohort study}

\author{
M eyke Roosink \\ Gerbert J Renzenbrink \\ Jan R Buitenweg \\ Robert TM van Dongen \\ Alexander CH Geurts \\ Maarten J IJzerman
}




\section{Abstract}

The objective of this prospective inception cohort study was to identify factors associated with persistent post-stroke shoulder pain (pPSSP) in the first 6 months after stroke.

The data of 31 patients with a clinical diagnosis of stroke from the stroke units of 2 teaching hospitals in the Netherlands were analyzed. Main outcome measure was the development of pPSSP within the first 6 months after stroke. Clinical assessment included motor, somatosensory, cognitive, emotional and autonomic functions, and was undertaken within 2 weeks (t0), at 3 months (t1) and at 6 months (t2) after stroke. Patients with pPSSP (n =9) were compared with patients without pPSSP $(n=22)$. Bivariate logistic regression analyses showed that pPSSP was significantly associated with impaired voluntary motor control (t0, $t 1, t 2)$, diminished proprioception ( $t 0, t 1)$, tactile extinction (t1), abnormal sensation ( $t 1$, t2), spasticity of the elbow flexor muscles $(t 1, t 2)$, restricted range of motion (ROM) for both shoulder abduction (t2) and shoulder external rotation (t1, t2), trophic changes (t1) and non-insulin-dependent diabetes mellitus (t0).These findings suggest a multi-factorial etiology of pPSSP. The association of pPSSP with restricted passive pain-free ROM and signs indicative of somatosensory sensitization may implicate a vicious cycle of repetitive (micro) trauma which can establish itself rapidly after stroke. Intervention should, therefore, be focused on maintaining and restoring joint ROM as well as preventing injury and somatosensory sensitization. In this perspective, strategies that aim to intervene simultaneously at various levels of function can be expected to be more effective than treatment directed at merely one level. 


\section{Introduction}

Pain is a common complication after stroke.18,21,23 Post-stroke shoulder pain (PSSP) is reported in 5 to $84 \%$ of the patients, is located at the affected upper extremity and has a typical onset of 2 to 3 months after stroke.3,34,38 The clinical presentations of PSSP, central post-stroke pain (CPSP) and shoulder-hand syndrome (SHS),15 a form of post-stroke complex regional pain syndrome (CRPS),8,24 may overlap considerably, complicating diagnosis and treatment. ${ }^{19,29}$

Traditionally, the initiation of PSSP has been associated with loss of neuromuscular control related to paresis and spasticity.1,4,12,26 In addition, PSSP has been associated with glenohumeral subluxation, impingement of the supraspinatus tendon, adhesive capsulitis and restricted humeral external rotation. ${ }^{38}$ Moreover, somatosensory loss, cognitive deficits and depression may contribute to PSSP development.13,14,16,20,27 Although the general prognosis for PSSP in the first 6 months after stroke has been reported to be good,14 a substantial number of patients develop persistent PSSP.20,27,43 Interestingly, persistent PSSP in the chronic phase after stroke was no longer associated with impaired motor function, glenohumeral subluxation or spasticity, but rather with hypersensitivity and depressive symptoms, suggesting that the initiation and perpetuation of PSSP may involve different mechanisms.7,30 This is further supported by the fact that the management of PSSP, which is mostly focused at a normalization of muscle tone, reduction of glenohumeral subluxation and/or treatment of the presumed inflammation of the shoulder capsule and/or surrounding tissues, is generally unsatisfactory. $32,34,42$

Although previous prospective studies of PSSP identified several risk factors for its development, these studies were mostly analyzed using cross-sectional correlations without reference to the onset of pain post-stroke nor to the duration of the pain episode (i.e. recovered or persistent pain).13,14,16,20,27 Moreover, several studies did not include ${ }^{1}$ or did not report16,20,33 on follow-up measurements. Due to these short-comings, the causal relation between the reported clinical determinants and PSSP remains largely unclear.

The present study addressed these shortcomings by specifically focusing on the identification of factors associated with persistent PSSP in the first 6 months after stroke. Clinical assessment took place within 2 weeks (t0), at 3 months (t1) and at 6 months (t2) after stroke and included motor, somatosensory, cognitive, emotional and autonomic functions. 


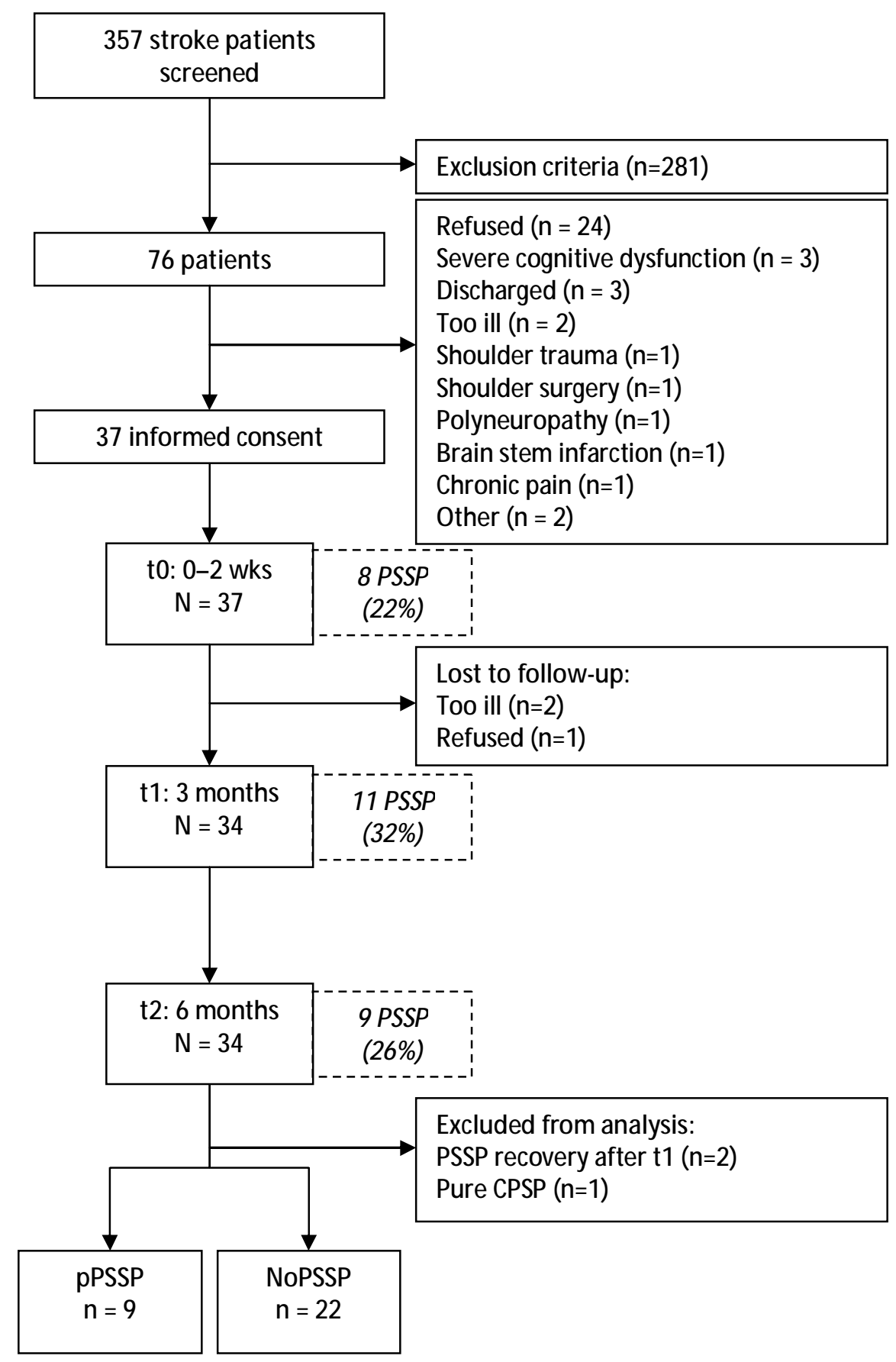

Figure 6.1 Flowchart of patient inclusion. PSSP: post-stroke shoulder pain. Definitions: pPSSP: pain at both $\mathrm{t} 1$ and $\mathrm{t2}$; NoPSSP: pain neither at $\mathrm{t} 1$ nor at $\mathrm{t} 2$.

\section{Methods}

\section{Subjects}

All consecutive patients ( $\geq 18$ years old) admitted to the stroke units of 2 teaching hospitals in the Netherlands (Ziekenhuisgroep Twente and Medisch Spectrum Twente) with a clinical 
diagnosis of stroke were screened for participation between May and December 2009. All stroke patients who had sustained a first-ever cortical or subcortical unilateral stroke (infarction or hemorrhage) resulting in somatosensory and/ or motor symptoms or signs were deemed eligible. Based on the screening of medical records (357), a total of 281 patients were excluded from participation (see Appendix 6.1). Thus, 76 patients were approached for participation (see Figure 6.1). The study was approved by the local medical ethical committee (Medisch Spectrum Twente). Patients received oral and written information about the study protocol and signed informed consent prior to participation.

\section{Pain classification}

PSSP was defined as shoulder pain confined to the shoulder and/ or C5 dermatome of the contralesional side with an onset after stroke and present during rest or during active or passive motion. Persistent PSSP ( $p$ PSSP) was defined as non-remitting PSSP present at both 3 and 6 months post-stroke. Patients who did not develop pain during the study period or who had PSSP only at baseline and not at 3 and 6 months after stroke were included in the control group (NoPSSP). CPSP was diagnosed according to the grading system recently proposed by Klit et al. ${ }^{19}$ SHS was diagnosed according to the grading system proposed by Tepperman et al. 35

\section{Study protocol}

Patients were interviewed and examined within 2 weeks (t0), at 3 months (t1) and at 6 months (t2) after stroke. Assessment at t0 was performed during hospital stay, whereas assessments at $\mathrm{t} 1$ and $\mathrm{t} 2$ were performed at a regional rehabilitation clinic or, if the patient had no transportation, at the patient's residence. All data were collected by the same researcher (M.R).

\section{Demographic and clinical data}

At $\mathrm{t} 0$, age, gender, lesion side, days since stroke onset, handedness (patient-reported), prestroke residence (independent yes/no), type of stroke (ischemic, hemorrhage) and prestroke comorbidities were registered. Non-severe pre-stroke pain that did not affect the contralesional upper extremity was classified as acute pain (duration $>1$ week in the 3 months prior to stroke), chronic pain (duration $>3$ months) or recovered chronic pain (no pain in the 3 months prior to stroke). Medication use was registered at each time point. 


\section{Pain complaints}

Pain complaints were recorded at each time point using a pain diagram and pain intensity was scored during rest and during movement using a numeric rating scale (pain: $0=$ no pain, 10 = maximum conceivable pain). In addition, PSSP distribution (localized, radiating,

shooting), PSSP frequency (sometimes, at least 2 days a week, daily, continuous) and PSSP pattern (attacks: pain-free periods in between periods of pain, intermittent: never pain-free but pain intensity varies, constant: pain is constantly present and pain intensity is also constant) were assessed. Moreover, PSSP was assessed using the neuropathic pain diagnostic questionnaire (DN4).6,31,39 The DN4 consists of 10 items comprising pain descriptors and somatosensory signs. Scoring at least 4 items positively is suggestive of pain of predominantly neuropathic origin.

\section{Clinical assessment}

M otor function

The level of voluntary motor control was assessed using the Motricity Index (MI) (0 = complete paresis, $100=$ normal function). ${ }^{10}$ Passive pain-free range of motion (ROM) was assessed for shoulder abduction ( 0 - 180 degrees) and for shoulder external rotation (0 90 degrees). For both ROM values, a ratio between sides was calculated (affected/ unaffected). Spasticity was assessed at the elbow flexor muscles and shoulder internal rotator muscles using the Modified Ashworth Scale (MAS, range 0-4). ${ }^{5}$ Spasticity was defined as MAS $\geq 1$. Glenohumeral subluxation was assessed by manual palpation $(0=$ no subluxation, 1 = subluxation $\geq 5 \mathrm{~mm}$ ).

\section{Somatosensory function}

Sensation to touch, cold and sharpness was tested at the face (over the zygomatic bones), lateral side of the upper arms, posterior sides of the hands and lower legs (over the tibial bones), using a cotton wool swab, a metal tuning fork at room temperature and a Semmes Weinstein filament (force: 300 grams, North Coast Medical, Inc, UK), respectively.41 Proprioception (joint position sense) was tested at the thumbs of both hands. Tests were always first performed at the unaffected (ipsilesional) side. Sensation at the affected side was scored as equal, diminished or increased compared to the unaffected side. Abnormal sensation at the affected side was defined as either diminished or increased sensation. For analysis, the somatosensory abnormalities at the arm and hand were pooled. 
Cognitive and emotional function

Cognitive function was assessed using the Mini Mental State Examination. ${ }^{37}$ Visual inattention and visual extinction were assessed by presenting unilateral right, unilateral left and bilateral visual stimuli (slight finger movement) at head and shoulder levels at approximately 1 meter distance. Tactile inattention and extinction were assessed by presenting a gentle tactile left, right or bilateral stimulus on the dorsum of the forearms and hands. Inattention was considered present when subjects inconsistently perceived the respective stimulus contralateral to their stroke lesion. Extinction was considered present when bilateral stimuli were consistently perceived unilaterally at the ipsilesional side. Depressive symptoms were assessed using the Zung Self-rating Depression Scale. 46

\section{Autonomic function}

The presence of trophic changes (yes/no) at the arm and hand was assessed by visual inspection. Symptoms could include changes and/ or asymmetry in 1) color, 2) temperature or 3) perspiration, 4) edema or 5) textural changes in nails or hair.

\section{Data processing and statistical analysis}

Statistical software package SPSS 16.0 for Windows was used (SPSS Inc., Chicago, IL, USA). Bivariate associations between all possible determinants (demographic data and motor, somatosensory, cognitive, emotional and autonomic functions) and groups (pPSSP, NoPSSP) were calculated for each time point ( $0, \mathrm{t} 1, \mathrm{t} 2)$ separately using 1-way analyses of variance and $\chi^{2}$ tests. Clinical functions that were significantly associated $(p<0.05)$ with pPSSP were tested for their independent contribution to explaining the presence or absence of pPSSP using bivariate logistic regression analyses. The MI and pain-free ROMs were dichotomized preceding logistic analysis. Impaired voluntary motor control was defined as a $\mathrm{MI} \leq 47$ (i.e. scoring $\leq 19$ on the pinch sub-task and $\leq 14$ on the active elbow flexion and shoulder abduction sub-tasks). A restricted ROM was defined as a side-to-side ratio $\leq 0.75$ (i.e. the ROM at the affected side was less than $75 \%$ of the ROM at the unaffected side). Statistical significance was assigned at the $\mathrm{p}<0.05$ level.

\section{Results}

\section{pPSSP development}

Thirty-seven patients entered the study (see Figure 6.1). Three patients were lost to follow up. PSSP was observed at all time points, with the highest frequency at $\mathrm{t1}$ ( $\mathrm{n}=11,32 \%)$. Nine patients developed PSSP at both $\mathrm{t} 1$ and $\mathrm{t} 2$ and formed the pPSSP group. None of the patients with pPSSP could be classified as having SHS or CPSP. 
Chapter 6

Table 6.1 Demographic data at t0, number of subjects (\%).

\begin{tabular}{lccc}
\hline & $\begin{array}{c}\text { pPSSP } \\
(\mathbf{n = 9}\end{array}$ & $\begin{array}{c}\text { NoPSSP } \\
(\mathbf{n = 2 2})\end{array}$ & $\mathbf{p}$ \\
\hline Age (years) & $72 \pm 10$ & $65 \pm 13$ & 0.153 \\
Male & $6(67)$ & $8(36)$ & 0.124 \\
Right hemispheric stroke & $6(67)$ & $14(64)$ & 0.873 \\
Baseline (days after stroke) & $8 \pm 3$ & $7 \pm 3$ & 0.189 \\
Right-handed & $8(89)$ & $19(86)$ & 0.849 \\
Independent living before stroke & $8(89)$ & $22(100)$ & 0.237 \\
Ischemic stroke & $9(100)$ & $22(100)$ & na \\
Comorbidities & & & \\
TIA & $0(0)$ & $3(14)$ & 0.244 \\
NIDDM & $4(44)$ & $2(9)$ & $0.024 *$ \\
Hypertension & $1(11)$ & $9(41)$ & 0.107 \\
COPD & $1(11)$ & $4(18)$ & 0.627 \\
Obesity & $1(11)$ & $2(9)$ & 0.863 \\
Pre-stroke pain & $7(78)$ & $15(68)$ & 0.873 \\
$\quad$ Acute pain & $0(0)$ & $1(5)$ & 0.516 \\
Chronic pain & $3(33)$ & $7(32)$ & 0.935 \\
Recovered chronic pain & $4(44)$ & $7(32)$ & 0.736 \\
\hline
\end{tabular}

p: p-value for statistical testing; TIA: transient ischemic attack; NIDDM : non-insulin-dependent diabetes mellitus; COPD: chronic obstructive pulmonary disease; na: not applicable. $* p<0.05$.

Patients that recovered from PSSP after t1 $(\mathrm{n}=2)$ or developed central post-stroke pain at another location $(n=1)$ were excluded from the analysis. The remaining patients formed the NoPSSP group $(\mathrm{n}=22)$.

\section{Demographic and clinical data}

All strokes were ischemic (see Table 6.1). Only pre-morbid non-insulin-dependent diabetes mellitus (NIDDM) was more frequent in the pPSSP group ( $44 \%$ versus $9 \%, p=0.024$ ).

\section{Pain complaints in patients with pPSSP}

At t2, 6 patients reported daily pain, 2 patients reported pain at least 2 times per week and 1 patient reported that pain occurred sometimes. Pain had a radiating character in 3 patients (upper arm and/ or scapula) and a shooting character in 1 patient. Pain attacks were reported by 7 and intermittent pain by 2 patients. None of the patients had a DN4 score $\geq 4$. Three patients used paracetamol or non-steroidal anti-inflammatory drugs on a regular basis. 
A

Motricity index

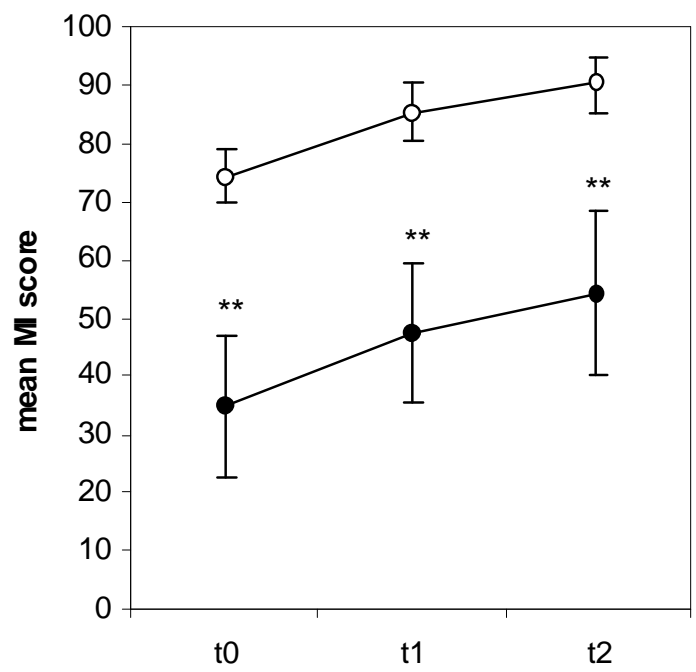

C

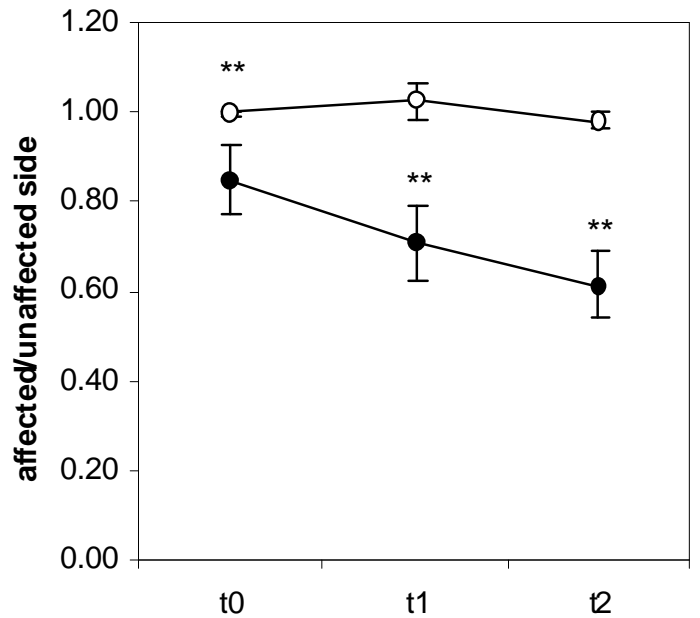

B

Spasticity

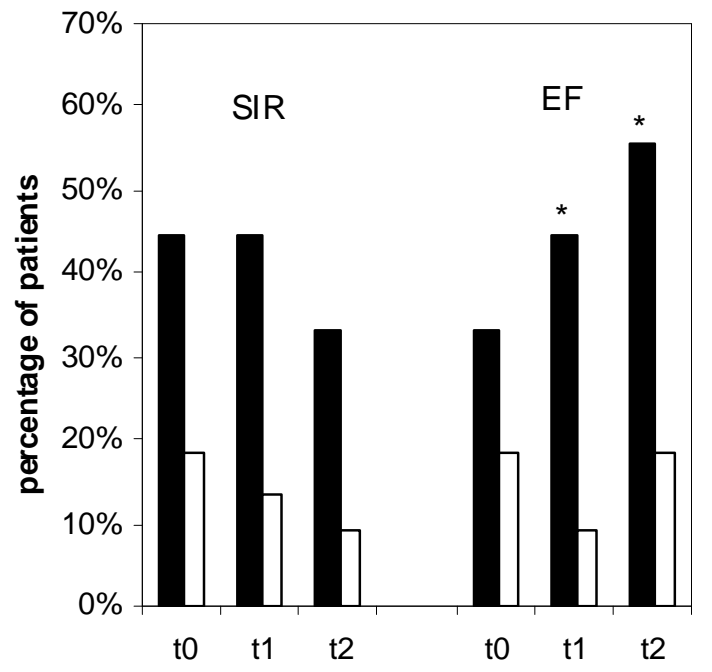

D ROM shoulder external rotation

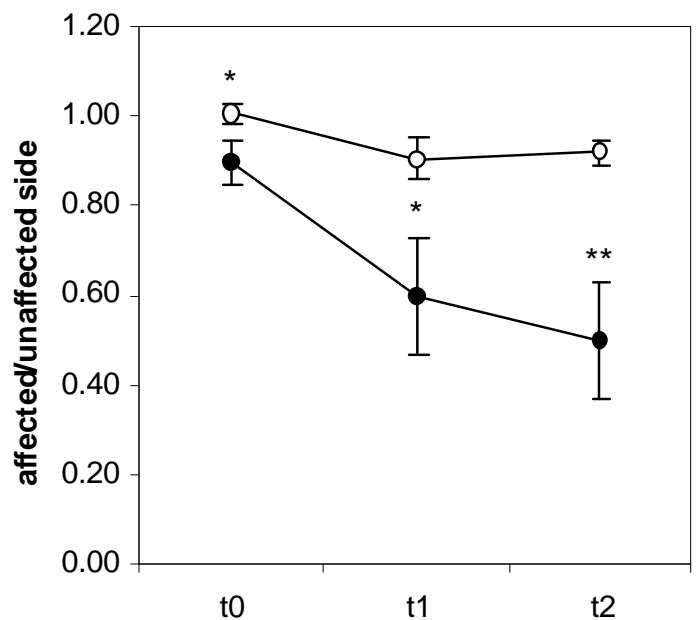

Figure 6.2 M otor function: M otricity Index (A), spasticity (B) and pain-free passive range of motion (C\&D). Error bars are standard errors. Black dots and bars represent the pPSSP group $(n=9)$, white dots and bars represent NoPSSP group $(n=20)$. SIR: shoulder internal rotation; EF: elbow flexion. ${ }^{\dagger} n=21$ at t0. ${ }^{*} p<0.05$, $* * p<0.01$.

\section{Clinical assessment}

On average, patients with pPSSP scored 36 to 38 points lower on the MI at all time points ( $p$ $<0.05$ ) (see Figure 6.2). Spasticity of the elbow flexor muscles was significantly more common in patients with pPSSP at t1 (44\% versus $9 \%$ ) and t2 (56\% versus $18 \%$ ). 
At all time points, ROM ratios for shoulder abduction and external rotation were on average $10 \%$ (t0) to $42 \%$ (t2) lower in patients with pPSSP ( $\mathrm{p}<0.05$ ). Only at $\mathrm{t} 2$, the presence of glenohumeral subluxation (not in Figure 6.2) was significantly more frequent in patients with pPSSP ( $22 \%$ versus $0 \%, p=0.022$ ).

Abnormal (t2) and increased (t2) tactile sensation, abnormal (t1) and increased (t2) cold sensation and diminished proprioception (t0, t1) were more frequent in patients with pPSSP ( $p$ < 0.05) (see Table 6.2).Tactile extinction ( $t 0, t 1, t 2)$, visual inattention ( 0 ) and visual extinction (t2) were more frequent in patients with pPSSP $(\mathrm{p}<0.05)$ (see Table 6.2). Trophic changes (t1), although mild, were more frequent in patients with pPSSP $(p<0.05)$ (see Table 6.2).

\section{Logistic regression analysis}

At t0, significant bivariate associations with pPSSP (Odds Ratio, p-value) were found for impaired voluntary motor control $(25.00, \mathrm{p}=0.009)$, NIDDM $(8.00, \mathrm{p}=0.038)$, tactile extinction (7.60, $\mathrm{p}=0.043$ ) and diminished proprioception $(6.40, \mathrm{p}=0.034$ ) (see Table 6.3). At $\mathrm{t} 1$, significant bivariate associations with pPSSP (Odds Ratio, $\mathrm{p}$-value) were found for restricted ROM for passive pain-free shoulder external rotation $(22.17, p=0.002)$, impaired voluntary motor control $(16.80, \mathrm{p}=0.021)$, spasticity at the elbow flexor muscles $(8.00, \mathrm{p}=$ $0.038)$, diminished proprioception (8.00, $p=0.038)$, trophic changes $(7.92, p=0.024)$ and abnormal cold sensation $(7.50, \mathrm{p}=0.029)$. At $\mathrm{t} 2$, significant bivariate associations were found for restricted ROM for passive pain-free shoulder abduction (73.50, p =0.001) and external rotation (22.17, $\mathrm{p}=0.002)$, impaired voluntary motor control $(16.80, \mathrm{p}=0.021)$, spasticity of elbow flexor muscles $(7.50, \mathrm{p}=0.028)$ and abnormal touch sensation $(6.80, \mathrm{p}=$ 0.028). 
Table 6.2 Somatosensory, cognitive, emotional and autonomic functions, number of subjects (\%) or median [min-max].

\begin{tabular}{|c|c|c|c|c|c|c|c|c|c|}
\hline & $\begin{array}{c}\text { pPSSP } \\
(n=9)\end{array}$ & $\begin{array}{l}\text { to } \\
\text { NoPSSP } \\
\text { (n=21) }\end{array}$ & $\mathbf{p}$ & $\begin{array}{c}\text { pPSSP } \\
(n=9)\end{array}$ & $\begin{array}{l}1 \\
\text { NoPSSP } \\
(n=22) \\
\end{array}$ & $\mathbf{p}$ & $\begin{array}{c}\text { pPSSP } \\
(n=9)\end{array}$ & $\begin{array}{l}\text { t2 } \\
\text { NoPSSP } \\
(n=22) \\
\end{array}$ & $\mathbf{p}$ \\
\hline \multicolumn{10}{|l|}{ Somatosensory function } \\
\hline Abnormal Touch & $5(56)$ & $9(43)$ & 0.457 & $7(78)$ & $14(64)$ & 0.445 & $6(67)$ & $5(23)$ & 0.020 \\
\hline diminished & $5(56)$ & $7(33)$ & 0.218 & $5(56)$ & $8(36)$ & 0.326 & $4(44)$ & $5(23)$ & 0.227 \\
\hline increased & $1(11)$ & $2(10)$ & 0.863 & $5(56)$ & $10(45)$ & 0.609 & $2(22)$ & $0(0)$ & 0.022 \\
\hline Abnormal Cold & $6(67)$ & $9(43)$ & 0.193 & $7(78)$ & $7(32)$ & 0.020 & $4(44)$ & $9(41)$ & 0.856 \\
\hline diminished & $4(44)$ & $7(33)$ & 0.505 & $4(44)$ & $5(23)$ & 0.227 & $2(22)$ & $9(41)$ & 0.324 \\
\hline increased & $2(22)$ & $2(9)$ & 0.322 & $3(33)$ & $2(9)$ & 0.096 & $3(33)$ & $0(0)$ & 0.004 \\
\hline Abnormal Sharpness & $8(89)$ & $12(57)$ & 0.070 & $5(56)$ & $11(50)$ & 0.779 & $6(67)$ & $10(45)$ & 0.283 \\
\hline diminished & $6(67)$ & $8(38)$ & 0.124 & $2(22)$ & $8(36)$ & 0.445 & $3(33)$ & $4(18)$ & 0.360 \\
\hline increased & $2(22)$ & $6(29)$ & 0.771 & $3(33)$ & $3(14)$ & 0.208 & $3(33)$ & $6(29)$ & 0.736 \\
\hline Diminished Proprioception & $6(67)$ & $5(24)$ & 0.026 & $4(44)$ & $2(9)$ & 0.024 & $3(33)$ & $2(9)$ & 0.096 \\
\hline \multicolumn{10}{|l|}{ Cognitive/emotional function } \\
\hline Cognitive dysfunction & $2(22)$ & $2(9)$ & 0.102 & $0(0)$ & $1(5)$ & 0.516 & $0(0)$ & $0(0)$ & na \\
\hline Visual inattention & $2(22)$ & $0(0)$ & 0.025 & $1(11)$ & $0(0)$ & 0.112 & $0(0)$ & $0(0)$ & na \\
\hline Tactile inattention & $0(0)$ & $0(0)$ & na & $0(0)$ & $0(0)$ & na & $1(11)$ & $0(0)$ & 0.112 \\
\hline Visual extinction & $3(33)$ & $3(14)$ & 0.232 & $1(11)$ & $0(0)$ & 0.112 & $2(22)$ & $0(0)$ & 0.022 \\
\hline Tactile extinction & $4(44)$ & $2(9)$ & 0.028 & $2(22)$ & $0(0)$ & 0.022 & $2(22)$ & $0(0)$ & 0.022 \\
\hline Depression score (ZUNG) & $36[25-51]$ & $34[25-56]$ & 0.871 & $36[32-54]$ & $36[24-54]$ & 0.149 & $35[27-47]$ & 34 [23-59] & 0.902 \\
\hline \multicolumn{10}{|l|}{ Autonomic function } \\
\hline Trophic changes arm/hand & $4(44)$ & $4(18)$ & 0.149 & $5(56)$ & $3(14)$ & 0.015 & $2(22)$ & $2(9)$ & 0.322 \\
\hline
\end{tabular}

A: affected side, UA: unaffected side; M M SE: M ini Mental State Examination; ZUNG: Zung self-rating depression score. 
Table 6.3 Bivariate associations between pPSSP and candidate determinants as determined by logistic regression coefficients.

\begin{tabular}{|c|c|c|c|c|c|c|c|c|c|}
\hline & \multicolumn{3}{|c|}{ to } & \multicolumn{3}{|c|}{ t1 } & \multicolumn{3}{|c|}{ t2 } \\
\hline & OR & $95 \% \mathrm{Cl}$ & p & OR & $95 \% \mathrm{Cl}$ & p & OR & $95 \% \mathrm{Cl}$ & p \\
\hline $\operatorname{NIDDM}(0=0,1=1)$ & 8.00 & $1.13-56.73$ & 0.038 & na & na & na & na & na & na \\
\hline Motricity Index $(0<47 ; 1>47)$ & 25.00 & $2.27-275.71$ & 0.009 & 16.80 & $1.52-14.92$ & 0.021 & 16.80 & $1.53-184.92$ & 0.021 \\
\hline ROM abduction $(0<0.75 ; 1>0.75)$ & 0.00 & na & 1.000 & 0.00 & na & 1.000 & 73.50 & $5.75-939.74$ & 0.001 \\
\hline ROM external rotation $(0<0.75 ; 1>0.75)$ & 6.00 & $0.47-76.71$ & 0.168 & 22.17 & $3.04-161.84$ & 0.002 & 22.17 & 3.04-161.84 & 0.002 \\
\hline Spasticity elbow flexors $(0=0,1=1)$ & na & na & na & 8.00 & $1.13-56.79$ & 0.038 & 7.50 & $1.25-45.15$ & 0.028 \\
\hline Glenohumeral subluxation $(0=0,1=1)$ & na & na & na & na & na & na & 0.00 & na & 1.000 \\
\hline Abnormal touch sensation $(0=0,1=1)$ & na & na & na & na & na & na & 6.80 & $1.23-37.50$ & 0.028 \\
\hline Increased touch sensation $(0=0,1=1)$ & na & na & na & na & na & na & 0.00 & na & 1.000 \\
\hline Abnormal cold sensation $(0=0 ; 1=1)$ & na & na & na & 7.50 & $1.23-45.81$ & 0.029 & na & na & na \\
\hline Increased cold sensation $(0=0 ; 1=1)$ & na & na & na & na & na & na & 0.00 & na & 1.000 \\
\hline Diminished proprioception $(0=0 ; 1=1)$ & 6.40 & $1.16-35.44$ & 0.034 & 8.00 & $1.13-56.79$ & 0.038 & 5.00 & $0.67-37.26$ & 0.116 \\
\hline Visual inattention $(0=0,1=1)$ & 0.00 & na & 1.000 & na & na & na & na & na & na \\
\hline Visual extinction $(0=0,1=1)$ & na & na & na & na & na & na & 0.00 & na & 1.000 \\
\hline Tactile extinction $(0=0,1=1)$ & 7.60 & $1.07-54.09$ & 0.043 & 0.00 & na & 1.000 & 0.00 & na & 1.000 \\
\hline Trophic changes $(0=0,1=1)$ & na & na & na & 7.92 & $1.31-47.51$ & 0.024 & na & na & na \\
\hline
\end{tabular}

Cut-off scores are presented between brackets. NIDDM : non-insulin-dependent diabetes mellitus; ROM : shoulder passive pain-free range of motion; OR: odds ratio; Cl: confidence interval; na: not applicable. 


\section{Discussion and conclusions}

The aim of the present study was to identify factors associated with pPSSP in the first 6 months after stroke. pPSSP was associated with impaired voluntary motor control, diminished proprioception, tactile extinction, abnormal sensation, spasticity of the elbow flexor muscles, restricted ROM for both shoulder abduction and shoulder external rotation, trophic changes and NIDDM. The associations depended on the time after stroke, suggesting that different factors may be involved in the initiation versus the perpetuation of pPSSP.

\section{PSSP initiation}

Previous studies have related several clinical determinants to the initiation of PSSP in the acute and subacute phases after stroke, including a low score on the National Institutes of Health Stroke Scale,20 impaired voluntary motor control,1,14,20,26,27 glenohumeral subluxation,33 spasticity,22,45 somatosensory loss, 13,14,16,20,27 anxiety and depression 13,14,16 and advanced age ${ }^{16}$, but without reference to the onset of pain post-stroke nor to the duration of the pain episode.

The present study specifically defined the minimum duration of the pain episode and found impaired voluntary motor control, NIDDM, diminished proprioception and tactile extinction to be associated with pPSSP already within 2 weeks after stroke. Hence, impairments of motor and somatosensory functions might be considered as relevant initiating factors of (p)PSSP. This is consistent with the "trauma-hypothesis", which postulates that shoulder pain is initiated by (repetitive) micro-trauma of soft tissues around the shoulder joint due to impaired active motor control, impaired perception of (minor) injury and/ or hemineglect.34 In addition, shoulder pain is often associated with co-morbid diabetes mellitus. ${ }^{27,40}$ Premorbid metabolic alterations associated with diabetes mellitus may lead to an increased risk of shoulder pathology after stroke. ${ }^{2}$

Spasticity, restricted ROM of joints, throphic changes and abnormal cold sensation were not associated with pPSSP until 3 months after stroke. Spasticity could be an initiating factor of PSSP, for example by inducing muscle cramps, ischemia and contractures, and its onset after stroke has previously been associated with the onset of PSSP. ${ }^{22,45}$ However, since the association between spasticity and pPSSP was not found until 3 months after stroke, it is questionable whether PSSP was induced by spasticity. It is more likely that spasticity developed alongside or perhaps as a result of PSSP. A similar explanation may be given for restricted passive joint ROM and trophic changes $8,15,36$. For example, passive joint ROM may be related to impaired active motor control after stroke, to spasticity, to concomitant soft tissue inflammation, but also to abnormal use of the upper extremity due to pain-related fear of movement. 25 
The association between pPSSP and abnormal cold sensation is consistent with previous studies 13,14 although specifically increased sensation was more frequently observed in the present study. Abnormal thermal processing due to spino-thalamo-cortical lesions has also been associated with central somatosensory sensitization, central pain ${ }^{19}$ and CRPS17. Since abnormal thermal processing may be related to both peripheral and central pain mechanisms, ${ }^{11}$ it remains unclear whether and how abnormal cold sensation contributed to the initiation pPSSP.

\section{PSSP perpetuation}

Since no previous prospective study has specifically investigated possible perpetuating factors of PSSP, explanations of PSSP maintenance have remained largely speculative. PSSP may become persistent simply because the initiating factors remain present. In the present study, several clinical functions were associated with pPSSP at all time points after stroke. Six months after stroke, however, the presence of pPSSP appeared to be more strongly associated with restricted ROM for shoulder abduction and elbow flexion than with impaired voluntary motor control, spasticity or diminished proprioception. Since the relationship between restricted joint ROM and PSSP may be bidirectional, restricted joint ROM could, thus, be a critical element in a vicious cycle leading to pPSSP. The notion of a gradually decreasing influence of initiating factors is consistent with the finding that impaired voluntary motor control, spasticity, glenohumeral subluxation and diminished proprioception were no longer related to pPSSP on average 19 months ${ }^{30}$ and 4 years ${ }^{7}$ after stroke.

Similar as described for other types of persistent pain,11 PSSP may be maintained or even worsened by somatosensory sensitization. Indeed, somatosensory sensitization has been previously observed in patients with pPSSP in the chronic phase after stroke..31,44 In the present study, pPSSP was associated with abnormal cold sensation (t1) and abnormal touch sensation (t2), and increased tactile and cold sensations (suggestive of somatosensory sensitization) were specifically more frequent in patients with pPSSP.

\section{Study limitations}

The number of subjects included in this study was relatively small, although a large number of patients was assessed for eligibility. The main reason for using a strict selection of patients was to minimize the influence of many potential confounders such as pre-morbid pain complaints, other neurological or musculoskeletal diseases, cognitive deficits and bilateral stroke symptoms. As such, the internal validity of temporal (and possibly) causal 
relationships was considered more important than the statistical power or generalizability to all patients with stroke.

Although we followed our patients up to 6 months after stroke onset, a longer follow-up would have provided more information about the long-term evolution of pPSSP, specifically in relation to somatosensory sensitization.

\section{Conclusions}

The findings suggest a multi-factorial etiology of pPSSP and warrant a multi-factorial approach to both prevention and treatment. The association of pPSSP with restricted passive pain-free joint ROM and with signs indicative of somatosensory sensitization may implicate a vicious cycle of pain, limited ROM, re-injury and somatosensory sensitization which seems to establish itself quite rapidly (i.e. within 3 months after PSSP onset). Prevention of (repetitive) (micro-)trauma at the shoulder should therefore be a priority in all phases of stroke rehabilitation and should be part of the education of both the patient and caregivers. Interventions should be multidimensional focusing on maintaining and restoring passive pain-free ROM, reducing spasticity, improving active motor control and preventing somatosensory sensitization. Possibly, treatment strategies that intervene at various levels simultaneously, such as neuromuscular electrical stimulation, may prove to be specifically effective both in acute ${ }^{9}$ and persistent ${ }^{28}$ PSSP. Lastly, the multi-factorial etiology of PSSP and its distinction from central post-stroke pain and shoulder-hand syndrome necessitates careful clinical assessment beyond the examination of the shoulder alone, including motor (active and passive), somatosensory, cognitive, emotional and autonomic functions. 


\section{References}

1 Aras MD, Gokkaya NK, Comert D, Kaya A, Cakci A. Shoulder pain in hemiplegia: results from a national rehabilitation hospital in Turkey. Am J Phys Med Rehabil 83:713-719, 2004.

2 Arkkila PE, Gautier JF. Musculoskeletal disorders in diabetes mellitus: an update. Best Pract Res Clin Rheumatol 17:945-970, 2003.

3 Bender L, McKenna K. Hemiplegic shoulder pain: defining the problem and its management. Disabil Rehabil 23:698-705, 2001.

4 Bohannon RW, Larkin PA, Smith MB, Horton MG. Shoulder pain in hemiplegia: statistical relationship with five variables. Arch Phys Med Rehabil 67:514-516, 1986.

5 Bohannon RW, Smith MB. Interrater reliability of a modified Ashworth scale of muscle spasticity. Phys Ther 67:206207, 1987.

6 Bouhassira D, Attal $\mathrm{N}$, Alchaar $\mathrm{H}$, Boureau F, Brochet B, Bruxelle J, Cunin G, Fermanian J, Ginies P, GrunOverdyking $A$, Jafari-Schluep $\mathrm{H}$, LanteriMinet M, Laurent B, Mick G, Serrie A, Valade $D$, Vicaut $E$. Comparison of pain syndromes associated with nervous or somatic lesions and development of a new neuropathic pain diagnostic questionnaire (DN4). Pain 114:29-36, 2005.

7 Broeks JG, Lankhorst GJ, Rumping K, Prevo AJ. The long-term outcome of arm function after stroke: results of a follow-up study. Disabil Rehabil 21:357364, 1999.

8 Chae J. Poststroke complex regional pain syndrome. Top Stroke Rehabil 17:151-162, 2010.
Chae J, Ng A, Yu DT, Kirsteins A, Elovic EP, Flanagan SR, Harvey RL, Zorowitz RD, Fang ZP. Intramuscular electrical stimulation for shoulder pain in hemiplegia: does time from stroke onset predict treatment success? Neurorehabil Neural Repair 21:561567, 2007.

10 Collin C, Wade D. Assessing motor impairment after stroke: a pilot reliability study. I Neurol Neurosurg Psychiatry 53:576-579, 1990.

11 Curatolo $M$, Arendt-Nielsen $L$, Petersen-Felix S. Central Hypersensitivity in Chronic Pain: Mechanisms and Clinical Implications. Phys Med Rehabil Clin N Am 17:287302, 2006.

12 Dromerick AW, Edwards DF, Kumar A. Hemiplegic shoulder pain syndrome: frequency and characteristics during inpatient stroke rehabilitation. Arch Phys Med Rehabil 89:1589-1593, 2008.

13 Gamble GE, Barberan E, Bowsher D, Tyrrell PJ, Jones AK. Post stroke shoulder pain: more common than previously realized. Eur J Pain 4:313315, 2000.

14 Gamble GE, Barberan E, Laasch HU, Bowsher D, Tyrrell PJ, Jones AK. Poststroke shoulder pain: a prospective study of the association and risk factors in 152 patients from a consecutive cohort of 205 patients presenting with stroke. Eur J Pain 6:467-474, 2002.

15 Geurts AC, Visschers BA, van Limbeek J, Ribbers GM. Systematic review of aetiology and treatment of post-stroke hand oedema and shoulder-hand syndrome. Scand J Rehabil Med 32:410, 2000.

16 Hadianfard H, Hadianfard MJ. Predictor factors of hemiplegic shoulder pain in a 
group of stroke patients. Iran Red Crescent M e 10:215-219, 2008.

Huge V, Lauchart $M$, Forderreuther $S$, Kaufhold W, Valet M, Azad SC, Beyer A, Magerl W. Interaction of hyperalgesia and sensory loss in complex regional pain syndrome type I (CRPS I). PLoS ONE 3:e2742, 2008.

18 Jönsson $A C$, Lindgren I, Hallström $B$, Norrving $B$, Lindgren A. Prevalence and intensity of pain after stroke: a population based study focusing on patients' perspectives. J Neurol Neurosurg Psychiatry 77:590-595, 2006.

19 Klit H, Finnerup NB, Jensen TS. Central post-stroke pain: clinical characteristics, pathophysiology, and management. Lancet Neurol 8:857-868, 2009.

Lindgren I, Jönsson AC, Norrving B, Lindgren $A$. Shoulder pain after stroke: A prospective population-based study. Stroke 38:343-348, 2007.

21 Lundström E, Smits A, Terént A, Borg J. Risk factors for stroke-related pain 1 year after first-ever stroke. Eur J Neurol 16:188-193, 2009.

22 Moura RDCDR, Fukujima MM, Aguiar AS, Fontes SV, Dauar RFB, Do Prado GF. Predictive factors for spasticity among ischemic stroke patients. Arq Neuropsiquiatr 67:1029-1036, 2009.

23 Naess $\mathrm{H}$, Lunde L, Brogger J, WajeAndreassen $U$. Post-stroke pain on long-term follow-up: the Bergen stroke study. J Neurol 257:1446-1452 2010.

24 Pertoldi S, Di Benedetto P. Shoulderhand syndrome after stroke. A complex regional pain syndrome. Eura Medicophys 41:283-292, 2005.

25 Pruimboom L, van Dam AC. Chronic pain: A non-use disease. Med Hypotheses, 2006.
26 Rajaratnam BS, Venketasubramanian N, Kumar PV, Goh JC, Chan YH. Predictability of simple clinical tests to identify shoulder pain after stroke. Arch Phys Med Rehabil 88:1016-1021, 2007.

27 Ratnasabapathy Y, Broad J, Baskett J, Pledger M, Marshall J, Bonita R. Shoulder pain in people with a stroke: a population-based study. Clin Rehabil 17:304-311, 2003.

28 Renzenbrink GJ, Jzerman MJ. Percutaneous neuromuscular electrical stimulation (P-NMES) for treating shoulder pain in chronic hemiplegia. Effects on shoulder pain and quality of life. Clin Rehabil 18:359-365, 2004.

29 Roosink M, Geurts ACH, IJzerman MJ. Defining post-stroke pain: diagnostic challenges. Lancet Neurol 9:344-344, 2010.

30 Roosink M, Renzenbrink GJ, Buitenweg JR, van Dongen RTM, Geurts AC, IJzerman MJ. Somatosensory symptoms and signs and conditioned pain modulation in chronic post-stroke shoulder pain. J Pain in press, 2010.

31 Roosink $M$, Van Dongen RTM, Renzenbrink $G$, IJzerman MJ. Classifying post-stroke shoulder pain: Can the DN4 be helpful? Eur J Pain 15:99-102, 2011.

32 Snels IA, Dekker JH, van der Lee JH, Lankhorst GJ, Beckerman H, Bouter LM . Treating patients with hemiplegic shoulder pain. Am J Phys Med Rehabil 81:150-160, 2002.

33 Suethanapornkul S, Kuptniratsaikul PS, Kuptniratsaikul $V$, Uthensut $P$, Dajpratha P, Wongwisethkarn J. Post stroke shoulder subluxation and shoulder pain: a cohort multicenter study. J Med Assoc Thai 91:1885-1892, 2008.

34 Teasell RW, Bhogal SK, Foley NC. Painful Hemiplegic Shoulder. In: Teasell 
RW, Bhogal SK, Foley NC, editors. Evidence-based Review of Stroke Rehabilitation. London, Ontario, Canada: University of Western Ontario, 2007. pp. 1-57.

35 Tepperman PS, Greyson ND, Hilbert L, Jimenez J, Williams Jl. Reflex sympathetic dystrophy in hemiplegia. Arch Phys Med Rehabil 65:442-447, 1984.

36 Terkelsen AJ, Bach FW, Jensen TS. Experimental forearm immobilization in humans induces cold and mechanical hyperalgesia. Anesthesiology 109:297307, 2008.

37 Tombaugh TN, Mclntyre NJ. The MiniMental State Examination: A comprehensive review. J Am Geriatr Soc 40:922-935, 1992.

38 Turner-Stokes L, Jackson D. Shoulder pain after stroke: a review of the evidence base to inform the development of an integrated care pathway. Clin Rehabil 16:276-298, 2002.

39 Van Seventer R, Vos C, Meerding W, Mear I, Le Gal M, Bouhassira D, Huygen FJ. Linguistic validation of the DN4 for use in international studies. Eur J Pain 14:58-63, 2010.

40 Viikari-Juntura E, Shiri R, Solovieva S, Karppinen J, Leino-Arjas $P$, Varonen $H$,
Kalso E, Ukkola O. Risk factors of atherosclerosis and shoulder pain - Is there an association? A systematic review. Eur J Pain 12:412-426, 2008.

41 Walk D, Sehgal N, Moeller-Bertram T, Edwards RR, Wasan A, Wallace $M$, Irving G, Argoff C, Backonja MM. Quantitative sensory testing and mapping: a review of nonautomated quantitative methods for examination of the patient with neuropathic pain. Clin J Pain 25:632-640, 2009.

42 Walsh K. Management of shoulder pain in patients with stroke. Postgrad Med J 77:645-649, 2001.

43 Wanklyn $\mathrm{P}$, Forster A, Young J. Hemiplegic shoulder pain (HSP): Natural history and investigation of associated features. Disabil Rehabil 18:497-501, 1996.

44 Widar M, Samuelsson L, KarlssonTivenius S, Ahlstrom G. Long-term pain conditions after a stroke. J Rehabil Med 34:165-170, 2002.

45 Wissel J, Schelosky LD, Scott J, Christe W, Faiss JH, Mueller J. Early development of spasticity following stroke: A prospective, observational trial. J Neurol 257:1067-1072, 2010.

46 Zung WW. A Self-Rating Depression Scale. Arch Gen Psychiatry 12:63-70, 1965. 
Appendix 6.1 Exclusion criteria.

\begin{tabular}{llc}
\hline Exclusion criteria & $\mathbf{n}$ \\
\hline Stroke & Recurrent & 82 \\
& Brain stem/ cerebellum & 22 \\
& Bilateral & 2 \\
& Onset >14 days prior to participation & 7 \\
& No motor or somatosensory symptoms & 37 \\
Medical & Complications (e.g. coma, infections, combination of exclusion criteria) & 36 \\
& Trauma & 4 \\
& Cancer & 4 \\
& Alcohol abuse & 2 \\
& Upper extremity fracture/prosthesis & 5 \\
& Signs of any possible concomitant neurological condition affecting the central or & 13 \\
& the peripheral nervous system (including diabetic polyneuropathy) & 4 \\
& Pre-morbid psychiatric disorders & 10 \\
& Pre-morbid cognitive disorders & 12 \\
& Concomitant diseases affecting the regions of somatosensory examination (face, & \\
& lateral upper arms, back of the hands, front sides of the lower leg) & 20 \\
Pain & Pre-morbid pain complaints, either severe and/or affecting the contralesional & 11 \\
Other & upperextremity & 10 \\
& Discharge within the first 3 days after stroke & Total excluded \\
& No adequate response to closed (yes/no) questions & 281 \\
\hline
\end{tabular}





\title{
Chapter 7
}

\section{Somatosensory sensitization in persistent shoulder pain after stroke: Results of a prospective cohort study}

\author{
M eyke Roosink \\ Robert TM van Dongen \\ Jan R Buitenweg \\ Gerbert J Renzenbrink \\ Alexander $\mathrm{CH}$ Geurts \\ M aarten J IJzerman
}




\section{Abstract}

The mechanisms underlying persistent post-stroke shoulder pain (pPSSP) are largely unclear. This study explored the relationship between the onset of somatosensory symptoms and signs and the development of pPSSP in the first 6 months after stroke. Extensive assessment of somatosensory signs was performed within 2 weeks (t0), at 3 months (t1) and at 6 months (t2) after stroke using clinical examination and quantitative sensory testing. Supraspinal endogenous inhibitory functions were assessed using a conditioned pain modulation paradigm. At the affected side, pPSSP $(n=9)$ was associated with diminished proprioception ( $t 0, t 1)$, with diminished sensation for touch (t1) and sharpness (t2), with increased QST threshold ratios (TDT, EST, EPT, EPTT, PPT) and with increased cold sensation (t2). At the unaffected side, pPSSP was associated with reduced cold pain tolerance thresholds (t1). In patients with pPSSP reporting increased sensation at the affected side, multiple body sites across multiple stimulus modalities were involved and increased sensation persisted from $\mathrm{t} 1$ to $\mathrm{t} 2$. Conditioned pain modulation was not different from patients without pPSSP $(n=22)$. Pain complaints were mostly suggestive of nociceptive pain, and the relationship between pPSSP and somatosensory loss is consistent with the "trauma-hypothesis". The relationship between pPSSP and increased sensation, indicative of somatosensory sensitization, has not been reported before in the first 6 months after stroke. Since somatosensory sensitization may contribute to the progression of pPSSP and is also observed in patients with central post-stroke pain, it is important to extensively monitor somatosensory abnormalities in all phases after stroke. 


\section{Introduction}

Pain is a common complication after stroke.16,25 Post-stroke shoulder pain (PSSP) has been reported in 5 to $84 \%$ of patients and has a typical onset of 2 to 3 months after stroke.,245 Among others, PSSP has been associated with impaired voluntary motor control8,12,33, somatosensory loss ${ }^{12,23,33}$, spasticity27,54 and glenohumeral subluxation ${ }^{40}$. Each of these factors could potentially contribute to (repetitive) injury of the shoulder joint or upper extremity and subsequent peripheral nociceptive input. PSSP treatment is, therefore, mostly focused at a normalization of muscle tone, a reduction of glenohumeral subluxation or treatment of the presumed inflammation of the shoulder capsule or surrounding tissues. However, pain reduction is generally unsatisfactory $39,41,50$ and persistent PSSP (pPSSP) is common. 23

Interestingly, previous cross-sectional studies concluded that pPSSP was not associated with impaired voluntary motor control4, spasticity or glenohumeral subluxation, but rather with somatosensory abnormalities and depression. ${ }^{37}$ Somatosensory abnormalities included both signs indicative of somatosensory loss as well as of somatosensory sensitization. ${ }^{24}$ In addition, patients with pPSSP often reported neuropathic-like pain complaints ${ }^{3}$ which, combined with an abnormal spino-thalamo-cortical function, could be indicative of neuropathic pain. 38

The discrepancies between sub-acute versus pPSSP suggest that mechanisms other than peripheral nociception could be responsible for the development of shoulder pain after stroke. However, the causal relationship between somatosensory abnormalities and the development of pPSSP remains largely speculative. Previous prospective studies often lacked extensive assessment of somatosensory symptoms and signs ${ }^{11,23}$ and generally did not take into account the onset of pain post stroke nor the duration of the pain episode.12,14,23,32,33 Theoretically, somatosensory abnormalities in patients with PSSP may be explained by ongoing nociceptive input from the shoulder as well as by central lesions affecting somatosensory pathways. ${ }^{6}$ In addition, other factors such as depression ${ }^{18,44}$ and altered cognition, 22,30 either predisposing or related to the stroke or to ongoing pain, may indirectly contribute to abnormal somatosensory processing in patients with pPSSP.

This study aimed to bridge part of the gap between findings in sub-acute versus pPSSP by exploring the relationship between the onset of somatosensory symptoms and signs and the development of persistent shoulder pain in the first 6 months after stroke. Extensive somatosensory assessment was performed within 2 weeks (t0), at 3 months (t1) and at 6 months (t2) after stroke. 


\section{Methods}

\section{Subjects}

All consecutive patients (age $\geq 18$ years) admitted to the neurological and stroke units of two teaching hospitals in the Netherlands (Ziekenhuisgroep Twente and Medisch Spectrum Twente) with a clinical diagnosis of stroke were screened for participation between May and December 2009.

All stroke patients who had sustained a first-ever cortical or subcortical unilateral stroke (infarction or hemorrhage) resulting in somatosensory and/ or motor symptoms or signs were eligible. Based on the screening of medical records $(n=357)$, a total of 281 patients were excluded from participation. The exclusion criteria are listed in Appendix 7.1. Thus, a total of 76 patients were approached for participation. The study was approved by the local medical ethical committee (Medisch Spectrum Twente). Patients received oral and written information about the study protocol and signed informed consent prior to participation.

\section{Pain classification}

PSSP was defined as shoulder pain confined to the shoulder and/ or C5 dermatome of the contralesional side with an onset after stroke and present during rest or during active or passive motion. Persistent PSSP (pPSSP) was defined as non-remitting PSSP present at both 3 and 6 months post stroke. Patients who did not develop pain during the study period, or who had PSSP only at baseline without having PSSP at 3 and 6 months after stroke were included in the control group (NoPSSP). Central post-stroke pain ${ }^{19}$ and post-stroke complex regional pain syndrome ${ }^{42}$ were diagnosed according to proposed grading systems.

\section{Study protocol}

Patients were interviewed and examined within 2 weeks (t0), at 3 months (t1) and at 6 months (t2) after stroke. t0 was performed during hospital stay, t1 and t2 were performed at a regional rehabilitation clinic or, if the patient had no transportation, at the patient's residence. Quantitative sensory testing (QST) and conditioned pain modulation (CPM) were only performed at $\mathrm{t} 1$ and $\mathrm{t} 2$. CPM was only performed when the measurements took place at the rehabilitation centre. All data were collected by the same researcher (M.R).

\section{Demographic and clinical data}

At t0, age, gender, handedness (patient-reported), type of stroke (ischemic, hemorrhage), lesion side, days since stroke onset, and pre-stroke comorbidities (e.g. diabetes, hypertension, pain) were registered. In addition, at every time point, medication use, cognitive function (Mini Mental State Examination)43, depressive symptoms (ZUNG self- 
rating depression scale) ${ }^{58}$ and upper extremity motor function (Motricity Index, $0=$ complete paresis, $100=$ no paresis) ${ }^{5}$ were assessed.

\section{Pain complaints in patients with pPSSP}

Pain complaints were recorded at each time point using a pain diagram. Pain intensity was scored using a numeric rating scale ( 0 = no pain, $10=$ maximum conceivable pain). In addition, PSSP distribution (localized, radiating, shooting), PSSP frequency (continuous, daily, at least 2 days a week, sometimes) and PSSP pattern (attacks: pain-free periods in between periods of pain, intermittent: never pain-free but pain intensity varies, constant: pain is constantly present and pain intensity is also constant) were assessed. Moreover, PSSP was assessed using the neuropathic pain diagnostic questionnaire (DN4) .,47 The DN4 consists of 10 items comprising pain descriptors and somatosensory signs. A positive score on at least 4 items is suggestive of pain of predominantly neuropathic origin.

\section{Somatosensory symptoms}

At each time point, patients were interviewed about the presence of spontaneous or evoked paresthesia and dysesthesia using a pain diagram. According to the definition of the International Association for the Study of Pain, paresthesia was defined as an abnormal sensation, whereas dysesthesia was defined as an unpleasant abnormal sensation ${ }^{26}$.

\section{Somatosensory signs - Clinical examination}

Sensation to touch, cold and sharpness was tested at the face (over the zygomatic bones), upper arms (C5 dermatomes), posterior sides of the hands and lower legs (over the tibial bones), using a cotton wool swab, a metal object at room temperature and a 6.65 (force: 300 grams) Semmes Weinstein filament (North Coast Medical, Inc, UK), respectively. 49 Proprioception was tested at the thumbs of both hands (joint position sense). Tests were always first performed at the unaffected (ipsilesional) side. Subjects had to indicate whether sensation at the affected side was equal, diminished or increased compared to the unaffected side. All tests were perceived as being painless at the unaffected side. If any of the evoked sensations was painful in patients, this was considered as allodynia (tactile, cold, sharpness). ${ }^{24}$ If the evoked sensation was reported as unpleasant and abnormal, this was recorded as dysesthesia. ${ }^{26}$ If the evoked sensation was reported as being merely abnormal, this was recorded as paresthesia. ${ }^{26}$ The sensations recorded at the arm, hand and face were used for analysis. 


\section{Somatosensory signs - Quantitative sensory testing}

All QST thresholds, except the vibration detection threshold (VDT), were determined as described in a previous study. ${ }^{37}$ In brief, modality-specific assessment was performed using mechanical QST. ${ }^{15}$ The VDT was determined at the styloid process of the ulnar bone using a $128 \mathrm{~Hz}$ Rydel Seiffer tuning fork (Arno Barthelmes \& Co. GmbH, Germany). The VDT was defined as the score ( $0=$ maximal vibration intensity, $8=$ minimal vibration intensity) belonging to the lowest vibration intensity that could be perceived. The VDT was recorded once at each side. The TDT was determined using Semmes Weinstein filaments (Touch-Test Hand Kit, North Coast Medical, Inc, UK) over the middle deltoid muscle. The TDT was defined as the smallest filament that could be perceived at both locations. The pressure pain threshold (PPT) was determined using a pressure-algometer (Somedic, Sweden) with a stimulation surface of $1 \mathrm{~cm}^{2}$, a slope of $50 \mathrm{kPa} / \mathrm{s}$ and a cut-off point of $1000 \mathrm{kPa}$. The PPT was determined 3 times at both upper arms over the middle deltoid muscle. The PPT was defined as the pressure intensity at which patients first perceived the pressure as painful. The 3 PPTs were averaged for further analysis.

Non-receptor mediated assessment was performed using electrical QST. The electrical sensation threshold (EST), electrical pain threshold (EPT) and electrical pain tolerance threshold (EPTT) were determined using a custom built stimulator (pulse width: $0.2 \mathrm{~ms}$, frequency: $100 \mathrm{~Hz}$, ramp: $0.4 \mathrm{~mA} / \mathrm{s}$, maximum stimulus amplitude: $16 \mathrm{~mA}$ ). The stimulator was attached to the upper arm via $2 \mathrm{Ag} / \mathrm{AgCl}$ electrodes that were placed just above the deltoid tuberosity of the humerus. Patients could manually activate the stimulator by pressing a switch. The EST was defined as the stimulus intensity at which the electrical pulses were perceived for the first time. The EPT was defined as the stimulus intensity at which the electrical pulses were perceived as both stinging and annoying. The EPTT was defined as the stimulus intensity at which the electrical pulses were perceived as burning and very annoying. Thresholds were determined 4 times on each side. The last 3 thresholds were averaged for further analysis.

\section{Conditioned pain modulation}

CPM was used to test supraspinal endogenous inhibitory functions, i.e. diffuse noxious inhibitory controls. $31,48,56$ The procedure was similar as described in a previous study. ${ }^{37}$ After QST, patients placed their unaffected hand in a polystyrene box filled with ice-water (0-0.5 $\left.{ }^{\circ} \mathrm{C}\right)$. The hand was immersed up to the wrist with the fingers spread. Patients were instructed to keep their hand in the water as long as tolerable but with a maximum of 3 minutes. Immersion time was recorded as a measure of cold pain tolerance. After removing the hand from the water, patients rated the pain in their hand using a $\operatorname{NRS}(0=$ no pain, $10=$ 
maximum conceivable pain). Directly afterwards, the EPT and PPT were determined twice at the affected side similar as before. The 2 thresholds were averaged for further analysis.

\section{Data processing}

For each group (pPSSP, NoPSSP), average and standard deviations, median [range] or frequencies were determined. In addition to the raw QST data, a within-subject ratio was calculated for all QST thresholds (affected/ unaffected side). Moreover, individual QST ratios of patients were normalized to a previously obtained HC data $\operatorname{set}^{37}$ using a ztransformation. ${ }^{35}$ Hypoesthesia (VDT, TDT, EST) and hypoalgesia (EPT, EPTT, PPT) were defined as a QST ratio z-score higher than 2. Hyperesthesia (VDT, TDT, EST) and hyperalgesia (EPT, EPTT, PPT) were defined as a QST ratio z-score lower than -2. CPM was assessed by calculating a pre-post ratio of the QST thresholds measured before and after the cold pressor test (thresholds post/ pre). All QST thresholds and ratios were log-transformed prior to statistical analysis. 35

\section{Statistical analysis}

Statistical software package SPSS 16.0 for Windows was used (SPSS Inc., Chicago, IL, USA) to analyze differences between groups (pPSSP, NoPSSP). Differences in frequencies of somatosensory symptoms (dysesthesia, paresthesia) and signs as assessed with clinical examination (increased/ diminished sensation, allodynia/ dysesthesia, paresthesia) or QST (z-score analysis) at t0, t1 and t2 were only statistically tested when the difference between groups was greater than $30 \%$ (Chi-square tests). Differences in raw QST thresholds (unaffected side only) and QST threshold ratios were statistically tested using 1-way analyses of variance (ANOVAs). Data related to CPM was analyzed using 1-way ANOVAs. To assess the relation between initial stroke severity at t0 and somatosensory sensory abnormalities at $\mathrm{t} 1$ and $\mathrm{t} 2$, the correlation between Motricity Index scores and the presence of diminished or increased sensation (touch, cold, sharpness, proprioception) at the arm or hand at $\mathrm{t} 0$ and the presence of diminished or increased sensation (touch, cold, sharpness, proprioception) at the arm or hand at $\mathrm{t} 1$ and $\mathrm{t} 2$ was determined using Pearson and Spearman Rank Correlations. For all tests, statistical significance was assigned at the $\mathrm{p}<$ 0.05 level using 2-tailed analysis.

\section{Results}

\section{Patient inclusion}

Patient flow is summarized in Appendix 7.2. Nine patients reported PSSP at both $t 1$ and t2 and formed the pPSSP group. 
Table 7.1 Demographics and clinical data, mean \pm SD, number of subjects (\%) or median [range].

\begin{tabular}{lcc}
\hline & $\begin{array}{c}\text { pPSSP } \\
(\mathbf{n = 9})\end{array}$ & $\begin{array}{c}\text { NoPSSP } \\
(\mathbf{n = 2 2})\end{array}$ \\
\hline Age (years) & $72 \pm 10$ & $65 \pm 13$ \\
Male & $6(67)$ & $8(36)$ \\
Right-handed & $8(89)$ & $19(86)$ \\
Type of stroke & & \\
$\quad$ Infarction & $9(100)$ & $22(100)$ \\
Right-hemispheric stroke & $6(67)$ & $14(64)$ \\
Baseline (days after stroke) & $8 \pm 3$ & $7 \pm 3$ \\
Comorbidities & & \\
$\quad$ Pre-stroke pain & $3(33)$ & $8(36)$ \\
$\quad$ NIDDM & $4(44)$ & $2(9)$ \\
$\quad$ Hypertension & $1(11)$ & $9(41)$ \\
Cognitive dysfunction (M M SE <24) & $2(22)$ & $2(9)$ \\
Depression score (ZUNG) & $36[25-51]$ & $34[25-56]$ \\
M otor function & $47[0-100]$ & $76[9-100]$ \\
\hline
\end{tabular}

NIDDM : non-insulin dependent diabetes mellitus; MMSE: mini mental state examination; ZUNG: selfrating depression scale.

None of these patients could be classified as having CPSP or post-stroke complex regional pain syndrome. Patients that recovered from PSSP after $\mathrm{t} 1(\mathrm{n}=2)$ or that developed isolated central post-stroke pain ${ }^{19}$ at another location $(n=1)$ were excluded from the analysis. The remaining 22 patients formed the NoPSSP group.

\section{Demographic and clinical data}

Demographic and clinical data at t0 are summarized in Table 7.1. All strokes were ischemic. In the pPSSP group the age was somewhat higher, the proportion of male patients was higher and premorbid non-insulin dependent diabetes mellitus was more frequently observed. Premorbid hypertension was more frequently observed in the NoPSSP group. Motor function was impaired in both patient groups, but this was more pronounced in patients developing pPSSP. Pre-stroke pain was equally common in both patient groups.

\section{Pain complaints in patients with pPSSP}

Pain complaints in patients developing pPSSP are summarized in Table 7.2. Pain was increased during movement in all patients at all time points and occurred mostly in attacks.

\section{Somatosensory symptoms}

Frequencies of self-reported dysesthesia and paresthesia were generally low and were not different between groups (see Appendix 7.3). 
Table 7.2 Pain complaints in patients with pPSSP, median [range] or number of subjects.

\begin{tabular}{lccc}
\hline & $\begin{array}{c}\mathbf{t 0} \\
\mathbf{( n = 4 )}\end{array}$ & $\begin{array}{c}\mathbf{t 1} \\
\mathbf{( n = 9 )}\end{array}$ & $\begin{array}{c}\mathbf{t 2} \\
\mathbf{( n = 9 )}\end{array}$ \\
\hline $\begin{array}{l}\text { Pain intensity } \\
\text { rest }\end{array}$ & $1.5[0-5]$ & $0[0-4]$ & $0[0-3]$ \\
$\quad$ movement & $5[3-10]$ & $8[7-10]$ & $6[3-10]$ \\
$\begin{array}{l}\text { Pain worsened by movement } \\
\text { Pain frequency }\end{array}$ & 4 & 9 & 9 \\
$\quad$ sometimes & 1 & 3 & 1 \\
$\quad \begin{array}{l}\text { 2days/week } \\
\text { daily }\end{array}$ & 0 & 0 & 2 \\
$\quad$ Constant & 2 & 6 & 6 \\
Pain pattern & 1 & 0 & 0 \\
$\quad$ attacks & & 7 & 7 \\
intermittent & 3 & 2 & 2 \\
Neuropathic pain (DN4 $\geq 4)$ & 1 & 1 & 0 \\
Analgesic medication & 1 & 2 & 3 \\
\hline
\end{tabular}

Analgesic medications were paracetamol or non-steroidal anti-inflammatory drugs.

Table 7.3 Clinical examination at the affected versus the unaffected side, number of subjects (\%).

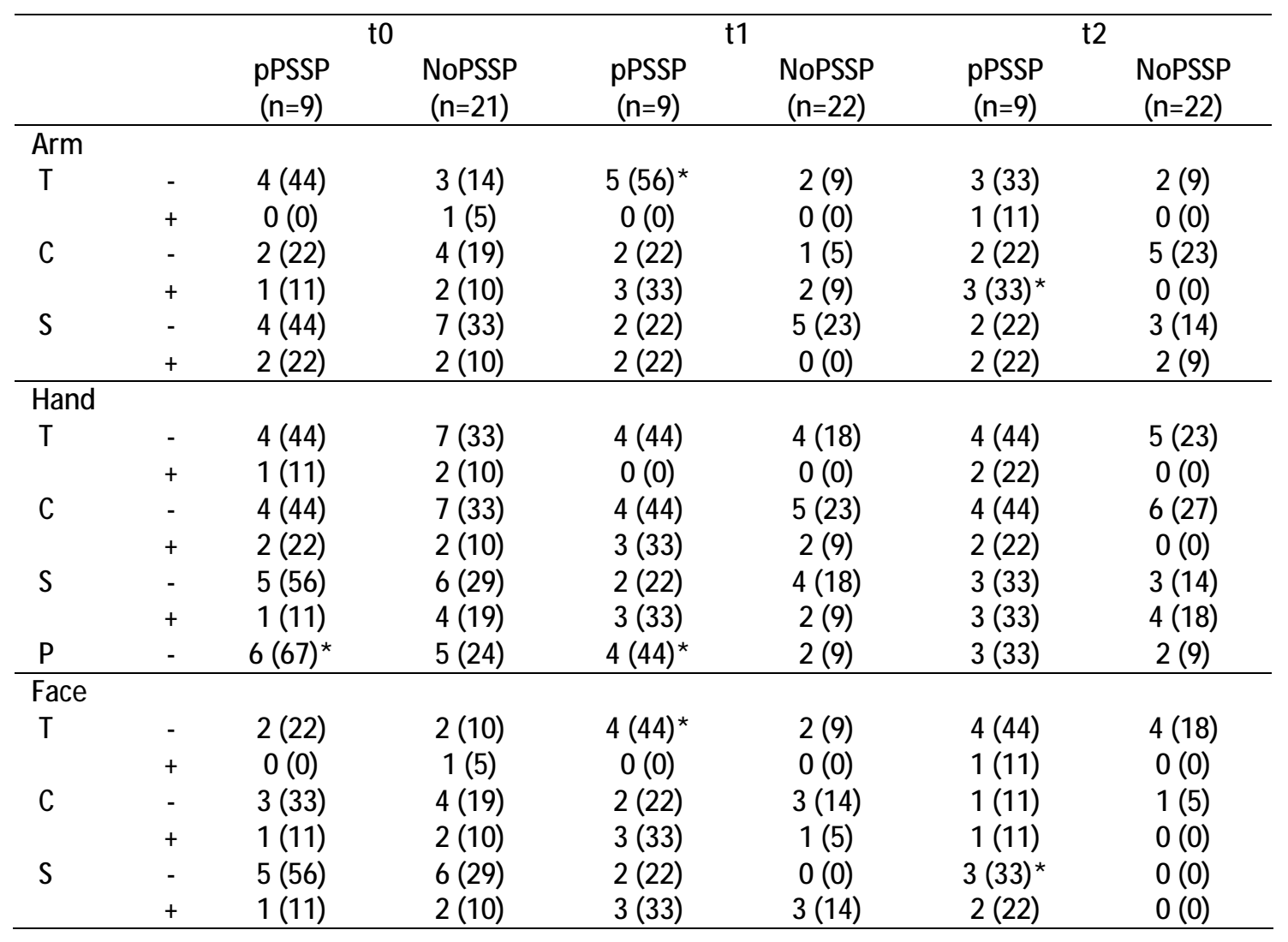

T: touch; C: cold; S: sharpness; P: proprioception; -: diminished, +: increased. * risk difference $>30 \%$ and $p<0.05$ (Chi-square tests). 


\section{Somatosensory signs - Clinical examination}

Frequencies of diminished and increased sensation at the affected versus the unaffected side are presented in Table 7.3. At t0, diminished proprioception (hand) was more common in patients developing pPSSP. At t1, diminished touch sensation (arm and face) and diminished proprioception (hand) were significantly more common in patients developing pPSSP. At t2, increased sensation to cold (arm) and decreased sensation to sharpness (face) were more common in patients with pPSSP.

Interestingly, at t2, increased sensation to touch and cold (all locations) was only observed in patients with pPSSP. Moreover, all of the patients with pPSSP reporting increased sensation to cold or sharpness at the affected upper arm at t2 also reported increased sensation to cold or sharpness at $t 1$.

Frequencies of evoked allodynia/dysesthesia and paresthesia at the affected side were generally low and were not different between groups (see Appendix 7.4).

\section{Somatosensory signs - Quantitative sensory testing}

Raw QST thresholds measured at the unaffected and affected side at $\mathrm{t} 1$ and $\mathrm{t} 2$ are presented in Table 7.4. At the unaffected side, thresholds were not significantly different between groups, although at t2, median pain thresholds were somewhat higher in patients with pPSSP. QST thresholds ratios (affected/ unaffected side) are presented in Figure 7.1.

Table 7.4 Quantitative sensory testing: raw thresholds, median [range].

\begin{tabular}{|c|c|c|c|c|}
\hline & \multicolumn{2}{|c|}{ t1 } & \multicolumn{2}{|c|}{ t2 } \\
\hline & $\begin{array}{l}\text { pPSSP } \\
(n=9)\end{array}$ & $\begin{array}{c}\text { NoPSSP } \\
(n=22)\end{array}$ & $\begin{array}{l}\text { pPSSP } \\
(n=9)\end{array}$ & $\begin{array}{c}\text { NoPSSP } \\
(n=22)\end{array}$ \\
\hline \multicolumn{5}{|l|}{ UA } \\
\hline VDT & $8[7-8]$ & $7[6-8]$ & $8[7-8]$ & $8[6-8]$ \\
\hline TDT & $3.61[2.83-4.31]$ & $3.61[2.82-4.31]^{\mathrm{a}}$ & $3.61[2.83-4.31]$ & $3.61[2.82-4.31]$ \\
\hline EST & $1.18[0.59-2.16]$ & $1.10[0.43-2.16]$ & $1.02[0.65-2.08]$ & $1.06[0.58-2.14]$ \\
\hline EPT & $2.52[1.45-3.53]$ & $2.16[1.10-10.09]$ & $2.97[1.33-7.07]$ & $1.89[0.95-12.54]^{b}$ \\
\hline EPPT & 3.31 [1.29-6.57] & $3.62[1.75-13.61]$ & 5.13 [1.28-11.27] & $3.01[1.36-15.47]$ \\
\hline PPT & $332[172-597]$ & 335 [156-939] & 305 [115-669] & 275 [165-1000] \\
\hline \multicolumn{5}{|r|}{$x_{2}+r_{1}$} \\
\hline VDT & 7 [1-8] & $7[1-8]$ & $8[1-8]$ & $8[1-8]$ \\
\hline TDT & $4.31[2.83-6.65]$ & $3.61[2.83-4.31]^{\mathrm{a}}$ & $4.31[3.61-6.65]$ & $3.61[2.83-4.56]$ \\
\hline EST & $1.84[0.69-7.57]$ & $1.05[0.57-3.24]$ & $1.56[0.64-16.00]$ & $1.09[0.60-2.89]$ \\
\hline EPT & 2.74 [1.57-11.33] & $2.32[0.80-7.70]$ & $2.52[2.11-16.00]$ & $1.85[0.69-13.15]$ \\
\hline EPPT & $4.56[2.78-8.27]$ & 3.54 [1.13-11.59] & $5.24[3.30-16.00]$ & $2.68[0.69-16.00]$ \\
\hline PPT & $353[224-587]$ & 276 [158-1000] & 350 [213-621] & $237[100-1000]$ \\
\hline
\end{tabular}

UA: unaffected side; A: affected side; VDT: vibration detection threshold ( $8=$ normal sensation); TDT: tactile detection threshold; EST: electrical sensation threshold; EPT: electrical pain threshold; EPTT: electrical pain tolerance threshold; PPT: pressure pain threshold. ${ }^{a} n=21,{ }^{b} n=8$. 
A

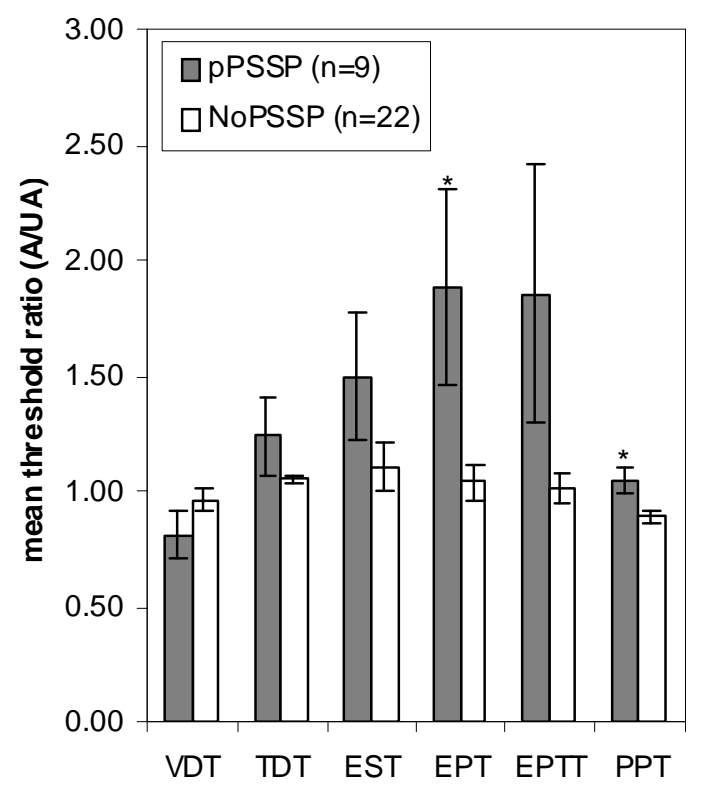

B

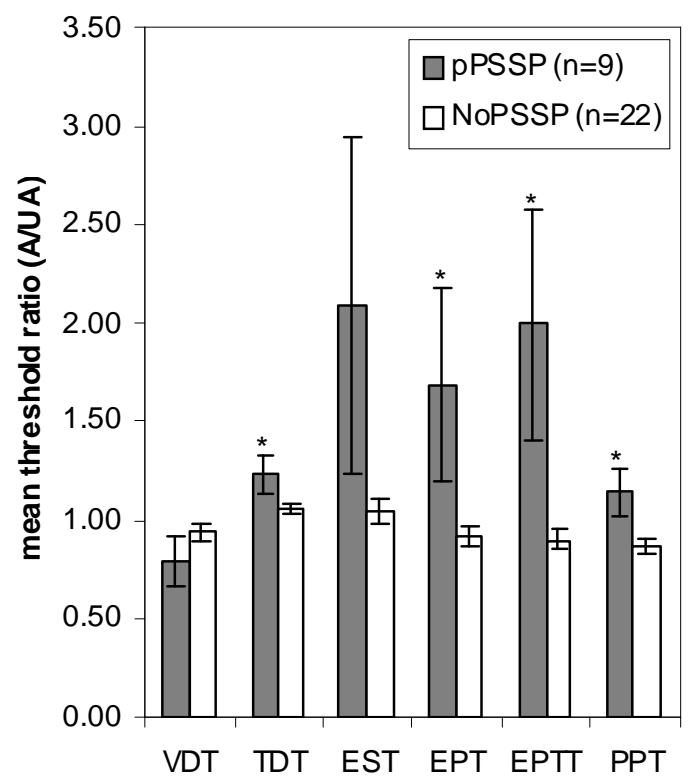

Figure 7.1 Quantitative sensory testing: threshold ratios at $t 1(A)$ and $t 2(B)$, mean $\pm S E$. VDT: vibration detection threshold; TDT: tactile detection threshold; EST: electrical sensation threshold; EPT: electrical pain threshold; EPTT: electrical pain tolerance threshold; PPT: pressure pain threshold; A/UA: affected/unaffected. $* p<0.05$.

Table 7.5 Abnormal z-scores of threshold ratios, number of subjects (\%).

\begin{tabular}{cccccc}
\hline & & $\begin{array}{c}\text { PSSP } \\
(\mathbf{n = 9 )}\end{array}$ & $\begin{array}{c}\text { t1 } \\
(\mathbf{n = 2 2 )}\end{array}$ & $\begin{array}{c}\text { PSSP } \\
(\mathbf{n}=9)\end{array}$ & $\begin{array}{c}\text { t2 } \\
\text { NoPSSP } \\
(\mathbf{n}=\mathbf{2 2})\end{array}$ \\
\hline TDT & - & $3(33)$ & $5(23)^{\mathrm{a}}$ & $6(67)$ & $7(32)$ \\
& + & $0(0)$ & $0(0)^{\mathrm{a}}$ & $0(0)$ & $0(0)$ \\
EST & - & $2(22)$ & $2(9)$ & $3(33)^{*}$ & $0(0)$ \\
& + & $0(0)$ & $1(5)$ & $0(0)$ & $0(0)$ \\
EPT & - & $2(22)$ & $0(0)$ & $2(22)$ & $0(0)$ \\
& + & $0(0)$ & $0(0)$ & $1(11)$ & $1(5)$ \\
EPTT & - & $4(44)$ & $5(23)$ & $5(56)^{*}$ & $0(0)$ \\
& + & $1(11)$ & $2(9)$ & $0(0)$ & $2(9)$ \\
PPT & - & $0(0)$ & $0(0)$ & $2(22)$ & $1(5)$ \\
& + & $0(0)$ & $0(0)$ & $0(0)$ & $2(9)$ \\
\hline
\end{tabular}

-: diminished; + : increased. ${ }^{a} n=21 . *$ risk difference $>30 \%$ and $p<0.05$ (Chi-square tests).

At t1, all mean QST thresholds (except the VDT) were higher in patients with pPSSP, however, only the mean EPT and PPT ratios showed significant group differences. At t2, all mean QST ratios (except the VDT and the EST) were significantly higher in patients with pPSSP. 
In addition, z-score analysis of individual QST ratios showed that, only at t2, hypoesthesia (EST) and hypoalgesia (EPTT) were more common in patients with pPSSP (see Table 7.5).

The frequencies of hyperesthesia and hyperalgesia were low and were not different comparing groups.

Conditioned pain modulation

At t1, CPM was performed in a subgroup of pPSSP $(n=4)$ and NoPSSP $(n=10)$ patients. Immersion time (cold pain tolerance) was significantly lower in the pPSSP group (median [range]: 42 [22-62] versus 117 [30-180] seconds, $p=0.043$ ). Although the EPT and PPT ratios were lower in the pPSSP group, no significant differences were observed between groups for the EPT ratio (1.00 [0.59-3.07] versus 1.45 [1.04-2.55], $\mathrm{p}=0.314)$, the PPT ratio $(0.95$ [0.80-1.12] versus 1.08 [0.73-1.42], $\mathrm{p}=0.508$ ) or the cold pressor pain intensity (6 [5$8]$ versus 7 [2-8]). CPM was also performed at $t 2$, but these results were not analyzed since only 2 patients with pPSSP could be tested.

Table 7.6 Correlations between motor and somatosensory functions at $\mathrm{t} 0, \mathrm{t} 1$ and $\mathrm{t} 2$.

\begin{tabular}{|c|c|c|c|c|c|c|c|c|c|c|}
\hline & & & to & - & & & & + & & \\
\hline & & & MI & $\mathbf{T}$ & C & $\mathbf{S}$ & $\mathbf{P}$ & $T$ & C & S \\
\hline t0 & - & $\bar{T}$ & -.254 & 1.000 & na & na & na & na & na & na \\
\hline & & C & -.112 & $.508 * *$ & 1.000 & na & na & na & na & na \\
\hline & & S & .004 & .327 & $.397 *$ & 1.000 & na & na & na & na \\
\hline & & P & $-.385^{*}$ & $.649 * *$ & $.569 * *$ & .120 & 1.000 & na & na & na \\
\hline & + & T & -.061 & -.045 & -.254 & -.089 & -.023 & 1.000 & na & na \\
\hline & & C & -059 & .080 & -.298 & .026 & -.095 & $.850 * *$ & 1.000 & na \\
\hline & & $S$ & .008 & .123 & .010 & -.262 & .167 & $.553 * *$ & $.429 *$ & 1.000 \\
\hline t1 & - & $\bar{T}$ & -.246 & .247 & .172 & .126 & .172 & .157 & .053 & .385* \\
\hline & & C & -.153 & .208 & $.408 *$ & $.408^{*}$ & .257 & -.218 & -.257 & -.066 \\
\hline & & $S$ & .096 & .289 & $.489 * *$ & .331 & .196 & -.236 & -.277 & -.107 \\
\hline & & P & $-.562 * *$ & $.442 *$ & .311 & .033 & $.484 * *$ & .111 & .049 & .075 \\
\hline & + & To & -.063 & .272 & .208 & .267 & .208 & .111 & .196 & .000 \\
\hline & & $C$ & -.089 & .000 & -.155 & .120 & .031 & $.447 *$ & $.614^{* *}$ & .135 \\
\hline & & $S$ & -.079 & .272 & -.035 & .033 & .138 & $.389 *$ & $.539 * *$ & .264 \\
\hline t2 & - & $T$ & -.292 & .208 & $.408^{*}$ & .408* & .257 & -.218 & -.257 & $-.395^{*}$ \\
\hline & & C & .146 & .226 & .282 & $.397^{*}$ & .139 & .208 & .109 & .010 \\
\hline & & $S$ & -.058 & .032 & .234 & $.590 * *$ & .071 & -.184 & -.216 & -.333 \\
\hline & & $P$ & $-.425 *$ & $.365^{*}$ & $.402 *$ & .120 & $.402 *$ & -.149 & -.175 & -.067 \\
\hline & + & $T$ & -.272 & .327 & -.203 & .018 & .074 & .356 & $.681 * *$ & .141 \\
\hline & & C & -.132 & -.045 & -.254 & -.089 & .208 & .259 & .196 & .050 \\
\hline & & S & .072 & .208 & -.045 & -.029 & .106 & $.509 * *$ & $.599 * *$ & $.428 *$ \\
\hline
\end{tabular}

MI: Motricity Index; T: touch; C: cold; S: sharpness; P: proprioception; -: diminished sensation; +: increased sensation; na: not applicable. Moderate to strong correlations $(>0.5)$ are depicted in bold. * $p<$ $0.05, * * p<0.001$ 
Initial stroke severity and diminished and increased sensation at t0, t1 and t2

Motricity Index scores at t0 were not correlated to the presence of abnormal sensation at either $\mathrm{t} 0$, $\mathrm{t} 1$ or $\mathrm{t} 2$ except for the presence of diminished proprioception at $\mathrm{t} 0$, $\mathrm{t} 1$ and $\mathrm{t} 2$ (see Table 7.6).

At $t 0$, the presence of diminished and increased sensation correlated between modalities (see Table 7.6). Diminished sensation at t0 was either not or only weakly $(<0.5)$ correlated to diminished sensation at $\mathrm{t} 1$ or $\mathrm{t} 2$, except for diminished sharpness sensation at $\mathrm{t} 2$. Increased touch sensation at t0 was moderately to strongly correlated with increased sharpness sensation at t2. Increased cold sensation at t0 was moderately to strongly correlated with increased cold and sharpness sensation at $\mathrm{t} 1$, and with increased touch sensation and increased sharpness sensation at $\mathrm{t} 2$.

\section{Discussion and conclusions}

The goal of the present prospective cohort study was to explore the relationship between the onset of somatosensory symptoms and signs and the development of persistent shoulder pain in the first 6 months after stroke. At the affected side, pPSSP was associated with diminished proprioception ( $\mathrm{t} 0, \mathrm{t} 1$ ), with diminished sensation for touch ( $\mathrm{t} 1$ ) and sharpness (t2), with increased QST threshold ratios (TDT, EST, EPT, EPTT, PPT) and with increased cold sensation (t2). At the unaffected side, pPSSP was associated with reduced cold pain tolerance thresholds (t1). Notably, in those patients with pPSSP reporting increased sensation at the affected side, multiple body sites across multiple stimulus modalities were involved and increased sensation persisted from t1 to t2. Conditioned pain modulation was not significantly different between groups.

\section{Somatosensory loss}

In previous studies, PSSP has been consistently associated with signs indicative of somatosensory loss at the affected side, in both acute and chronic stroke and with acute and persistent PSSP.8,33 In these studies, somatosensory loss has been observed for tactile $^{11,12,14,23,37}$, thermal ${ }^{11,12}$ and electrical ${ }^{37,38}$ stimuli and for proprioception $28,29,40$. In addition, an association between PSSP and somatosensory loss at the unaffected side has been found.29,37 However, except for our own studies, most of these studies have been performed using only a clinical examination and were only reported for innocuous stimuli. Consistent with previous studies, the present study showed that, in the first 6 months after stroke, diminished sensation was more frequently observed in patients with pPSSP, for both innocuous and noxious stimuli. Somatosensory loss at the affected side could contribute to the initiation of PSSP by increasing the risk of (repetitive) micro-trauma of 
soft tissues around the shoulder joint, which, combined with impaired voluntary motor control and hemi-inattention, would be consistent with the "trauma-hypothesis".41 Most importantly, these factors may contribute independently to the development of pPSSP, since the level of voluntary motor control was generally not correlated to the presence of somatosensory loss at $\mathrm{t} 0, \mathrm{t} 1$ or $\mathrm{t} 2$, except for a negative correlation with diminished proprioception at t1. Moreover, the presence of somatosensory loss at t0 was not or only weakly positively correlated to the presence of somatosensory loss at t1 and t2, indicating that the observed differences between pPSSP and NoPSSP at t1 and t2 cannot be merely explained by differences in initial stroke severity. Nonetheless, somatosensory loss may have contributed to central hypersensitivity in patients with PSSP, similar as described for CPSP. 19

\section{Somatosensory sensitization}

So far, signs indicative of somatosensory sensitization have only been investigated in 2 cross-sectional studies of pPSSP. In the study by Widar et al (average PSSP duration 20 months), tactile allodynia at the affected side was observed in 2 out of 18 patients. ${ }^{33}$ In our own cross-sectional study, signs indicative of somatosensory sensitization were more frequently observed in patients with pPSSP (average PSSP duration 19 months) as compared to pain-free stroke patients. ${ }^{37}$ Signs included increased sensation to cold and sharpness, tactile, cold and sharpness allodynia and blunt pressure hyperalgesia at the affected side and reduced cold pain tolerance and blunt pressure pain thresholds at the unaffected side. ${ }^{37,38}$

In the present study, pPSSP was associated with increased sensation to cold at the affected side, and with reduced cold pain tolerance at the unaffected side (t1). In addition, all of the patients with pPSSP reporting increased sensation to cold or sharpness at the affected upper arm at $\mathrm{t} 2$ also reported increased sensation to cold or sharpness at t1. However, pPSSP was not associated with other signs of somatosensory sensitization, such as allodynia or hyperalgesia.

Since the signs at the affected side only imply mild somatosensory sensitization, and the number of included subjects was low, the underlying mechanisms remain unclear. Pain complaints were mostly suggestive of nociceptive pain. Pain was increased by movement and was generally absent during rest, the DN4 scores were low and none of the patients could be classified as having CPSP. ${ }^{19}$ However, increased sensation at the affected side was observed for multiple modalities across multiple body sites, was observed also in the NoPSSP group and the presence of increased sensation at t0 was correlated to the presence of increased sensation at $\mathrm{t} 1$ and $\mathrm{t} 2$. Moreover, reduced cold pain tolerance at the unaffected 
side is suggestive of a role for central pain mechanisms. This may implicate that somatosensory sensitization occurred centrally rather than peripherally. As has been suggested for other types of persistent pain, central somatosensory sensitization prior to (i.e. due to the brain lesion itself or due to pre-morbid conditions) or during actual tissue damage could have contributed to the perpetuation of pain in patients with PSSP. ${ }^{17,57}$

\section{Endogenous inhibitory functions}

CPM48,52 has previously been shown to be impaired in several types of chronic pain, such as fibromyalgia 20 , osteoarthritis ${ }^{21}$ and whiplash ${ }^{17}$, and may predict the development of chronic pain. ${ }^{7,57}$ In previous cross-sectional studies of pain-free stroke patients with thalamic or cortical lesions ${ }^{7}$, patients with central post-stroke pain ${ }^{46}$ and patients with pPSSP (average PSSP duration 19 months) ${ }^{37}$, CPM has been shown to be similar to controls, although these studies have not yet been replicated. CPM has not previously been assessed in relation to the development of PSSP during the first 6 months after stroke.

In the present study, CPM appeared to be reduced in patients with pPSSP as compared to pain-free controls, but this difference was not significant. Moreover, the interpretation of the present results is complicated by the small sample size and by the possible influence of differences between groups in the timing and intensity of the conditioning stimulus ${ }^{31}$. Moreover, differences between groups in age 9,51 and gender ${ }^{13}$ may have influenced the effect of CPM. CPM should therefore be re-assessed in a larger study.

\section{Methodological considerations}

Although many patients were assessed for eligibility, the number of patients included in this study was relatively small. By using a strict selection of patients we aimed to minimize the influence of many potential confounders, including premorbid pain complaints, other neurological or musculoskeletal diseases, cognitive deficits and bilateral stroke symptoms. As such, the homogeneity of the studied sample was considered more important than the statistical power or generalizability to other patients with stroke.

This study was explorative in nature and multiple test modalities and body sites were assessed. We therefore only statistically analyzed continuous data and data showing a risk difference of at least $30 \%$. Ideally, the present results should be replicated in a larger sample.

Lastly, a follow-up period of more than 6 months would have provided more information about the long-term evolution of pPSSP and associated somatosensory symptoms and signs. Therefore, a minimum follow-up period of at least 1 year is recommended for future studies. 


\section{Conclusions}

Despite the explorative nature of this prospective cohort study, the results are relevant for the clinical as well as the experimental approach to (p)PSSP. Notably, this study, for the first time, showed that pPSSP in the first 6 months after stroke was associated with both somatosensory loss as well as with signs indicative of somatosensory sensitization. Somatosensory loss may have contributed to pPSSP initiation due to an increased risk of (repetitive micro-) trauma at the shoulder joint. The mechanisms underlying somatosensory sensitization remain unclear, but seem to occur at the level of the central nervous system. Central somatosensory sensitization prior to or during actual tissue damage may have contributed to the perpetuation of pain in patients with PSSP.

The monitoring of somatosensory abnormalities is important for a better understanding of the mechanisms underlying PSSP. Detailed assessment should, therefore, not be limited to those patients suspected of having central pain, but should be performed in all patients presenting with pain after stroke. ${ }^{36}$ In addition to the current interventions for PSSP which are primarily aimed at the shoulder, prevention and treatment might be improved by addressing abnormal central somatosensory processing. Several non-pharmacological interventions have proven to be effective in the normalization of abnormal central somatosensory and motor processing in patients with pain and movement disorders, including electrical stimulation,34,55 mirror therapy and mental imagery.1,10 In addition, pharmacological interventions (e.g. anti-depressants and anti-convulsants) might reduce central somatosensory sensitization.19 The preventive and/ or therapeutic effects of such interventions for PSSP should be explored in future studies. 


\section{References}

1 Acerra NE, Souvlis T, Moseley GL. Stroke, complex regional pain syndrome and phantom limb pain: can commonalities direct future management? J Rehabil Med 39:109114, 2007.

2 Bender L, McKenna K. Hemiplegic shoulder pain: defining the problem and its management. Disabil Rehabil 23:698-705, 2001.

3 Bouhassira D, Attal N, Alchaar $\mathrm{H}$, Boureau F, Brochet B, Bruxelle J, Cunin $G$, Fermanian J, Ginies $P$, GrunOverdyking A, Jafari-Schluep $\mathrm{H}$, LanteriMinet $M$, Laurent $B$, Mick $G$, Serrie $A$, Valade D, Vicaut E. Comparison of pain syndromes associated with nervous or somatic lesions and development of a new neuropathic pain diagnostic questionnaire (DN4). Pain 114:29-36, 2005.

4 Broeks JG, Lankhorst GJ, Rumping K, Prevo AJ. The long-term outcome of arm function after stroke: results of a follow-up study. Disabil Rehabil 21:357364, 1999.

5 Collin C, Wade D. Assessing motor impairment after stroke: a pilot reliability study. J Neurol Neurosurg Psychiatry 53:576-579, 1990.

6 Curatolo M, Arendt-Nielsen L, Petersen-Felix S. Central Hypersensitivity in Chronic Pain: Mechanisms and Clinical Implications. Phys Med Rehabil Clin N Am 17:287302, 2006.

7 De Broucker T, Cesaro P, Willer JC, Le Bars D. Diffuse noxious inhibitory controls in man. Involvement of the spinoreticular tract. Brain 113:12231234, 1990.

8 Dromerick AW, Edwards DF, Kumar A. Hemiplegic shoulder pain syndrome: frequency and characteristics during inpatient stroke rehabilitation. Arch Phys Med Rehabil 89:1589-1593, 2008.

9 Edwards RR, Fillingim RB, Ness TJ. Agerelated differences in endogenous pain modulation: a comparison of diffuse noxious inhibitory controls in healthy older and younger adults. Pain 101:155-165, 2003.

10 Flor $H$, Diers M. Sensorimotor training and cortical reorganization. NeuroRehabilitation 25:19-27, 2009.

11 Gamble GE, Barberan E, Bowsher D, Tyrrell PJ, Jones AK. Post stroke shoulder pain: more common than previously realized. Eur J Pain 4:313315, 2000.

12 Gamble GE, Barberan E, Laasch HU, Bowsher D, Tyrrell PJ, Jones AK. Poststroke shoulder pain: a prospective study of the association and risk factors in 152 patients from a consecutive cohort of 205 patients presenting with stroke. Eur J Pain 6:467-474, 2002.

13 Granot $M$, Weissman-Fogel I, Crispel $Y$, Pud D, Granovsky Y, Sprecher E, Yarnitsky D. Determinants of endogenous analgesia magnitude in a diffuse noxious inhibitory control (DNIC) paradigm: Do conditioning stimulus painfulness, gender and personality variables matter? Pain 136:142-149, 2008.

14 Hadianfard H, Hadianfard MJ. Predictor factors of hemiplegic shoulder pain in a group of stroke patients. Iran Red Crescent Me 10:215-219, 2008.

15 Hansson P, Backonja M, Bouhassira D. Usefulness and limitations of quantitative sensory testing: Clinical and research application in neuropathic pain states. Pain 129:256-259, 2007. 
16 Jönsson $A C$, Lindgren I, Hallström $B$, Norrving $B$, Lindgren $A$. Prevalence and intensity of pain after stroke: a population based study focusing on patients' perspectives. J Neurol Neurosurg Psychiatry 77:590-595, 2006.

17 Kasch H, Qerama E, Bach FW, Jensen TS. Reduced cold pressor pain tolerance in non-recovered whiplash patients: A 1-year prospective study. Eur J Pain 9:561-569, 2005.

18 Klauenberg S, Maier C, Assion HJ, Hoffmann A, Krumova EK, Magerl W, Scherens A, Treede RD, Juckel G. Depression and changed pain perception: Hints for a central disinhibition mechanism. Pain 140:332343, 2008.

19 Klit H, Finnerup NB, Jensen TS. Central post-stroke pain: clinical characteristics, pathophysiology, and management. Lancet Neurol 8:857-868, 2009.

20 Kosek E, Hansson P. Modulatory influence on somatosensory perception from vibration and heterotopic noxious conditioning stimulation (HNCS) in fibromyalgia patients and healthy subjects. Pain 70:41-51, 1997.

21 Kosek E, Ordeberg G. Lack of pressure pain modulation by heterotopic noxious conditioning stimulation in patients with painful osteoarthritis before, but not following, surgical pain relief. Pain 88:69-78, 2000.

22 Legrain V, Damme SV, Eccleston C, Davis KD, Seminowicz DA, Crombez G. A neurocognitive model of attention to pain: Behavioral and neuroimaging evidence. Pain 144:230-232, 2009.

Lindgren I, Jönsson AC, Norrving B, Lindgren A. Shoulder pain after stroke: A prospective population-based study. Stroke 38:343-348, 2007.
24 Loeser JD, Treede R-D. The Kyoto protocol of IASP Basic Pain Terminology. Pain 137:473-477, 2008.

25 Lundström E, Smits A, Terént A, Borg J. Risk factors for stroke-related pain 1 year after first-ever stroke. Eur J Neurol 16:188-193, 2009.

26 Merskey H, Bogduk N editors|. Title|, Vol. Volume|. City| : Publisher|, Year|. ?]

27 Moura RDCDR, Fukujima MM, Aguiar AS, Fontes SV, Dauar RFB, Do Prado GF. Predictive factors for spasticity among ischemic stroke patients. Arq Neuropsiquiatr 67:1029-1036, 2009.

28 Niessen $\mathrm{MH}$, Veeger DH, Koppe PA, Konijnenbelt $\mathrm{MH}$, van Dieen J, Janssen TW. Proprioception of the shoulder after stroke. Arch Phys Med Rehabil 89:333-338, 2008.

29 Niessen $\mathrm{MH}$, Veeger $\mathrm{DH}$, Meskers CG, Koppe PA, Konijnenbelt $\mathrm{MH}$, Janssen TW. Relationship among shoulder proprioception, kinematics, and pain after stroke. Arch Phys Med Rehabil 90:1557-1564, 2009.

30 Patel MD, Coshall C, Rudd AG, Wolfe CDA. Cognitive impairment after stroke: Clinical determinants and its associations with long-term stroke outcomes. J Am Geriatr Soc 50:700706, 2002.

31 Pud D, Granovsky Y, Yarnitsky D. The methodology of experimentally induced diffuse noxious inhibitory control (DNIC)-like effect in humans. Pain, 2009.

32 Rajaratnam BS, Venketasubramanian N, Kumar PV, Goh JC, Chan YH. Predictability of simple clinical tests to identify shoulder pain after stroke. Arch Phys Med Rehabil 88:1016-1021, 2007.

33 Ratnasabapathy Y, Broad J, Baskett J, Pledger M, Marshall J, Bonita R. 
Shoulder pain in people with a stroke: a population-based study. Clin Rehabil 17:304-311, 2003.

Renzenbrink GJ, IJzerman MJ. Percutaneous neuromuscular electrical stimulation (P-NMES) for treating shoulder pain in chronic hemiplegia. Effects on shoulder pain and quality of life. Clin Rehabil 18:359-365, 2004.

Rolke R, Magerl W, Campbell KA, Schalber C, Caspari S, Birklein F, Treede RD. Quantitative sensory testing: a comprehensive protocol for clinical trials. Eur J Pain 10:77-88, 2006.

Roosink M, Geurts ACH, IJzerman MJ. Defining post-stroke pain: diagnostic challenges. Lancet Neurol 9:344-344, 2010.

37 Roosink M, Renzenbrink GJ, Buitenweg $J R$, van Dongen RTM, Geurts AC, IJzerman MJ. Somatosensory symptoms and signs and conditioned pain modulation in chronic post-stroke shoulder pain. J Pain in press, 2010.

38 Roosink $M$, Van Dongen RTM, Renzenbrink GJ, IJzerman MJ. Classifying post-stroke shoulder pain: Can the DN4 be helpful? Eur J Pain 15:99-102, 2011.

Snels IA, Dekker JH, van der Lee JH, Lankhorst GJ, Beckerman H, Bouter LM. Treating patients with hemiplegic shoulder pain. Am J Phys Med Rehabil 81:150-160, 2002.

Suethanapornkul S, Kuptniratsaikul PS, Kuptniratsaikul $V$, Uthensut $P$, Dajpratha P, Wongwisethkarn J. Post stroke shoulder subluxation and shoulder pain: a cohort multicenter study. J Med Assoc Thai 91:1885-1892, 2008.

41 Teasell RW, Bhogal SK, Foley NC. Painful Hemiplegic Shoulder. In: Teasell RW, Bhogal SK, Foley NC, editors. Evidence-based Review of Stroke
Rehabilitation. London, Ontario, Canada: University of Western Ontario, 2007. pp. 1-57.

42 Tepperman PS, Greyson ND, Hilbert L, Jimenez J, Williams JI. Reflex sympathetic dystrophy in hemiplegia. Arch Phys Med Rehabil 65:442-447, 1984.

43 Tombaugh TN, M clntyre NJ. The MiniMental State Examination: A comprehensive review. J Am Geriatr Soc 40:922-935, 1992.

44 Turner-Stokes L, Hassan N. Depression after stroke: a review of the evidence base to inform the development of an integrated care pathway. Part 1: Diagnosis, frequency and impact. Clin Rehabil 16:231-247, 2002.

45 Turner-Stokes L, Jackson D. Shoulder pain after stroke: a review of the evidence base to inform the development of an integrated care pathway. Clin Rehabil 16:276-298, 2002.

46 Tuveson B, Leffler A-S, Hansson $P$. Influence of heterotopic noxious conditioning stimulation on spontaneous pain and dynamic mechanical allodynia in central poststroke pain patients. Pain 143:84-91, 2009.

47 Van Seventer R, Vos C, Meerding W, M ear I, Le Gal M, Bouhassira D, Huygen FJ. Linguistic validation of the DN4 for use in international studies. Eur J Pain, 2009.

48 van Wijk G, Veldhuijzen DS. Perspective on Diffuse Noxious Inhibitory Controls as a Model of Endogenous Pain Modulation in Clinical Pain Syndromes. J Pain 11:408-419, 2010.

49 Walk D, Sehgal N, Moeller-Bertram T, Edwards RR, Wasan A, Wallace $M$, Irving G, Argoff C, Backonja MM. Quantitative sensory testing and 
mapping: a review of nonautomated quantitative methods for examination of the patient with neuropathic pain. Clin J Pain 25:632-640, 2009.

50 Walsh K. M anagement of shoulder pain in patients with stroke. Postgrad Med J 77:645-649, 2001.

51 Washington LL, Gibson SJ, Helme RD. Age-related differences in the endogenous analgesic response to repeated cold water immersion in human volunteers. Pain 89:89-96, 2000.

52 Watanabe $S$, Kakigi R, Hoshiyama M, Kitamura $Y$, Koyama S, Shimojo $M$. Effects of noxious cooling of the skin on pain perception in man. J Neurol Sci 135:68-73, 1996.

53 Widar M, Samuelsson L, KarlssonTivenius $\mathrm{S}$, Ahlstrom G. Long-term pain conditions after a stroke. J Rehabil Med 34:165-170, 2002.

54 Wissel J, Schelosky LD, Scott J, Christe W, Faiss JH, Mueller J. Early development of spasticity following stroke: A prospective, observational trial. J Neurol 257:1067-1072, 2010.
55 Wu CWH, van Gelderen P, Hanakawa T, Yaseen Z, Cohen LG. Enduring representational plasticity after somatosensory stimulation. Neurolmage 27:872-884, 2005.

56 Yarnitsky D, Arendt-Nielsen L, Bouhassira D, Edwards RR, Fillingim RB, Granot M, Hansson P, Lautenbacher S, Marchand S, Wilder-Smith 0 . Recommendations on terminology and practice of psychophysical DNIC testing. Eur J Pain 14:339, 2010.

57 Yarnitsky D, Crispel $Y$, Eisenberg E, Granovsky Y, Ben-Nun A, Sprecher E, Best LA, Granot M. Prediction of chronic post-operative pain: Preoperative DNIC testing identifies patients at risk. Pain 138:22-28, 2008.

58 Zung WW. A Self-Rating Depression Scale. Arch Gen Psychiatry 12:63-70, 1965. 
Appendix 7.1 Exclusion criteria.

\begin{tabular}{llc}
\hline Exclusion criteria & $\mathbf{n}$ \\
\hline Stroke & Recurrent & 82 \\
& Brain stem/cerebellum & 22 \\
& Bilateral & 2 \\
& Onset $>$ 14 days prior to participation & 7 \\
& No motor or somatosensory symptoms & 37 \\
Medical & Complications (e.g. coma, infections, combination of exclusion criteria) & 36 \\
& Trauma & 4 \\
& Cancer & 4 \\
& Alcohol abuse & 2 \\
& Upper extremity fracture/prosthesis & 5 \\
& Signs of any possible concomitant neurological condition affecting the central or & 13 \\
& the peripheral nervous system (including diabetic polyneuropathy) & 4 \\
& Pre-morbid psychiatric disorders & 10 \\
& Pre-morbid cognitive disorders & 12 \\
& Concomitant diseases affecting the regions of somatosensory examination (face, & 12 \\
& lateral upper arms, back of the hands, front sides of the lower leg) & \\
Pain & Pre-morbid pain complaints, either severe and/or affecting the contralesional & 20 \\
Other & Disperextremity & 11 \\
& Nischarge within the first 3 days after stroke & 10 \\
& $\quad$ No adequate response to closed (yes/no) questions & 281 \\
\hline
\end{tabular}


Appendix 7.2 Flowchart of patient inclusion.

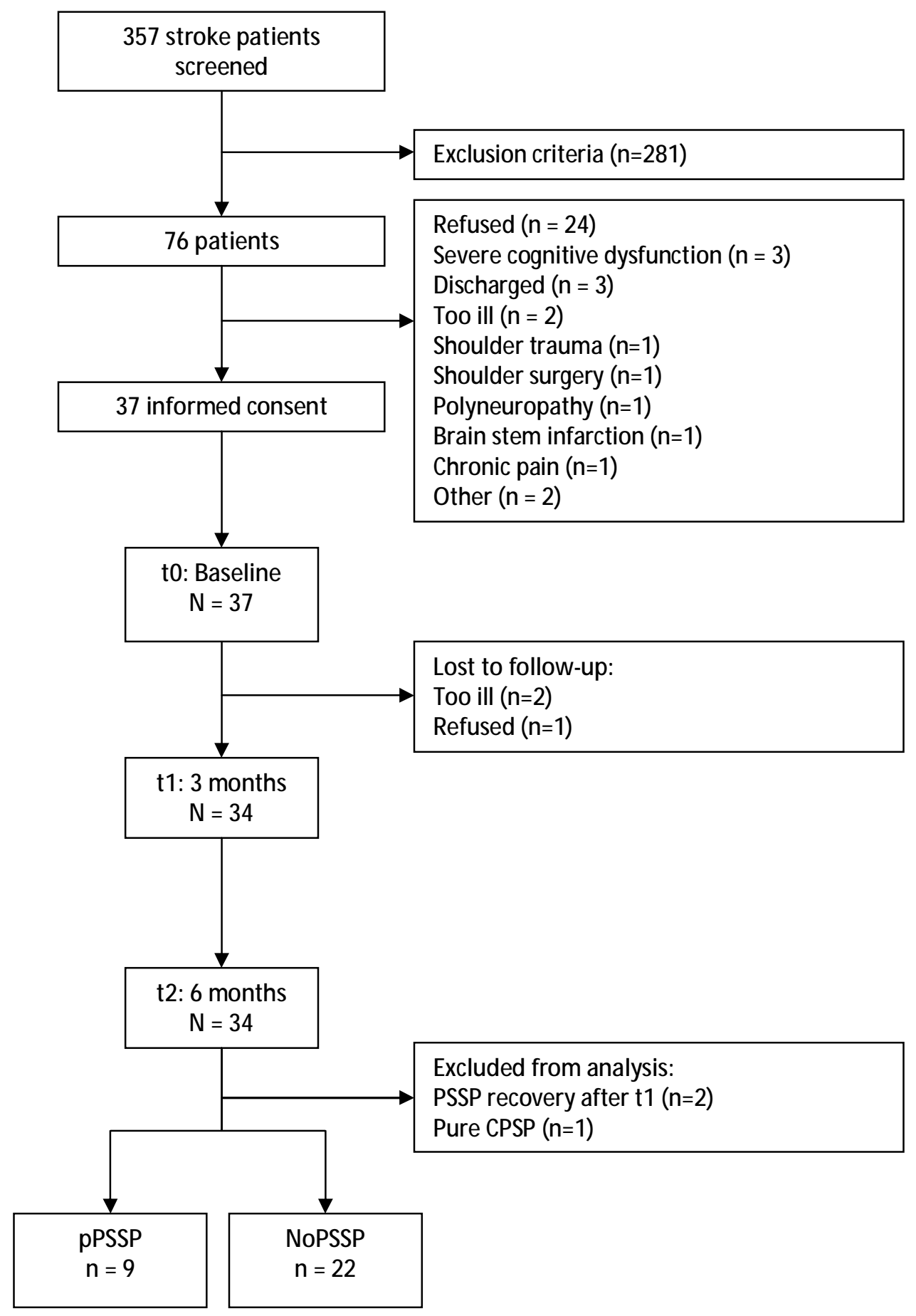

PSSP: post-stroke shoulder pain. Definitions: pPSSP: pain at both $\mathrm{t} 1$ and t2; NoPSSP: pain neither at t1 nor at $\mathrm{t} 2$. 
Appendix 7.3 Self-reported somatosensory symptoms, number of subjects (\%).

\begin{tabular}{lcccccc}
\hline & $\begin{array}{c}\text { pPSSP } \\
(\mathbf{n = 9 )}\end{array}$ & $\begin{array}{c}\text { NoPSSP } \\
(\mathbf{n = 2 1 )}\end{array}$ & $\begin{array}{c}\text { pPSSP } \\
(\mathbf{n}=\mathbf{9})\end{array}$ & $\begin{array}{c}\text { NoPSSP } \\
(\mathbf{n = 2 1 )}\end{array}$ & $\begin{array}{c}\text { pPSSP } \\
(\mathbf{n}=\mathbf{9})\end{array}$ & $\begin{array}{c}\text { NoPSSP } \\
(\mathbf{n = 2 1 )}\end{array}$ \\
\hline Dysesthesia & $1(11)$ & $6(29)$ & $3(33)$ & $7(32)$ & $2(22)$ & $8(36)$ \\
spontaneous & $1(11)$ & $5(24)$ & $1(11)$ & $5(23)$ & $2(22)$ & $6(27)$ \\
evoked & $0(0)$ & $1(5)$ & $3(33)$ & $2(9)$ & $0(0)$ & $3(14)$ \\
Paresthesia & $3(33)$ & $4(19)$ & $1(11)$ & $5(23)$ & $0(0)$ & $7(32)$ \\
spontaneous & $2(22)$ & $4(19)$ & $1(11)$ & $5(23)$ & $0(0)$ & $6(27)$ \\
evoked & $1(11)$ & $0(0)$ & $0(0)$ & $1(5)$ & $0(0)$ & $1(5)$ \\
\hline
\end{tabular}

Appendix 7.4 Evoked allodynia/dysesthesia and paresthesia at the affected side, number of subjects (\%).

\begin{tabular}{|c|c|c|c|c|c|c|c|}
\hline & & \multicolumn{2}{|c|}{ to } & \multicolumn{2}{|c|}{ t1 } & \multicolumn{2}{|c|}{ t2 } \\
\hline & & $\begin{array}{l}\text { pPSSP } \\
(n=9)\end{array}$ & $\begin{array}{c}\text { NoPSSP } \\
(n=21)\end{array}$ & $\begin{array}{l}\text { pPSSP } \\
(n=9)\end{array}$ & $\begin{array}{c}\text { NoPSSP } \\
(n=22)\end{array}$ & $\begin{array}{l}\text { pPSSP } \\
(n=9)\end{array}$ & $\begin{array}{c}\text { NoPSSP } \\
(n=22)\end{array}$ \\
\hline \multicolumn{8}{|l|}{ Arm } \\
\hline \multirow[t]{2}{*}{$\mathrm{T}$} & all/dys & $0(0)$ & 1 (5) & $0(0)$ & $0(0)$ & $0(0)$ & $0(0)$ \\
\hline & par & $0(0)$ & $0(0)$ & 1 (11) & $0(0)$ & $2(22)$ & $1(5)$ \\
\hline \multirow[t]{2}{*}{ C } & all/dys & $0(0)$ & $0(0)$ & $0(0)$ & $1(5)$ & $1(11)$ & $0(0)$ \\
\hline & par & $0(0)$ & $0(0)$ & 1 (11) & $0(0)$ & $0(0)$ & $1(5)$ \\
\hline \multirow[t]{2}{*}{$S$} & all/dys & $0(0)$ & $1(5)$ & $0(0)$ & $0(0)$ & $0(0)$ & $1(5)$ \\
\hline & par & $0(0)$ & $0(0)$ & 1 (11) & $0(0)$ & $1(11)$ & $0(0)$ \\
\hline \multicolumn{8}{|l|}{ Hand } \\
\hline \multirow[t]{2}{*}{$T$} & all/dys & $0(0)$ & 1 (5) & $0(0)$ & $0(0)$ & $0(0)$ & $0(0)$ \\
\hline & & $0(0)$ & $1(5)$ & 1 (11) & $0(0)$ & $2(22)$ & $1(5)$ \\
\hline \multirow[t]{2}{*}{ C } & all/dys & $0(0)$ & $0(0)$ & $0(0)$ & $1(5)$ & $1(11)$ & $0(0)$ \\
\hline & par & $0(0)$ & $0(0)$ & $1(11)$ & $0(0)$ & $0(0)$ & $1(5)$ \\
\hline \multirow[t]{2}{*}{$S$} & all/dys & $0(0)$ & $1(5)$ & $0(0)$ & $0(0)$ & $0(0)$ & $1(5)$ \\
\hline & par & $0(0)$ & $0(0)$ & $1(11)$ & $0(0)$ & $1(11)$ & $0(0)$ \\
\hline \multicolumn{8}{|l|}{ Face } \\
\hline \multirow[t]{2}{*}{$T$} & all/dys & $0(0)$ & $0(0)$ & $0(0)$ & $0(0)$ & $0(0)$ & $0(0)$ \\
\hline & par & $0(0)$ & $1(5)$ & $0(0)$ & $0(0)$ & $2(22)$ & $1(5)$ \\
\hline \multirow[t]{2}{*}{$C$} & all/dys & $0(0)$ & $0(0)$ & $0(0)$ & $0(0)$ & $1(11)$ & $0(0)$ \\
\hline & par & $0(0)$ & $0(0)$ & $0(0)$ & $0(0)$ & $0(0)$ & $0(0)$ \\
\hline \multirow[t]{2}{*}{$S$} & all/dys & $0(0)$ & $1(5)$ & $0(0)$ & $0(0)$ & $0(0)$ & $0(0)$ \\
\hline & par & $0(0)$ & $0(0)$ & $0(0)$ & $0(0)$ & $2(22)$ & $0(0)$ \\
\hline
\end{tabular}

T: touch; C: cold; S: sharpness; all: evoked allodynia; dys: evoked dysesthesia; par: evoked paresthesia. 

Chapter 8

General discussion: Towards a new view on PSSP? 


\section{Introduction}

Traditionally, post-stroke shoulder pain (PSSP) has been related to biomechanical abnormalities within the shoulder joint. Subsequently, the methods used for the assessment, prevention and treatment of PSSP are focused on nociceptive causes. However, despite active prevention and treatment strategies, a substantial number of stroke patients develop persistent PSSP and treatment results are generally disappointing. ${ }^{33}$ Moreover, the clinical presentations of PSSP and other types of post-stroke pain (i.e. central post-stroke pain and shoulder-hand syndrome) may show considerable overlap..$^{28}$ In addition to the uncertainties regarding the causes of PSSP, this hampers the classification and subsequent treatment of patients with post-stroke pain.

The prevention and treatment of PSSP may be improved by targeting the neurophysiological mechanisms responsible for the development of PSSP. Therefore, more knowledge is needed about the pathophysiology underlying PSSP, which requires other study designs and assessment methods than usually described in the literature.

In this thesis, novel steps towards a mechanism-based view on PSSP have been described. The primary objective of the thesis was to obtain a better understanding of the pathophysiology underlying the development of persistent PSSP (pPSSP). Several "pain research tools" have been introduced in part I (Chapter 2) and have subsequently been used to compare somatosensory functions between patients with pPSSP and pain-free stroke patients or healthy controls in parts II and III of the thesis (Chapters 3 to 8). These tools included pain questionnaires such as the neuropathic pain diagnostic questionnaire (DN4) ${ }^{7}$, extensive clinical neurological examination, quantitative sensory testing (QST), conditioned pain modulation (CPM) and, more experimentally, the recording of cortical evoked potentials (EPs).

\section{Somatosensory abnormalities in pPSSP}

In the presented studies, pPSSP was associated with somatosensory loss, consistent with previous studies.19,20,23,33,38 In addition, an association between pPSSP and signs suggestive of somatosensory sensitization could be established. Notably, pPSSP was associated with somatosensory abnormalities at both the affected and unaffected side involving multiple modalities, including electrical and noxious stimuli. Moreover, the associations between pPSSP and somatosensory abnormalities depended on the time of assessment, indicating that as PSSP continues to be present, central somatosensory sensitization may play an increasingly important role. 


\section{Somatosensory loss}

In Chapter 3, patients with pPSSP were compared to pain-free stroke patients and healthy controls. pPSSP was associated with a reduced sensation of tactile, cold and electrical stimuli and with reduced proprioception at the affected side. ${ }^{46}$ Besides being more frequent, somatosensory loss at the affected side for stimuli in the innocuous range was more severe in patients with pPSSP, as QST thresholds were much higher than in pain-free stroke patients or healthy controls. Moreover, pPSSP was associated with reduced tactile sensation at the unaffected side. Longitudinal assessment during the course of pPSSP development showed a similar picture. In Chapters 6 and 7, somatosensory abnormalities were assessed within 2 weeks (t0), at 3 months (t1) and at 6 months (t2) after stroke.45,47 The development of pPSSP in the first 6 months after stroke was associated with diminished sensation for proprioception (t0, t1), touch (t1) and sharpness (t2) and with increased QST threshold ratios (TDT, EST, EPT, EPTT, PPT), all indicative of somatosensory loss. In addition to these clinical findings, the association between pPSSP and somatosensory loss could also be demonstrated in the cortical processing of somatosensory stimuli. In Chapter 4, all included stroke patients had reduced EP amplitudes (N150, P300) and increased EP latencies (N90, N150, P300) in response to stimulation at both the affected and unaffected side.44 In addition, PSSP was associated with increased P200 and N150-P200 peak-to-peak latencies after stimulation at both sides.

Somatosensory loss at the affected side is likely to be directly related to the brain lesion. Indeed, PSSP has been associated with more extensive brain lesions. ${ }^{2}$ However, the loss of sensation found at the unaffected side (Chapter 3) and the bilateral alterations in cortical somatosensory processing (Chapter 4) may be related to both the brain lesion as well as to the central effects of chronic pain.11 Somatosensory loss at the affected side may have contributed to the initiation of pPSSP by increasing the risk of (repetitive) micro-trauma of soft tissues around the shoulder joint, which would be consistent with the "traumahypothesis". ${ }^{6}$ In addition, somatosensory loss may increase the risk of further abnormal somatosensory processing at spinal and supra-spinal levels. ${ }^{28,34}$

\section{Somatosensory sensitization}

In addition to somatosensory loss, pPSSP was also associated with signs indicative of somatosensory sensitization. In Chapter 3, signs included increased cold and sharpness sensation, tactile, cold and sharpness allodynia, and blunt pressure hyperalgesia at the affected side and reduced cold pain tolerance and blunt pressure pain hyperalgesia at the unaffected side. ${ }^{46}$ In contrast, cortical EPs were not indicative of central somatosensory hyperexcitability (Chapter 4). ${ }^{44}$ However, in the patients with pPSSP that could be included 
in the EP study, the incidence of clinical signs of central hyperexcitability (allodynia, generalized hyperalgesia) was generally low. In addition, ongoing cortical hyperexcitability after stroke may be masked by loss of somatosensory function and/ or loss of attentional capabilities.57 In Chapters 6 and 7, pPSSP was mainly associated with increased sensation to cold (t1) at the affected side.45,47 Moreover, all the patients with pPSSP reporting increased sensation to cold or sharpness at the affected upper arm at $\mathrm{t} 2$ also reported increased sensation to cold or sharpness at t1. In addition, pPSSP was associated with reduced cold pain tolerance at the unaffected side. Yet, pPSSP was not associated with other signs of somatosensory sensitization, such as allodynia or hyperalgesia.

In previous studies, the only sign indicative of somatosensory sensitization that has been reported in patients with PSSP was sharpness allodynia (punctate hyperalgesia).63 Generally, allodynia to touch or cold is considered to be a supportive factor for the diagnosis of central post-stroke pain.8,28,35 Increased sensation, allodynia and hyperalgesia may be related to peripheral and/ or to central somatosensory sensitization, or to a loss of endogenous inhibition.5,10,25,27,29,41,50,62 Whether central somatosensory sensitization in patients with pPSSP was due to the direct or indirect effects of prolonged nociception, to the brain lesion itself or to other (predisposing) factors remains uncertain.

\section{Differentiating between neuropathic and nociceptive pPSSP}

By showing that different somatosensory abnormalities are associated with pPSSP, the question rises whether patients can be classified into subtypes on the basis of such abnormalities. From a clinical perspective, especially the identification of pPSSP of predominantly neuropathic origin, as opposed to other (e.g. nociceptive) etiologies, is relevant for prognosis and treatment.

Chapter 5 explored whether the DN47 could be used for such purpose. ${ }^{48}$ The chronic stroke patients with pPSSP described in Chapter $3(n=19)$ were classified into subgroups of pPSSP of predominantly neuropathic or nociceptive origin using the DN4. Subsequently, these subgroups were compared regarding well known symptoms and signs suggestive of either neuropathic or nociceptive pain.

Subgroups differed regarding several symptoms and signs. pPSSP of predominantly neuropathic origin was associated with a higher frequency of somatosensory abnormalities (including impaired spino-thalamo-cortical tract function), spontaneous (constant) pain and a trend towards reduced thresholds for pain at the unaffected side, suggestive of central sensitization.6,28,63 In contrast, pain attacks primarily related to movement were only reported by patients classified as having pPSSP of predominantly nociceptive origin..$^{20}$ 
Although the DN4 could be used to classify PSSP subgroups that differed with respect to pain complaints and somatosensory abnormalities, the pathophysiological mechanisms remained unclear. Moreover, none of the somatosensory signs could be exclusively related to either of the PSSP subgroups. The classification of PSSP subtypes using the DN4 should, therefore, not be the sole basis for PSSP prognosis and treatment. Nonetheless, the diagnostic work-up of PSSP should involve a thorough assessment of both nociceptive and neuropathic pain complaints and somatosensory functions, for which the DN4 may be a useful standard.

\section{Other determinants of persistent post-stroke shoulder pain}

By assessing somatosensory abnormalities, the possible mechanisms (nociceptive, neuropathic, other) of facilitated nociceptive transmission were explored. However, also motor, cognitive, emotional and autonomic functions have been related to pPSSP and may be related to somatosensory functions. 13,30,55

Previous longitudinal studies have related several clinical determinants to the initiation of PSSP in the acute and subacute phases after stroke, but without reference to the onset of pain post stroke nor to the duration of the pain episode. Moreover, most studies did not include ${ }^{3}$ or did not report23,33,54 on follow-up assessments. Although cross-sectional analyses, like Chapter 3 in this thesis, provide some insight, the causal inference remains insufficient.

In the longitudinal studies presented in this thesis (Chapters 6 and 7), pPSSP in the first 6 months after stroke was associated with impaired voluntary motor control ( $\mathrm{t} 0, \mathrm{t} 1, \mathrm{t} 2)$, diminished proprioception ( $\mathrm{t} 0, \mathrm{t} 1)$, tactile extinction ( $\mathrm{t} 1)$, abnormal sensation ( $\mathrm{t} 1, \mathrm{t} 2)$, spasticity of the elbow flexor muscles (t1, t2), restricted range of motion (ROM) for both shoulder abduction (t2) and shoulder external rotation (t1, t2), trophic changes (t1) and non-insulin-dependent diabetes mellitus ( $\mathrm{t} 0$ ). ${ }_{45,47}$

Consistent with previous studies, these findings suggest that impairments of motor and somatosensory functions within the first 2 weeks after stroke onset might be considered as relevant initiating factors of PSSP. These findings are consistent with the "traumahypothesis", which postulates that shoulder pain is initiated by (repetitive) micro-trauma of soft tissues around the shoulder joint due to impaired active motor control, impaired perception of (minor) injury and/or hemineglect.56 In addition, pre-morbid metabolic alterations associated with diabetes mellitus may even further increase the risk of shoulder pathology after stroke. 4

Several determinants were associated with pPSSP at all time points after stroke. Six months after stroke, however, the presence of pPSSP appeared to be more strongly associated with 
restricted ROM for shoulder abduction and elbow flexion than with impaired voluntary motor control, spasticity or diminished proprioception. Together with the findings in Chapter 3 , this suggests that the influence of the presumed initiating factors may gradually decrease during the persistence of PSSP and that pain perpetuation may be related to a vicious circle of pain, limited range of motion, re-injury and somatosensory sensitization.

\section{Towards a new view on PSSP}

In Chapter 2 a theoretical framework of possible PSSP mechanisms was proposed which formed the basis of all following studies in this thesis. In contrast to other models, 38 this framework argues that, regardless of the precise combination of possible bio-psycho-social factors that may be related to PSSP development, PSSP is ultimately the final consequence of facilitated nociceptive transmission. Moreover, although pain may be localized to one region of the body, the mechanisms causing pain may occur at any level of the somatosensory neuro-axis. ${ }^{36}$ In this view, the mechanisms underlying PSSP may be related to the direct and indirect effects of prolonged nociception within the shoulder, to the brain lesion itself, but also to other (pre-morbid) factors that may influence the processing of somatosensory information. Importantly, the mechanisms responsible for pain initiation may be different than those responsible for pain perpetuation.

The cross-sectional and longitudinal studies presented in this thesis have, for the first time, performed an in depth assessment of the somatosensory abnormalities and pain complaints associated with pPSSP. In addition, by specifically defining the duration of pPSSP in the longitudinal studies (Chapters 6 and 7), an attempt was made to explore the temporal and causal relations between PSSP and its clinical determinants, distinguishing between initiating and perpetuating factors.45,47 For the first time, clear associations have been demonstrated between pPSSP and signs suggestive of somatosensory sensitization (Chapters 3 and 5).46,48 Moreover, it was shown that the influence of the presumed initiating factors may gradually decrease during the persistence of PSSP. Notably, pain perpetuation may be related to a vicious circle of pain, limited range of motion, re-injury and somatosensory sensitization which seemed to establish itself quite rapidly (i.e. within 3 months after PSSP onset) and may persist into the chronic phase after stroke. The precise mechanisms underlying the observed somatosensory sensitization remain unclear, although pain is not likely to be initiated by central somatosensory sensitization due to the brain lesion itself. As has been suggested for other types of persistent pain, ${ }^{26,65}$ central sensitization prior to or during actual tissue damage may have contributed to the perpetuation of pain in patients with pPSSP. These results shed a new light on the presumed 
pathophysiology of PSSP and, therefore, have important implications for the clinical approach to pPSSP assessment, prevention and treatment.

\section{Clinical implications}

The multi-factorial etiology of PSSP and its distinction from central post-stroke pain and shoulder-hand syndrome necessitates careful clinical assessment beyond the examination of the shoulder alone, including motor (active and passive), somatosensory, cognitive, emotional and autonomic functions. Regarding the assessment of somatosensory abnormalities, the use of "pain research tools", such as QST and CPM seems important since these may establish the presence of peripheral and/ or central sensitization by quantifying sensory changes on both the affected and unaffected body side and by assessing supraspinal inhibitory functions. The use of these tools should be promoted in order to better understand the pain mechanisms involved in individual stroke patients. The assessment of the ipsilesional (unaffected) side appears specifically important, as it may reveal the involvement of central (pain) mechanisms. When clinical examination is the only tool available, assessment should at least involve multi-modal stimuli and should be as standardized as possible. 61

Based on the findings in this thesis, the prevention of (repetitive) (micro-)trauma at the shoulder should be a priority in all phases of stroke rehabilitation and should be part of the education of both the patients and their caregivers. In contrast to the current approach to PSSP, which mostly involves unidimensional interventions primarily aimed at the shoulder joint, (preventive) interventions should be multidimensional focusing on maintaining and restoring passive pain-free range of joint motion, reducing spasticity, improving active motor control and preventing somatosensory sensitization.

Notably, since somatosensory sensitization may be due to prolonged nociception, to the brain lesion itself, or other (premorbid) factors such as depression, a broad spectrum of interventions may prove to be useful for a "normalization" of somatosensory abnormalities. A direct approach, specifically targeting somatosensory sensitization, is pharmacological intervention (i.e. anti-depressants and anti-convulsants). ${ }^{28}$ However, the preventive actions of these drugs in post-stroke pain are uncertain, 60 and these drugs may have many adverse side-effects. A recent systematic Cochrane review summarized interventions targeting somatosensory impairments after stroke.14 The authors concluded that "while there is insufficient evidence to reach conclusions about the effects of interventions [...], 3 studies provided preliminary evidence for the effects of some specific interventions, including mirror therapy for improving the detection of light touch, pressure and temperature pain; a thermal stimulation intervention for improving rate of recovery of tactile sensation; and 
intermittent pneumatic compression intervention for improving tactile and kinesthetic sensation".14 Interestingly, mirror therapy and (motor) imagery, have also proven to be beneficial for the reduction of pain and somatosensory abnormalities in patients with other pain syndromes, including complex regional pain syndrome type 1 and phantom limb pain. ${ }^{1,18}$ In addition, they may improve motor function after stroke. ${ }^{37}$ Amongst others, the effects of mirror therapy and motor imagery have been attributed to a normalization of functional (and spatial) brain activation. Both interventions can be considered as complex interventions targeting different levels of functions (e.g. motor, somatosensory, cognitiveevaluative). Indeed, also other treatment strategies that intervene at various levels simultaneously, such as neuromuscular electrical stimulation, may be effective.9,16,17,42,49,64 Yet, the preventive and/ or therapeutic effects of these interventions for PSSP need to be further substantiated by future studies.

\section{Methodological considerations}

Being the first with such a rigorously different approach to PSSP, it is inevitable to experience some study limitations. The number of subjects included in the studies described in this thesis was relatively small, although, especially in part III (Chapters 6 and 7 ), a large number of patients ( $n=357$ ) was assessed for eligibility. Nonetheless, by using a strict selection of patients the influence of many potential confounders such as pre-morbid pain complaints, other neurological or musculoskeletal diseases, cognitive deficits and bilateral stroke symptoms was minimized, resulting in a relatively homogenous sample of stroke patients. As such, the internal validity of temporal and possibly causal relationships was considered more important than the generalizability to all patients with stroke. Although in the studies presented in part II (Chapters 3-5), age, gender, trophic changes and depression scores could be ruled out as possible confounders, possible confounders could not be controlled for in part III (Chapters 6 and 7). These latter results should, therefore, be interpreted with caution.

The methods applied in this thesis are not commonly used in PSSP research, so studies were mostly of an explorative nature. Although the intention was to explore possible neurophysiological mechanisms underlying the development of pPSSP, the applied measurement tools allowed only an indirect judgment of pain mechanisms. Moreover, measurements were mostly reliant on subjective assessments of somatosensory abnormalities. Nevertheless, the combination of clinical examination, QST and CPM allowed extensive assessment of both the presence as well as the severity of somatosensory abnormalities on both the affected and unaffected sides, which could then be compared to findings obtained from experimental human and animal pain models. 
A limitation regarding the assessment of CPM was that the duration of the conditioning stimulus was not equal across groups and that assessment was performed after rather than during the conditioning stimulus. We standardized the cold pressor pain using self-reported pain intensities. Possibly, standardization using a fixed immersion time or assessment during the cold pressor test would have given different outcomes. Yet, the literature is inconsistent regarding the relation between the intensity of the conditioning stimulus and the magnitude of CPM. ${ }^{40}$ Moreover, subjects may or may not adapt to tonic painful cold stimuli, involving a different timing of pain perception over the course of immersion. 39 Lastly, in part III, patients were followed up until 6 months after stroke onset, yielding a pPSSP duration of merely 3 to 6 months, whereas in part II, the average time to stroke onset was 22 months and the average duration of pPSSP was 19 months. A longer follow-up in part III would have provided more information about the long-term evolution of pPSSP, specifically in relation to somatosensory sensitization. A longer follow-up might also have reduced some of the discrepancies between the results of parts II and III.

\section{Conclusions and directions for future research}

The findings in this thesis confirm the multi-factorial etiology of pPSSP and show that the factors responsible for the initiation of PSSP are likely to be different from the factors responsible for the perpetuation of PSSP. In addition, the role of abnormal somatosensory processing in PSSP maintenance may be much more prominent than previously assumed and may explain why treatment aimed at reducing peripheral nociception is generally unsatisfactory. Ongoing nociception, the brain lesion itself, and other (premorbid) factors may contribute to the development of pPSSP and, although the precise neurophysiological mechanisms still remain unclear, the findings reported in this thesis have important implications for the clinical as well as for the scientific approach to PSSP.

Different aspects of PSSP should be addressed in future studies. Ideally, the diagnostic work-up of PSSP involves a thorough assessment of both nociceptive and neuropathic pain complaints (e.g. using the DN4) and somatosensory functions, similar as described for central post-stroke pain. ${ }^{28}$ This may help to further identify markers of nociceptive and neuropathic pain mechanisms in PSSP which could lead to the development of a (set of) tool(s) that specifically deal(s) with classifying pain in the post-stroke pain population.

Somatosensory assessment may be performed more objectively. For example, using the nociceptive flexion reflex ${ }^{53}$ to assess spinal somatosensory excitability and functional15,22,52 or structural 24 magnetic resonance imaging to assess cortical somatosensory function. In addition, the use of other subjective tests may further characterize somatosensory abnormalities, such as thermal QST, supra-threshold stimulation, wind-up and ischemia- 
induced CPM.43,59 However, in all protocols, a balanced decision should be made considering feasibility and reliability and the burden for the individual patient.

The relationship between pain, somatosensory abnormalities, pain mechanisms and other clinical functions may be further explored in intervention studies. In the early phase after stroke, it is important that patients are first distinguished based on presumed pathophysiology (e.g. nociceptive/neuropathic, spasticity/inflammation) of PSSP after which these relatively homogenous groups may be randomized to a targeted treatment or control condition. For example, in patients with PSSP in which a neuropathic component is suspected, the treatment condition could be an anti-depressant and the control condition a corticosteroid injection. Likewise, in patients with PSSP presenting with hypertonicity and a reduced passive pain-free range of motion, botulinum toxin injections may be used as the treatment condition and corticosteroid injections as the control condition. Notably, this view differs from the approach of a previous randomized control trial by Lim and colleagues in which similar interventions were used, but in which all patients with a reduced range of passive joint motion were included, regardless of the (presumed) underlying pathophysiology. 32

When PSSP is persistent, no single intervention is expected to provide sufficient pain relief. Classifications and interventions for (sub)acute PSSP may no longer be appropriate. This requires new classifications (e.g. the presence or absence of central sensitization) and different interventions. Since the mechanisms underlying pPSSP may be complex, involving multiple levels of functions, multidimensional interventions (e.g. neuromuscular electrical stimulation or mirror therapy) may be expected to be specifically effective.

The effectiveness of new interventions, either multidimensional or specifically targeting somatosensory abnormalities should be evaluated. Because such interventions may also be effective for other types of post-stroke pain, these studies might include patients with PSSP as well as patients with post-stroke complex regional pain syndrome (shoulder-hand syndrome) or central post-stroke pain. In this way, the differences and similarities between these groups of patients can be studied based on their response to treatment.

In longitudinal studies with sufficient sample size, a comparison should be made between the clinical functions of stroke patients who develop persistent PSSP versus stroke patients who recover from PSSP spontaneously or with the help of treatment. For this purpose, a follow-up period of at least 1 year is recommended.

Lastly, to better understand the mechanisms underlying PSSP, it may prove to be of importance to know the relationship between pain, clinical functions and (pain) behaviors. For example, although the initiation of PSSP has been related to impaired motor function, both patients with severely impaired and those with mildly impaired motor functions may 
develop PSSP, depending on the behavior of the individual patient. In addition, both overuse and non-use of a relatively mildly affected arm may predispose to PSSP. ${ }^{21,58}$ Future studies should, therefore, also consider the assessment of pain and functional behaviors in patients with PSSP, either by using questionnaires, ${ }^{12}$ or by recording movement patterns of the affected upper extremity in daily life situations.31,51 


\section{References}

1 Acerra NE, Souvlis T, Moseley GL. Stroke, complex regional pain syndrome and phantom limb pain: can commonalities direct future management? J Rehabil Med 39:109114, 2007.

2 Appelros P. Prevalence and predictors of pain and fatigue after stroke: a population-based study. Int J Rehabil Res 29:329-333, 2006.

3 Aras MD, Gokkaya NK, Comert D, Kaya A, Cakci A. Shoulder pain in hemiplegia: results from a national rehabilitation hospital in Turkey. Am J Phys Med Rehabil 83:713-719, 2004.

$4 \quad$ Arkkila PE, Gautier JF. Musculoskeletal disorders in diabetes mellitus: an update. Best Pract Res Clin Rheumatol 17:945-970, 2003.

5 Binder $A$, Binder $A$, Maag $R$, Peller $M$, Wasner $G$, Siebner HR, Baron R. Differential coding of cold allodynia - A fmri study. Clinical Neurophysiology 118:e17-e17, 2007.

6 Boivie J, Leijon G, Johansson I. Central post-stroke pain--a study of the mechanisms through analyses of the sensory abnormalities. Pain 37:173185, 1989.

7 Bouhassira D, Attal $\mathrm{N}$, Alchaar $\mathrm{H}$, Boureau F, Brochet B, Bruxelle J, Cunin G, Fermanian J, Ginies P, GrunOverdyking $A$, Jafari-Schluep $H$, LanteriMinet M, Laurent B, Mick G, Serrie A, Valade $D$, Vicaut E. Comparison of pain syndromes associated with nervous or somatic lesions and development of a new neuropathic pain diagnostic questionnaire (DN4). Pain 114:29-36, 2005.

8 Bowsher D. Allodynia in relation to lesion site in central post-stroke pain. Pain 6:736-740, 2005.
Chae J, Ng A, Yu DT, Kirsteins A, Elovic $E P$, Flanagan SR, Harvey RL, Zorowitz RD, Fang ZP. Intramuscular electrical stimulation for shoulder pain in hemiplegia: does time from stroke onset predict treatment success? Neurorehabil Neural Repair 21:561567, 2007.

10 Chu LF, Clark DJ, Angst MS. Opioid tolerance and hyperalgesia in chronic pain patients after one month of oral morphine therapy: A preliminary prospective study. Journal of Pain 7:4348, 2006.

11 Curatolo $M$, Arendt-Nielsen $L$, Petersen-Felix S. Central Hypersensitivity in Chronic Pain: Mechanisms and Clinical Implications. Phys Med Rehabil Clin N Am 17:287302, 2006.

12 De Vlieger P, Bussche EVd, Eccleston C, Crombez $G$. Finding a solution to the problem of pain: Conceptual formulation and the development of the Pain Solutions Questionnaire (PaSol). Pain 123:285-293, 2006.

13 Diserens $K$, Vuadens $P$, Michel $P$, Reichhart M, Herrmann FR, Arnold P, Bogousslavsky J, Ghika J. Acute autonomic dysfunction contralateral to acute strokes: a prospective study of 100 consecutive cases. Eur J Neurol 13:1245-1250, 2006.

14 Doyle S, Bennett S, Fasoli SE, McKenna KT. Interventions for sensory impairment in the upper limb after stroke. Cochrane database of systematic reviews (Online) 6:CD006331 2010.

15 Ducreux D, Attal N, Parker F, Bouhassira D. Mechanisms of central neuropathic pain: a combined psychophysical and fMRI study in syringomyelia. Brain 129:963-976, 2006. 
Floel A, Cohen LG. Translational studies in neurorehabilitation: from bench to bedside. Cogn Behav Neurol 19:1-10, 2006.

17 Floel A, Nagorsen U, Werhahn KJ, Ravindran S, Birbaumer N, Knecht S, Cohen LG. Influence of somatosensory input on motor function in patients with chronic stroke. Annals of Neurology 56:206-212, 2004.

Flor $H$, Diers M. Sensorimotor training and cortical reorganization. NeuroRehabilitation 25:19-27, 2009.

Gamble GE, Barberan E, Bowsher D, Tyrrell PJ, Jones AK. Post stroke shoulder pain: more common than previously realized. Eur J Pain 4:313$315,2000$.

Gamble GE, Barberan E, Laasch HU, Bowsher D, Tyrrell PJ, Jones AK. Poststroke shoulder pain: a prospective study of the association and risk factors in 152 patients from a consecutive cohort of 205 patients presenting with stroke. Eur J Pain 6:467-474, 2002.

21 George SZ, Dover GC, Fillingim RB. Fear of pain influences outcomes after exercise-induced delayed onset muscle soreness at the shoulder. Clin J Pain 23:76-84, 2007.

22 Gwilym SE, Keltner JR, Warnaby CE, Carr AJ, Chizh B, Chessell I, Tracey I. Psychophysical and functional imaging evidence supporting the presence of central sensitization in a cohort of osteoarthritis patients. Arthritis Rheum 61:1226-1234, 2009.

23 Hadianfard $\mathrm{H}$, Hadianfard MJ. Predictor factors of hemiplegic shoulder pain in a group of stroke patients. Iran Red Crescent Me 10:215-219, 2008.

Hong JH, Bai DS, Jeong JY, Choi BY, Chang $\mathrm{CH}$, Kim SH, Ahn SH, Jang SH. Injury of the spino-thalamo-cortical pathway is necessary for central post- stroke pain. European Neurology 64:163-168.

25 Jørum E, Warncke T, Stubhaug A. Cold allodynia and hyperalgesia in neuropathic pain: the effect of $\mathrm{N}$ methyl--aspartate (NMDA) receptor antagonist ketamine - a double-blind, cross-over comparison with alfentanil and placebo. Pain 101:229-235, 2003.

26 Kasch H, Qerama E, Bach FW, Jensen TS. Reduced cold pressor pain tolerance in non-recovered whiplash patients: A 1-year prospective study. Eur J Pain 9:561-569, 2005.

27 Kilo S, Schmelz $M$, Koltzenburg $M$, Handwerker HO. Different patterns of hyperalgesia induced by experimental inflammation in human skin. Brain 117:385-396, 1994.

28 Klit H, Finnerup NB, Jensen TS. Central post-stroke pain: clinical characteristics, pathophysiology, and management. Lancet Neurol 8:857-868, 2009.

29 Koltzenburg M, Torebjörk HE, Wahren LK. Nociceptor modulated central sensitization causes mechanical hyperalgesia in acute chemogenic and chronic neuropathic pain. Brain 117:579-591, 1994.

30 Korpelainen JT, Sotaniemi KA, Myllyla VV. Autonomic nervous system disorders in stroke. Clin Auton Res 9:325-333, 1999.

31 Lim CK, Luo Z, Chen IM, Yeo SH. Wearable wireless sensing system for capturing human arm motion. Sensors and Actuators, A: Physical.

$32 \operatorname{Lim} J Y$, Koh JH, Paik NJ. Intramuscular botulinum toxin-A reduces hemiplegic shoulder pain: a randomized, doubleblind, comparative study versus intraarticular triamcinolone acetonide. Stroke 39:126-131, 2008. 
33 Lindgren I, Jönsson AC, Norrving B, Lindgren A. Shoulder pain after stroke: A prospective population-based study. Stroke 38:343-348, 2007.

34 Melzack R, Wall PD. Pain mechanisms: a new theory. Science 150:971-979, 1965.

35 M isra UK, Kalita J, Kumar B. A study of clinical, magnetic resonance imaging, and somatosensory-evoked potential in central post-stroke pain. J Pain 9:11161122, 2008.

Moseley GL. A pain neuromatrix approach to patients with chronic pain. Man Ther 8:130-140, 2003.

Mulder T. Motor imagery and action observation: Cognitive tools for rehabilitation. J Neural Transm 114:1265-1278, 2007.

Niessen $M H$, Veeger DH, M eskers CG, Koppe PA, Konijnenbelt $M H$, Janssen TW. Relationship among shoulder proprioception, kinematics, and pain after stroke. Arch Phys Med Rehabil 90:1557-1564, 2009.

39 Polianskis R, Graven-Nielsen T, ArendtNielsen L. Modality-specific facilitation and adaptation to painful tonic stimulation in humans. Eur J Pain 6:475-484, 2002.

Pud D, Granovsky Y, Yarnitsky D. The methodology of experimentally induced diffuse noxious inhibitory control (DNIC)-like effect in humans. Pain, 2009.

41 Ram KC, Eisenberg E, Haddad M, Pud D. Oral opioid use alters DNIC but not cold pain perception in patients with chronic pain - New perspective of opioidinduced hyperalgesia. Pain 139:431438, 2008.

42 Renzenbrink GJ, IJzerman MJ. Percutaneous neuromuscular electrical stimulation (P-NMES) for treating shoulder pain in chronic hemiplegia. Effects on shoulder pain and quality of life. Clin Rehabil 18:359-365, 2004.

43 Rolke R, Magerl W, Campbell KA, Schalber C, Caspari S, Birklein F, Treede RD. Quantitative sensory testing: a comprehensive protocol for clinical trials. Eur J Pain 10:77-88, 2006.

44 Roosink M, Buitenweg JR, Renzenbrink GJ, Van Dongen RTM, Geurts AC, IJzerman MJ. Altered cortical somatosensory processing in chronic stroke: a relationship with post-stroke shoulder pain. NeuroRehabilitation in press, 2010.

45 Roosink M, Renzenbrink GJ, Buitenweg JR, Van Dongen RTM, Geurts AC, IJzerman MJ. Persistent shoulder pain in the first six months after stroke: results of a prospective cohort study. Arch Phys Rehab Med accepted pending revisions, 2010.

46 Roosink M, Renzenbrink GJ, Buitenweg $J R$, van Dongen RTM, Geurts AC, IJzerman MJ. Somatosensory symptoms and signs and conditioned pain modulation in chronic post-stroke shoulder pain. J Pain in press, 2010.

47 Roosink $M$, Van Dongen RTM, Buitenweg JR, Renzenbrink GJ, Geurts $A C$, IJzerman MJ. Somatosensory sensitization in persistent shoulder pain after stroke: results of a prospective cohort study. Eur J Pain submitted for publication, 2010.

48 Roosink $M$, Van Dongen RTM, Renzenbrink GJ, IJzerman MJ. Classifying post-stroke shoulder pain: Can the DN4 be helpful? Eur J Pain 15:99-102, 2011.

49 Rottmann S, Jung K, Ellrich J. Electrical low-frequency stimulation induces long-term depression of sensory and affective components of pain in healthy man. European Journal of Pain 14:359365. 
Schneider GM, Smith AD, Hooper A, Stratford $P$, Schneider KJ, Westaway $M D$, Frizzell $B$, Olson L. Minimizing the source of nociception and its concurrent effect on sensory hypersensitivity: An exploratory study in chronic whiplash patients. BMC M usculoskeletal Disorders 11, 2010.

51 Schurr K, Ada L. Observation of arm behaviour in healthy elderly people: implications for contracture prevention after stroke. Aust J Physiother 52:129133, 2006.

52 Schweinhardt P, Glynn C, Brooks J, M cQuay H, Jack T, Chessell I, Bountra C, Tracey I. An fMRI study of cerebral processing of brush-evoked allodynia in neuropathic pain patients. Neuroimage 32:256-265, 2006.

53 Skljarevski V, Ramadan NM. The nociceptive flexion reflex in humans -review article. Pain 96:3-8, 2002.

54 Suethanapornkul S, Kuptniratsaikul PS, Kuptniratsaikul V, Uthensut $P$, Dajpratha P, Wongwisethkarn J. Post stroke shoulder subluxation and shoulder pain: a cohort multicenter study. J Med Assoc Thai 91:1885-1892, 2008.

55 Suzuki R, Rygh LJ, Dickenson AH. Bad news from the brain: descending 5-HT pathways that control spinal pain processing. Trends Pharmacol Sci 25:613-617, 2004.

56 Teasell RW, Bhogal SK, Foley NC. Painful Hemiplegic Shoulder. In: Teasell RW, Bhogal SK, Foley NC, editors. Evidence-based Review of Stroke Rehabilitation. London, Ontario, Canada: University of Western Ontario, 2007. pp. 1-57.

57 Treede RD, Lorenz J, Baumgartner U. Clinical usefulness of laser-evoked potentials. Neurophysiol Clin 33:303314, 2003.
58 Turk DC, Wilson HD. Fear of pain as a prognostic factor in chronic pain: conceptual models, assessment, and treatment implications. Curr Pain Headache Rep 14:88-95.

59 Tuveson B, Leffler A-S, Hansson $P$. Influence of heterotopic noxious conditioning stimulation on spontaneous pain and dynamic mechanical allodynia in central poststroke pain patients. Pain 143:84-91, 2009.

60 Vestergaard K, Nielsen J, Andersen G, Ingeman-Nielsen $M$, Arendt-Nielsen $L$, Jensen TS. Sensory abnormalities in consecutive, unselected patients with central post-stroke pain. Pain 61:177186, 1995.

61 Walk $D$, Sehgal $N$, Moeller-Bertram $T$, Edwards RR, Wasan A, Wallace $M$, Irving G, Argoff C, Backonja MM. Quantitative sensory testing and mapping: a review of nonautomated quantitative methods for examination of the patient with neuropathic pain. Clin J Pain 25:632-640, 2009.

62 Wasner G, Schattschneider J, Binder A, Baron R. Topical menthol--a human model for cold pain by activation and sensitization of $\mathrm{C}$ nociceptors. Brain 127:1159-1171, 2004.

63 Widar M, Samuelsson L, KarlssonTivenius S, Ahlstrom G. Long-term pain conditions after a stroke. J Rehabil M ed 34:165-170, 2002.

64 Wu CWH, van Gelderen P, Hanakawa T, Yaseen Z, Cohen LG. Enduring representational plasticity after somatosensory stimulation. Neurolmage 27:872-884, 2005.

65 Yarnitsky D, Crispel $\mathrm{Y}$, Eisenberg $\mathrm{E}$, Granovsky Y, Ben-Nun A, Sprecher E, Best LA, Granot M. Prediction of chronic post-operative pain: Preoperative DNIC testing identifies patients at risk. Pain 138:22-28, 2008. 

Summary 


\section{Persistent shoulder pain after stroke}

The most commonly reported type of pain after stroke is post-stroke shoulder pain (PSSP), also named hemiplegic shoulder pain. Traditionally, PSSP is regarded as nociceptive pain resulting from tissue damage due to biomechanical changes around the shoulder joint. PSSP treatment mostly focuses at reducing biomechanical stressors or inflammation, including normalization of muscle tone, reduction of glenohumeral subluxation and/ or treatment of the shoulder capsule. However, pain relief is often unsatisfactory, leading to a considerable number of patients with persistent pain. In order to improve the prevention and treatment of PSSP, a better understanding of the neurophysiological mechanisms underlying its development and maintenance is needed. This demands a broadening of the traditional view on and assessment of PSSP as being a type of biomechanical nociceptive pain. This thesis adopts a mechanism-based approach to the research of PSSP development. The primary objective of the thesis is to obtain a better understanding of the pathophysiological mechanisms responsible for the development of persistent PSSP (pPSSP).

The body of this thesis consists of 3 parts and includes a scientific intermezzo between part II and III. The first part is entitled 'A mechanism-based view on post-stroke shoulder pain' (Chapter 2). It introduces the terminology and the neurophysiological concepts of pain and describes a theoretical framework for a mechanism-based approach to PSSP.

The second part 'Cross-sectional studies of persistent PSSP' comprises 3 cross-sectional studies that were undertaken to test the usability of pain research tools for the assessment of pPSSP such as quantitative sensory testing and conditioned pain modulation (Chapter 3), cortical evoked potentials (Chapter 4), and the neuropathic pain diagnostic questionnaire (Chapter 5). Moreover, the outcome of these studies is interpreted in the light of possible neurophysiological pain mechanisms underlying pPSSP.

The intermezzo is entitled 'An ongoing debate on post-stroke pain classification'. It reflects a scientific discussion about a grading system for CPSP and discusses its implications for the clinical approach to PSSP.

The third part 'Follow-up studies on the development of persistent PSSP' focuses on the longitudinal assessment of pPSSP within 2 weeks, at 3 months and at 6 months after stroke. Chapter 6 focuses on the complete clinical picture of somatosensory, motor, cognitive, emotional and autonomic functions associated with the development of pPSSP during the first 6 months after stroke. Chapter 7 further addresses possible pain mechanisms underlying the development of pPSSP by describing the relationship between pPSSP and somatosensory loss, somatosensory sensitization and endogenous pain inhibition in the first 6 months after stroke using "pain research tools". 
In the last chapter of this thesis (Chapter 8) the results described in the previous chapters are discussed and used to update the current knowledge on PSSP development. The implications for clinical practice are discussed, leading to the main conclusions of this thesis with some suggestions for future research. Here, a summary is presented of parts I, II and III.

\section{Part I: A mechanism-based view on post-stroke shoulder pain}

Chapter 2 presents a theoretical framework for possible PSSP mechanisms and their assessment based on key concepts applied in pain research. This theoretical framework argues that, although pain may be localized in one region of the body, the mechanisms causing pain may occur at any level of the somatosensory neuro-axis. Detailed assessment of pain complaints and somatosensory abnormalities should, therefore, be a key element in PSSP research. However, so far, somatosensory assessment in patients with PSSP has been limited to clinical examination. Studies aiming to further characterize somatosensory functions in patients with PSSP (initially) need to take a broad methodological approach including both clinical as well as more experimental pain research tools, such as quantitative sensory testing, conditioned pain modulation and the assessment of cortical somatosensory processing.

\section{Part II: Cross-sectional studies of persistent PSSP}

Chapter 3 describes a study in which somatosensory abnormalities were assessed in chronic stroke patients with pPSSP $(n=19)$, pain-free stroke patients $(n=29)$ and healthy controls $(n=23)$, using clinical examination and electrical and mechanical quantitative sensory testing (QST). In addition, conditioned pain modulation (CPM) was assessed by comparing QST thresholds before and after applying a cold pressor test. Sensory abnormalities were more frequently observed and more severe in patients with PSSP, including positive signs, such as allodynia at the affected side and generalized hyperalgesia at the unaffected side. CPM was similar in stroke patients and healthy controls. This study showed that pPSSP was associated with several positive and negative somatosensory signs, implicating a role for central sensitization and possibly for disinhibition. Since the causal relationship remains unclear, and may be related to either neuroplasticity induced by prolonged nociception as well as to the brain lesion itself, prospective studies are warranted. Prevention and treatment of PSSP could benefit from a more detailed analysis of both peripheral and central pain mechanisms.

Chapter 4 describes an explorative study that addresses the possible changes in cortical somatosensory processing in patients with pPSSP. Cortical potentials were recorded 
following intracutaneous electrostimulaton in stroke patients with pPSSP $(n=6)$, pain-free stroke patients $(P F, n=14)$ and healthy controls $(H C, n=20)$ using electroencephalography (EEG). Amplitudes and latencies of both sensory discriminative (N90) as well as cognitive evaluative (N150, P200, the N150-P200 peak-to-peak difference, and P300) evoked potential components were evaluated. Stroke was associated with reduced N150 and P300 amplitudes and increased N90, N150 and P300 latencies at both sides. Compared to PF and HC, the P200 and N150-P200 latencies were increased in patients with pPSSP after stimulation at both sides, even when comparing subgroups with similar lesion size and location. Stroke was associated with reduced sensory-discriminative as well as cognitiveevaluative cortical somatosensory processing. This reduction was more pronounced in patients with PSSP and may be related to the central effects of persistent nociceptive pain. This study, therefore, warrants further assessment of the central nervous system changes associated with (p)PSSP.

In Chapter 5, the neuropathic pain diagnostic questionnaire (DN4) was used to categorize PSSP patients. Patients with pPSSP scoring at least four (DN4t, $n=9$ ) or less than four (DN4-, $\mathrm{n}=10$ ) on the DN4 were compared on the basis of symptoms and signs suggestive of either nociceptive or neuropathic pain. Pain was assessed using a numeric rating scale and the McGill pain questionnaire. Somatosensory functions were assessed using clinical examination and quantitative sensory testing combined with a cold pressor test. Patients classified as DN4+reported constant pain, higher pain intensity, a higher impact of pain on daily living, more frequent loss of cold sensation, reduced QST thresholds at the unaffected side and increased QST thresholds at the affected side. Notably, several symptoms and signs suggestive of either neuropathic or nociceptive pain corresponded to the subgroups DN4+ and DN4-, respectively. However, since the pathophysiological mechanisms remain unclear and none of the somatosensory signs could be exclusively related to either DN4+ or DN4-, PSSP prognosis and treatment should not be solely based on the DN4. The results of this study warrant a thorough assessment of neuropathic and nociceptive pain complaints and somatosensory functions in the diagnostic work-up of PSSP as well as in PSSP research.

\section{Part III: Follow-up studies on the development of persistent PSSP}

Chapter 6 identified factors associated with persistent post-stroke shoulder pain (pPSSP) in the first 6 months after stroke. Clinical assessment of motor, somatosensory, cognitive, emotional and autonomic functions was undertaken within 2 weeks (t0), at 3 months (t1) and at 6 months (t2) after stroke. Patients with pPSSP $(n=9)$ were compared with patients without pPSSP $(n=22)$. Bivariate logistic regression analyses showed that pPSSP was significantly associated with impaired voluntary motor control (t0, t1, t2), diminished 
proprioception ( $\mathrm{t} 0, \mathrm{t} 1)$, tactile extinction ( $\mathrm{t} 1)$, abnormal sensation ( $\mathrm{t} 1, \mathrm{t} 2)$, spasticity of the elbow flexor muscles $(\mathrm{t} 1, \mathrm{t} 2)$, restricted range of motion (ROM) for both shoulder abduction (t2) and shoulder external rotation ( $\mathrm{t} 1, \mathrm{t} 2)$, trophic changes ( $\mathrm{t} 1$ ) and non-insulin-dependent diabetes mellitus ( $\mathrm{t} 0)$. These findings suggest a multi-factorial etiology of pPSSP. The association of pPSSP with restricted passive pain-free ROM and signs indicative of somatosensory sensitization may implicate a vicious cycle of repetitive (micro-) trauma which can establish itself rapidly after stroke. Intervention should, therefore, be focused on maintaining and restoring joint ROM as well as preventing injury and somatosensory sensitization. In this perspective, strategies that aim to intervene simultaneously at various levels of function can be expected to be more effective than treatment directed at merely one level.

Chapter 7 explored the relationship between the onset of somatosensory symptoms and signs and the development of pPSSP in the first 6 months after stroke. Extensive assessment of somatosensory signs was performed within 2 weeks (t0), at 3 months (t1) and at 6 months (t2) after stroke using clinical examination and quantitative sensory testing. Supraspinal endogenous inhibitory functions were assessed using a conditioned pain modulation paradigm. At the affected side, pPSSP $(n=9)$ was associated with diminished proprioception ( $\mathrm{t} 0, \mathrm{t} 1$ ), with diminished sensation for touch (t1) and sharpness (t2), with increased QST threshold ratios (TDT, EST, EPT, EPTT, PPT) and with increased cold sensation (t2). At the unaffected side, pPSSP was associated with reduced cold pain tolerance thresholds (t1). In patients with pPSSP reporting increased sensation at the affected side, multiple body sites across multiple stimulus modalities were involved and increased sensation persisted from t1 to t2. Conditioned pain modulation was not different from patients without pPSSP $(n=22)$. Pain complaints were most often suggestive of nociceptive pain, and the relationship between pPSSP and somatosensory loss was consistent with the 'trauma-hypothesis'. The relationship between pPSSP and increased sensation, indicative of somatosensory sensitization, during the first 6 months after stroke, has not been reported before. Since somatosensory sensitization may contribute to the perpetuation of pPSSP and also occurs in patients with central post-stroke pain, it is important to extensively monitor somatosensory abnormalities in all phases after stroke.

In conclusion, the studies presented in this thesis confirm the multi-factorial etiology of pPSSP and show that the factors responsible for the initiation of PSSP are likely to be different from the factors responsible for the perpetuation of PSSP. In addition, the role of abnormal somatosensory processing in PSSP maintenance may be much more prominent than previously assumed and may explain why treatment aimed at reducing peripheral 
nociception is generally unsatisfactory. Ongoing nociception, the brain lesion itself, and other (premorbid) factors may contribute to the development of pPSSP. Although the precise neurophysiological mechanisms still remain unclear, these findings have important implications for the assessment, prevention and treatment of PSSP. 
Samenvatting 


\section{Chronische schouderpijn na een beroerte}

De meest voorkomende vorm van pijn na een beroerte (CVA) is hemiplegische schouderpijn (HSP). Traditioneel wordt HSP gezien als een nociceptieve pijn die voortkomt uit weefselschade ten gevolge van biomechanische veranderingen in het schoudergewricht. De behandeling van HSP richt zich vooral op het verminderen van biomechanische stressoren en/ of ontstekingsreacties in het schoudergewricht, bijvoorbeeld door het normaliseren van de spiertonus, het verminderen van glenohumerale subluxatie en/ of behandeling van het schouderkapsel. Echter, de behandeling van pijn is vaak suboptimaal en veel patiënten ontwikkelen chronische pijnklachten. Om de preventie en behandeling van HSP te verbeteren is meer kennis nodig over de neurofysiologische mechanismen die ten grondslag liggen aan de ontwikkeling van HSP. Dit vereist een verbreding van de traditionele klinische benadering van HSP als een vorm van nociceptieve pijn. Het doel van het proefschrift is een beter begrip te verkrijgen van de pathofysiologische mechanismen die ten grondslag liggen aan de ontwikkeling van chronische HSP.

Dit proefschrift bestaat uit 3 delen, met een wetenschappelijk intermezzo tussen deel 2 en 3. Het eerste deel introduceert de terminologie en de neurofysiologie van pijn en beschrijft een theoretisch kader voor de mechanistische benadering van HSP.

Het tweede deel bestaat uit 3 cross-sectionele studies waarin de bruikbaarheid van methoden uit het pijnonderzoek is onderzocht, zoals het bepalen van gevoelsdrempels en het toepassen van conditionerende pijnmodulatie (Hoofdstuk 3), het meten van corticaal opgewekte potentialen (Hoofdstuk 4) en het afnemen van een neuropathische pijnvragenlijst (Hoofdstuk 5). De uitkomsten van deze studies worden gekoppeld aan mogelijke pijn mechanismen.

Het intermezzo betreft een wetenschappelijke discussie over een classificatiesysteem voor centrale pijn na een beroerte en gaat in op de gevolgen van dit classificatiesysteem voor de klinische benadering van HSP.

Het derde deel bestaat uit 2 longitudinale studies waarin is gekeken naar de ontwikkeling van chronische HSP. Metingen zijn verricht op 0-2 weken, 3 maanden en 6 maanden na de beroerte. Hoofdstuk 6 richt zich op het complete klinische plaatje van sensorische, motorische, cognitieve, emotionele en autonome functies en de relaties met de ontwikkeling van chronische HSP in de eerste 6 maanden na de beroerte. Hoofdstuk 7 gaat weer dieper in op mogelijke pijnmechanismen door de relatie tussen chronische HSP, verlies van sensorische functie, overgevoeligheid en endogene pijnmodulatie te onderzoeken,

In Hoofdstuk 8 worden alle resultaten uit vorige hoofdstukken bediscussieerd en gebruikt om de huidige kennis over het ontstaan van HSP bij te stellen. De gevolgen voor de klinische 
praktijk worden besproken, leidend tot de algemene conclusies en suggesties voor verder onderzoek. Hier vindt u een samenvatting van deel 1, 2 en 3.

\section{Deel 1: 'Een neurofysiologische kijk op HSP'}

Hoofdstuk 2 beschrijft een mechanistische kijk op het ontstaan en het meten aan HSP op basis van kernprincipes uit pijnonderzoek. Hierbij wordt aangenomen dat de mechanismen die ten grondslag liggen aan pijn op elk niveau van de somatosensorische as kunnen plaatsvinden. Het gedetailleerd uitvragen van pijnklachten en het onderzoeken van somatosensorische functies zouden daarom een vast onderdeel moeten zijn in onderzoek naar HSP. Echter, tot dusver heeft somatosensorisch onderzoek in patiënten met HSP zich beperkt tot enkele klinische neurologische testen. Voor de verdere karakterisering van somatosensorische functies in HSP is een bredere methodologische aanpak vereist met zowel klinische als meer experimentele methoden uit het pijnonderzoek, zoals het bepalen van gevoelsdrempels, het toepassen van conditionerende pijnmodulatie en het meten van corticaal opgewekte potentialen.

\section{Deel 2: 'Cross-sectionele studies naar chronische HSP'}

Hoofdstuk 3 beschrijft een studie waarin somatosensorische functies zijn onderzocht in CVA patiënten met chronische HSP $(n=19)$, in pijn-vrije CVA patiënten $(n=29)$ en in gezonde controles $(n=23)$, met behulp van klinische neurologische tests en door het bepalen van gevoelsdrempels. Ook is gekeken naar het effect van conditionerende pijnmodulatie op de gevoelsdrempels met behulp van een ijswatertest. Somatosensorische functies waren vaker en meer aangedaan in CVA patiënten met chronische HSP. Dit betrof zowel gevoelsverlies als overgevoeligheid (allodynie, hyperalgesie), aan zowel de aangedane als niet-aangedane zijde. Conditionerende pijnmodulatie was niet verschillend tussen groepen. Deze resultaten wijzen op een mogelijke rol van sensitizatie en disinhibitie van het somatosensorische systeem in CVA patiënten met chronische HSP. Omdat het oorzakelijke verband onduidelijk blijft en de resultaten zowel verklaard kunnen worden door langdurige nociceptie als door het herseninfarct, zijn longitudinale studies nodig.

Hoofdstuk 4 beschrijft een verkennend onderzoek naar de corticale verwerking van somatosensorische prikkels in CVA patiënten met chronische HSP $(n=6)$, in pijn-vrije CVA patiënten $(n=14)$ en in gezonde controles $(n=20)$. Corticale potentialen werden opgewekt door middel van electrocutane stimulatie en gemeten met behulp van electroencefaografie (EEG). Amplitudes en latentietijden van sensorisch-discriminatieve (N90) en cognitiefevaluatieve (N150, P200, piekverschil N150-P200 en P300) werden onderzocht. 
Het doorgemaakt hebben van een beroerte was geassocieerd met verlaagde N150 en P300 amplitudes en met verhoogde N90, N150 en P300 latentietijden aan beide lichaamszijden. In vergelijking met pijn-vrije CVA patiënten en gezonde controles hadden CVA patiënten met chronische HSP verhoogde P200 en N150-P200 latentietijden aan beide lichaamszijden, zelfs als werd gematched op laesiegrootte en -locatie. Concluderend, het doorgemaakt hebben van een beroerte was geassocieerd met een verminderde sensorischdiscriminatieve en cognitief-evaluatieve corticale verwerking. Dit was meer uitgesproken in CVA patiënten met chronische HSP en zou te maken kunnen hebben met de centrale effecten van chronische nociceptieve pijn. Er zou daarom meer onderzoek moeten plaatsvinden naar de werking van het centrale zenuwstelsel in CVA patiënten met chronische HSP.

In Hoofdstuk 5 is een neuropathische pijnvragenlijst (DN4) gebruikt om CVA patiënten met chronische HSP te categoriseren. Patiënten die tenminste 4 punten scoorden (DN4+, n =9) of minder dan 4 punten scoorden (DN4-, $\mathrm{n}=10$ ) werden vergeleken aan de hand van bekende symptomen van neuropathische en nociceptieve pijn. Pijn werd gemeten met behulp van een numerieke schaal en de McGill pijnvragenlijst. Somatosensorische functies werden gemeten met behulp van klinische neurologische testen en door het bepalen van gevoelsdrempels voor en na een ijswatertest. Patiënten die geclassificeerd waren als DN4+ rapporteerden constante pijn, een hogere pijnintensiteit, een hogere impact van pijn op het dagelijks leven, gevoelsverlies voor koude, hogere gevoelsdrempels aan de aangedane zijde en lagere gevoelsdrempels aan de niet-aangedane zijde. Verschillende bekende symptomen van neuropathische en nociceptieve pijn kwamen overeen met de ingedeelde categorieën, respectievelijk DN4+ en DN4-. Echter, omdat de pathofysiologische mechanismen onduidelijk blijven, en geen van de symptomen exclusief gerelateerd konden worden aan één van de 2 subgroepen, zou de prognose en behandeling van HSP niet alleen op basis van de DN4 moeten geschieden. Echter, deze resultaten laten zien dat het uitgebreid onderzoeken van pijnklachten en het testen van somatosensorische functies thuishoren in zowel het diagnostisch traject van HSP, alsmede in het wetenschappelijk onderzoek ernaar.

\section{Deel 3: Longitudinale studies naar de ontwikkeling van chronische HSP}

In Hoofdstuk 6 worden factoren beschreven die geassocieerd zijn met chronische schouderpijn in de eerste 6 maanden na de beroerte. Motorische, sensorische, cognitieve, emotionele en autonome functies weren onderzocht binnen 2 weken (t0), op 3 maanden (t1) en op 6 maanden (t2) na de beroerte. CVA patiënten met chronische HSP ( $n=9)$ werden vergeleken met CVA patiënten zonder HSP $(n=22)$. Chronische HSP was geassocieerd met verminderde motorische functies (t0, t1, t2), verlies van propriocepsis (t0, t1), 
gevoelsstoornissen (t1, t2), spacticiteit van de elleboog flexoren $(t 1, t 2)$, verminderde bewegingsuitslagen voor abductie (t2) en intere rotatie $(\mathrm{t} 1, \mathrm{t} 2)$ van de schouder, trofische veranderingen aan de arm/ hand (t1) en diabetes mellitus type 2 (t0). De resultaten wijzen op een multifactoriele etiologie van chronische HSP. De associatie tussen chronische HSP, verminderde bewegingsuitslagen en symptomen van somatosensorische sensitizatie, zouden kunnen doelen op een vicieuze cirkel van herhaalde weefselschade in de schouder, die relatief kort na de beroerte kan ontstaan. Interventies moeten daarom gericht zijn op het behoud en/ of herstellen van bewegingsuitslagen van de schouder en het voorkomen van schade en somatosensorische sensitizatie. Interventies die tegelijkertijd op meerdere niveaus van functie aangrijpen zullen naar verwachting effectiever zijn dan behandelingen die zich slechts op 1 niveau richten.

In Hoofdstuk 7 is de relatie tussen het ontstaan van somatosensorische symptomen en de ontwikkeling van chronische HSP in de eerste 6 maanden na een beroerte nader onderzocht. Uitgebreid onderzoek vond plaats binnen 2 weken (t0), op 3 maanden (t1) en op 6 maanden (t2) na de beroerte, met behulp van klinische neurologische testen en door het bepalen van gevoelsdrempels voor en na een ijswatertest. Chronische HSP ( $n=9)$ was, aan de aangedane zijde, geassocieerd met een verlies van propriocepsis ( $\mathrm{t} 0, \mathrm{t} 1)$, een verlies van sensatie voor lichte tast (t1) en scherpte (t2), verhoogde gevoelsdrempels (t1, t2) en een overgevoeligheid voor koude (t2). Aan de niet-aangedane zijde was chronische HSP geassocieerd met een verlaagde pijntolerantiedrempel voor koude (t1). In patiënten met somatosensorische overgevoeligheid waren vaak meerdere lichaamsdelen overgevoelig voor verschillende soorten prikkels, en was de overgevoeligheid aanwezig op zowel t1 als t2. Het effect van de ijswatertest in CVA patiënten met chronische HSP verschilde niet van CVA patiënten zonder chronische HSP $(n=22)$. De pijnklachten duiden op nociceptieve pijn en de relatie tussen chronische HSP en verlies van somatosensorische functie komt overeen met de "trauma-hypothese". Echter, deze studie laat zien dat chronische HSP ook geassocieerd is met symptomen van somatosensorische sensitizatie in de eerste 6 maanden na de beroerte. Somatosensorische sensitizatie kan bijdragen aan de instandhouding van HSP en komt tevens voor in patiënten met centrale pijn na een beroerte. Gedegen somatosensorisch onderzoek is daarom belangrijk in alle fases na een beroerte.

Concluderend bevestigen de studies die beschreven zijn in dit proefschrift de multifactoriele ontstaanswijze van chronische HSP na een beroerte. Tevens laten zij zien dat de factoren die verantwoordelijk zijn voor het ontstaan van chronische HSP hoogstwaarschijnlijk verschillen van de factoren die chronische HSP in stand houden. De rol van een verstoorde functie van het somatosensorische systeem in het in stand houden van 
chronische HSP lijkt groter dan voorheen werd aangenomen. Dit zou kunnen verklaren waarom behandelingen die gericht zijn op het verminderen van perifere nociceptie niet voldoende effectief zijn. Zowel langdurige nociceptie, de hersenlaesie, alsmede andere (premorbide) factoren kunnen bijdragen aan de ontwikkeling van chronische HSP na een beroerte. Ondanks dat de neurofysiologische mechanismen grotendeels onbekend blijven, hebben deze resultaten belangrijke gevolgen voor zowel de klinische als de wetenschappelijke benadering van schouderpijn na een beroerte. 


\section{Dankwoord}

\section{En op het einde van onze verkenning Komen we op ons vertrekpunt aan En voor het eerst kennen we die plek}

T.S. Eliot

Geen verkenning zonder vertrekpunt. Dit proefschrift en de voltooiing ervan kent meerdere vertrekpunten. Graag wil ik hier een poging doen om alle personen te bedanken die voor mij een vertrekpunt zijn geweest in dit promotietraject en zonder wie mijn verkenning niet had kunnen slagen.

Als eerste wil ik alle mensen die hebben deelgenomen aan de onderzoeken bedanken. De situatie waarin we elkaar troffen, na een beroerte en in vele gevallen met chronische pijnklachten, was vaak niet de meest rooskleurige. En dan waren sommige van de metingen ook nog pijnlijk! Zonder de bereidwilligheid, tijd en moeite van deze mensen was er geen project geweest. Daarom allen BEDANKT!

Dan de wetenschappelijke basis van dit project. Deze werd gevormd door mijn promotor Maarten IJzerman en Bertjo Renzenbrink, revalidatiearts bij het Roessingh Revalidatiecentrum. Maarten, jou wil ik vooral bedanken voor het bewaken van het overzicht van dit project en voor het vertrouwen in mijn kunnen. Daarnaast heb ik samen met jou veel plezier beleefd aan de, voor een eerstejaars promovenda ongebruikelijke, trip naar een congres op Bermuda. Bertjo, wij hebben heel wat afgepraat de afgelopen jaren. Ik kon altijd bij je terecht voor hulp bij klinische zaken, met mijn verhalen over patiënten, maar ook voor relativerende en bemoedigende woorden op persoonlijk vlak. Heel erg bedankt hiervoor, en ik wens je veel succes met jouw eigen promotietraject!

Voor de technische en neurofysiologische kanten van het verhaal, was daar elektrotechnicus Jan Buitenweg, betrokken als begeleider en assistent-promotor. Ik herinner me nog goed ons eerste pilot-experiment met de ijswatertest waarbij je mij de kneepjes van de electrostimulatie bijbracht en ik na 40 seconden zo'n beetje van mijn stokje ging... Bedankt voor jouw kritische inbreng in dit project, en voor de samenwerking op het gebied van VWO-voorlichting en student-begeleiding.

In de loop van mijn verkenning kwamen er nog 2 nieuwe vertrekpunten bij: promotor en revalidatiearts Sander Geurts en referent en anesthesioloog Robert van Dongen, beide werkzaam bij het UMC St Radboud in Nijmegen. Sander, jouw inbreng als ervaren onderzoeker op het gebied van revalidatieonderzoek is ontzettend waardevol geweest voor 
het welslagen van dit project. Daarnaast heb ik ook veel gehad aan je praktische tips en je vaak razendsnelle, maar zeer uitgebreide feedback op mijn manuscripten. Dank hiervoor! Robert, als anesthesioloog en kenner op het gebied van neuropathische pijn, bewaakte jij de mogelijkheid voor een "centrale verklaring" van de schouderklachten. Tevens was jij één van mijn trouwe posterbezoekers op alle pijncongressen die ik de afgelopen jaren heb mogen bezoeken. Hartelijk bedankt voor je inbreng in dit project.

Doordat dit project op de grens van revalidatie- en pijnonderzoek balanceerde, organisatorisch gesitueerd was op de UT, maar veelal plaatsvond in allerlei zorginstellingen in de regio heb ik het geluk gehad te kunnen samenwerken en ervaringen uit te wisselen met vele collega's.

Te beginnen met de Universiteit Twente. Alle (oud) collega's bij BSS, bedankt voor jullie collegialiteit en de vele lol tijdens pauzes, wandelingen en uitjes de afgelopen jaren! In het bijzonder wil ik hier nog noemen de "oude" promovendi bij BSS die ik ook regelmatig buiten de deuren van de Zuidhorst zag en zie, Esther en Jan, bedankt voor de nodige ontspanning tijdens de avonduurtjes in de afgelopen jaren! Taras en Simone, mijn kamergenoten, bedankt voor de gezelligheid op de kamer! Eva en Daphne bedankt voor de sportieve motivatie en Peter S voor de inhoudelijke discussies op het gebied van het somatosensorische systeem en EEG. Daarnaast wil ik Jessica Askamp bedanken voor haar hulp bij een gedeelte van de dataverzameling in het kader van haar bacheloropdracht Biomedische Technologie. Wies Elfers, secretarieel en mentaal ondersteunende rots in de branding bij BSS, bedankt voor alle hulp en alle goede gesprekken! Ook heb ik de afgelopen jaren in verschillende contexten goed contact gehad met de collega's van BW. In het bijzonder wil ik Tjitske en Gerdine bedanken voor hun mental support en voor de muzikale en sportieve ontspanning tijdens de afgelopen jaren.

Dan de zorginstellingen. Bij het Roessingh Revalidatiecentrum wil ik graag bedanken: Joke Boerman, alle superbehulpzame portiers, de medewerkers op Afdeling 3 en alle anderen die mij op enig moment hebben geholpen tijdens dit project. Bij RRD heb ik alle EEG metingen verricht. Leendert en Rik, bedankt bij de technische ondersteuning hiervan. Tevens was er zowel bij het FHT clusteroverleg als bij de koffieautomaat altijd interesse voor mijn onderzoek en ik waardeer dit enorm! Alle medewerkers van RRD daarom bedankt! Alle CVA-revalidatieartsen werkzaam bij de Sint Maartenskliniek Nijmegen en het Revalidatie Medisch Centrum Groot Klimmendaal wil ik bedanken voor hun hulp bij de patiënteninclusie van het cross-sectionele onderzoek. Bij de Ziekenhuisgroep Twente en het Medisch Spectrum Twente wil ik alle medewerkers op de afdelingen neurologie bedanken voor hun ondersteuning bij het longitudinale onderzoek. Johannes Avenarius (MST, radiologie) wil ik bedanken voor alle hulp bij het beoordelen van de hersenscans uit 
hoofdstuk 4. Tevens wil ik hier Michel van Putten, Cecile de Vos en de hele club enthousiaste jonge onderzoekers bedanken voor alle levendige discussies tijdens KNF research meetings en bijbehorende BBQs.

A special thanks to the researchers from the Danish Pain Research Center in Arhus, in specific Henriette Klit, for the good contacts we have had during the past few years at conferences, during my Arhus work-visit in 2008 and in many correspondences, such as the one reprinted in the Intermezzo of this dissertation! Ik ben mijn voormalige stagebegeleidster aan de Rijksuniversiteit Groningen, Inge Zijdewind, erg dankbaar voor haar bijdrage aan de basis van mijn interesse voor wetenschappelijk onderzoek. Met vereende krachten hebben we het zelfs gepresteerd ons onderzoek 6 jaar na dato alsnog gepubliceerd te krijgen! Ook wil ik mijn nieuwe collega's bij Eerstelijnsgeneeskunde van het UMC St Radboud bedanken voor de gezelligheid, de kans om me op wetenschappelijk gebied als postdoc verder te ontwikkelen en de interesse voor mijn wel en wee tijdens de laatste loodjes van mijn promotieonderzoek.

Dan de persoonlijke vertrekpunten. Afscheid nemen van studiestad Groningen bleek gedurende de eerste promotiejaren in Twente nog niet zo gemakkelijk. De goede vriendschappen en de mooie herinneringen waren reden om in de weekenden nog regelmatig naar het noorden af te reizen om bij te kletsen en voor het nodige nachtelijk dansvertier. Alle vrienden en kennissen "van vroeger" die mij de afgelopen jaren hebben gesteund: bedankt! In het bijzonder Nanda en Jurriaan, Giselle en Eerk, Truus en Bram, Willemijn, Margreet en Mark en Marjolein: bedankt voor jullie vriendschap!

In Enschede bleek naast het werk gelukkig ook genoeg te beleven. Al tijdens de introductiedag van de UT leerde ik mijn muzikale wederhelft van het duo 'Camembert' kennen, inclusief gezinsvervangend tehuis en een cursus Frans. Daarom: Nicolas, Marian en sinds anderhalf jaar ook Amélie, bedankt! Bij Concordia vond ik als zaalwacht bij de film de nodige afleiding van het "hoofdwerk" op de UT. Alle collega-vrijwilligers en CKV-ers bedankt voor de gezellige tijd! Louis bedankt voor alle diepgaande gesprekken over promoveren en groots en meeslepend leven. Debbie bedankt dat je de laatste-loodjeswerkplek in Eindhoven alvast een beetje opgewarmde met je vriendschap.

Een bijkomend voordeel van promoveren in Twente was dat een groot gedeelte van de familie per fiets kon worden bezocht. Veel van hen heb ik daardoor de afgelopen jaren een stuk vaker kunnen zien! Graag wil ik alle familieleden bedanken voor de momenten samen, hun interesse in mij en hun Twentse nuchterheid. Mijn moeder en broer wil ik graag in het bijzonder noemen, omdat zij samen al het andere relatief maken.

En tot slot bedank ik Gerbert, omdat hij er is om van te houden en als vertrekpunt voor de toekomst. 


\section{Biography}

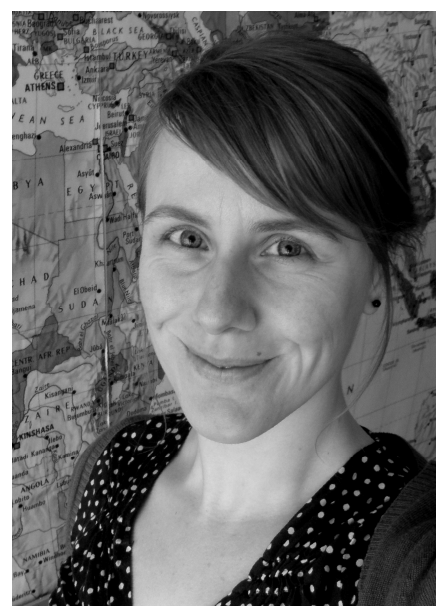

Meyke Roosink was born on September $3^{\text {rd }} 1982$ in Hengelo (o), the Netherlands. She studied Biology at the University of Groningen from 2000-2005, specializing in Behavioral and Cognitive Neurosciences. She received her Master of Science degree in 2005. She completed two master theses. The first focused on motor learning through cognitive strategies and was titled: 'Corticospinal activation during observation, imagery and execution of a simple and complex hand-task, a transcranial magnetic stimulation study'. The second focused on the role of neurodegeneration in psychiatric diseases and was titled: 'Pathophysiology of neurodegenerative diseases: Positron emission tomography and verapamil as a functional assay of the blood-brainbarrier in patients with major depression or schizophrenia'.

Her interest in the neurophysiological processes involved in human perception, action and cognition lead her to pursue a career in research. From 2006-2010 she worked as a PhDstudent at the department of Biomedical Signals and System at the University of Twente in Enschede, the Netherlands. Her PhD project, entitled 'Persistent shoulder pain after stroke', was a collaboration between the University of Twente, Roessingh Rehabilitation Center, Roessingh Research \& Development and Radboud University Nijmegen Medical Centre. During this project she worked on the neurophysiological assessment of persistent shoulder pain in stroke patients, and became fascinated by the complexity of chronic medical conditions.

From 2010, she has been working as a postdoctoral researcher at the department of Primary Care at the Radboud University Nijmegen Medical Center, in Nijmegen, the Netherlands. Here, she contributes to the development of new research projects in the fields of health and healthcare for people with intellectual disabilities. 


\section{Publications}

\section{Journal Articles}

- Roosink M, Van Dongen RTM, Renzenbrink GJ, IJzerman MJ. Classifying post-stroke shoulder pain: Can the DN4 be helpful? Eur J Pain 15:99-102, 2011.

- Roosink M, Geurts AC, IJzerman MJ. Defining post-stroke pain: diagnostic challenges. Lancet Neurol 9:344, 2010.

- Roosink M, Zijdewind I. Corticospinal excitability during observation and imagery of simple and complex hand tasks: Implications for motor rehabilitation. Behavioural Brain Research 213:35-41, 2010.

- de Klerk OL, Willemsen AT, Roosink M, Bartels AL, Harry Hendrikse N, Bosker FJ, den Boer JA. Locally increased P-glycoprotein function in major depression: a PET study with [11C]verapamil as a probe for P-glycoprotein function in the blood-brain barrier. Int J Neuropsychopharmacol 19:1-10, 2009.

- Roosink M, Renzenbrink GJ, Buitenweg JR, van Dongen RTM, Geurts AC, IJzerman MJ. Somatosensory symptoms and signs and conditioned pain modulation in chronic poststroke shoulder pain.J Pain in press.

- Roosink M, Buitenweg JR, Renzenbrink GJ, Van Dongen RTM, Geurts AC, IJzerman MJ. Altered cortical somatosensory processing in chronic stroke: a relationship with poststroke shoulder pain. NeuroRehabilitation in press.

- Roosink M, Renzenbrink GJ, Buitenweg JR, Van Dongen RTM, Geurts AC, IJzerman MJ. Persistent shoulder pain in the first six months after stroke: results of a prospective cohort study. Arch Phys Rehab Med in press.

- Roosink M, Geurts AC, IJzerman MJ. Towards a new view on post-stroke shoulder pain: Theoretical considerations and clinical implications. Submitted.

- Roosink M, Van Dongen RTM, Buitenweg JR, Renzenbrink GJ, Geurts AC, IJzerman MJ. Somatosensory sensitization in persistent shoulder pain after stroke: results of a prospective cohort study. Submitted.

\section{Conference contributions}

- Roosink M, Renzenbrink GJ, Buitenweg JR, van Dongen RTM, Geurts AC, IJzerman MJ. Somatosensory abnormalities at baseline and follow-up in patients developing poststroke shoulder pain. IASP 13th World Congress on Pain 2010. Montreal, Canada. 
Publications

- Roosink M, Renzenbrink GJ, Buitenweg JR, van Dongen RTM, Geurts AC, IJzerman MJ. Somatosensory and diffuse noxious inhibitory control functions in post-stroke shoulder pain. Third International Congress on Neuropathic Pain. 2010. Athens, Greece.

- Roosink M, Buitenweg JR, Renzenbrink GJ, van Dongen RTM, Geurts AC, IJzerman MJ. Cortical processing of electrocutaneous stimuli in chronic stroke patients: a relationship with post-stroke shoulder pain. 6th World Congress for Neurorehabilitation. 2010. Vienna, Austria.

- Roosink M, Renzenbrink GJ, Buitenweg JR, van Dongen RTM, Geurts AC, IJzerman MJ. Evidence for central pain mechanisms in chronic post-stroke shoulder pain. 6th World Congress for Neurorehabiliation. 2010. Vienna, Austria.

- Roosink M, BuitenwegJR, Renzenbrink GJ, Geurts AC, IJzerman MJ. Cortical processing of electrocutaneous stimuli in chronic post-stroke shoulder pain. Annual symposium of the IEEE-EMBS Benelux Chapter. 2009. Enschede, the Netherlands: IEEE-EMBS Benelux.

- Roosink M, Renzenbrink GJ, Buitenweg JR, van Dongen RTM, Geurts AC, IJzerman MJ. 120 Central neuropathic mechanisms in post-stroke shoulder pain. European Journal of Pain, 2009. 13(Supplement 1): p. S44.

- Roosink M, Renzenbrink GJ, Buitenweg JR, van Dongen RTM, Geurts AC, IJzerman MJ. Somatosensory and nociceptive changes in chronic post-stroke shoulder pain. Symposium Highlights in BioMedical Technology. 2008. Enschede, the Netherlands.

- Roosink M, van Dongen RTM, Renzenbrink GJ, Buitenweg JR, Geurts AC, IJzerman MJ. Diagnostic uncertainties in post-stroke pain classification. IASP 12th World Congress on Pain. 2008. Glasgow, Scotland: IASP Press.

- Roosink M, Renzenbrink GJ, Buitenweg JR, van Dongen RTM, Geurts AC, IJzerman MJ. Neurophysiologic characterization of shoulder pain in stroke patients. IEEE Benelux EMBS symposium. 2007. Eindhoven, the Netherlands.

- Roosink M and Zijdewind I. Corticospinal activation during observation, imagery and execution of a simple and complex hand-task: a TMS study. International Student Congress of Medical Sciences. 2004. Groningen, the Netherlands.

- Roosink M and Zijdewind I. Corticospinal activation during observation, imagery and execution of a simple and complex hand-task: a TMS study. 3rd Dutch Endo-NeuroPsycho Meeting. 2004. Doorwerth, the Netherlands. 


\title{
Stellingen
}

\author{
Behorende bij het proefschrift \\ Persistent Shoulder Pain after Stroke \\ door M eyke Roosink te verdedigen op 28 april 2011
}

1. Persisterende schouderpijn na een beroerte kan uit zowel nociceptieve als neuropathische componenten bestaan.

(hoofdstukken 2 en 5)

2. Persisterende schouderpijn na een beroerte is niet alleen geassocieerd met gevoelsverlies maar ook met somatosensorische overgevoeligheid en een veranderde cognitief-evaluatieve verwerking van somatosensorische prikkels. (hoofdstukken 3 en 4)

3. Vragenlijsten of 'beoordelingssystemen' ten behoeve van de diagnose van neuropathische pijn zijn slechts in beperkte mate bruikbaar voor de classificatie van schouderpijn na een beroerte.

(hoofdstuk 5)

4. Veranderingen in het centrale somatosensorische systeem dragen zowel in de subacute als in de chronische fase na een beroerte bij aan het in stand houden van persisterende schouderpijn.

(hoofdstukken 3, 6 en 7)

5. De interpretatie van somatosensorisch onderzoek wordt bemoeilijkt door het feit dat één symptoom door meerdere mechanismen veroorzaakt kan worden en één mechanisme ten grondslag kan liggen aan meerdere symptomen.

6. Voor patiëntgebonden onderzoek heb je minstens één betrokken clinicus nodig.

7. Een bioloog heeft binnen zorginstellingen nogal eens wat uit te leggen.

8. Het nieuwe werken werkt niet als je gehecht bent aan je avonden en je weekend. 